UNIVERSITY OF B.C. LIBRARY

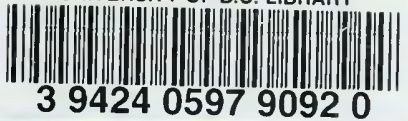

STORAGE ITEM

PROCLES 1 NG-CNE

Lp 1-W $17 \mathrm{C}$

U.B.C. LIBRARY

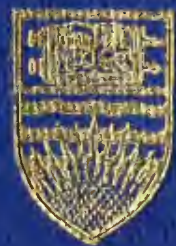




\section{THE LIBRARY}

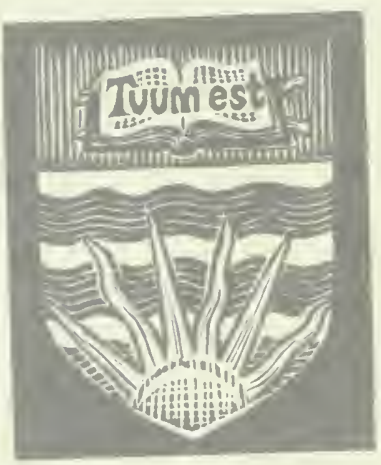

THE UNIVERSITY OF BRITISH COLUMBIA 
Digitized by the Internet Archive in 2010 with funding from

University of British Columbia Library 



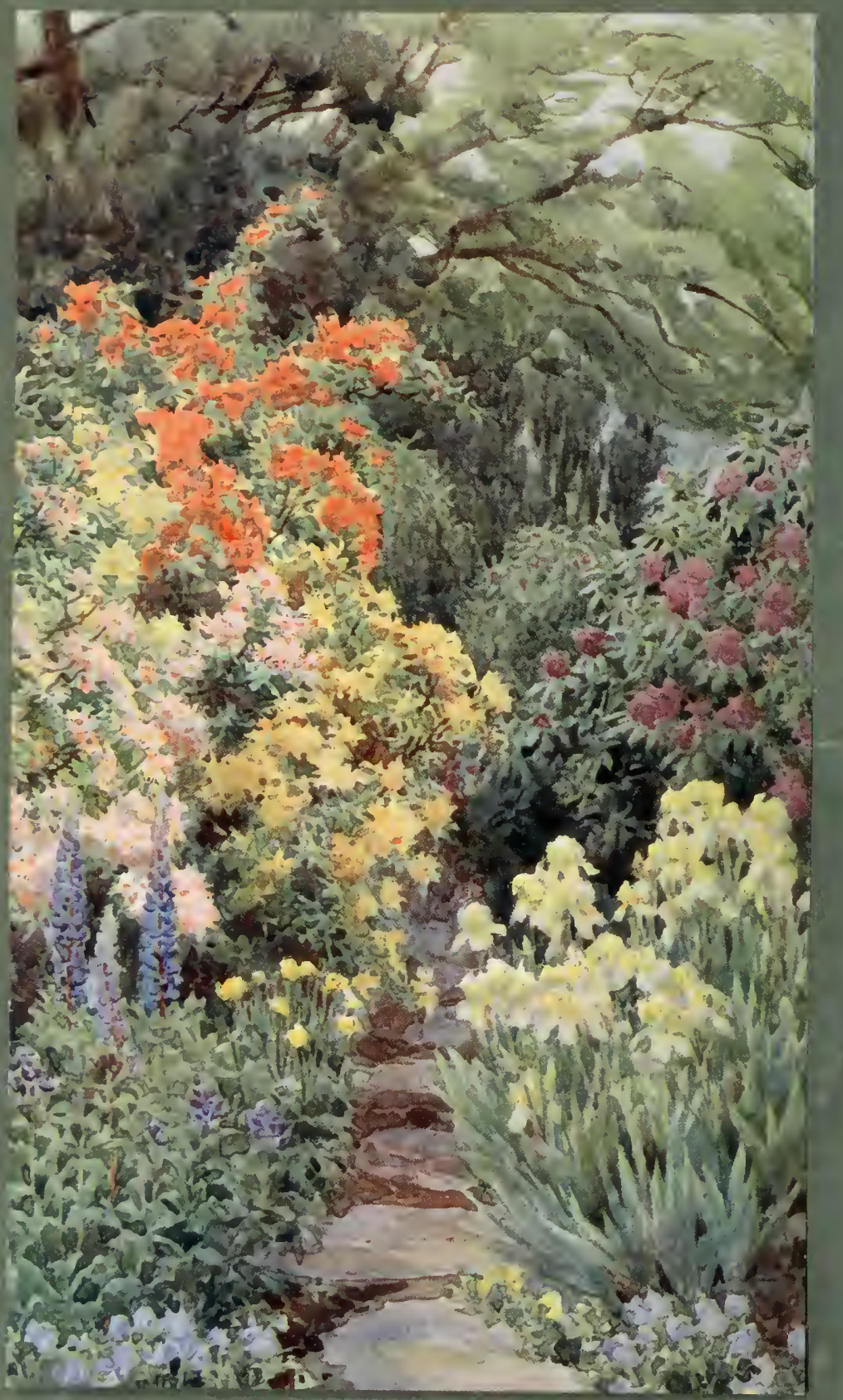


“THE WALK THAT LEADS TO THE WATERSIDE."

(See page 29.)

Azaleas and Spring-flowering perennials.

Painted by BeAtrice Parsons. 



\section{Garden Trees}

\section{AND \\ SHRUBS}

ILLUSTRATED IN COLOUR

\section{BY \\ WALTER P. WRIGHT}

AUTHOR OF

"Alpine Flowers and Rock Gardens," "Roses and Rose Gardens,"

"Hardy Perennials and Herbaceous Borders," etc.

LONDON :

HEADLEY BROTHERS

BISHOPSGATE, E.C. 


\section{Preface.}

In modern gardens, informed as they are with the spirit of natural beauty and informality, the cultivation of good hardy plants under conditions which give them scope for showing their true characters, such as among stones and in spacious borders, must necessarily engage the earnest attention of true flower-lovers. But shrubs and trees have an importance at least as great as that of Alpine and herbaceous plants.

Happily this fact is fully acknowledged, and the attention devoted to this great class has led to active exploration, with the result that in quite recent years a considerable number of fine new species have been introduced to cultivation. So remarkable, indeed, have been the modern " finds," particularly those of Wilson, that works on shrubs and trees but a few years old are already out of date; hence the preparation of the present volume.

The book is not, however, a mere record of modern discovery; on the contrary, it deals with the best standard kinds as well as with the newcomers, so that it makes an appeal equally to 
those in search of novelties and to those who wish to furnish their gardens with less expensive but good kinds.

The same liberal illustration with coloured plates by eminent artists, and with half-tone engravings of subjects in growth, that helped the sister volumes in the series to popularity, is invoked in aid of the present volume.

Walter P. Wright.

October, I9I3. 


\section{Contents}

CHAPTEK

PAGE

PART I. THE BEAUTY AND VALUE OF SHRUBS AND TREES.

I.-AN Ideal and a Conception - - - - - I3

II.-Garden Seclusiox and Woodland Mrstery - I9

III.-The Threshold of The Woodland - - - 23

IV.-Shady Walk and Shadowed Water - $\quad 27$

- V.-The Place of Shrubs and Trees in Modern Gardens 31

VI.-Shrub Beds and Shrub Borders-Spring Beauty 36

PART II. PRACTICAL.

ViI.-Mistakes in the Culture of Shrubs and Trees-

Planting, Thinning, Pruning, etc. - -

Vili.-Practical Considerations in Planting Shrubs and

TREES-FORMS OF BEDS AND BORDERS-LAND-

SCAPE EFFECTS-BACKGROUNDS - - - - 55

IX.-Arrangement of Shrubs and Trees both For

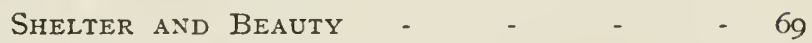

X.-Moving Shrubs and Trees - - - - - 83

XI.-Propagation of Shrubs and Trees - - - 9 -

Xil.-Enemies of Shrubs and Trees - $\quad$ - $\quad$ - 106

XIII.-Pruning Shrubs and Trees - $\quad$ - $\quad$ - 109

PART III. SELECTIVE.

XIV.-Lawn Shrubs and Trees-Pendulous or Weeping

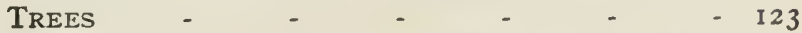

XV.-Leaf and Stem Tints-Beautiful Fruits and

BERRIES - $\quad$ - $\quad$ - $\quad$ - $\quad$ - $\quad$ - 127

XVI.-Evergreen Shrubs and Trees, other than Conifers I 37

XVII._CONIFERS

XVIII.-Climbing Shrubs - $\quad$ - $\quad$ - $\quad$ - $\quad$ - I55 
CHAPTER

XIX.-Shrubs For the Rock Garden

XX.-Shrubs and Trees for Town and Suburban Gardens AND FOR THE GARDEN CITY - - - I80

XXI.-Shrubs and Trees for Seaside Gardens - - 184 XXII.-Shrubs and TREes FOR the Waterside - - 188 XXili.-The Clipped Trees of the Old Dutch Garden - 193 XXIV.-Shrubs and Trees for Hedges - - - $\quad$ - 99 XXV.-Shrubs for Shady Places and Undergrowth - 205 XXVI.-Shrubs aNd TREes For Forcing - - - 210

PART IV. DESCRIPTIVE.

Modern Shrubs and Trees, Chiefly Chinese - 221

The Best Shrubs and Trees in Alphabetical

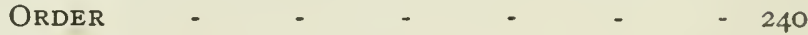




\title{
List of Illustrations.
}

\author{
In Ciclour.
}

"The walk that leads to the waterside." Azaleas and Spring-

PAGE flowering perennials - - - - - -Frontispiccc.

"The pearly tints of an horizon arched over the curve of a hill." Rhododendrons massed in the foreground- - 13

"The sparkling garniture of spiked Thorns." - - - - Is

"A place of cheerful peace." The Lily Pool at Wisley showing an effective background of beautiful trees - - - 27

"Colour beauty from the first days of Spring." Forsythia, Almond, Magnolia stellata, Berberis and Prunus - - 36

"The Flowering Currants are among the earliest shrubs to bloom" - - - - - - - 40

"We can obtain beautiful spring pictures in the garden." The Double White Cherry, Prunus serrulata - - - 46

"The Apple and Crab are pre-eminently beautiful when in bloom." Apple blossom in a cottage garden - - 62

"The Tree Pxonies are among the finest of flowering shrubs, bearing immense blooms of brilliant colours." Pronia Moutan, Grand Frederic - $\quad$ - $\quad$ -

" The Almond, one of the carliest trees to bloom and in mild winters may be in flower in February." It is here shown with Prunus Pissarclii - $\quad-\quad-\quad-\quad$ -

"The Pyrus (spectabilis) is one of the most beautiful of all flowering trees." The double form is here shown - - $\quad 78$

"The Great Rhododendrons . . . grouped in lawn beds." Pink Pearl at Kew - $\quad$ - $\quad$ - $\quad$ - $\quad$ - 94

Magnolia Soulangeana-a glorious Trec Tulip - - - $\quad 98$ 
"Veitch's Virginian Creeper is a true climber and assumes exquisite shades in the fall " - _ _ _ - 106

"The popular Pyracantha ; Lalandii is a splendid form" - I27

"The Brooms have the interest of green stems as well as of brilliant flowers." Cytisus Andreanus at Kew - - 130

"Cydonia (Pyrus) japonica and Maulei, with their varieties, have large red fruits that are often jellied" - - $\quad$ - 38

Group of Firs on the edge of the Lawn - _ - _ - 143

"Lawn plantings have a rich and at the same time refined effect" -- - - - - - - - 146

"All the forms of Clematis Jackmanii are beautiful " - - I55

"The Ceanothuses are beautiful deciduous shrubs for walls" - ${ }_{15} 8$

"Clematis montana is a truly charming plant for a wall, arch or arbour" - - - - _ _ - ${ }_{1} 62$

"The Brooms comprise species of widely varying habit . . . admirably adapted for the rockery." Cytisus precox and C. kewensis are hore shown

"The three best Daphnes, Blagayana, Cneorum and Mezereurn, are all suitable for the rock garden." Daphne Cneorum is here shown - $\quad$ - $\quad$ -

"In districts where the natural soil is peaty, Heaths should be planted freely." Erica carnea and alba - - - I78

Abutilon vitifolium. A free-flowering shrub for a sheltered corner

"Double Cherries and Peaches . . . bloom profusely with very gentle forcing, and the flowers are exquisite." Prunus Pseudo-Cerasus Yoshino, a Japanese variety- -

"Shrubs should be considered for the rock garden, because they enter into harmonious relations with other occupants." Spirac arguta is here shown - - - -

"The Laburnum may be planted in the suburbs and in garden cities." The Laburnum is here shown growing in Kew Gardens

Rhododendron Yunnanense

Prunus Pseudo-Cerasus Choskin

Rhododendron Loderii

Magnolia L.ennei 
In Monotone.

Slender Birch and Solid Yew - PAGE.

Water Garden at Alden Xew $-{ }_{-}-{ }_{-}-14$

Water Garden at Aldenham - $\quad$ - $\quad$ - $\quad$ - $\quad$ - $\quad$ - 15

Golden Irish Yew and Cupressus Lawsoniana erecta viridis - 22

Rhododendron ponticum - - _ - - - $\quad$ - 23

The Monkey Puzzle, Araucaria imbricata - - - 30

Yucca blooming after Forty Years' Growth - - - - $3 \mathbf{I}$

Rhododendron Mrs. R. G. Shaw - - $\quad$ - $\quad$ - $\quad$ - 50

The Wilderness, Aldenham - $\quad$ - $\quad$ - $\quad$ - $\quad$ - $\quad$ - $\quad$ - $5 \mathrm{I}$

Bridge in Water-garden, Aldenham - $\quad$ - $\quad$ - $\quad-58$

Early Morning Mlists - $\quad$ - $\quad$ - $\quad$ - $\quad$ - $\quad$ - 59

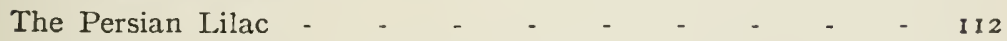

Kolwitzia amabilis - $\quad$ - $\quad$ - $\quad$ - $\quad$ - $\quad$ - $\quad-113$

The Monarch of the Terrace, a noble Weeping Willow - - 118

Stone Pine at Kew - $\quad$ - $\quad$ - $\quad$ - $\quad$ - $\quad$ - $\quad$ - $\quad$ - $\quad$ - 119

Grace and shade on the sun-scorched grass-a good Weeping Birch - - $\quad$ - $\quad$ - $\quad$ - $\quad$ - $~ I 24$

Weeping Thorn at Kew-Cratægus oxyacantha pendula - - 125

The Short-leaved Silver-lined Fir, Abies brachyphylla - . 148

The Silver-Frosted Fir, Picea pungens glauca - - - $\quad$ - 149

The Golden Japanese Juniper, Juniperus japonica aurea - $\quad$ - 152

The Golden Cypress, Cupressus Lawsoniana lutea - - $\quad$ - 153

Ceanothus thyrsifiorus grisens - _ _ - _ - - 164

Buddleia Veitchiana - _ _ _ _ _ - $\quad$ - 165

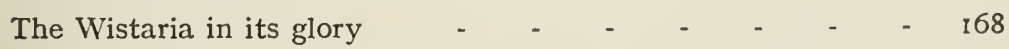

Italian Arch with Climbing Shrubs - - - - - 169

The Wrestler's Pond, Aldenham - - - - - $\quad$ - 190

Trees and Shrubs by the Waterside, Aldenham - - - 19 I

Topiary Garden at Brocklehurst, Hants - - - $\quad$ - 194

Cedar dreaming by the Fountain - _ _ - _ - 195

Veronica Traversii - $\quad$ - $\quad$ - $\quad$ - $\quad$ - $\quad$ - 202

Dipelta floribunda at Kew - $\quad$ - $\quad$ - $\quad$ - $\quad$ - $\quad$ - $\quad$ - 203

A Modern Tree Pæony, Paeonia Veitchii - - - 206

Two Modern Deutzias, D. Wilsoni and D. Veitchii - - $\quad$ - 222

Two new Chinese Barberries, B. acuminata and B. Gagnepainii 223 
One of the best of the Snowball Trees (Viburnum plicatum page A remarkable new Vine, Vitis Henryana - - • - 239 Clematis montana rubens - - - - - - $\quad 242$ Raphiolepis japonica - $\quad$ - $\quad$ - $\quad$ - $\quad$ - $\quad$ - $\quad$ - $\quad$ - 243

A beautiful hybrid Mock Orange, Philadelphus Rosace - - 250 A little-known Rock Rose, Cistus creticus - - - - $25 \mathrm{I}$

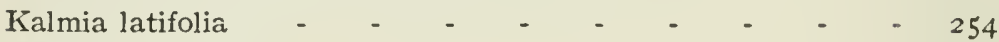

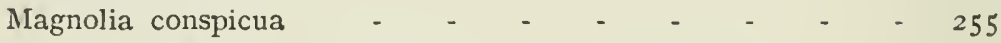

A Queen of Modern Deutzias, D. discolor grandifiora - - 270

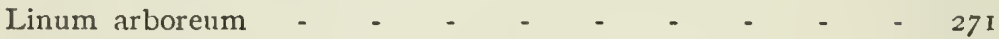

A Modern Honeysuckle, Lonicera Maackii - - - $\quad 286$ Magnolia parviflora - $\quad$ - $\quad$ - $\quad$ - $\quad$ - $\quad$ - 287 Stranvæsia undulata - $\quad$ - $\quad$ - $\quad$ - $\quad$ - $\quad$ - $\quad$ - $\quad$ - 290

Two useful Rock Shrubs, Thuja dolabrata mana and Picea

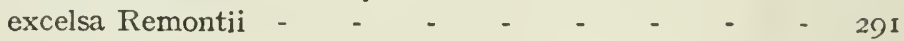

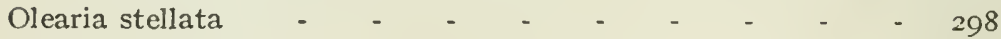

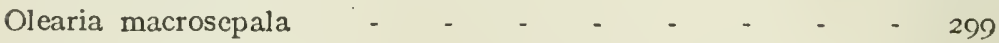

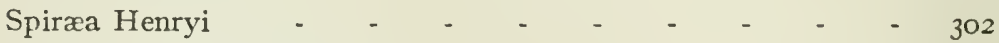

Philadelphus Pavillon Blanc - - - - - - - 303

\section{DIAGRAMS.}

Suggestions for planting trees in front of house - - - 7 I

Suggestion for beds of Shrubs and Trees beside a walk - - 72

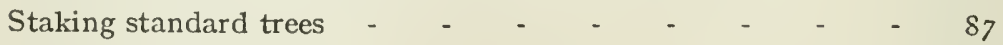

Depth of planting trees - - - $\quad$ - $\quad-\quad-\quad-87$

Lifting Evergreen Shrubs - - $\quad$ - $\quad$ - $\quad$ - - - 8 ?

Methods of Propagating Shrubs - $\quad$ - $\quad$ - $\quad$ - 95

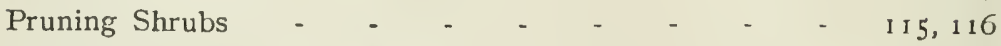

Use of Shrubs in Rock Gardens - - - _ - $\quad$ - 172 


\section{PART I.}

The Beauty and Value of Shrubs and Trees. 



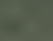

in 1

$\because$

is

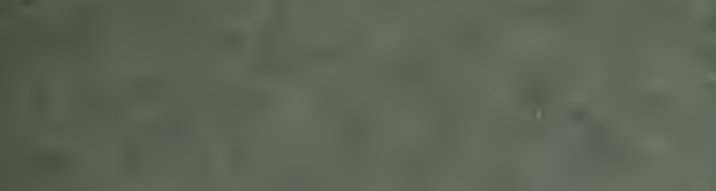

$=$

i.

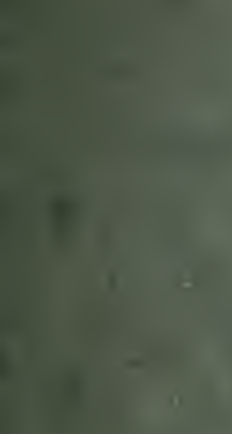

-

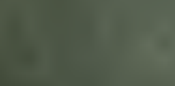

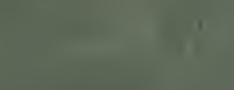

19.

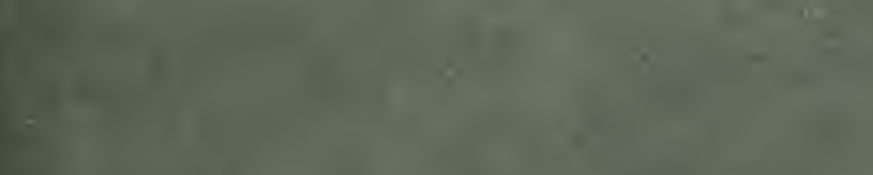

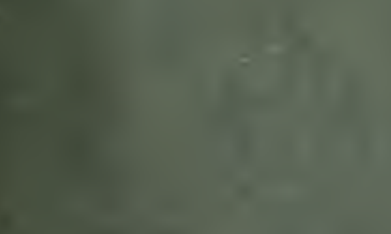

(2)

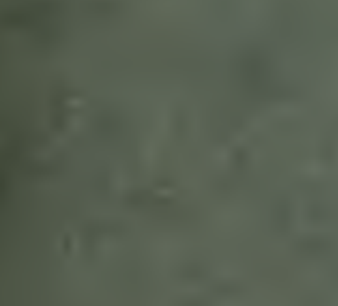

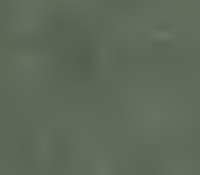

한.

$x^{2}+1$

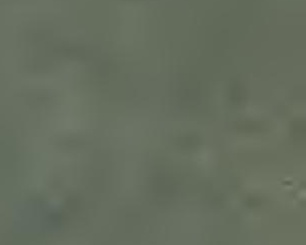

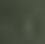

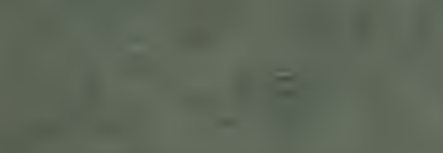

$\sin =$

81:

$\sqrt{1+3}$

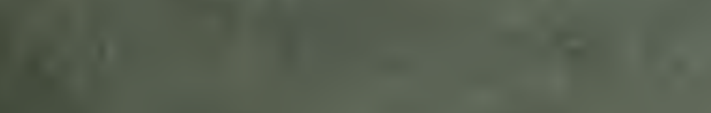

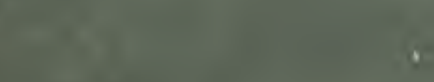




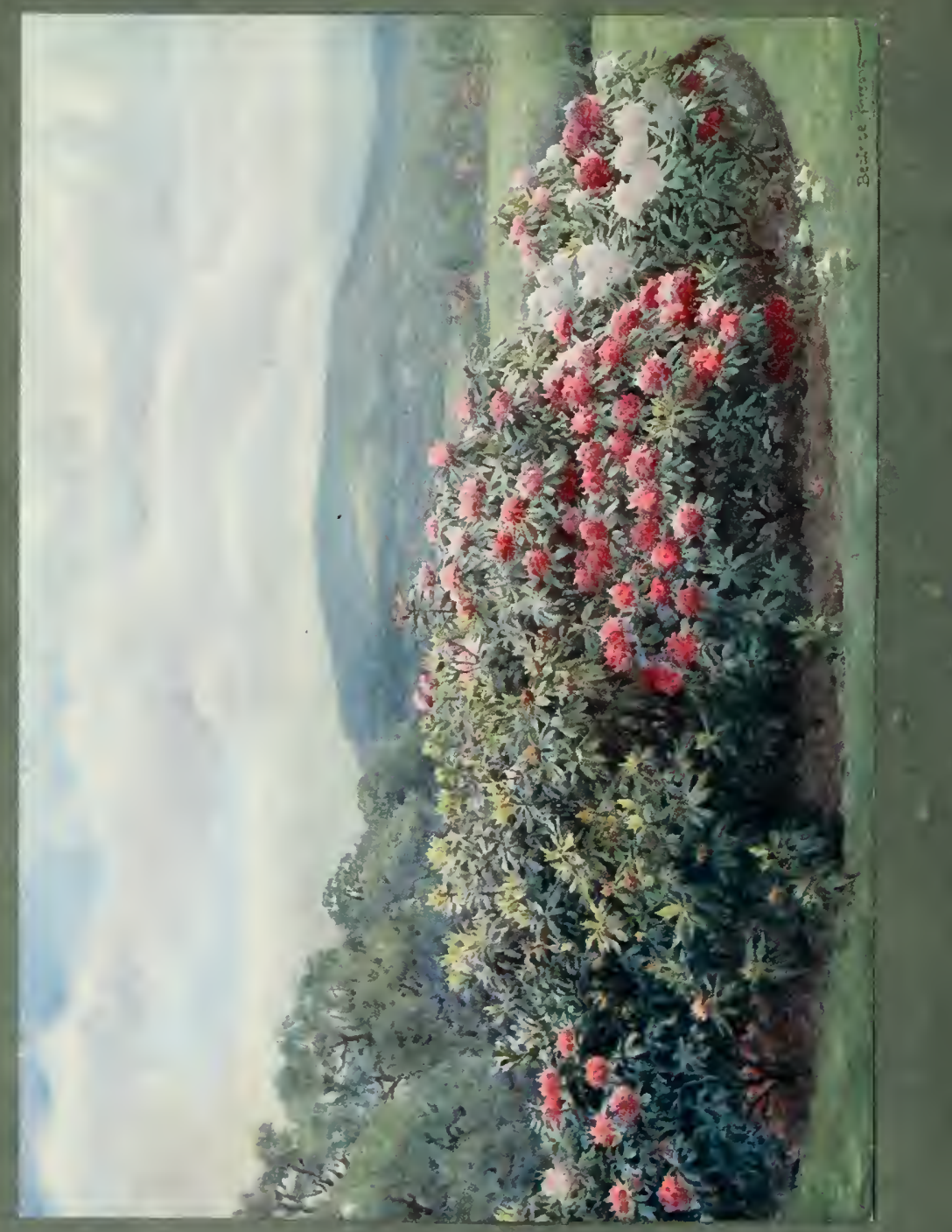


"THE PEARLY TINTS OF AN HORIZON ARCHED OVER THE CURVE OF A HILL."

(See page $I_{4}$ ).

Rhododendrons massed in the foreground.

Painted by BEATRICE Parsons. 


\section{CHAP'TER I.}

\section{An Ideal and a Conception.}

IN making bold garden pictures, in working in harmony with beautiful landscapes, in creating the glamour of distant colour, in giving a definite meaning to space, in linking up the perspective of earth, horizon and sky, in calling up the peaceful and soothing influences of dew and shade-in these operations there is brought back some of the spirit of adventure, some of the buoyant imagery, which are often held to be the special prerogative of adolescence.

A true conception of the value of shrubs and trees is not gained by merely calculating their uses as screens, or even as belts of colour ; it only comes when they are regarded as the media through which space is enchained, hill and vale put in bonds with the garden, shade held captive and a sense of the mystery of Nature retained even in the immediate surroundings of the home.

Considered from this wider point of view, the great class of plants which it is the object of the present work to consider attains a scope and dignity that no other can claim.

It is good to be able to recall that fervour of the high endeavour which imparts so strong a zest to youth, 
for it is accompanied by an inspiring and cheery optimism. One may get a taste of it in the building of a rockery, but it only comes back in full measure, so far as the garden is concerned, when the mind is given freer play in bold landscape gardening. Recognizing this, it is safe to predict, not only that garden-making will grow in favour as the years pass, but that the culture of shrubs and trees in particular will mount on an ever-swelling wave of popularity.

With judicious planting, shrubs and trees are not only beautiful in themselves, but form a connecting link with the landscape and even with the firmament. A bare knoll, unsatisfactory, even repellent, when it lies cold and pallid under a grey winter sky, takes life and character from a clump of Pines. The pearly tint of an horizon arched over the curve of a hill becomes firm and purposeful when seen through a woodland vista or through the tracery of leafless trees.

It does not follow that shrubs and trees-and particularly trees-are out of place in small enclosed gardens where considerations of landscape cannot operate. Shelter and shade remain to assert their claims. The demands of privacy are insistent in some cases. And above all, there is intrinsic grace and beauty. In the purposes which they serve, in the diversity of their habits, in the elegance of their forms, in the luxuriance of their foliage, in the large size and brilliant colours of their flowers, shrubs and trees provide material for almost every garden purpose. Certainly there is no garden, however small, in which they are incapable of playing an important part. 


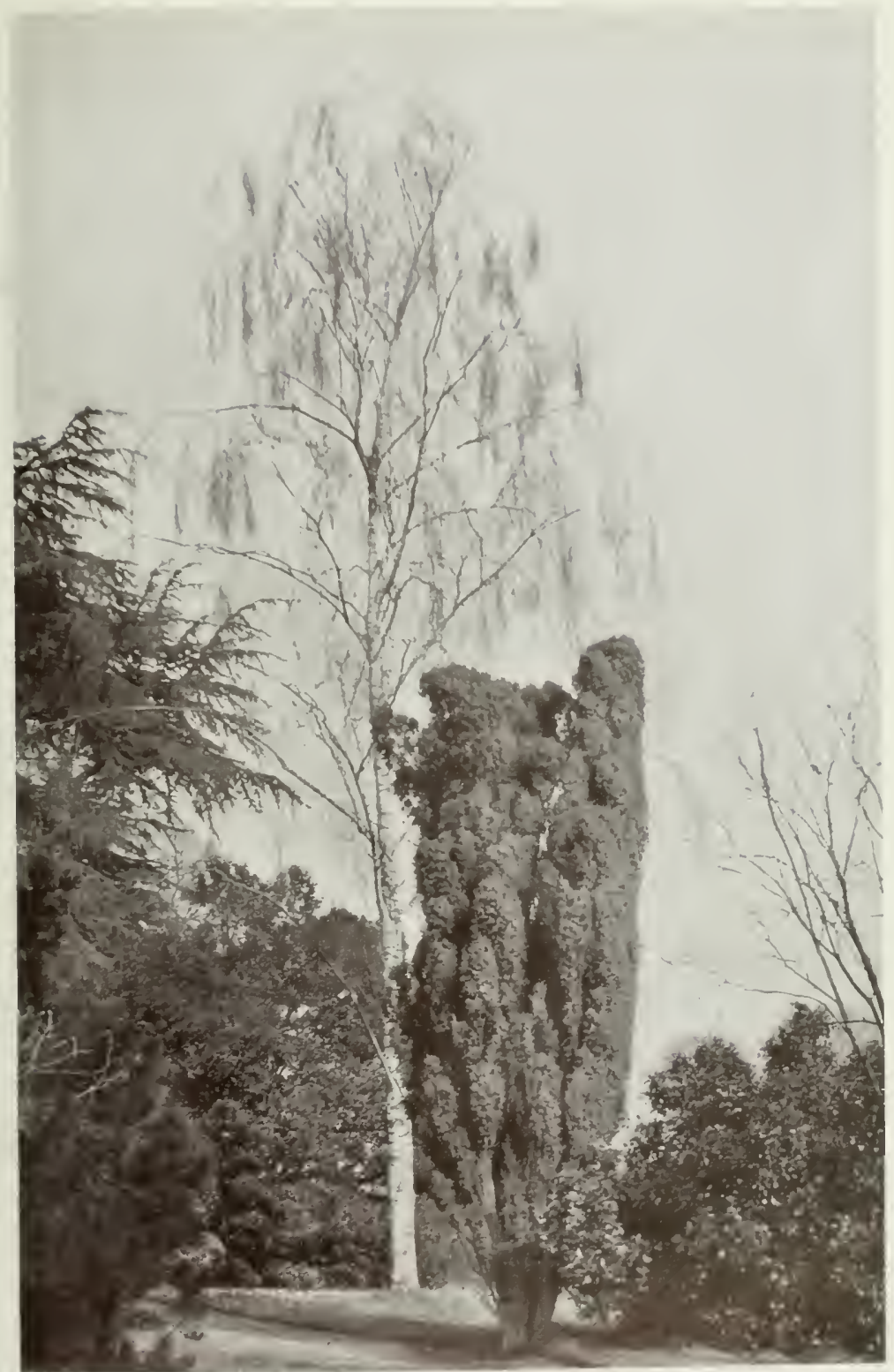

SLEADER PIRCH AND SOIID YEW:

A successful grouping of Trees. Photo by R. A. Malby. 


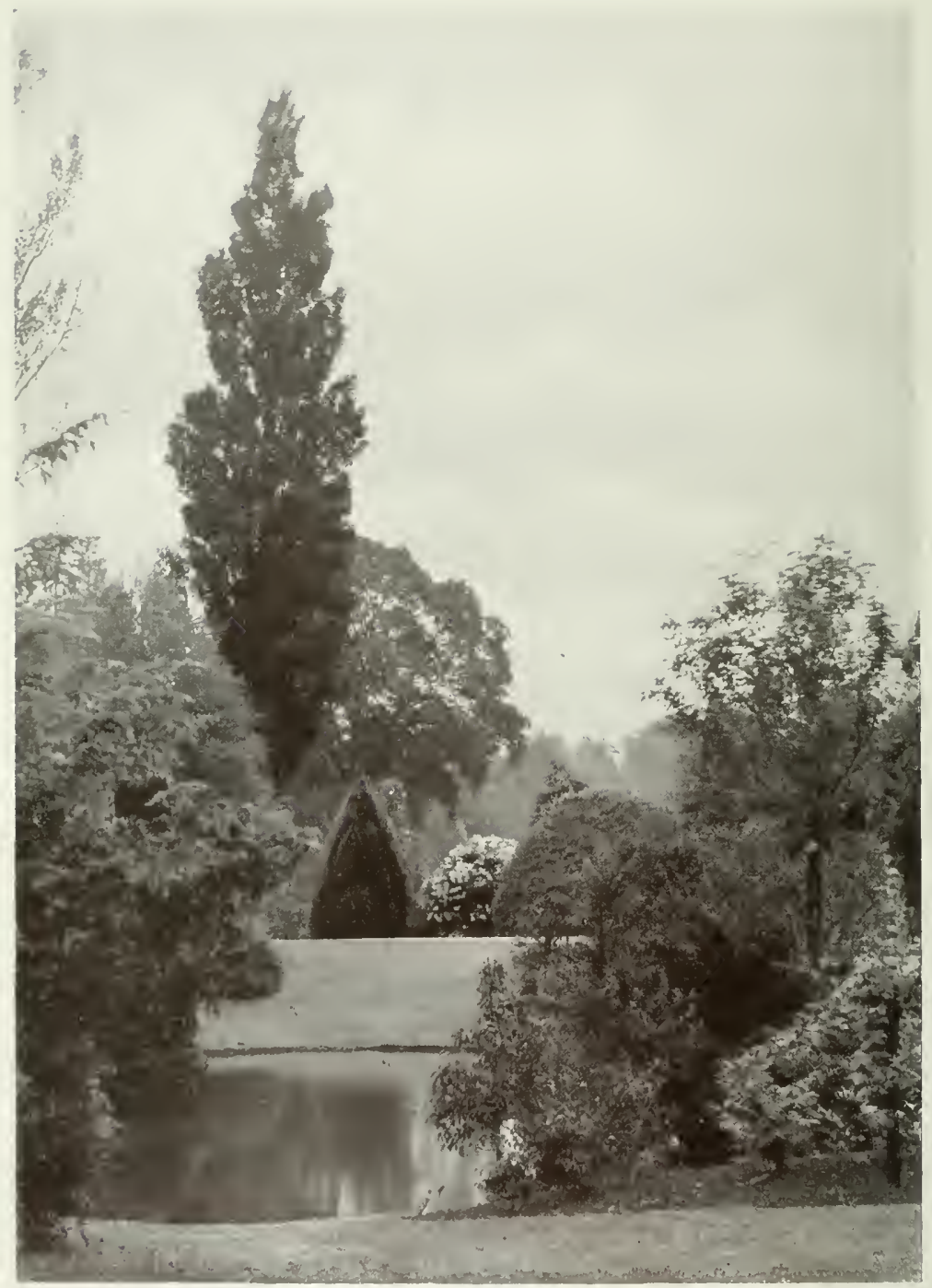

A VIEW IN THE WATER GARDEN AT ALDENHAM HOUSE, ELSTIREE, SHOIVING CYTISUS SEAIPERFLORENS ON THE RIGHT. For description see Part IV. Photo by R. A. Malby. 
There was a time when shrubs and trees were used almost entirely for shelter and shade, and this lasted long enough to spread common kinds, of no real beauty, far and wide. The nurseryman fell to propagating them in large numbers, and having stocked himself abundantly, he quoted cheaply, offering a strong temptation to people of limited means. A vicious circle was thus created and it still operates forcefully.

There is this danger about common shrubs-the amateur who considers himself justified in planting them for quick shelter does not always adopt the precaution of limiting strictly the area which they can usefully occupy, and almost before he realises what is happening they have encroached on space that is worthy of better things.

We have arrived at an epoch when shrubs and trees are valued for their intrinsic beauty, just like every other class of plants. Numerous ornamental kinds await the amateur's commands. More than ever, therefore, does it behove him to plant coarse sorts with restraint; and to watch their development with unceasing vigilance. He must guard his garden space jealously. If it be small, every foot is precious, and the more limited the area the more important the choice of plants.

One may sometimes see a line of Laurels planted with an eye to quick shelter on an exposed site in a new garden. The amateur argues, and rightly, that he cannot have a good garden until the force of strong, cold winds is broken. The nurseryman tells him, 
and truthfully, that Laurels will make a dense evergreen screen rapidly. There follows a cheap offer of plants. The Laurels are planted. They grow fast and soon afford appreciable shelter. But now weakness on the part of the amateur may supervene. Appreciating the sheltering power of the Laurels, and failing to realise that they are difficult to control when they have grown woody, he lets them get six, eight, ten feet high. Meantime, they are spreading laterally. Presently he realises that they are becoming somewhat of a nuisance, and talks of curbing them. A year or two later he begins the task. Alas! the branches have grown thick and hard. Shears are of no use in pruning them. Tedious work with the knife has to be resorted to, and even with that, much care has to be exercised, or large "caves" are formed. The end often is that the attempt is given up in despair, and the Laurels are left master of the situation.

If a cheap shrub is brought into the garden to give shelter it is prudent to turn it into a hedge. Stiff though that may be, it is in character, and is far preferable to insolent and encroaching independence, which so often results in good shrubs being crowded out altogether, or if planted, overgrown and spoiled by rampageous neighbours. The Laurel, the Yew, the Holly, the Privet, the Hornbeam, the Beech, the Thorn-all of these are best turned into hedges if planted for shelter, because then strict bounds are set for them.

With the magnificent array of material at our command in these days it certainly must not be that our 
gardens become half filled with objects of no intrinsic beauty, even if they serve a definite purpose. We must be able to give good kinds all the conditions which they require for healthful and beautiful growth.

It is a common delusion that the more beautiful and sacred purposes of a garden-the capture of shade, the enchainment of seclusion, the suggestion of the spirit of mystery-can be fulfilled with a very meagre equipment of knowledge as to plants and their culture. There may even be found critics who, writing with the presumption which is only born of ignorance, suggest that what they may describe as "professionalism" is an actual bar to the attainment of these ends. It is only the garden-maker who fully realises the grossness of this error. The triumphs of modern gardening are due less to what is often spoken of vaguely as "artistic treatment" than to that thorough study of plants and their requirements which garden-lovers now give. It is, indeed, out of the study of plants that has arisen the capacity for making beautiful gardens. It is plants, not phrases, that make gardens. When the proper plants for particular purposes are chosen, and grown under the conditions that favour their development, there come naturally into being the results which the flower-lover set before himself at the outset. This may be called "professionalism," but it is none the less true art.

To choose the right plant, to put it in the right place, to grow it in the right way-this triune task is never so important as when the matter under consideration is that of shrubs and trees. Not only are errors more 
conspicuous when made with large than with small subjects, but they are more difficult and expensive to rectify.

It is for this reason that the reader is asked to repel that encouragement to make gardens out of phrases which leads to so much ineffective work, and to study the shrubs and trees which he sees around him-in Nature, in gardens, and at shows. Out of the knowledge which he acquires, garden-pictures will grow. He will see the soft and tender tints of young spring leafage, the snowy billows of fruit bloom, the great ivory hyacinths of towering Chestnuts, the sparkling garniture of spiked Thorns, the glittering wreaths of Mock Oranges, the glowing brasiers of Rhododendrons. His senses will be lulled by visions of shady paths and enveloping arbours; by smooth, soft lawns screened by banks of shrubs; by remote, tree-shaded walks; by cool vistas where the spirit of mystery lurks; by glimpses of shadowed water seen through a quivering heat-haze. And he will have the consciousness of reality about these things, for he will know that he has learned how to create them, and will proceed with confidence to the completion of a delightful task. 
"THE SPARKLING GARNITURE OF SPIKED THORNS" (See page $I$.)

Painted by A. C. IVyatr. 


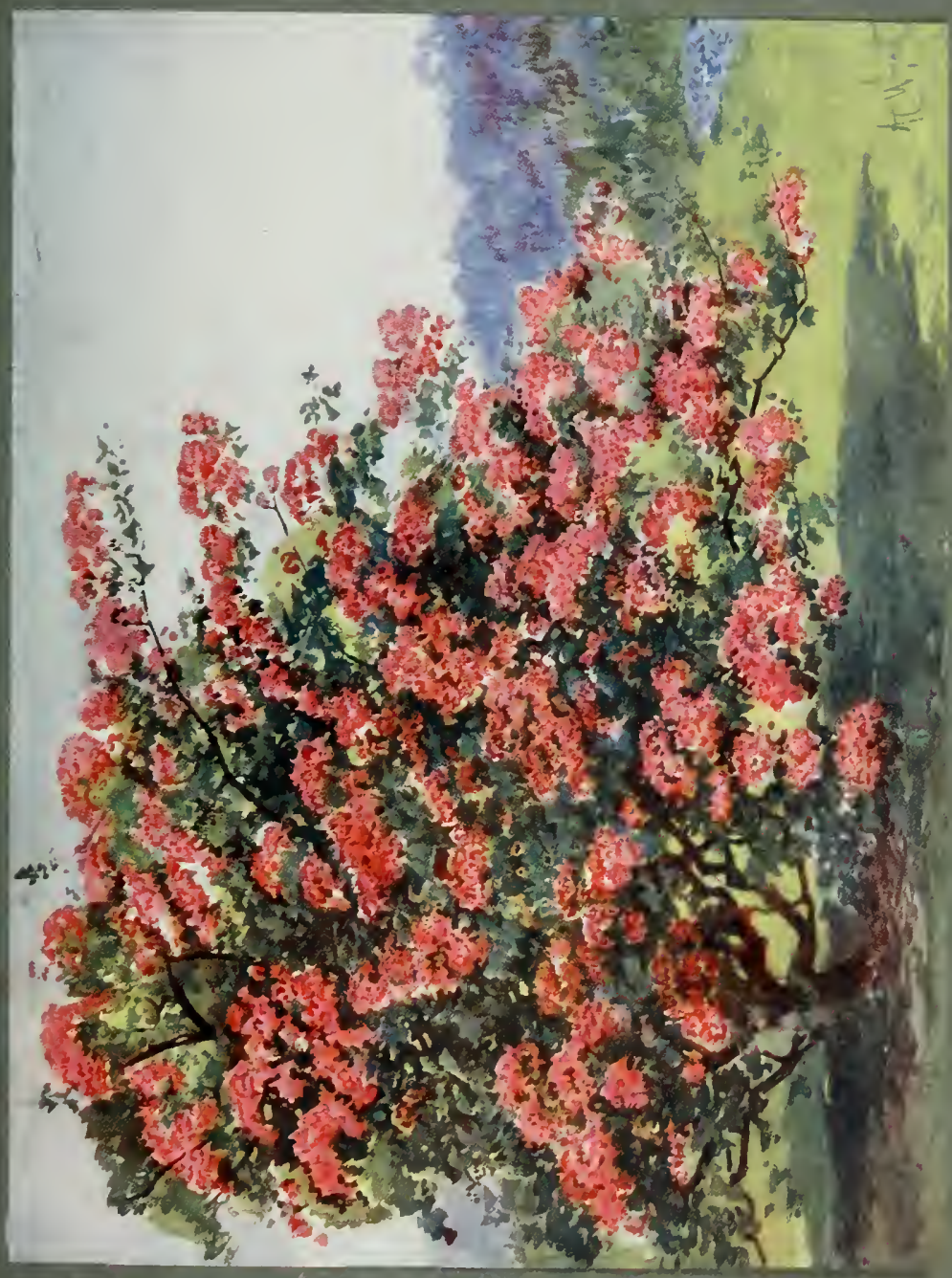





\section{CHAPTER II. \\ Garden Seclusion and Woodland Mystery.}

It is well that the garden-maker should be imaginative, so long as he be not a mere visionary. It is well that there should come before him pictures of peaceful and shadowed beauty. It is all to the good that he should dream of a garden that is more than a mere glare and riot of colour.

We all love the garden of shade and repose. It possesses an intimate and rarely comprehended appeal. Deep within us there stirs a vague love of its tender seclusion. One hardly dare hazard a speculation as to the origin of this feeling--whether, for example, it springs from some primitive hereditary instinct, fruit of an arboreal existence in past ages. Sufficient that it exists, and that it is a real factor in the projects of nearly all garden-lovers.

In a garden that is judiciously furnished with shrubs and trees there will be many moods. Light and shade will have meanings there that do not exist in the onelevel garden. The music of the winds will have a greater range of notes. There will be play of sunlight and shadow on grass. Dew will fall more lavishly. There will be a softer touch in the air. 
The garden-maker realises a new power. He can influence the effects of dawn and sunset, wind and climate. Not only can he change the ground which he delves, but also the round of Nature which plays over it.

Should there not be more garden-making in which seclusion and mystery lurk behind beauty? In the home confines flowers must, of course, predominate; but there might often be a hinterland, not distant, and yet remote, where a fresh and not less beautiful spirit could reign. Those who love flowers well can never really grow weary of them, but there are times when the sweet coolness of secluded spaces presents an overpowering appeal. The wander-love is something more intimate, more searching and conversely less ebullient than the flower-passion, but it is every whit as real.

When the garden-maker turns to shrubs and trees for a part of the material with which to furnish his domain, he might do well to consider whether he cannot use them for other purposes than display - whether, indeed, he cannot call into being that sense of restful solitude, of benign secrecy, which have so soothing an influence on mind and body. To achieve this purpose is to gain one of the most profound gifts which a garden can bestow. With no other class of plants is it possible. With them it can be accomplished.

It is more particularly when woodland exists on the estate that the end in view can be reached. For the woodland can be taken as the ultimate expression, and everything else can lead up to it. There can be a 
gradual linking together of home and trees. The more formal gardening of the house-confines can be gradually, almost imperceptibly, softened and attenuated as it approaches the trees. And if no woodland exists, some rough planting can be done, if only the formation of a shaw, thicket or roundel, which will stand for forest.

It is in the belief that gardening conveys more to many minds than the provision of blocks of colour round a house, that thus early in our consideration of shrubs and trees the suggestion is thrown out that a modulated blend of planting, systematic although not stiff near the dwelling, informal, even scattered, beyond its confines, be considered. To take an illustration from the paths. Near the house they must be neat and ordered to the point of formality ; they will probably be of gravel. There are good, sound, practical reasons for these things, which need not be discussed at the moment. Beyond the lawn, hard paths may end, and grass walks begin. They will be dressed, if only with the scythe. Nearer the woodland, where shade operates more strongly, moss will assert itself. There may, too, be a fall of pine needles, which has its influence on the turf. In peaty districts there may be a carpet of heath. Note the gradual dropping away from cultivation : first the rolled, swept gravel; next the mown turf; then the carpet of moss, or pine needles, or heath. Each will be right in its place.

The planting may follow some such course. It may not be stiff and formal near the house, but it will be systematic and ordered. On the outskirts of the 
lawns it will be freer-a little disjointed as it were. Farther still it will be semi-wild.

This is a conception of gardening which makes for the linking of the home with Nature. It does not call for costly schemes or expensive plants. It asks for nothing more than a note of gradation. In future chapters we shall see what material there is for giving effect to the theory, and the means by which it can be employed. 


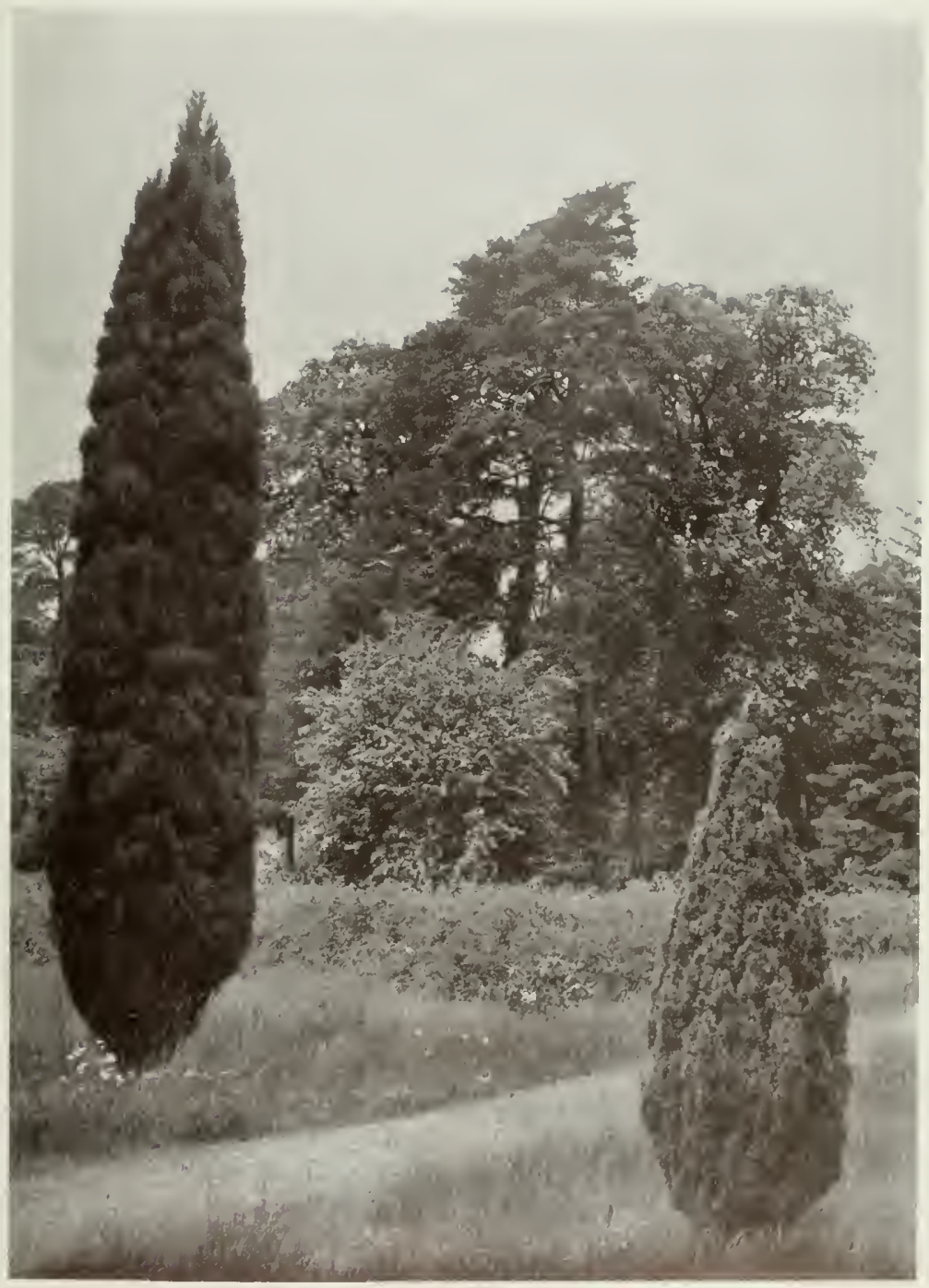

GOLDEN IRISH YEW (on right) and CUPRESSUS LAWSUNIANA ERECTA VIRIDIS (on left).

For description see Chapter XVII.

Photo by $R$ A. Malby. 


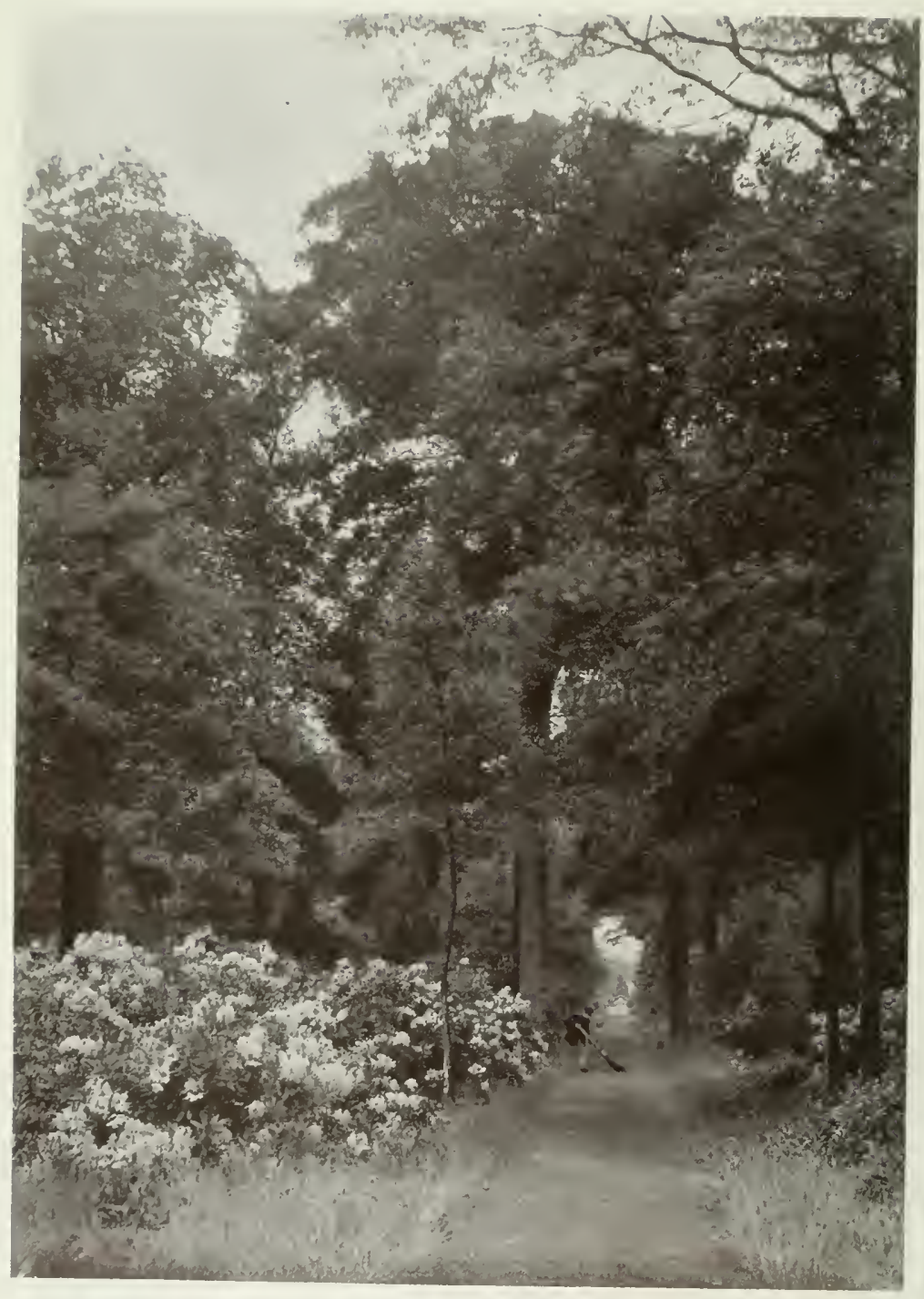

RHODODENDRON GLORY IN THE WOODLAND GLADE. R. ponticum at Aldenham.

For description see Part IV.

Photo by R. A. Nalby. 


\section{CHAPTER III.}

\section{The Threshold of the Woodland.}

THE point where the garden ends and the woodland begins should be a place of joy. Trees are great, kindly friends. They extend welcoming arms and utter welcoming sounds. Those who have held companionship with the trees in childhood never forget the love which grew up for them.

The garden-maker must not be despondent because he cannot call woodland into being as fast as he can create lawns and kitchen gardens. He must plant, wait and watch. More speedily than he expects the goodly stems will lengthen. The years will glide by, and as he awakens to find that his children have grown up to manhood and womanhood, so he will awaken to the realisation that the bare earth is covered and now the saplings are giving shelter and shade.

Few garden-lovers, perhaps, realise the interest that there is in watching the development of trees; but experience quickly teaches them that it fully equals the interest of Rose beds, herbaceous borders and Alpine gardens. There is the interest of calculating increase of height and development of girth. Form of stem and shape of head, colour of leaf and tracery of bare 
branch against blue of sky-all these points arouse attention. The trees have individual interest as trees, and collective interest as wood.

It is the way of most trees to grow slowly in their early years and fast when they are established. They have their root-system to make. They have to become firmly and securely anchored. Let the planter do good work in planting and staking, and then be patient for three or four years. The trees will slowly bind themselves to the earth. They will prepare deliberately for a lengthened habitation of the place allotted to them. Too wise to make hazardous experiments, they will not run swiftly upward on a flimsy foundation, but will bed themselves well in. After that they will bound upward.

On the threshold of the woodland we look back to the garden and forward to the trees. Each in its way has a charm for us. We love the brightness, the cheerfulness, the refinement, the perfume of the garden; and we love the clean boles, the tossing plumes, the hum and sob and rustle of the woodland. There may be moments when our mood is tuned to the one, and moments when it is best suited by the other. But the trees will always be constant.

In making gardens there must ever be an early, warm thought for trees. If the garden can only be a small one there may still be trees. We cannot in this case plant the monarchs of the glade-the Oak, the Beech, the Elm, the Ash, the Sycamore, the Chestnutin any quantity. But we can plant Birches, perhaps a purple Beech and even a selected variety of Oak. 
The rest must be smaller trees, and of these there are many remarkable for beauty of bloom, which will give us ample choice.

In the smallest garden there should be an attempt at cover, if it consists of no more than a cluster of silver Birches and Austrian Pines, with quick-growing, dense, yet beautiful shrubs such as Barberries, the Amelanchier and the flowering Currant, planted near. Rhododendron ponticum may be planted, too, if there is no lime, although it will grow more slowly, for it is dense in habit and beautiful in bloom, while no game will touch it. However small the thicket it will serve to provide the woodland mood.

There will be bird song on the threshold of the woodland. This will be the best of garden-music to the Nature-lover. We shall have to guard our fruit the more carefully for the shelter that we give to the birds, but we shall not count that cost too high in the end, although we shall have our moments of exasperation when ravished buds and berries and torn flowers come to be counted. The maker of a garden feels a singular, almost a thrilling interest on the discovery of the first nest on his domain. His garden is no longer an empty and desolate flat of bare earth. The birds have set their seal on his efforts.

Woodland! The word has a moving sound. It conjures up memories of swaying tops and singing winds ; of cool, humid paths; of dun, darting shapes; of soft carpetings of soft-toned flowers. There we have sought the bluebells, the periwinkles, the primroses, the windflowers, the wild orchids. Happy the garden- 
lover who has woodland on his property. Let him not permit it to become the exclusive possession of gamekeepers. Let him not regard it as alien to the garden. Let him rather link up the garden with it and learn the communion of the trees. 

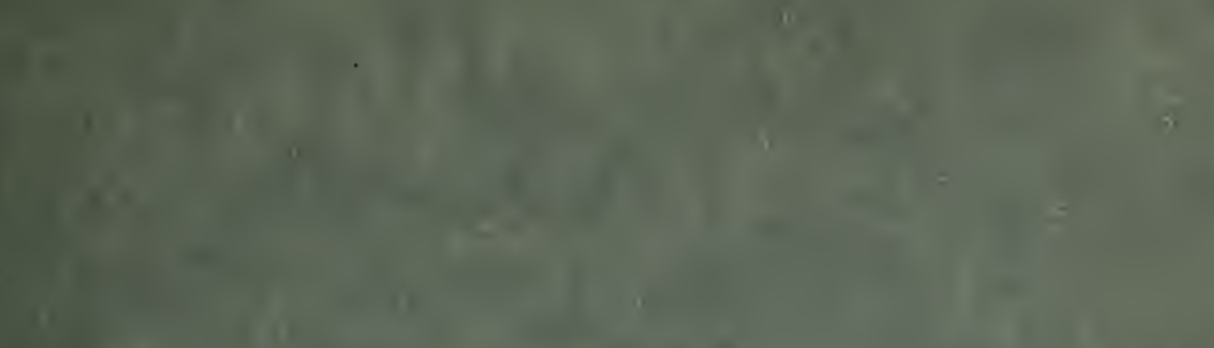

s

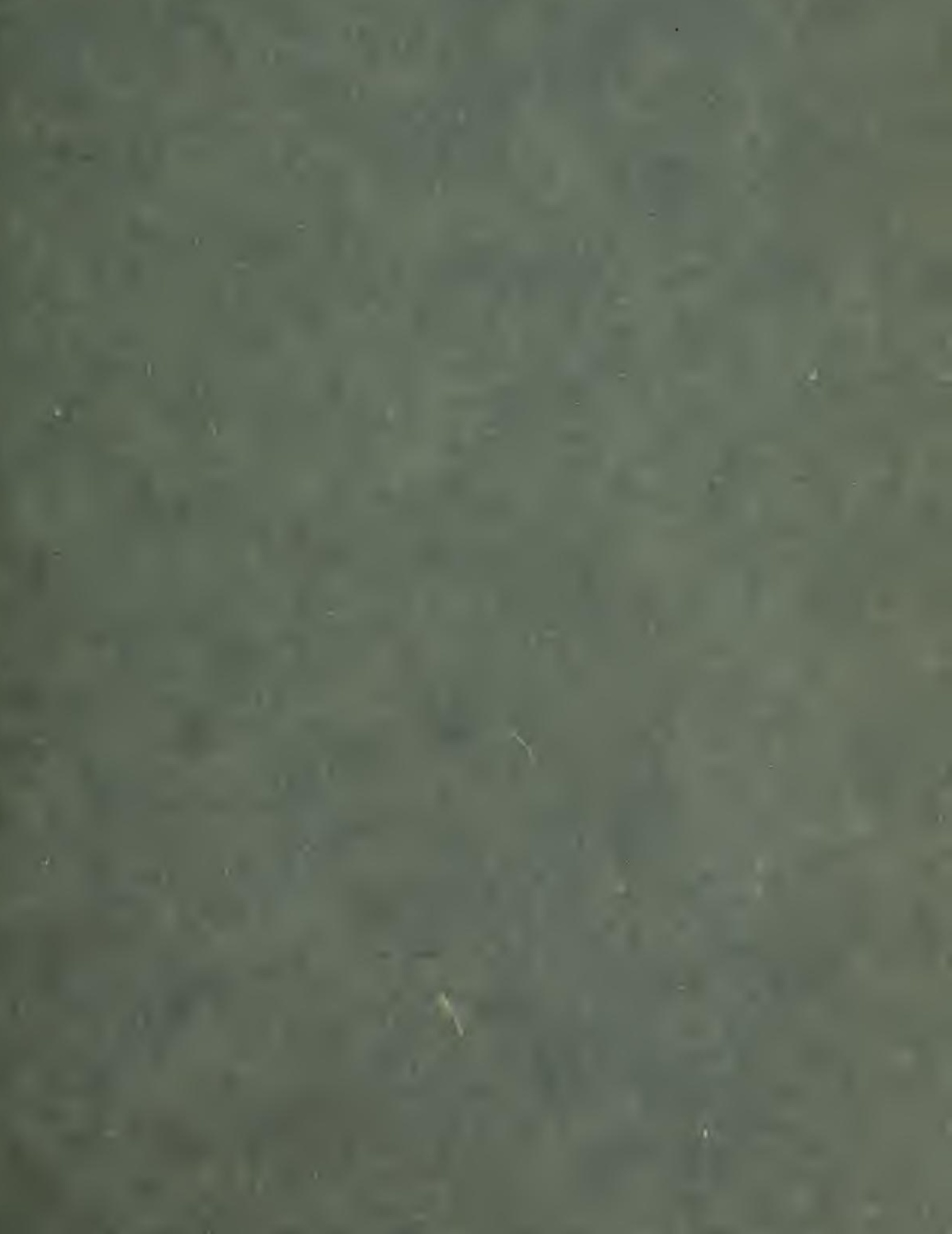




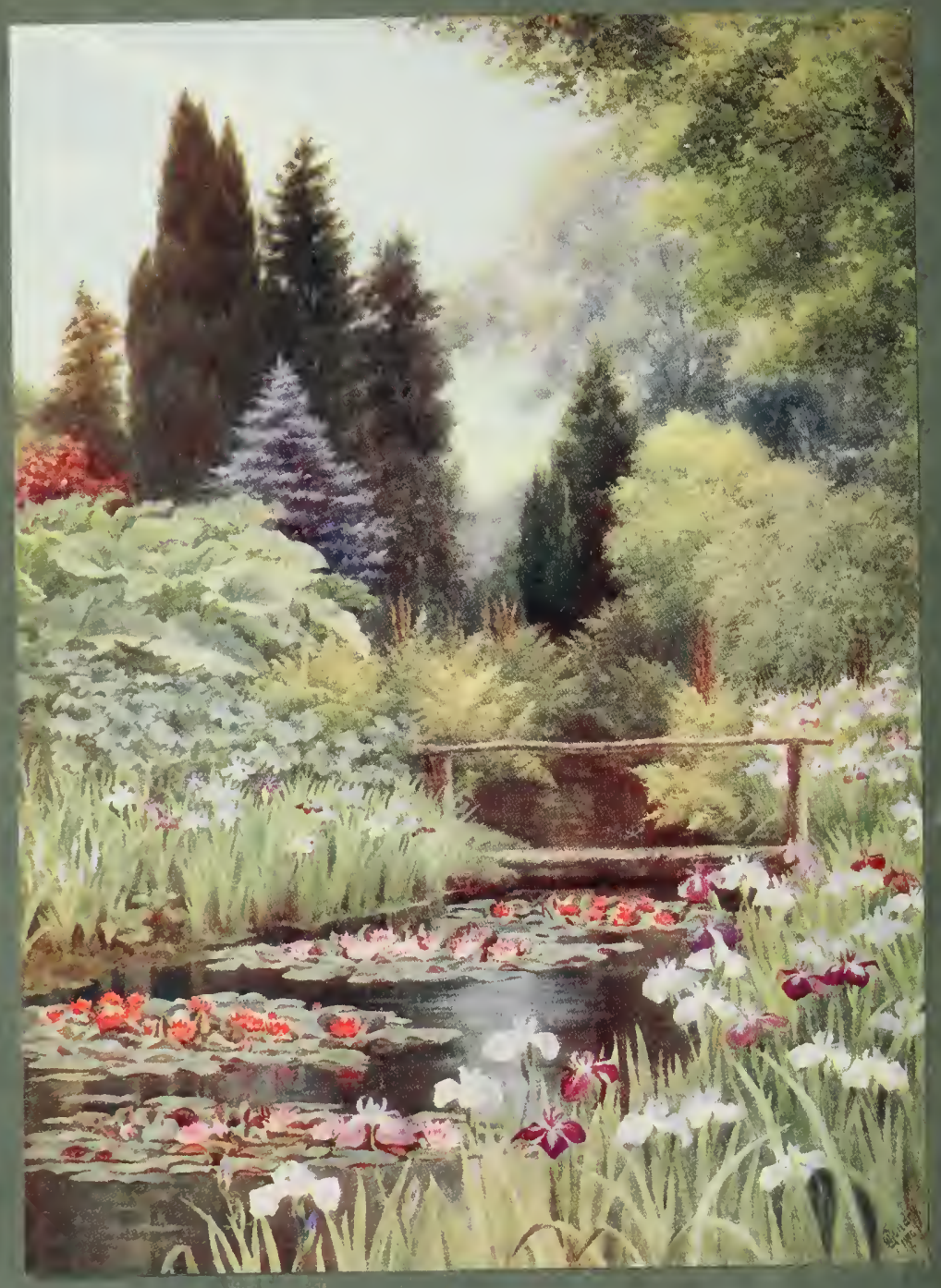


"A PLACE OF CHEERFUL PEACE."

(See page 29).

The Lily Pool at IVisley, showing an effective background of beautiful trees. Painted by JosEPHINE GUNDRY. 



\section{CHAPTER IV.}

\section{Shady Walk and Shadowed Water.}

AMONG the readers of this work there may be many whose gardens do not permit of extensive planting. Woodland in the expansive sense of that alluring term is denied to them. Even so, they may, as I have shown, capture the woodland spirit. The purpose of the present chapter is to suggest that they may also aim at seclusion and shade through the media of walks and water.

The typical garden walk requires no description. One is glad, in a sense, that it is so completely a side issue of the subjects dealt with in the present work that it calls for no more than passing reference. There must be firm, hard walks in certain parts of every garden. These walks are serious works in the making. They are drained and ballasted, gravelled and cambered. When they are finished they have a decorous and correct air. We cannot be light-hearted on walks like these. They are in, but not of, the garden. They come into being because there must be relatively clean, dry access to houses in all weathers, and they are tolerated as macadam roads are tolerated.

The walks in gardens which we really love are those winding, undulating, shady, soft-footed walks which 
have no fixed duty and no sense of responsibility. They never look stiff. They do not jar. They seem to be as much a part of the garden as the leaf is of the tree. We do not feel that they call for polished footwear. We can even, on occasion, traverse them barefooted. Birds love them. Flowers spring in them. Moss spreads over them.

Walks such as these never look as if they have been made. They seem to have grown. Yet it is not every garden owner who finds one on his place, and he may wonder if, like the mushrooms, they have spots which they favour. It may seem merely a coincidence to him that after the walk has rambled on in its inconsequent way for some distance it presently ends by a shadowy pool. This kind of walk has that kind of way.

Perhaps the walk never really more than half grew. In a year long past someone did something that started it on its way. It may have been a very simple thing, no more than planting a line of shrubs and scattering a few grass seeds beside them, but it was something and it sufficed. Nature took the walk in hand after that and finished it off.

Does the garden-maker realise how easily a grass garden-walk is framed? A few shrubs and a few seeds will do it. First, of course, there must be a conception. There must be two points fixed, now detached, but presently to be linked up. The ultimate point may be wood, or water, or summerhouse, or seat, or whatever makes the strongest appeal. That objective which interests the garden lover the most may serve for the termination of the walk. 
Does the gardener want to form his walk in a series of flowing curves? Then let him lay on the ground a waved cord, following the outline which he desires. On one side of the line he will sow his seeds, on the other he will plant his shrubs. He will plant for beauty and he will plant for shade. He will intermingle leaftrees such as Birch and Oak with flowering trees such as Thorn and Lilac. His shrubs will include the Rhododendron, the Azalea, the Berberis, the flowering Currant, the Forsythia, the Deutzia and the Weigela. He will plant for berries the Cotoneaster, the Holly, the Aucuba, and perhaps the little Pernettya.

Where space permits the walk may be wide-eight feet or more, because then a portion may be planted with bulbs for spring beauty. A strip in the centre may be kept mown in spring in order to provide reasonably dry walking, and in July the whole may be scythed over, taking down the yellow tops of the bulbs together with the tall grasses then in bloom. Daffodils will, of course, form the bulk of the bulbs.

There may be groups of Tree Pæonies beside the walk. There may be clumps of Bamboo. Dwarf flowers can fringe the front.

The walk that leads to the water-side will carry with it all the way the sense of coolness and shade. Willows may be planted to overhang the pool. Details as to kinds and treatments are given in later chapters.

The waterside is dull, even melancholy, in winter, but in summer it is a place of cheerful peace. In every garden there must be parts suited to the seasons. We cannot have every portion of every garden topically 
beautiful and interesting at every period of the year There is, however, one thing that we can do, we can draw on memory and cultivate imagination; then, when the planting season is with us, we can form pictures for this part of the garden and that, for this season and the other. It is thus that the most beautiful and enjoyable gardens are made. 


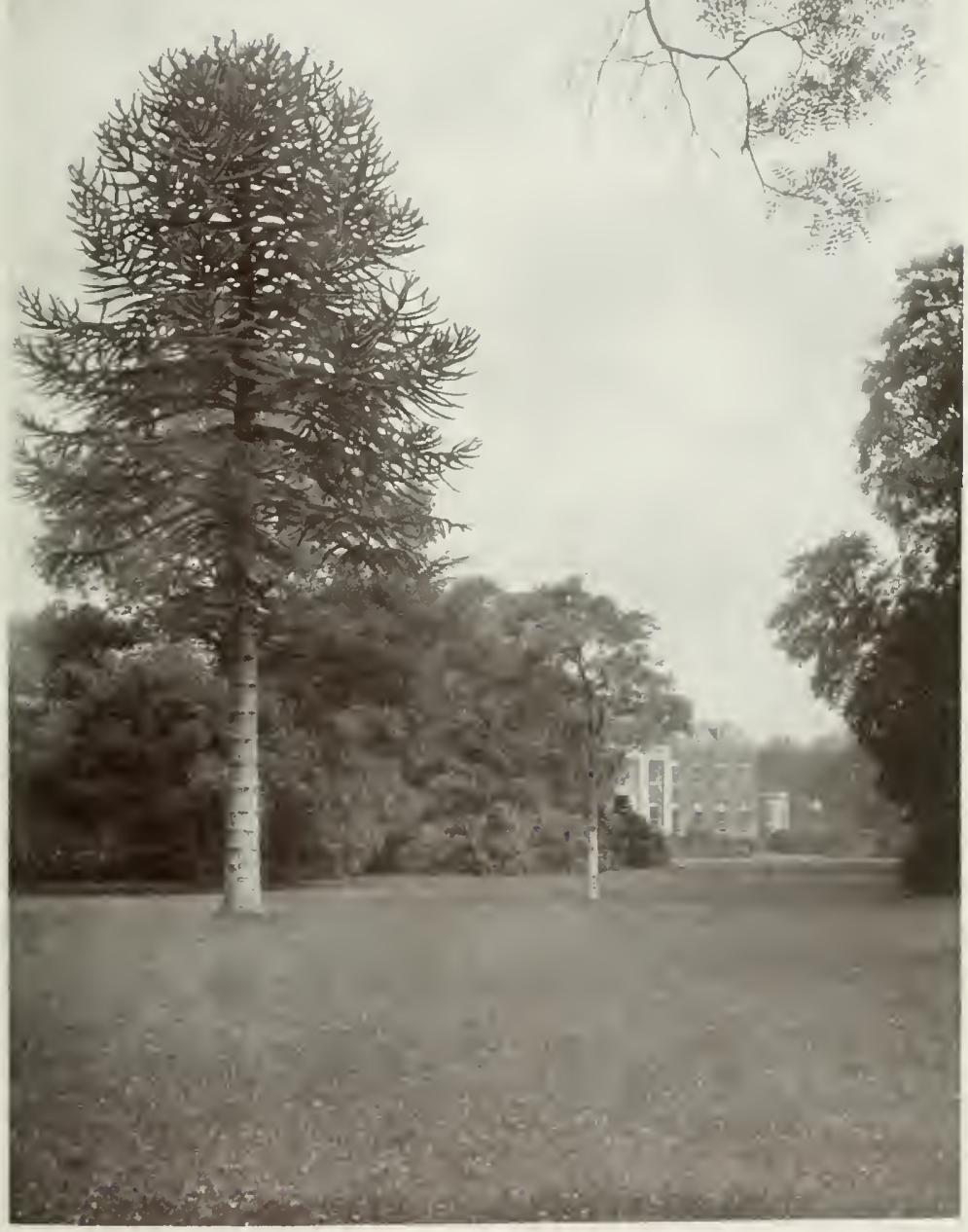

THE MONKEY PLZZLE OS AV EXPANSE OF TURF.

Araucaria imbricatá at Hinsley l'ark. For description see Chapter XVII. Photo by I: Mason Good. 


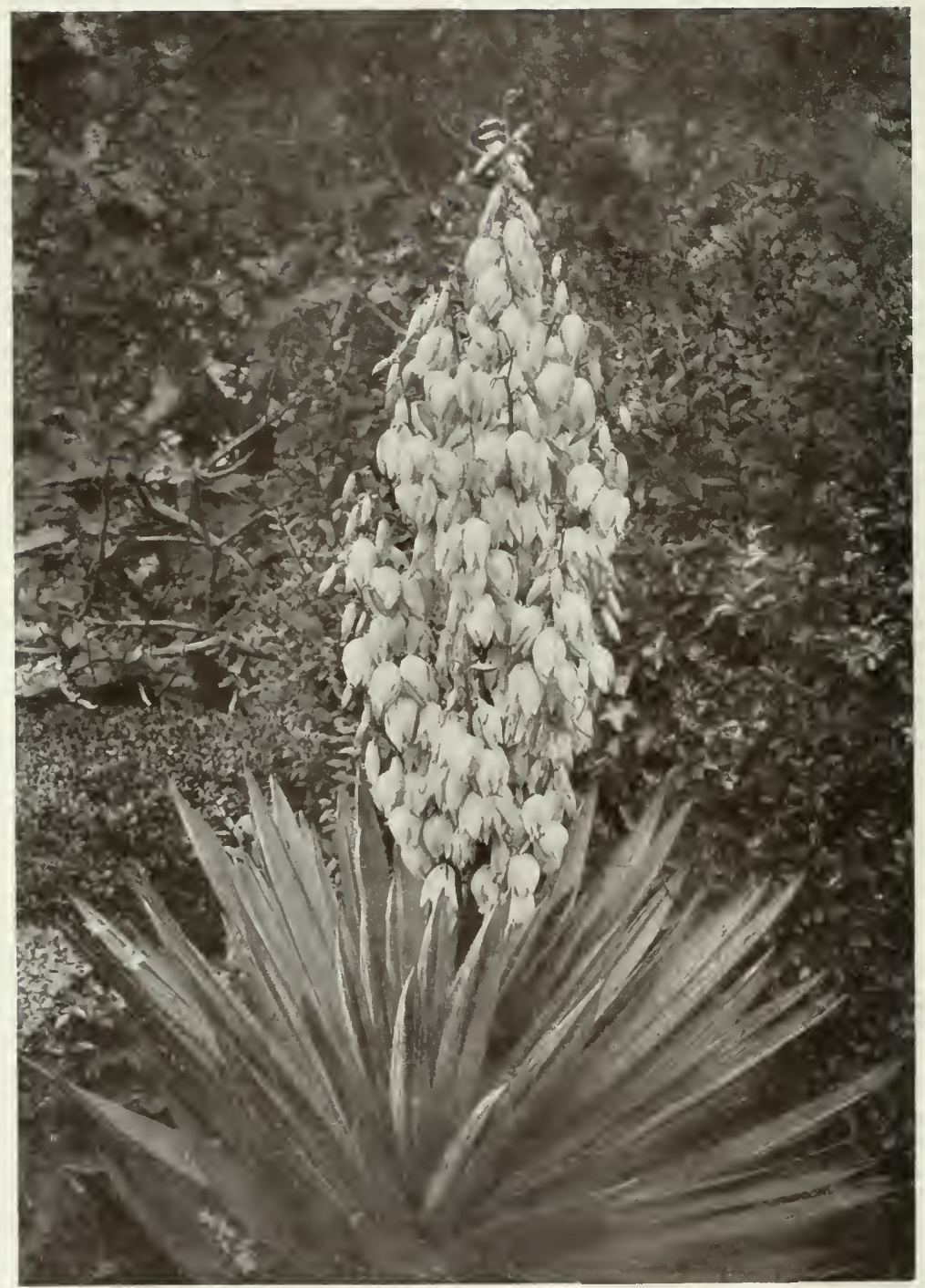

AT PEACE WITH TIME.

A YUCCA BLOOMING AFTER FORTY YEARS GROWTH. For description see Chapters XVI. and XIX.

Photo by F. Mason Good. 


\section{CHAPTER V. \\ The Place of Shrubs and Trees in Modern Gardens.}

In considering the part played in modern gardens by shrubs and trees we might first take the early bloom of certain standard flowering trees, such as Plums, Almonds, Cherries, and various Pyruses. It is to be remembered that this comes as early as April. A little later we have the Thorns, then the Robinias, the Catalpas, and many others.

The spring-flowering trees allied to the great domestic fruit genera are beautiful in a very young state; they grow slowly and they never attain to great proportions. It follows, therefore, that they are suitable for small, as well as for large, gardens. No garden-maker can afford to overlook them. He may have at the bottom of his heart a particular love for some special flower; he may have within himself the makings of a narrow specialist in Carnations, Roses, Dahlias, or Sweet Peas; but if his garden is to be a garden at all, it must have some permanent features.

The amateur should not permit himself to be prejudiced against the spring trees because they are artificially propagated by budding or grafting on tall standard stocks of Crab, Gean, Thorn, or Plum. This, 
indeed, gives them their instant value, for it lifts them at once on to a conspicuous plane, and permits of their being associated with beautiful bushes, which hide the bare stems of the standards and in no way interfere with the spreading heads.

The flowering trees are a glorious feature of the garden in spring. It may be that they are ornamental with fruit or berry in the autumn, but be that as it may, their spring charm amply justifies their existence. They rarely fail to bloom, and generally they clothe their branches in flowers from base to tip. They are not long-lasting, but they serve their purpose, opening the garden year with a flush of beauty. It is not necessary to plant them thickly. A few trees here and there, or spaced in shrub borders, will give a touch of warmth, life and colour at a time when the cuckoo begins her call.

Timber trees will be planted sparingly in small gardens, and he who is tempted by dreams of coolness and shade will do well to remember that he can get these agreeable features without introducing coarse and greedy trees such as the Elm and Poplar. He may think of the Copper Beech, the Mulberry, the Catalpa, the Tulip Tree, ornamental species of Oak, and others which are described in their proper chapters. There are, of course, many places in which garden melts into park and woodland; and here the trees of the forest will have their appropriate place. This question of tree-planting presents, perhaps, as nice a problem as any which besets the garden-maker. He has to think not only of the benign influences of dew and 
shade, but of the maleficent effects of drip and rootforaging. A balance has to be struck. Isolated lawn trees cannot be planted with as little consideration as belts of Larch. Trees for the inner garden, for the house-confines, must be kinds which do not send out locust-like plagues of root, nor grow stiffly, but which have graceful habit and ornamental foliage. One often sees heavy belts of cabbagy trees quite close to the walls of a house, where there is inadequate perspective. These are cases in which the same mistake has been made as is made by the small gardener with his Laurels. A belt of trees has been planted for shelter, without thought as to their ultimate dimensions. The trees have grown, thinning has been neglected, and presently a gloomy mass is formed.

There can be no doubt that a new garden requires constant observation for several years in order to maintain its balance. This is not least the case with gardens which have been formed under the supervision of a competent landscape gardener. $\mathrm{He}$ is bound to give an immediate effect, and he cannot do that without leaving some thinning and rearrangement to be done afterwards. A shrubbery must be either painfully thin in its youth or gorged in its maturity that is to need no manipulation during its adolescence.

When the flowering and the large foliage trees have been considered there remain two great classes: the flowering shrubs and the coniferous trees. The part of the former is growing yearly in importance. It is to this class that the greatest additions have been made in modern times. Many entirely new shrubs 
have been brought from China, and while exploration has been going on in the Far East hybridizers have been at work at home, so that novelties have come from two entirely distinct sources.

If flowering shrubs were planted at all in the old days it was in the form of groups of Rhododendrons, which were generally set on the outskirts of lawns. It was rare to see beds or broad belts of various kinds of flowering shrubs, associated harmoniously. That, however, we are beginning to see now, and what we may expect to see more and more frequently as the years pass. Lovers of herbaceous plants mix their favourites with greater or less skill in borders, and just as they do this, so will shrub-lovers make borders of the plants which they like best. It is often the ideal way of growing a shrub to mass it in a bed to itself, but owners of small gardens cannot do this to any extent, and so they will put the kinds together in beds, borders or belts.

Does a comparison between shrub-borders and herbaceous-borders suggest itself? Such a thing is pardonable. The shrub-lover can point to permanent effect. He is able to claim superiority in the fact that his areas are never bare, nay more, that by a judicious use of evergreens, or such deciduous shrubs as have coloured stems, he can have winter as well as summer beauty. Nor can it be said that the balance is redressed by superior brilliance in the summer. No herbaceous plants are gayer than Weigelas.

It is probable that as time passes, and more and more beautiful shrubs are introduced, there will be a 
growing tendency to form shrub-borders. Not a few amateurs, enamoured of the new shrubs, but reluctant to give up herbaceous plants, will try to form joint borders. With care and restraint success is not impossible.

The less hardy shrubs will find appropriate places on or under the lee of walls. Many beautiful kinds that are in danger in the open are safe on walls, where it is easy to fix a mat or other shelter over them in severe weather.

The conifers present a striking contrast with the foregoing classes. For the most part they are distinguished by dense habit and small leaves. Viewing them broadly, we consider them as dense, evergreen, columnar or pyramidal trees, in no sense brilliant or showy; but with a refined and "well-bred" air, which renders them admirable isolated objects in selected parts of the garden.

With so much ground to cover in a not inadequate but still limited space, this survey of the part played by shrubs and trees in modern gardens must necessarily be brief. We see, however, that while giving that play of light and shade, that suggestion of cool and dewy peace, which forms so great a charm of the garden, they do far more, giving us colour beauty from the first days of spring, exquisite tints of leaf and stem throughout the year, brilliant fruits and berries and graceful and elegant habit. 


\section{CHAPTER VI.}

\section{Shrub Beds and Shrub Borders- Spring Beauty.}

THE old-time "shrubbery," with its massed Laurels and such-like common places, must give place to shrub-beds and shrub-borders in which a more artistic and varied system of planting is adopted.

Although there are many summer-flowering shrubs it is in spring that the shrub-planter who devotes real care and thought to his collection reaps his richest reward. Some kinds will be in bloom before the winter quarter expires; a few, notably the deliciouslyscented little Mezereon (Daphne Mezereum) will be in flower in advance of their leaves. March will give blossoms, April, May and June will be rich in bloom.

One of the great delights of spring to the gardenlover is to see the first soft and tender film of green spreading over the beds and borders where deciduous shrubs are planted. At first it is only faintly perceptible, but it derives substance day by day. Some of the Spiræas are particularly pleasing in their gauzy garb. The beds become interesting at once, and their charm grows as the days lengthen and spring establishes itself more and more firmly. The long ruddy rods of Deutzias become studded with dove- 

"COLOUR BEAUTY FROM THE FIRST DAYS OF SPRING." (See page 35.)

Forsythia, Almond, Magnolia stellata, Berberis and Prunus. Painted by Josephine Gundry. 


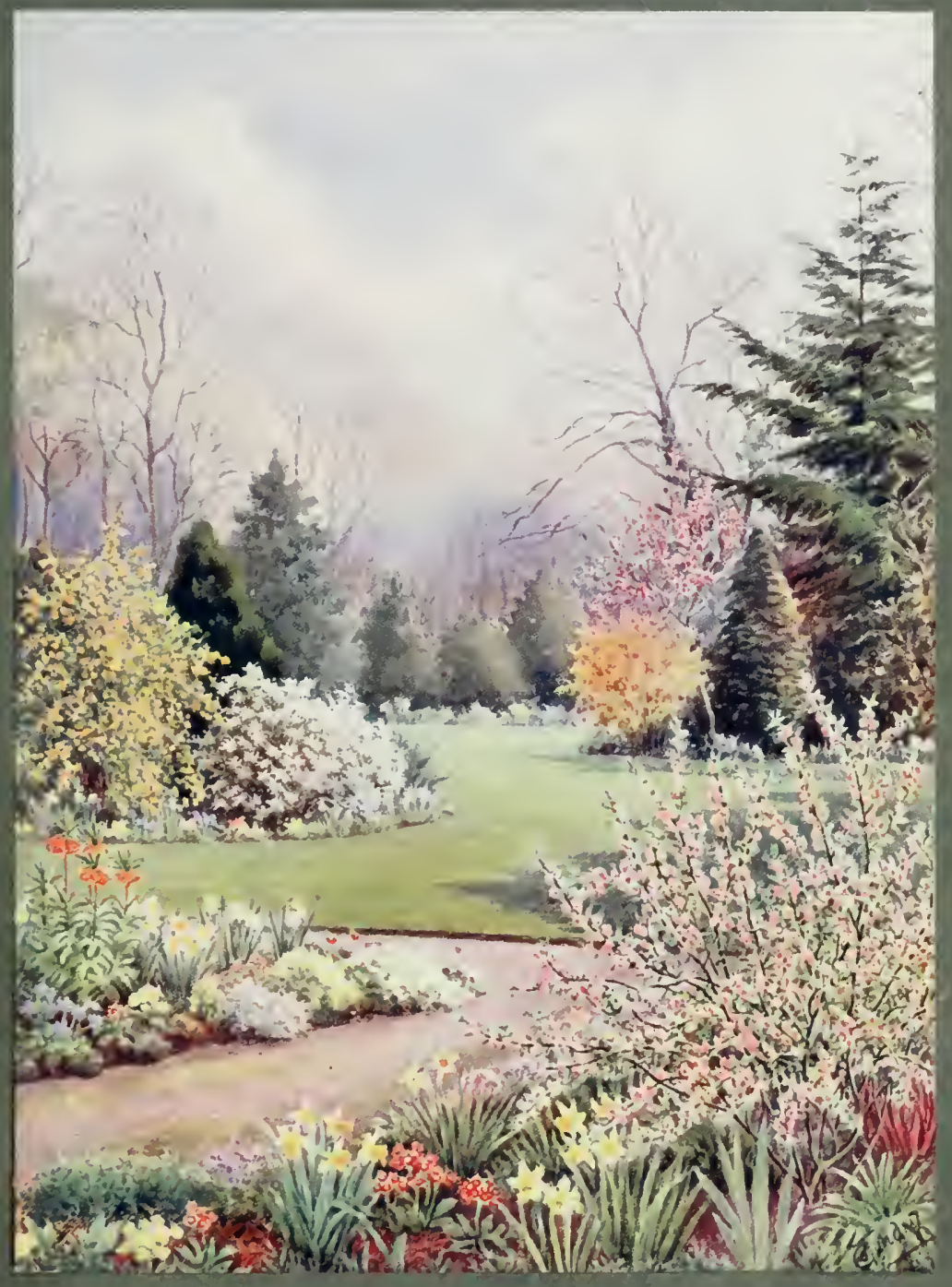




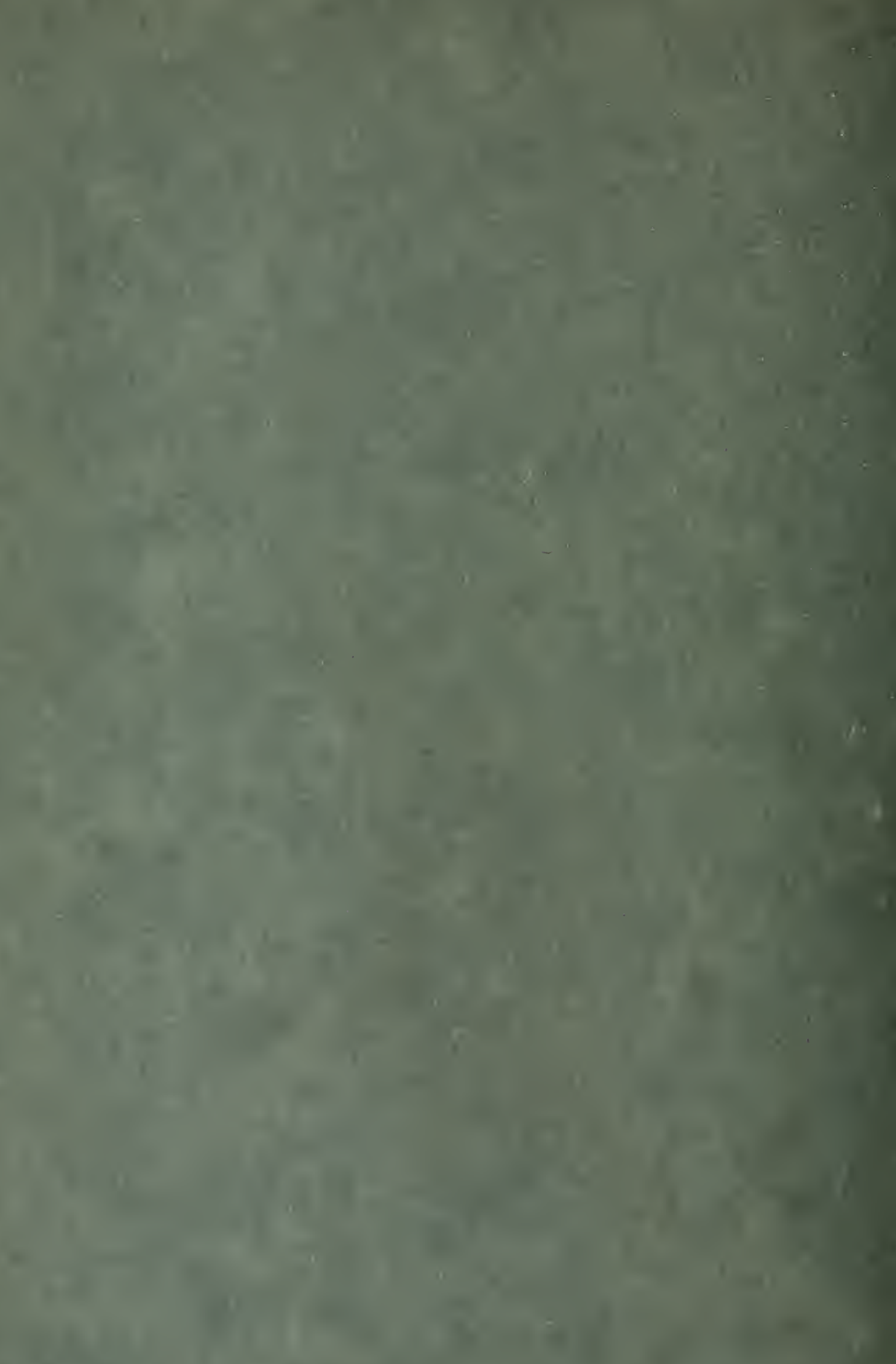

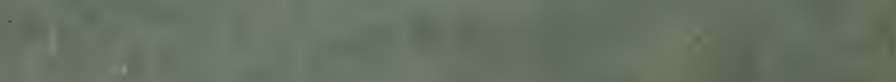


green swellings; the thick canes of the Weigelas are stained with fresh verdure; the grey, frail, almost substanceless shoots of the Mock Oranges pulse with vigorous life; sturdy green knots appear on the Honeysuckles. One by one the shrubs respond to the gentle and sympathetic touch of spring, and for many weeks the entrancing picture of unfolding goes on, growing in volume as the April days wind their course towards May.

However insignificant the other features of a garden may be, he who has a collection of shrubs will lack neither interest nor beauty in the joyous spring days. He may sympathize with, but assuredly will not envy, the Alpine enthusiast, whose rockeries are also bright with flowers.

When the grower realises how much delight there is in the pageant of spring he will take steps not only to enrich but to prolong it. He will not only plant beautiful shrubs, but he will make a judicious selection of kinds, so that from the first days of spring until the Rose-season begins, he may have beauty.

In those old-time shrubberies that we wot of a thick belt of shrubs and trees came right to the edge of the lawn, drive or path. Things were kept " neat" with shears, mower and besom. The grass was cut, the belt clipped and the gravel swept. Vegetation was dense, almost impenetrable. Well, this was at least good for the birds. They swarmed in the thicket, and found the fruit-crops in the adjacent kitchen garden conveniently near. But garden interest was lacking. Spring was a happier time for the birds 
than for the gardener. What we now do is to keep the shelter-belts back from lawn and path, in order that we may have objects of interest and beauty to see when we wander in the garden.

Turf is the best of all foils for shrubs, and even where they are planted in borders by the side of walks, a margin of grass, perhaps two feet wide, should be provided between border and path. When the grass is there the mowing machine must be used, and this simple fact will tend as a check on the straggling over paths which is so often seen. The mower will see to that for the convenience of his work.

The old packing resulted from the almost exclusive use of evergreens. In nine cases out of ten they were not put in with any gardening interest, but merely to fill up space. Modern horticultural taste will not tolerate this. The melancholy thing is that it went on in small gardens, where every inch of space was valuable. Now, broadly speaking, the evergreens are not important for their flowers (there are exceptions, Berberis Darwinii and the Rhododendrons to wit) and indubitably there is a temptation to pack them and leave them. The greater the proportion of evergreens in a collection of shrubs the more likely is a sense of sameness, with concomitant loss of interest, to take possession of the mind of the owner. Partly because of this deadening influence, and partly because the bloom is relatively unimportant, evergreens should not predominate.

It is the deciduous flowering shrubs that are the chief joy of spring, and they should be the most largely 
represented in modern gardens. The fact that they will need cultivation is in their favour, for culture maintains interest. A person who prunes his shrubs as he prunes his Roses and his fruit trees will always have a lively interest in them. He will feel that their success or failure hangs directly on his own handiwork. When they thrive he will have a gush of pleasure that far exceeds any passive enjoyment.

Perhaps the ideal plan of making what might be termed mixed borders or beds of shrubs and trees is to plant both deciduous and evergreen kinds, the former mainly to give flower-beauty, the latter to give a "furnished " and substantial effect, particularly in winter. Some of the evergreens may be members of the great Conifer or cone-bearing class, many of which are admirably adapted for planting among leaf-losing shrubs. This point is kept in mind in the illustrated suggestions for planting which appear in other parts of the present volume.

It is beside lawns and paths rather than beside drives that the most important shrub-planting should be done. The commoner, cheaper kinds of evergreens may be set near drives, where it may be assumed that movement is more rapid and time for detailed inspection less abundant. Here there may be such massing as is contemplated, for broad effects are appropriate.

In the larger places much richer and better garden treatment beside the main drives may be expected in future than is generally attempted now. Such drives often pass through a large park, and until the im- 
mediate surroundings of the house are reached, little of horticultural interest is attempted. Yet by the simple plan of forming groups of shrubs at suitable intervals, garden interest and beauty could be unbroken from lodge gate to house door. The groups would have to be fenced to keep stock at bay, and in exposed sites it might be necessary to set up close wattles for protection in winter. But neither would entail a great deal of labour or expense.

In such cases I would certainly plant groups of one kind at each station rather than adopt the mixing system, because with the rapid transit bold clumps of colour would be more suitable than blends.

It is not only beside drives, lawns and paths that we can utilize shrubs, but also beside water. The islands of garden lakes form splendid beds for shrubs, and we may learn lessons for our work in this direction from the Japanese, whose skill as landscape gardeners makes their system well worthy of study. Inasmuch as the waterside presents its greatest charm in summer, when the hot weather makes the coolness and humidity grateful, we may here plant or otherwise utilize summer-blooming plants. The Hydrangea ought to have a prominent place, and it can be conveniently used in the form of large plants growing in tubs, which can be shifted under cover, or to a sheltered place, for the winter. The soft tone of the flowers, the freedom with which they are produced, and their long duration, are strong points in favour of this splendid shrub as an ornament for the waterside.

The Flowering Currants (Ribes) are among the 

THE FLOWERING CURRANTS ARE AMONG THE EARLIEST SHRUBS TO BLOOM." (See pages 40-4r.)

Painted by $\mathrm{A}$. C. WYatT. 


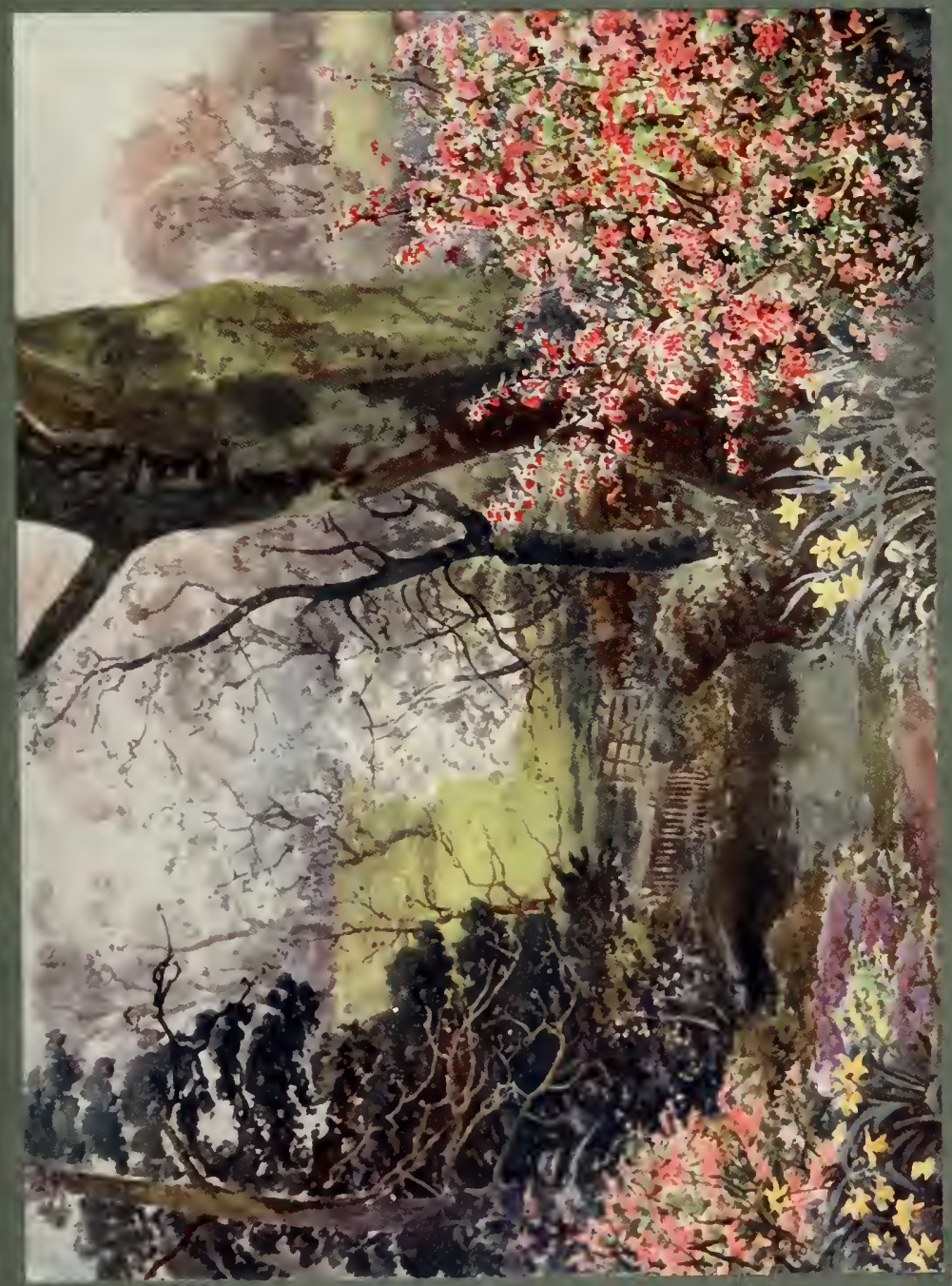


11

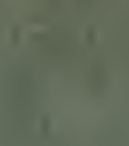

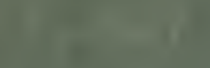

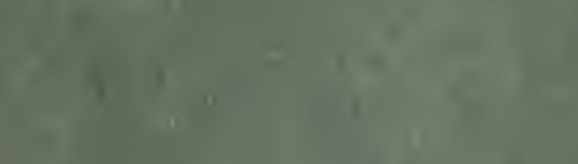
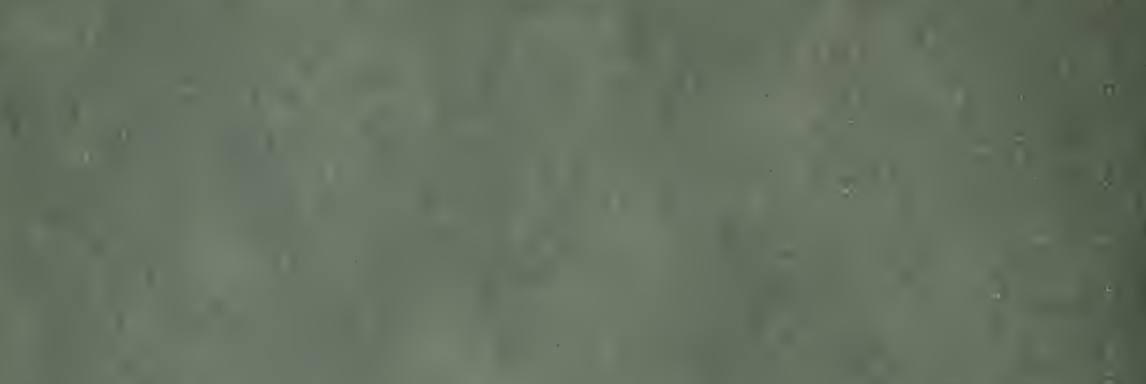

i. $1+2 x+2=$

in

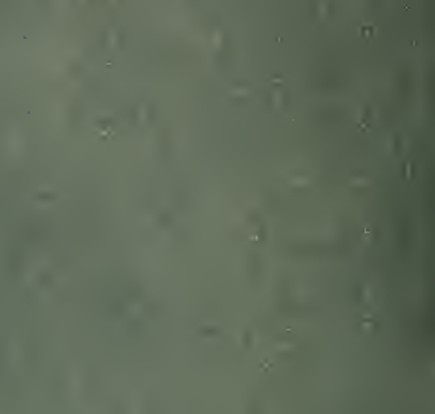

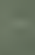

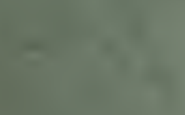<smiles>C1CCCC1</smiles>

$\sqrt{1+}$<smiles>c1ccsc1</smiles>

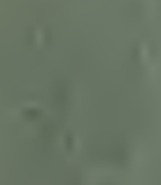

1

$+\frac{1}{x+1}+1$

ati

1.

11.
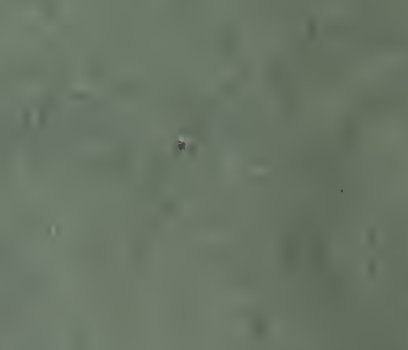

(1)

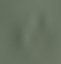

I1.

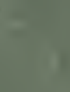

$y+x^{2}$
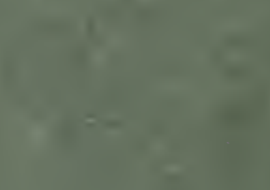

7

to

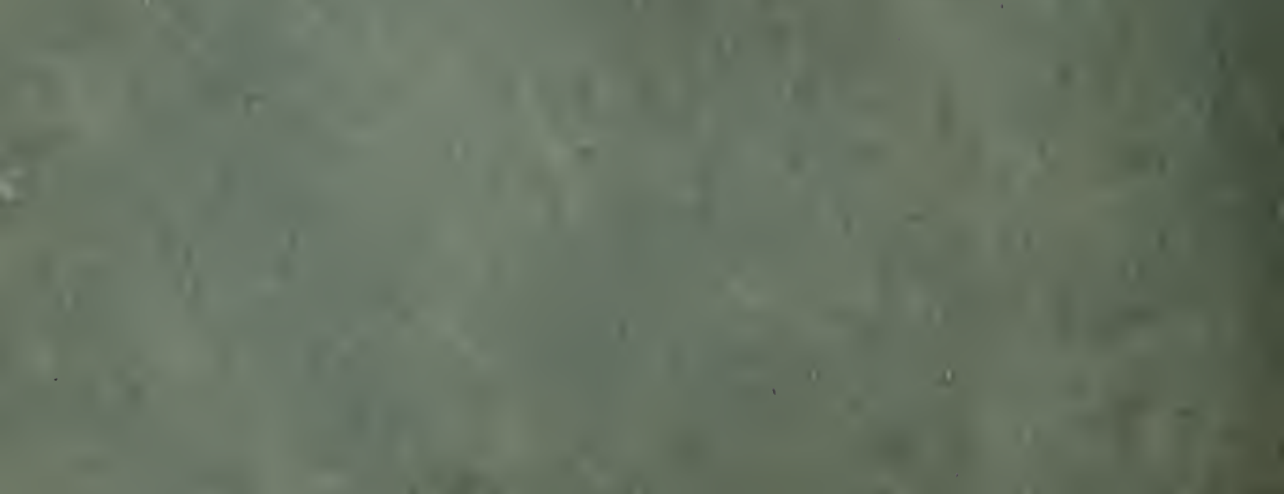


earliest of deciduous shrubs to bloom. Their precocity is such that a mild winter may find them in flower in February, and this is regrettable, because the sprays have no protection from the leaves, which often open behind the flowers, and a spell of sharp weather may spoil the blossoming, taking the colour out of the flowers and leaving them pallid and limp. They are such gross growers that rich soil should be eschewed and plenty of room should be given. The Forsythias may be in bloom with the Flowering Currants, and the Mezereon will also be early. A little later the earlier Magnolias, such as stellata, the Weigelas, and the Deutzias will open. Later still, and yet in anticipation of summer, will come the hardy Azaleas, Rhododendrons, Kerrias, Viburnums, Mock Oranges (Philadelphus), Brooms (Cytisus), Barberries (Berberis), Lilacs and the earlier Spiræas such as arguta and prunifolia flore pleno.

The flowering trees of spring embrace the Almond, Cherries, Plums, Thorns, Lilacs, Laburnums, and the lovely Pyrus spectabilis, all suitable for planting on standard stems among shrubs, where they break up the level and give a happy suggestion of "finish" even to a young bed.

The shrub-lover will naturally try to get all the best kinds represented in his garden, whatever their flowering season; but he will make a special effort to plant all the best of the kinds which bloom in springthat season when flowers have the most cheering influence, and when the awakening activities of Nature excite the most active response in the human heart. 

PART II.

\section{Practical.}





\section{CHAPTER VII.}

Mistakes in the Culture of Shrubs and Trees-Planting, Thinning, Moving, Pruning, Soil, etc.

CUlTuRAL errors in gardening are serious in proportion to the cost and size of the plants. The point that it is less easy to rectify a mistake in planting an Oak than in planting a Snowdrop is so obvious as to call for little emphasis.

There are people who rely for their principal garden effects on flower beds, which are planted at least twice a year. Changes can be rung on these from year to year, but shrubs and trees are planted for permanence, and it is, therefore, the more necessary to give careful consideration to every point, particularly to site, soil and preparation, before planting begins.

Shrubs and trees respond to different methods of treatment just the same as other classes of plant. A person who takes the trouble to observe the ill-effects of over-crowding on a seed-pan of Ten-week Stocks or Tomatoes has an object-lesson that should serve him well in planting his shrubberies.

It is, unhappily, rather the rule than the exception 
to see trees interlacing, and shrubs thrusting at each other in gardens. The nearest woodland or thicket gives examples of what comes from crowding, and yet the same doleful evidence of neglect is allowed to accumulate in gardens.

As regards pruning, let the amateur note what happens in the hedgerows, where a tangled growth of brier, hazel, wayfaring tree, bramble, and many another wilding is seen. What a mass of growth for a sparse and fugitive display of bloom! Old gnarled branches, long past the stage of flowering, mingle with younger shoots, half-smothering them, and robbing them of food and light.

Lessons from Nature are abundant on every hand, but for the most part they are unheeded, and so it is that shrubberies become unkempt and ineffective. One must confess that there are moments when the tangle of hedge or thicket is picturesque. Those who see it in its summer beauty, and never realize that it has another and a longer phase, may even hold it up as a model. Seen only from a passing motor-car in summer a large hedge may suggest grace and natural beauty in a form worthy of imitation in gardens. But keep in touch with that hedge through the round of the year, and a different opinion is formed. It is the casual visitor to countryside and garden who condemns as mere professionalism the demand for good culture in gardens.

If we take any one of the great flowering shrubs, and study two plants, one grown in suitable soil with plenty of room and properly pruned, the other crowded 

"WE CAN OBTAIN BEAUTIFUL PICTURES IN THE GARDEN." (See page 55).

The Double White Cherry, Prunus serrulata. Painted by Beatrice Parsons. 
4.

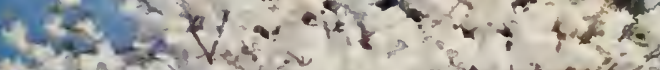

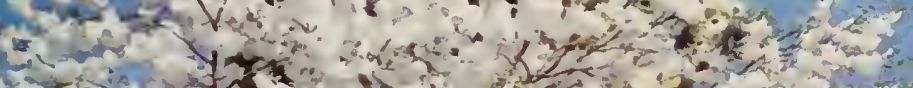

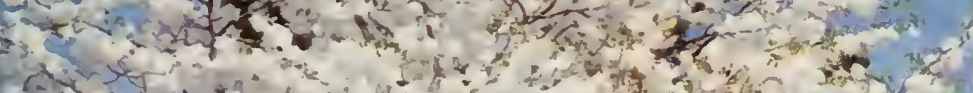

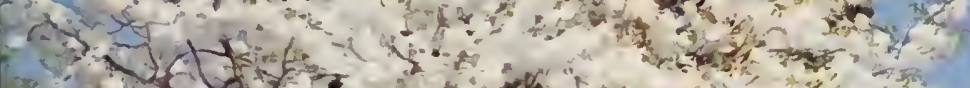

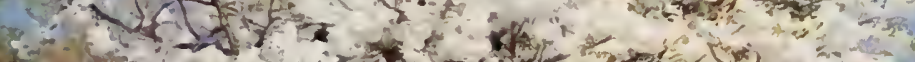

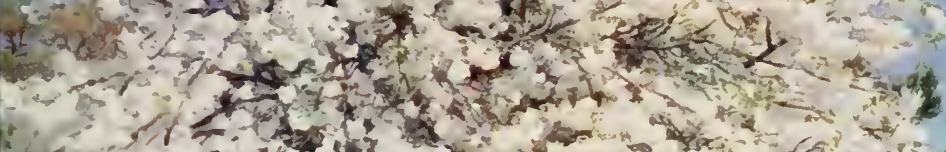

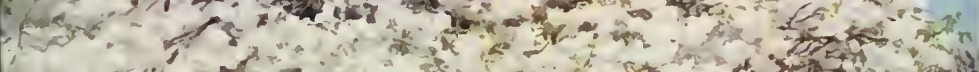

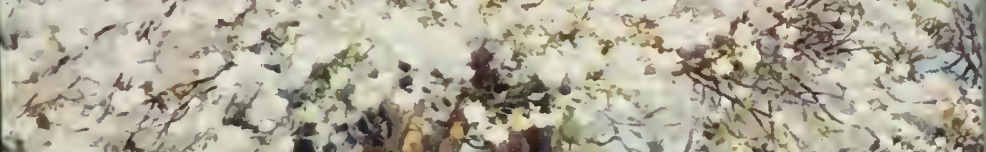

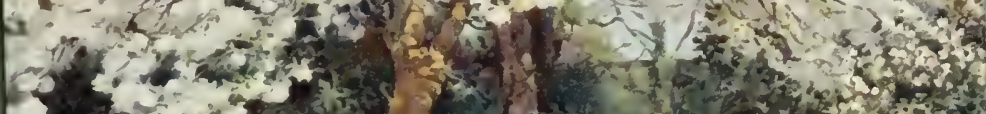

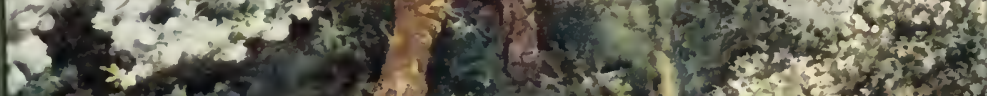

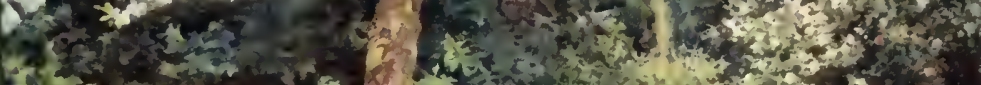

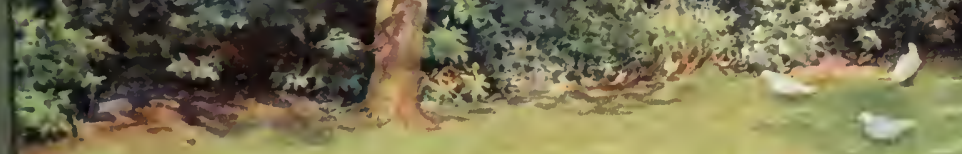

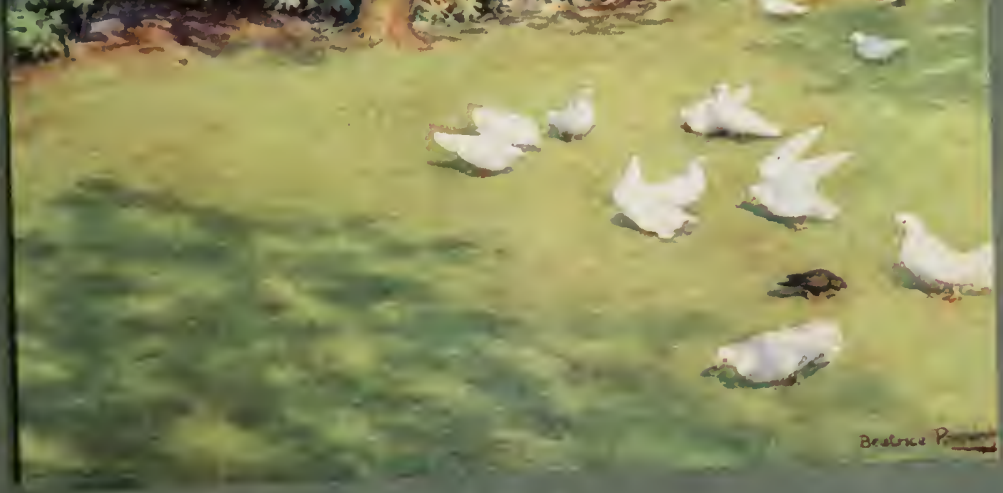




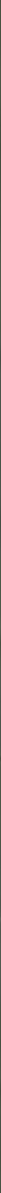


with a mass of shrubs in poor ground and left uncared for, we shall have an unforgetable lesson.

It is not stiff and formal professionalism which asks for good culture with shrubs. A well-pruned shrub is much more graceful than an unpruned one. It is a fallacy to suppose that most plants in Nature are graceful. It is only for a few odd days of the year that they are pleasing, most of the time they are ugly. Well-managed shrubs are attractive even in winter.

Most failures with shrubs spring from overcrowding. When the plants begin to mass, the cultural sense degenerates, with the result that pruning is neglected, and the plants grow into each other. The weaker are overborne by the stronger, and their growth dwindles. Instead of long spikes or racemes of bloom we see a few feeble blossoms on weak twigs.

Every good shrub has an individuality of its own, and that ought to be developed, not allowed to become submerged.

There is perhaps the least tendency to crowding when standard flowering and foliage trees are planted amid shrubs, and that in itself, apart from their admitted beauty, gives a good reason for planting them. These trees give a sense of "furnishing," which a low belt of shrubs does not. Let the reader who is oppressed by a sense of emptiness in a newly-planted shrubbery, and is tempted to put more shrubs in, set a few standard trees among the shrubs at distances of fifteen to twenty feet apart, and he will find that the change in perspective has a remarkably satisfying effect. 
Another plan that may be adopted is to set tall standard Roses of vigorous, free-growing kinds, preferably Wichuraianas, among shrubs. These also have a "furnishing" effect, and exercise a restraining influence on that tendency to pack which is so fatal a lure to most planters when they are forming shrubberies.

Perhaps sparing use ought to be made of the word "shrubbery," because it has grown to have an association in the minds of most people with dense masses of Laurels, Aucubas, and such commonplace things. It is this type of shrubbery that it is most desirable to get away from, except as a means of cheap shelter, which, as we have already seen, a hedge provides. The "shrubberies" that I have in mind are rather shrubbeds, planted with selected kinds, just as Roses are planted in beds by Rose-lovers, every plant standing out by itself, with its individual beauty fully displayed.

One is reluctant to speak of the massing of Rhododendrons as a mistake, in view of the fact that they are evergreen, and that a large bed presents a brilliant spectacle in early summer; but when one sees them grown as separate plants, as in the great Cornish gardens like Tremough, and at Kew, one sees that the plan is superior, for each piant becomes a noteworthy individual, symmetrical, evenly-balanced and with finer trusses of bloom. Following this plan, one would space Rhododendrons in large beds, or set them at intervals beside a walk, rather than plant them so close that they grew into masses. While saying this, it may be admitted that Rhododendrons lend them- 
selves better to massing than most shrubs, and their comparative success under such conditions cannot be taken as a guarantee of success with other kinds.

Sites for shrub-beds or belts can be found beside drives and paths, on the extremities of lawns, and on that half-way space or no-man's-land which often intervenes between the garden proper and the woodland. One often sees in gardens belts twenty or thirty feet thick of shapeless, graceless trees and tubby shrubs. Not a single tree or shrub in the whole area will bear a moment's inspection, and all the shelter that is provided would be given by a six-foot Laurel hedge. Consider the waste here.

The garden-maker should look out for good sites, and by no means be content to give his choice kinds the fag-end of a mass of Laurels, where the area is limited and the soil impoverished.

The fact that shrubs have to stand for many years should convince the planter that liberal preparation is necessary, and there should be no such thing as planting in poor, shallow ground. The soil should be dug deeply. Manuring is beneficial, but not, as some think, essential if the natural soil is a good loam or clay. The important thing is to provide a deep-rooting area, especially for deciduous shrubs; it is not so important for evergreens. Given this, mosi shrubs will thrive without heavy manuring. Manure is given with the greatest advantage as a top-dressing or mulching a few years after the shrubs have been planted. A coat spread on every other year has marked effects. 
I have noted with an interest not unmixed with surprise, the rapid progress of shrubs on ground much lacking in humus and fibre, in some cases with chalk less than a foot from the surface. The loosening of the chalk is not a laborious process, and deepens the bed. It should be recognised that the great majority of shrubs do not share the dislike of Rhododendrons for limestone. The success of the shrubs in the absence of much manure points a lesson, and I have little doubt that water is more important than manure for the first two or three years. A shrub will not miss manure if it has plenty of water. $\mathrm{He}$ who can turn a hose on to a bed of newly planted shrubs in dry spells the first year after planting will do more for their future welfare than can be effected with a whole farmyard of dung. In light, sandy soil manure is beneficial.

When a mistake has been made in planting shrubs too thickly it should be rectified by thinning. The great majority of shrubs "move," as gardeners say, quite well when they have been planted three or four years. Evergreens move better than deciduous kinds. I have no fear whatever of moving most evergreens in summer, provided rainy weather prevails. In a wet August I have shifted numbers of evergreens of various kinds, some so large as to tax the energies of three men, and not a plant showed the slightest sign of flagging, either at the time of moving or later. Long before leaf-fall, big deciduous shrubs have been shifted, and they, too, remained perfectly happy. Shrublovers are far too nervous about shifting. It is this fear that leads to overcrowding. When new gardens 


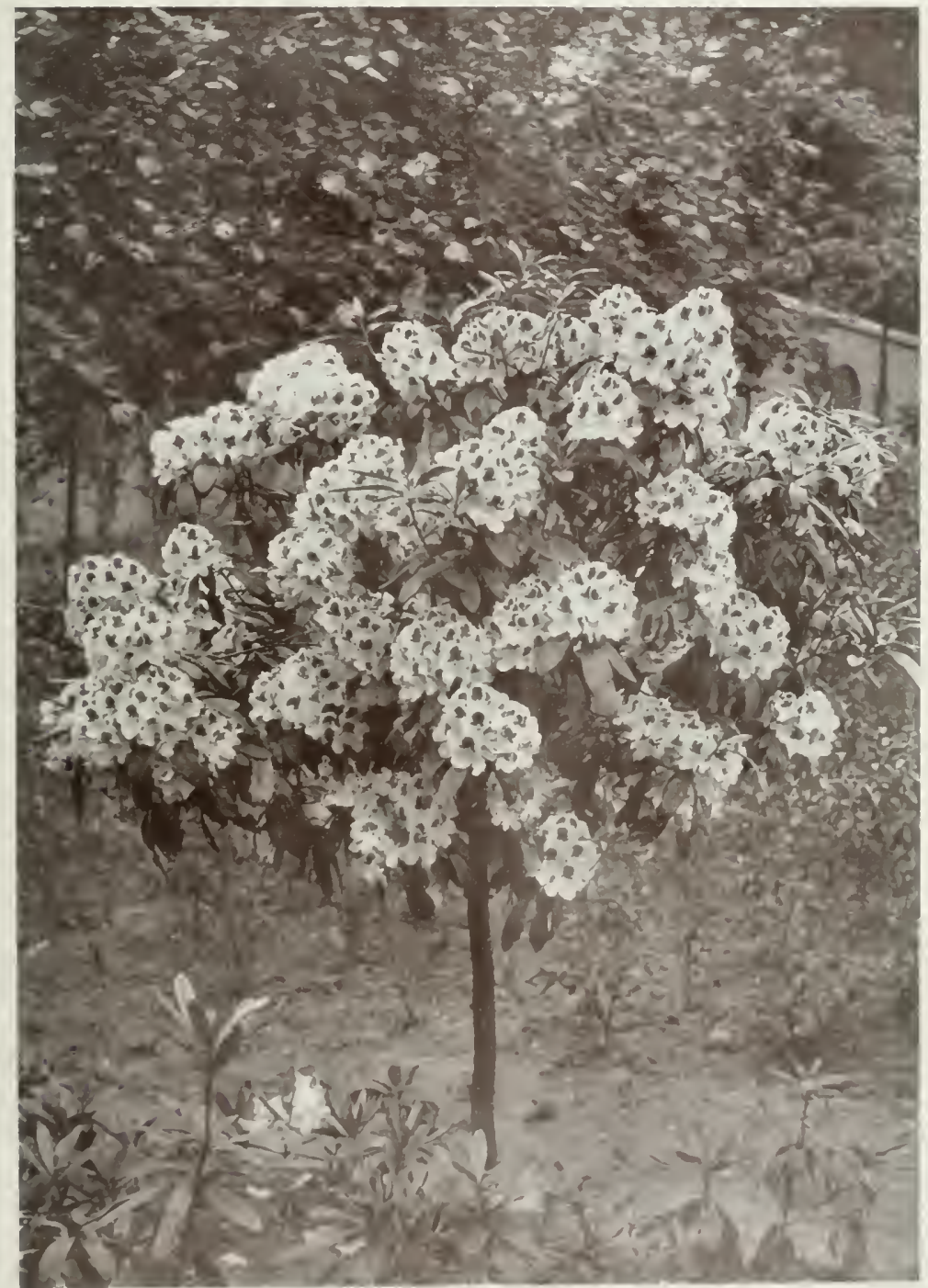

RHODOJENI)RON IKS. R. (i. SHIII:

Palc blush with latrge maroon bloten.

For notes on Rhododenchrons see l'art IV. I'hoto by K. A. Mally. 


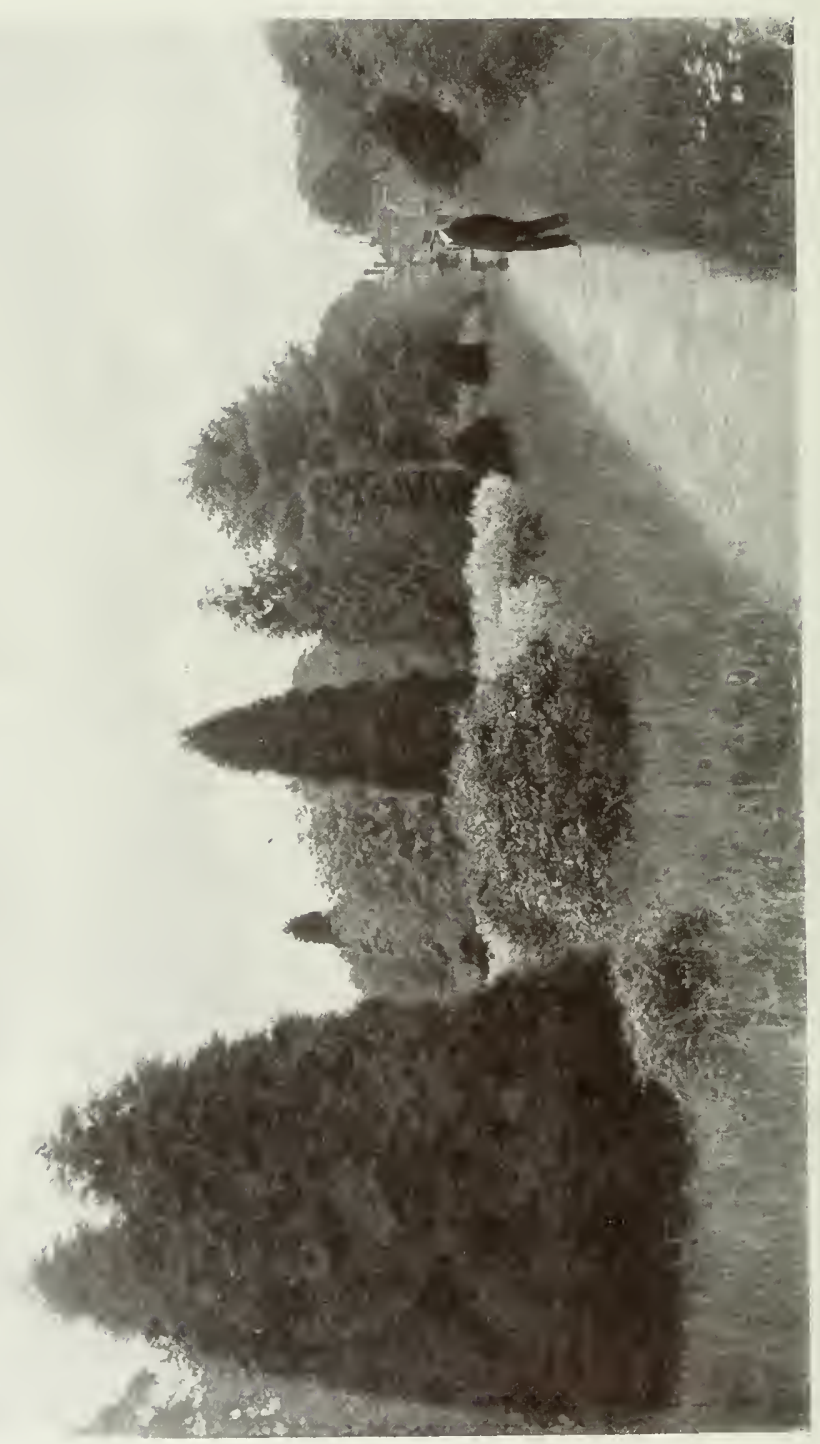

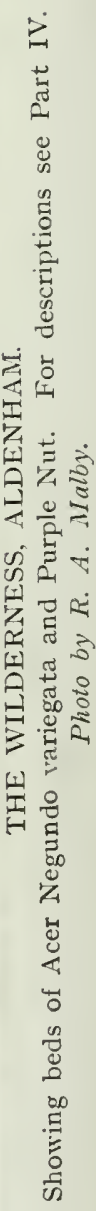


are being made by people of limited means many good sites which are to be planted eventually with shrubs or herbaceous plants can be filled with annual cropsplain vegetables such as potatoes, perhaps-for three or four years. Such beds as are planted at the outset with shrubs and herbaceous perennials can then be fully furnished at once so as to get immediate effects, and when the things begin to crowd thinning can be practised, and new permanent beds formed. This is an economical way of making a garden and the interest is prolonged.

The reason why shrubs often fail under the shifting ordeal is that insufficient care is taken to lift them with a "ball" of moist earth round the roots. Perhaps, too, the roots are left exposed for some time. See the remarks on this subject in Chapter X., where the best methods and the best times of moving the most important shrubs are stated.

Mistakes in planting are not more common than mistakes in pruning. In case "mistake" suggests something active, I had better substitute " neglect," for it is the passive attitude towards pruning which is generally responsible for the trouble that ensues. To put it in another way, more shrubs suffer from no pruning at all than from bad pruning. The habit of an ordinary garden Raspberry gives the cue for the pruning of the vast majority of leaf-losing shrubs, and just as the Raspberry forms weaker and weaker shoots as, under neglect, it becomes crowded with old wood, so do many shrubs suffer in their growth if the old stems are not removed periodically. I do not mean that the 
shrubs do not become thick, indeed, they become masses of wood; what I mean is that the energy of the plant is dissipated on a large quantity of small, thin shoots, none of which is capable of producing good flowers.

The shrub-grower can learn the flowering habit of his shrubs by merely looking at them while they are in bloom. A simple process, surely, and a pleasant. All that he has to do is to see whether the flowers of the spring-flowering kinds are borne on the young or the old wood, and his course is clear. If on the young wood -as most are-all that he has to do is to cut out the old and encourage new wood. The difference in the colour and texture of the bark would serve to distinguish old wood from young, even if the shrubs were not in bloom, but the thing to do is to study the habit of the plants while they are in flower, then there can be no mistake. By "young wood" I do not mean, in the case of the spring bloomers, shoots of the current year's growth, but shoots formed the previous year. This is the wood that gives the season's flowers. The young shoots that spring from the base of the plants will give the bloom of the following year.

From the pruner's point of view, shrub-wood is old directly it has gone out of flower, and there is no reason why it should not be cut away soon after the flowering is over in the case of those kinds which bloom best on one-year-old wood. The longer it is left, indeed, the more risk there is of its being forgotten.

In dealing with long-neglected shrubs, the first thing is to get rid of the accumulations of hard, dark, hide- 
bound wood, several years old, which disputes place with the softer, paler young shoots. In shrubs that are pruned regularly there are no such accumulations, and the bush is always young.

There may be-there probably will be-cases in which cutting away the older wood right to its base means sacrificing a certain amount of young wood that has grown from the upper part instead of direct from the root. Here judgment is necessary. It may be desirable to leave the lower part of an old shoot for the sake of retaining a young shoot growing on it. But, broadly speaking, the old wood should go after flowering in most cases. For details see Chapter XIII.

Do many failures arise in consequence of the absence of provision for special composts? I should be disposed to assess this as one of the least common of the causes of failure. The majority of shrubs, whether evergreen or deciduous, do not call for special composts. Rhododendrons like peat, it is true, and they share this liking with their close allies the Azaleas, with Heaths, and with the majority of American shrubs and other members of the Ericaceæ; but modern experience goes to show that Rhododendrons, in common with many other peat-lovers, will thrive in loam, provided it is well drained and friable. They are not suited to clay, because this soil is apt to be dense. When, however, clay is made crumbly with additions of peat, leaf mould and wood ashes, it becomes suitable.

The matter of special composts may be considered in connection with hardiness. The rank and file of hardy 
shrubs and trees thrive in any fairly deep and substantial garden soil, such as loam or clay. The great majority do well on limestone if there is a foot or more of soil above the chalk; and most evergreens, other than the Ericaceæ, are quite at home on shallow limestone soils, knitting their roots into chalk contentedly. But there are some kinds of imperfect hardiness in northern climes which are favoured by warm, friable, fertile soil, such as loam lightened with sand or leaf mould. The requirements of particular kinds are noted in Part IV. 
CHAPTER VIII.

\section{Practical Considerations in Planting Shrubs and Trees-Forms of Beds and Borders- Landscape Effects-Backgrounds.}

WE have seen in earlier chapters that several important purposes are served by shrubs and trees, and that more particularly we can obtain by their use beautiful spring pictures in the garden. Let us now go a step farther, and consider those details which arise out of projects for the extended use of this great class. The choice of site, the shape and area of beds and borders, the selection and arrangement of the kinds-all these matters must have consideration.

Areas that are to be planted with shrubs and trees must be considered in relation to everything else in the garden and its surroundings, if only by reason of the space which the plants occupy and the plane on which they grow. The shrub-planter, in fine, has a greater responsibility on his shoulders than his fellow amateur who is engrossed in one special flower and concerns himself solely with growing it to the standard recognised in his particular circle. Beds of Daffodils, of Tulips, of Carnations, of Roses, even of Sweet Peas and Dahlias, owe no particular debt to the landscape. 
They are not gardening at all in its true sense. But shrubs and trees are on a different footing. They cannot be worked on the watertight compartment system. They are not merely themselves, they are also an active, inseparable part of the garden. They are linked up with all its other sections.

It is this distinction which puts the shrub-planter under a definite obligation. It forces him to consider the landscape, the surroundings. It makes him pian. It may be that he is forming a new garden. If he were merely going to grow vegetables, plant fruit trees and devote the rest of his attention to one flower, he could afford to feel his way. But directly the formation of beds and borders for shrubs and trees is decided upon a definite plan of procedure becomes desirable. The present volume embraces pictorial suggestions for help in that matter.

Because sites at the side of paths, lawns and water are good for shrub-borders the planting of shrubs must be considered in connection with paths, lawns and water. Because trees rise to altitudes which bring them into relationship with the landscape the planting of trees must be considered in connection with the landscape. Observe that these points have nothing to do with the questions of shade and shelter, which are separate considerations.

But one reader or another may say that questions of landscape at least do not come into his case, because his garden is enclosed, or he may desire to shut out all external features, which are objectionable; what then ? The task is simplified, but the case for a ground plan 
holds good, because the shrubs and trees will still have to be considered in relation to the house, paths, lawn and water.

We may first consider shrubs and trees in relation to the house. One consideration certainly is that a considerable proportion of the planting shall be in view from the principal windnws. At once our thoughts go to the lawn and its surroundings, because grass is the most appropriate covering for the area immediately in front of, and often beside, the house. It is a common mistake to cut up a considerable part of the front area of a lawn for flower-beds. There should always be a broad stretch of green between the house and the nearest beds. Adopting this principle of pushing away the beds, we may eventually decide that the principal features of the lawn shall lie on the confines in the form of borders.

Here, then, we have something to work upon-a certain area of ground in view from the principal windows of the house is to be devoted to lawn, on the margins of which adequate space is to be left for borders. Thus we make openings for our trees and shrubs. We do not arrange that lawn-edge and border shall form a straight line. We provide for bays and promontories.

A slight modification of this plan is to set apart a strip a few feet wide between lawn and border for a path; in other words, we do not carry the grass right up to the shrubs, but provide for a walk to intervene.

The question of path or no path may be settled by the consideration of whether a path is necessary for 
domestic purposes. There must be approaches to the rear of the house, but it does not follow that there is any necessity for a path across the front. In most cases it will probably be found convenient to carry the lawn right to the border opposite the main front, and to provide an intervening path at the sides. In cases where the side walk or road is one used for the coarser domestic purposes-carting manure and coal, the passage of tradesmen's vehicles and the like-it may be completely screened by a belt of shrubs and trees on the edge of the lawn; but a path which is used for ordinary garden purposes alone need not. There may be beds or borders beside it with open spaces between. For the farther elucidation of these points the reader is referred to the plans, in which will be found cases of lawn and shrubbery with and without path, and examples of the planting of isolated trees and beds of shrubs on lawns.

The first phase of the planning problem is disposed of when the position of paths (under which the reader is requested to understand also drives and roads) and of lawn is settled. The second is that of the site, area and form of the borders and beds. These matters we will now consider.

Dealing with the area in front of the principal windows of the house, we may take as our first point consideration of the following questions: do we want to obscure the view beyond the garden boundary because of something uninteresting or unsightly, or do we want to keep it exposed-to "work it in with the landscape" ? 


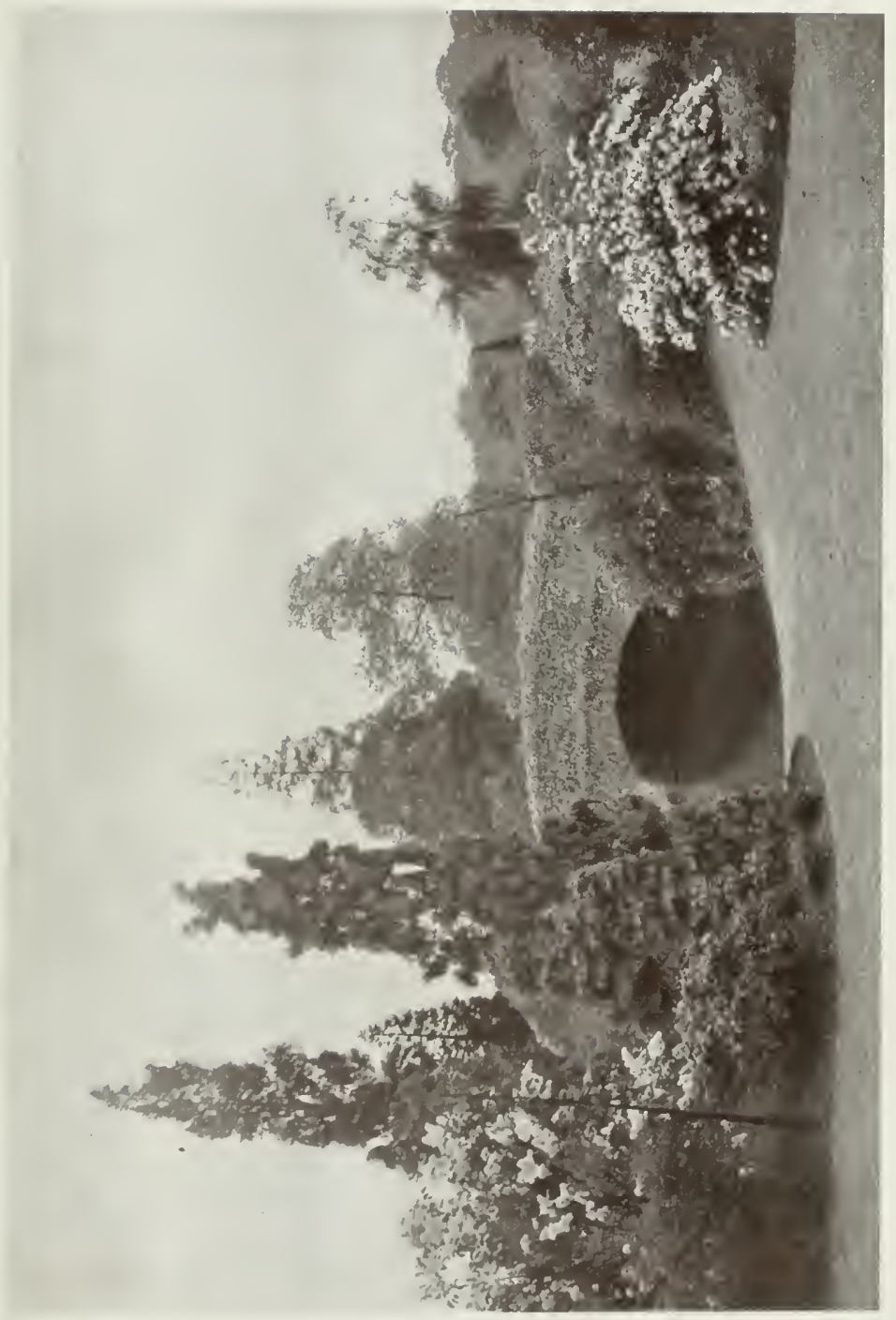

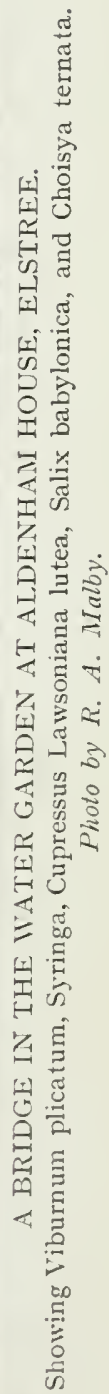




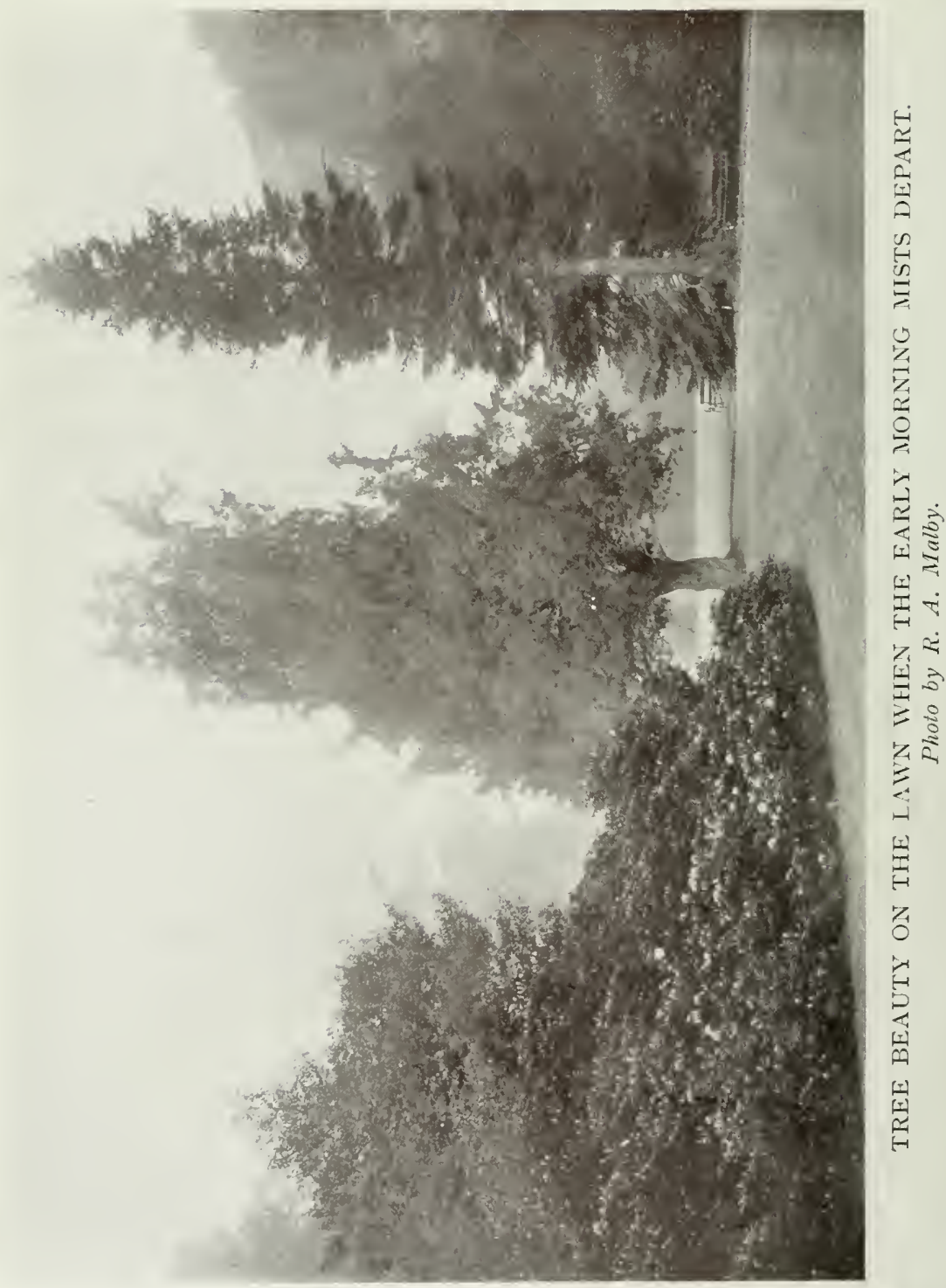


If the view is to be limited to the confines of the garden and exterior objects shut out, it may or may not be desirable to plant tall-growing trees somewhat closely. If the ground outside falls away, and the undesirable objects are low, many tall trees will not be needed, the lower flowering trees will suffice in the main; but if the ground is high, or the objects to be hidden are lofty, then tall trees are called for. In cases where ugly factory chimneys or other tall unsightly objects are in view from the house, quick-growing trees are called for. Poplars may be thought of, not alone the stiff, cylindrical Lombardy variety, but the more spreading Black or Austrian and the White or Abele; likewise the Sycamore. The Oak, the Beech and the Elm are noble trees, but their growth is slower.

Whenever it is desired to shut out an ugly object as quickly as possible, the temptation to plant a close belt comes in, and inasmuch as the Lombardy Poplar breaks freely into growth from the bole when the head is cut off at eight or ten feet high it is often planted in a close rank and topped. The result is a screen, quite dense when the trees are in leaf, but it is stiff, and is little better than a glorified hedge. If used it should be looked at in the light of a tall hedge, not as a real ornament to the garden, and more interesting things should be planted in front of it, so that something better is seen from the house than a belt of Poplars little more attractive than a row of telegraph poles or a range of huts.

The shutting in of a house with trees must be considered in various ways. Shade and shelter have 
their claims, but take care that they do not degenerate into gloom and enervating closeness. There is often one particularly exposed quarter, where, at certain periods of the year, cold winds rage, pinching the plants and making the residents uncomfortable. By all means let that quarter be given tree-shelter. Again, there may be one part where something ugly shows up, or (with the presence of building land outside) may be expected to show up. By all means let that be screened too. But do not let any belt-planting, which may be called for in such circumstances, be the signal for the wholesale planting of Poplars, Sycamores, and such like close to the house.

Where trees envelop a garden on a low site there is likely to be an enervating atmosphere for long periods, and during the winter there is gloom and damp. I admit that such gardens have their moments of joy. In spells of hot, dry, summerweather, they are veritable havens of shade and peace. But there are other times.

Broadly speaking, the system of belt-planting near a house is objectionable, and should only be resorted to for a particular purpose. Except for that definite object, the planting of trees in gardens finds nobler expression in choosing special sites for individual specimens and groups farther away from the building.

Assuming that no screen-belt or shelter-belt of quickgrowing trees is required, shall there be no tall trees on the confines of the place in front of the house? I think that in all places of moderate and large size provision should be made for planting a suitable number of tall trees such as Oak, Beech, Chestnut, 
Birch, Elm, Maple and Poplar; and some of these should come in front of the house. There are, too, the Conifers to consider-the Cedars, the Pines, the Firs. The large deciduous trees, such as the Oak and Beech, might be planted in groups or singly, thirty to forty yards apart; the Conifers in groups a few feet apart or in some cases singly. The effects of group and single planting are described in Chapter XIII., where pruning is dealt with.

When the sites for the large trees have been chosen those for the small ornamental-leaved and flowering trees may be found. These may be set as near as six to eight yards apart. Almonds, Pyrus spectabilis, Plums, Cherries, the dark-leaved Prunus Pissardii, Pyrus Malus floribunda, Lilacs, Thorns, Crabs, Robinias, Magnolias and variegated Maples will all provide welcome colour of leaf or bloom. The Pyrus family, which includes the Apple and Crab, is pre-eminently beautiful when in bloom, and there is real beauty in the fruits of the Crabs when they line the branches almost from base to tip in those seasons when they bear well. The dual beauty of some of the Thorns must also be remembered. Some of the singleflowered varieties berry freely and are very ornamental in late summer. The double Thorns are magnificent when in full bloom. In order to get as long a period of beauty as possible it is well to plant the various kinds alternately.

There is no appreciable amount of shade and drip from the low-growing ornamental trees when planted in the way advised, and shrubs, both flowering and 
coniferous, may be planted among them. The shrubs should not be set close up to the stems of the trees. There is always the temptation to plant up too close to trees on tall, clean standard stems. Fruit-growers make the mistake and shrub-planters are liable to imitate it. Shrubs should not be put nearer than four feet. One may be set directly in front of each standard, so that the bare stem is hidden.

Several important points arise in connection with the selection and planting of shrubs. Shall evergreen or deciduous kinds predominate? Shall individual plants or groups of each kind be used ? In what order shall they be set?

Deciduous shrubs should predominate where life and beauty rather than a mere screen are desired. Perhaps a proportion of two to one may be suggested. There will then be abundant life in spring and summer, with a suggestion of substance in winter. A border in which deciduous shrubs predominate is often rather ugly than otherwise in winter. It has an unkempt look. It suggests wildness, untidiness. The main cause of this is absence of culture. If the shrubs are properly pruned they will be clean and shapely. There will be plenty of young, brightly coloured wood, which will have a cheerful effect. Furthermore, kinds may be introduced which have boldly coloured stems. And colonies of cheerful bulbs, such as Scillas, Anemones, and Winter Aconites, may be planted among them.

The question whether individual plants or groups should be planted must turn to some extent upon the 

"THE APPLE AND CRAB ARE PRE-EMINENTLY BEAUTIFUL WHEN IN BLOOM." (See page 6r.) Apple Blossom in a Cottage Garden. Painted by A. C. IVyatT. 


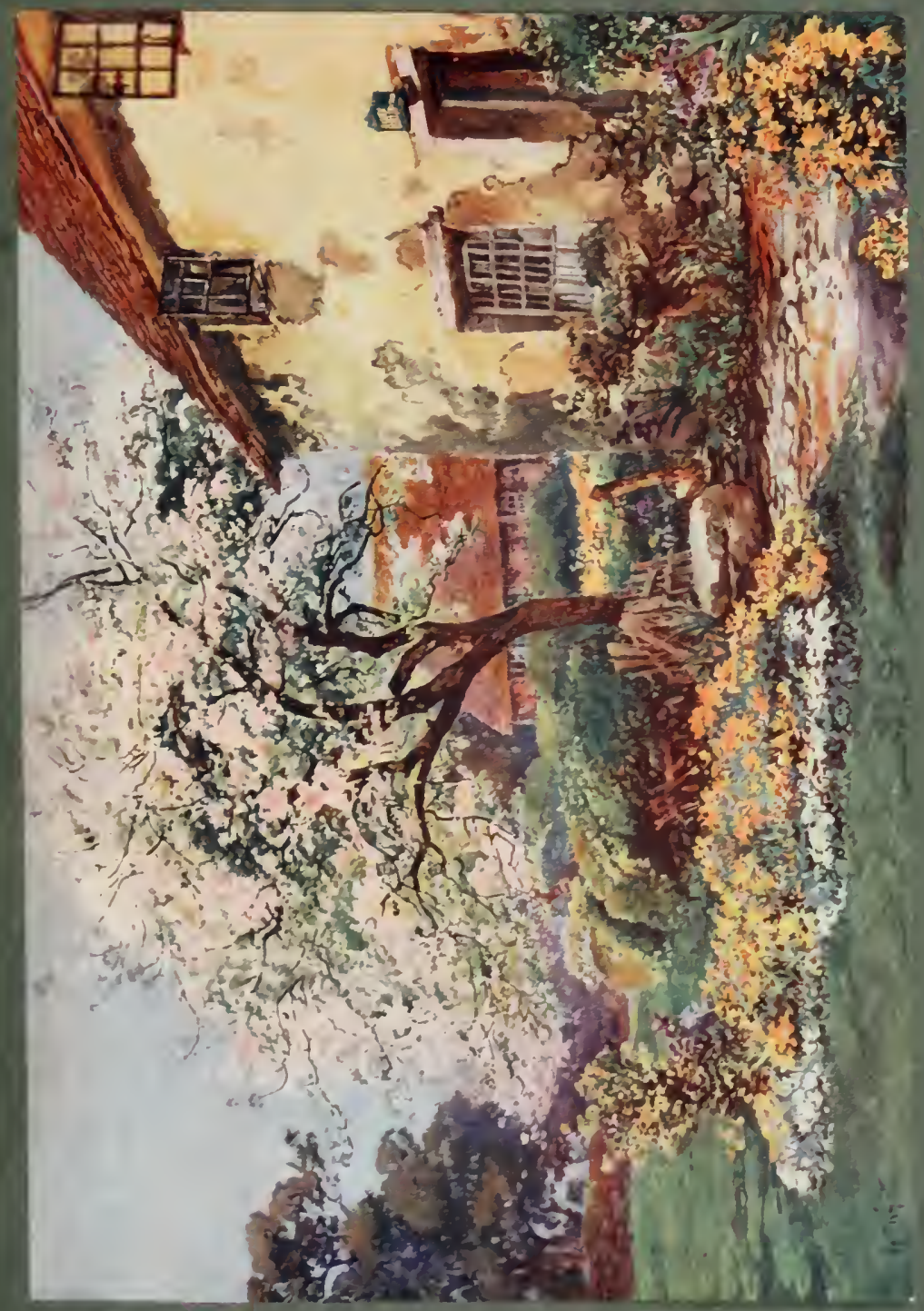


space available. The group system has the great advantage of giving bold, rich masses of colour. Groups of Rhododendrons, Azaleas, Berberises, Brooms, Hydrangeas, etc., have a noble effect. Certain plants, indeed, notably Azaleas, are apt to look ineffective when set singly. But the owner of a small garden cannot have the massed effects which are possible in large places, and would make a mistake to strain at them. He will do better to strive for good single specimens than to have crowded, ineffectual groups. One Rhododendron, or Weigela, or Berberis Darwinii, or Hydrangea, or Spiræa arguta-to mention at the moment only a few things that form beautiful isolated plants-will be more satisfying when well grown than a group of packed and meagre plants. Attention concentrated on these single plants-attention, I mean, in providing the right kind of soil, aspect, shelter and pruning-will be richly rewarded.

With respect to the order in which shrubs should be set, it may be advised that when the group system is adopted the face of the border should be deeply indented, so that a series of bays and promontories is formed. The richer, bolder things, such as Rhododendrons, Azaleas, Berberises and Brooms, may form large promontories; the more subdued kinds, such as Spiræas, the bays. One may imagine a lawn stretching in front of a house, with an ebb and flow of shrub-grouping extending along both sides and the back of the lawn. With selected trees beyond, and a strictly limited provision of interesting objects on the lawn, such as specimen trees, shrubs, Pampas 
grass, Bamboos, and possibly a few flower beds, a beautiful effect would be produced.

In planting individual trees and shrubs it will probably be found best to work on the "opposite vacancy" principle. The shrubs are really planted in lines, but the components of each line do not face the components of the line behind, they face a vacant point midway between each pair. This is a common gardening plan in planting flower-beds and fruit bushes. It gives order without stiffness. And there must be system in the border. Let the amateur dump in his shrubs here, there and everywhere, and in a few years the shrubbery is a wild hotch-potch. In improving an unsatisfactory shrubbery I have often found that the simplest way of starting is to rearrange the shrubs on the "opposite vacancy" principle. Afterwards pruning and other cultural details come into play. To learn the system by the fireside, let the reader form a square with four pins and then set a fifth pin in the centre; he will then have a quincunx. By repeating the quincunxes he gets the system. He may, of course, retain it with a straight or a curved line of planting.

Ground that is to carry a considerable variety of trees and shrubs should be well drained. Areas that are swampy in a wet winter are liable to cause trouble. A piece of swampy ground can always be made an interesting feature of a garden, but it is not suitable for most shrubs and trees. It is rarely, however, that a piece of ground chosen for a house and garden is of such a character that it cannot be made suitable. If 
it were of the shape of a saucer, and water could not be got away, the gardener would form a pond or lake where the water naturally collected-at the middle of the saucer, the banked sides of which he would plant with shrubs. He would also plant the edges of the saucer. That, however, is an extreme case. Wet sites should certainly not be chosen for planting beds or borders of the principal ornamental shrubs until the under-water had been taken away from it by means of drain pipes.

The area of ground for beds and borders may range from six feet square upwards. But it is desirable to have freedom for working with reasonable boldness. Given a strip of border only six feet wide the planter will find himself handicapped. $\mathrm{He}$ can only plant small kinds. He will, in fact, have to do without all the great kinds, both deciduous and evergreen; and probably he would do well to restrict himself to small neat evergreens. With twelve feet before him he is in much better case. Here he can introduce small standard trees. Here he can get in a few fairly large kinds. And he can complete his quincunxes by planting three rows. If he is making a border which will have only one face he may put his trees and large shrubs towards the back; if a border to be seen from two sides then the larger things must go near the centre.

The preparation of the ground may well be thorough, particularly if light, in respect to the depth of working. If it is well broken up two spades deep and liberally manured it will carry not only the shrubs but 
also a ground work of bulbous and other flowers. I have already said, however, that I consider an abundant supply of moisture for the first year or two the most important item of culture, provided it is not stagnant under-water. Trenching and manuring, though good, are not vital, surface moisture is. Now surface moisture may be conserved by keeping the surface either carpeted with close-growing plants or else by maintaining a loose "crumb" of soil. Exposed soil should therefore be well dug at least once a year, and regularly hoed. After heavy summer rains a strong crop of weeds may be turned over with the digging fork.

It is prudent to keep shrub beds and borders under regular cultivation for more reasons than one. In going among shrubs to hoe in summer the gardener is reminded of the pruning. He sees the upspringing new shoots, that will flower the following year, crowded by the older wood which has recently gone out of bloom, and consequently he sees the necessity of pruning out the latter, in accordance with the instructions already given and amplified in Chapter XIII.

$\mathrm{W}^{\top}$ e may devote a little consideration to shrubs and trees in relation to the paths. Near one or other of the side boundaries of a garden there is likely to be a path or road affording access to the kitchen, stables and garden outbuildings. In a large place this roadfor road it will be-need not be screened on the outside, if there is park, meadow, or wood beyond it on the same property. But when it skirts another property the question of screening it on the outside may have to 

“ THE TREE PEONIES ARE ANONG THE FINEST OF FLOWVERING SHRUBS, BEATING IMILENSE BLOOMS OF BRILLIANT COLOURS." (See page 76.) Pæonia Moutan, Grand Frederic.

Colour photo by R. A. MaLBY. 


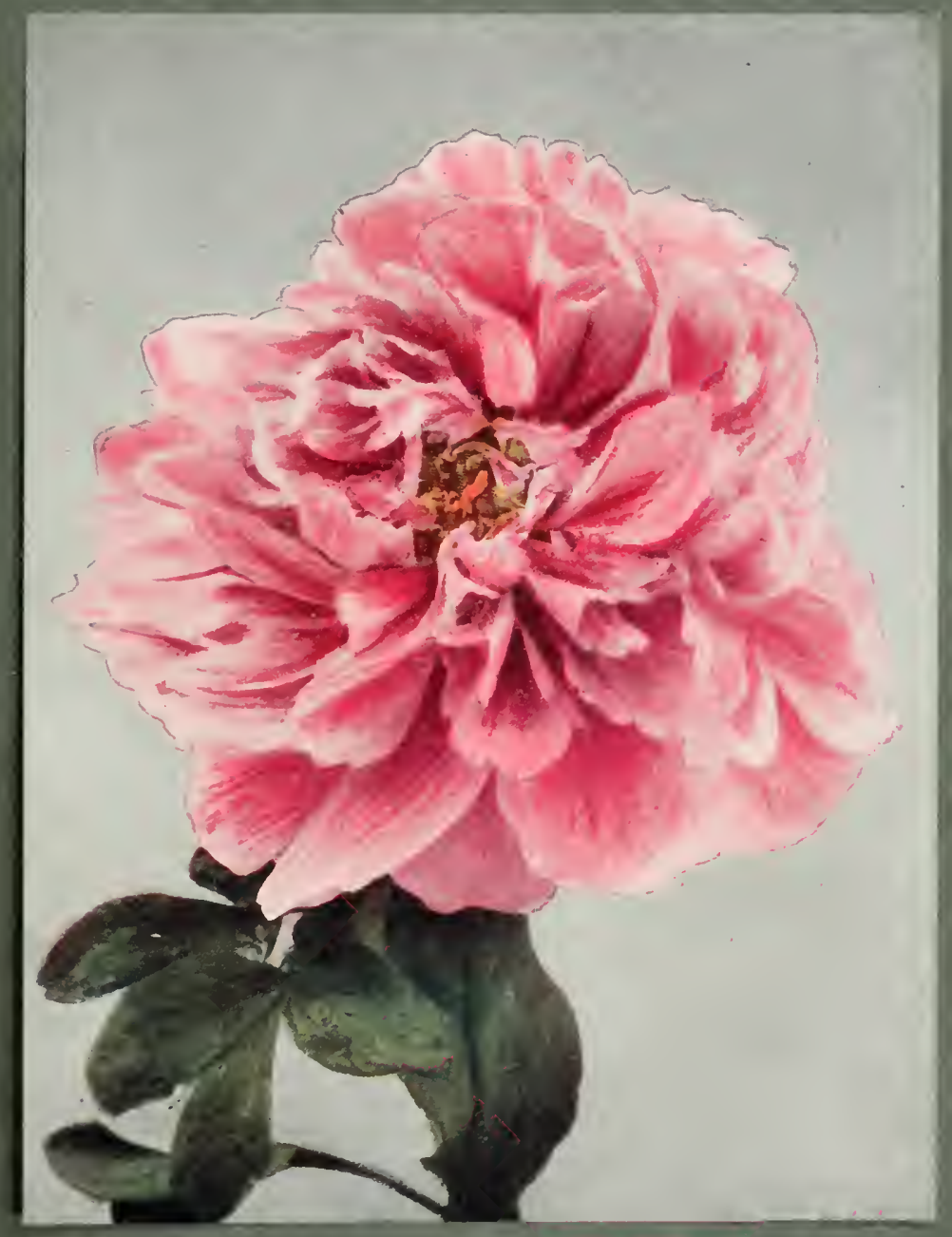




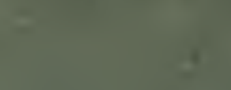

12

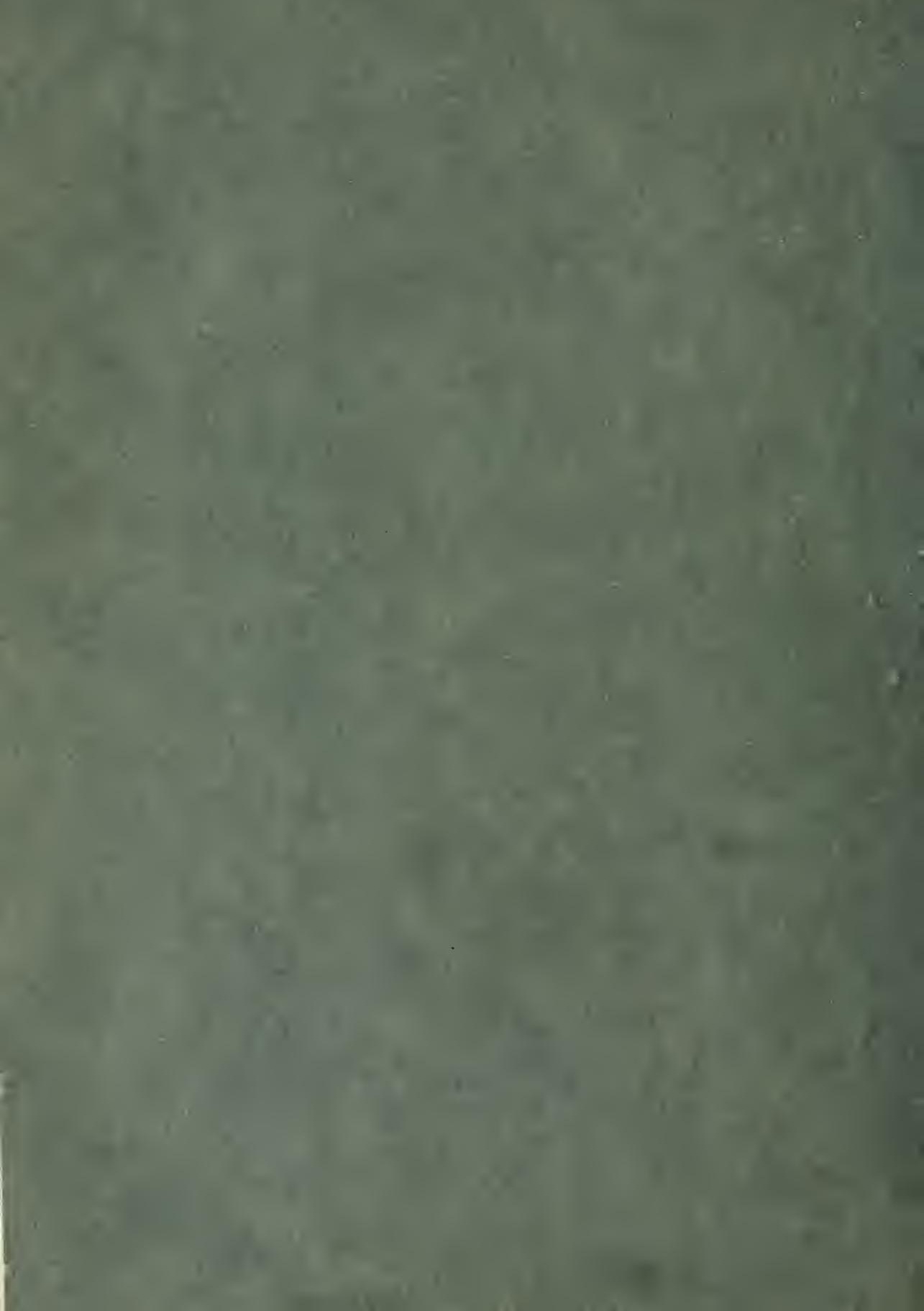


be considered. Here a belt of such cheap shrubs and trees as Laurels, Hollies, Aucubas, Larches, Poplars, Birches and Austrian Pines may be planted. The inner or garden side will also have to be screened, and here the hints already given will apply.

We may, however, go a little farther. In many gardens there are long inner paths-paths round lawns, paths along the face of shrubberies, paths leading to tennis lawns, Rose gardens or rockeries. Such paths may run for a considerable stretch between two sections of a lawn, or between a lawn and a shrubbery. In the former case, particularly, it is desirable to have objects of interest at intervals-a bed here, a specimen shrub or tree there, perhaps a group of Rose or Clematis pillars. These objects give variety and interest to the garden. Shrubs and trees may thus be used in relation to paths just as they may in relation to the house and the lawn.

There remains the water. Ground approaching water may be planted with things that love humidityBamboos, giant Rhubarb (Rheum palmatum tanghuticum), Meadowsweets, Phormium tenax, ferns, etc. The banks and island may be planted with Willows, Royal ferns, Reeds, drooping forms of Beech and other large trees, Dogwoods, Alders, Tamarisks, Elders, Bamboos, Gunnera manicata, Pampas Grass, etc.

The main points of water treatment are the planting of suitable approach groups, the clothing of banks with appropriate subjects, and the furnishing of islands with shrubs and trees that have a natural appearance at the waterside. 
The popularity of modern hybrid Water Lilies leads flower-lovers to seize on any flow of water to form ponds, and even to devote considerable sums of money to making artificial pools. In the hot weather of summer these pools look beautiful when they are flashing under the sunlight. But their effect is enhanced when the banks are taken in hand and planted with groups of suitable shrubs, and with individual examples of Bamboos, Pampas Grass and other bold subjects; still more when islands are formed in the ponds and planted with pendulous trees.

A small stream may provide the water for such a pool. The soil excavated to make the bed of a pond will serve to form the islands. At a suitable place a rustic bridge may be built over the stream at a point near the pool.

The lover of Alpine flowers will doubtless do more than plant shrubs; he will form tiers of stone and plant colonies of rock plants. That, however, is another subject, and is dealt with in the companion volume,"Alpine Flowers and Rock Gardens."

It is in seeking to correlate his planting with the landscape that the garden-maker may find his most baffling problem. If the area to be planted is considerable he may be well advised to call in the services of an experienced landscape gardener, for the matter is one in which theory is inadequate. Nevertheless, natural good taste, aided by the illustrations in the present volume, will do much. Meantime, some suggestions as to arrangement may be given in another chapter. 


\section{CHAPTER IX.}

\section{Arrangement of Shrubs and Trees both for Shelter and Beauty.}

THE multitude of shrubs and trees, and the countless ways in which they may be planted, present a keen problem for the planter. He has to consider (I) the balance between shrubs and trees, (2) the proportions of evergreen and deciduous kinds, (3) blending of habits and harmonizing of colours, (4) beauty for all seasons of the year, (5) the respective claims of many candidates for comparatively few places.

It may facilitate the accomplishment of a difficult task if we take an imaginary border and work our way round it, making suggestions for selection and arrangement as we go.

For the sake of completeness we will assume that shelter is required. Farther, we will assume that a nice selection of flowering and ornamental-leaved trees is required for the main area, associated with shrubs of dense habit for cover. Finally we will assume that groups of shrubs of brilliant colour or special interest are wanted for the front.

We work, therefore, on the basis of employing three distinct areas: at the back, an area of material for shelter; in the middle, an area for small trees and 


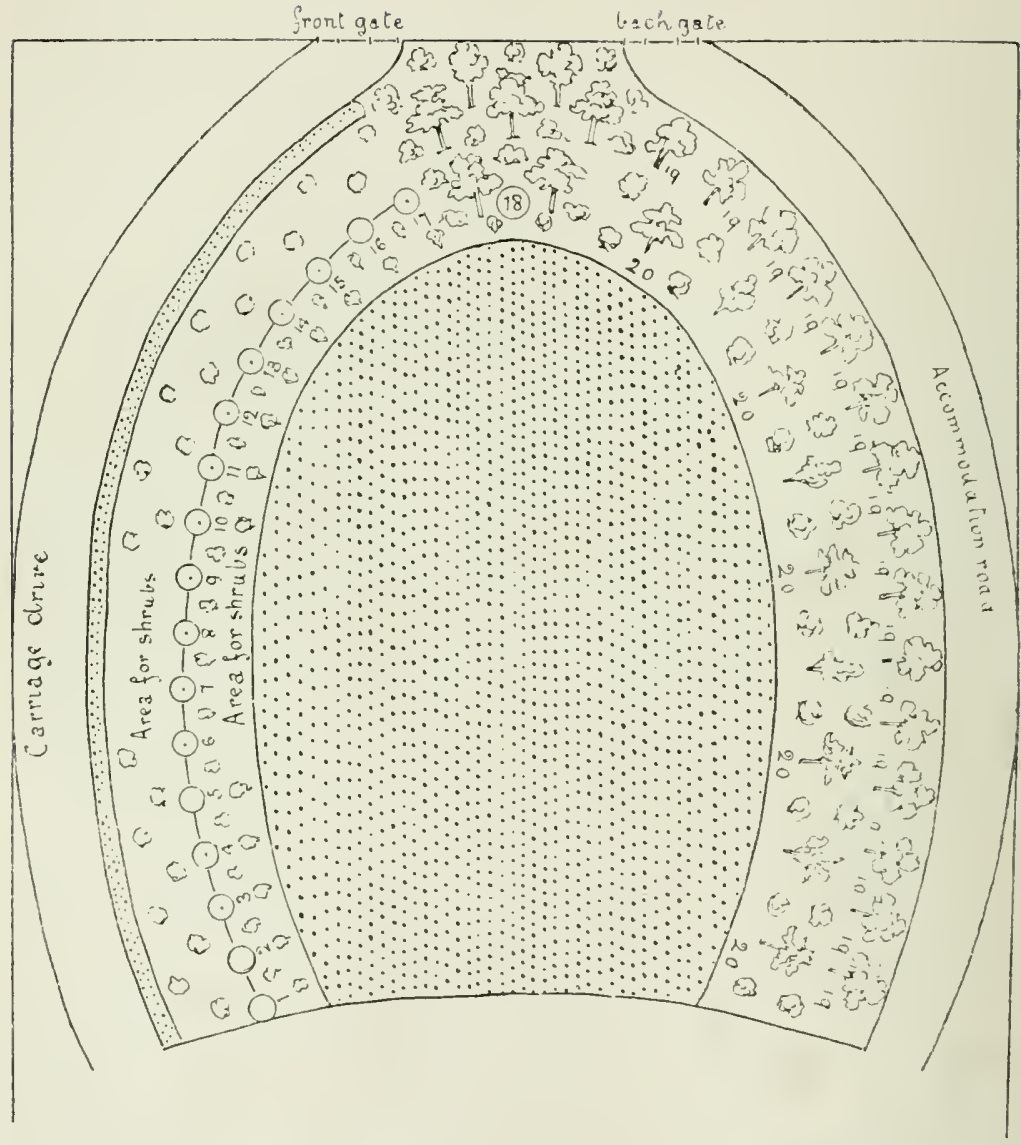

A SUGGESTION FOR TREATING AN AREA OF GROUND IN FRONT OF A HOUSE.

The main features are: a central oval of turf; on the left a wide border with a series of connected Rose pillars ( $\mathrm{I}$ to $\mathrm{I} 7$ ) along the middle, and shrubs on each side, a grass edging and a carriage drive ; in the centre a screen clump of trees with groundwork of shrubs (I8); on the right an accommodation road to the back of the house, a screen of trees (19), and a series of small flowering trees (20), with a groundwork of shrubs. 
cover; at the front, an area for special shrubs. This at once gives us something tangible. It provides a definite idea of procedure.

Needless to say, stiff, rectangular blocks are not contemplated. Let us work on flowing lines. The border shall vary in width and shall be broadest at those parts where, owing to exposure, the most shelter is required.

First as to this shelter. The planting of rows of trees has been deprecated. It gives a maximum of stiffness with a minimum of shelter. Groups are preferable to lines, and certainly at the points of greatest exposure clumps should be planted. At other points the belt may thin down almost to a single line.

The Austrian Pine (Pinus austriaca) is greatly in demand as a shelter tree on account of its hardiness, adaptability to most soils, including poor ground, fairly quick growth and dense habit. The principal point against it is its sombre appearance. When planted in quantity, and unrelieved, it is apt to have a gloomy effect. It is at its worst when planted, as one sometimes sees it, in a series of straight rows. When set in groups and brightened by an adjacent cluster of Silver Birch, an entirely different effect is produced. The Silver Birch is a graceful tree with clean, straight, even stems and beautiful bark. It is very hardy, and, while not quite so much at home as the Austrian Pine on the worst of soils, it is by no means exacting.

Other Pines than the Austrian are available. Pinus Lambertiana is one of the hardiest, and revels in the buffeting of the gales. Ponderosa is a glaucous species 
that will thrive in the poorest soil. Pinaster, the Cluster Pine, will also do in poor soil, and thrives near the sea. The Scotch Fir, Pinus sylvestris, is perhaps the best known of all, and does well on peaty soil. While the Pines are often effective as specimen trees, they are best grouped in clusters of five, seven or more, especially for shelter. Trees of brighter appearance, such as varieties of Elm and Poplar, may be planted near them. There are many good varieties of the common Elm (Ulmus campestris), notably variegata, a silver-leaved form; and antarctica aurea, a goldenleaved form. These make excellent companions to the Pines. The Necklace Poplar (Populus deltoidea, commonly known as canadensis) has a beautiful golden form called aurea, and this makes a good associate for sombre Pines or for the copper Beech. The lastnamed beautiful tree is quite good enough for a garden specimen, but when considerable areas are available for the shelter belts it may be planted there, with bright-leaved trees such as those mentioned adjacent. Of the Poplars, the white (Abele) is the best for damp sites, and the black (nigra) for drier places. They are both hardy trees, and the former often grows into fine specimens. The black Poplar has dark stems. It can be made to give low shelter very quickly if planted as a standard tree, and the head shortened in order to encourage back breaks; it then soon forms a spreading head from eight feet high upwards. The Lombardy Poplar is a form of it. The Aspen (P. tremula) is an interesting Poplar with ever-quivering leaves. 


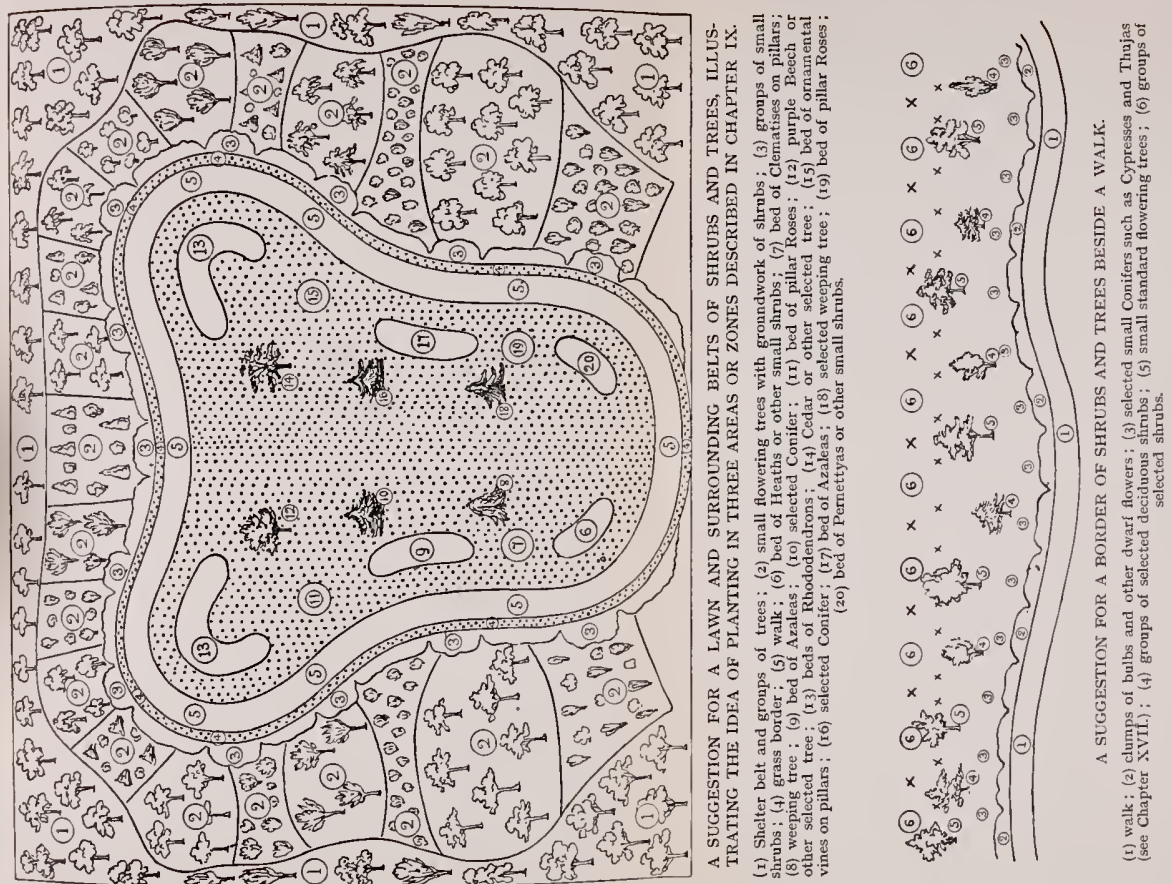



The Evergreen Oak, also known as the Holly or Holm Oak (Quercus Ilex), may be planted for shelter groups. It does not grow to a great height, but it is of dense habit and its foliage is evergreen. This again may be planted with bright-leaved deciduous trees as a companion, such as one of the Poplars, Elms or Beeches already mentioned. The deciduous trees give that glow and play of light and shade in summer which are so grateful in the garden. The Elms should be planted sparingly, especially at points near walks and cultivated quarters, because in the first place they are liable to cast their branches, and in the second they send out large numbers of greedy foraging roots.

The great beauty of Chestnuts when the trees are well developed must secure them a place among plantings of large trees. No trees can vie with them for beauty when they are in full bloom in late spring. But they are not suited for bleak, windy spots.

Hollies and Robinias (false Acacia) will also be considered for positions in front of the larger trees.

When more trees are wanted for shelter the Sycamore may be considered. It is hardy and a fairly free grower. There are forms with silver-variegated and also with golden-variegated leaves.

With respect to grouping, it is not suggested that close masses of deciduous trees should be planted. Groups of three, five or more trees, the components of each group set thirty feet apart, will suffice. The groups of trees, like the single shrubs referred to in Chapter VIII., may be set quincunx fashion, so that there are no unprotected openings. But a vista may 
be provided at a selected point. Conifers may be planted much closer in the groups for the sake of getting long, clean, beautiful stems.

The question of the outer zone disposed of, we may turn to the middle area. Here, as we have already seen, low trees with ornamental leaves, flowers or fruit should predominate; and if there is plenty of room they may be set in groups of three or more, about twenty feet apart. Associated with each group of ornamental trees there may be low shrubs, mainly evergreen, for ground cover. The following are suggestions for groups of trees and cover : (I) Pyrus floribunda (syn. Malus floribunda) with the evergreen Box (Buxus sempervirens). This Pyrus is a particularly beautiful flowering tree, one of the special charms of which are its bright red buds. It is hardy, blooms in May, and with time grows to about fifteen feet high on a standard stem, forming a large spreading head. It may, however, be grown as a bush. The fruits are round. There is a beautiful semi-double form of it called Scheideckeri, which is also well worth grouping; and there is a double. There are likewise several forms of the Box, including silvery (argentea) and golden (aurea). (2) Crimson Thorn with ground of Berberis Darwinii. The best double red Thorns, such as Paul's Scarlet, have large, richly coloured flowers, and are very beautiful when in bloom in May. They do not quickly grow to a large size. There are also pink and white varieties. Berberis Darwinii is one of the most beautiful of all evergreen shrubs, and its condition when growing exposed in poor soil affords 

"THE ALIIOND, ONE OF THE EARLIEST TREES TO BLOOM, AND IN IIILD WINTERS MAY BE IN FLOWER IN FEBRUARY:"

(See page 77.)

It is here shown with Prunus Pissardii.

Painted by JOSEPHINE GUNDRY. 


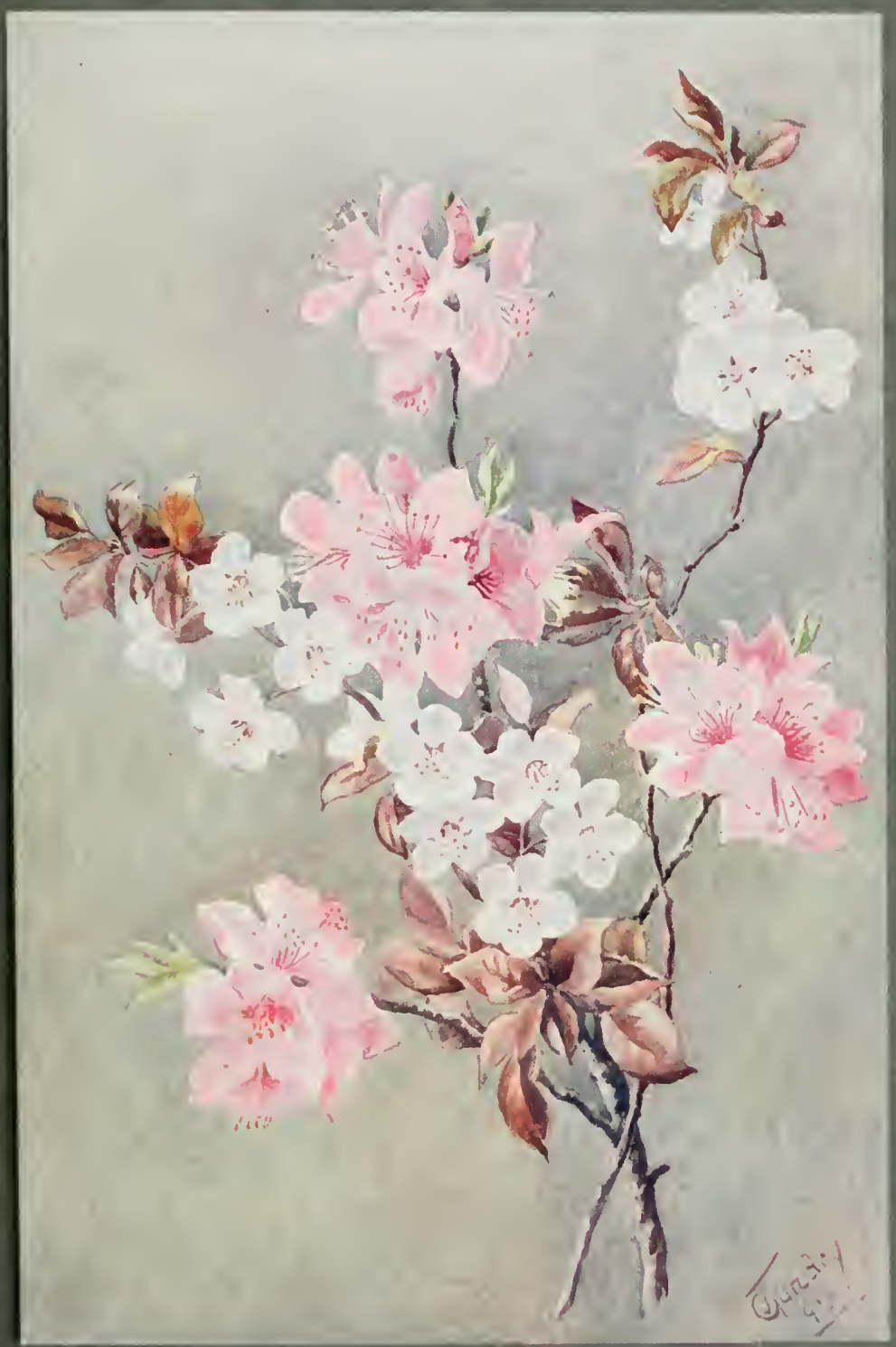




$$
=x^{-1}+x^{2}
$$

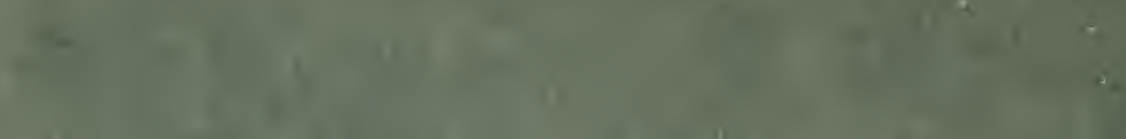

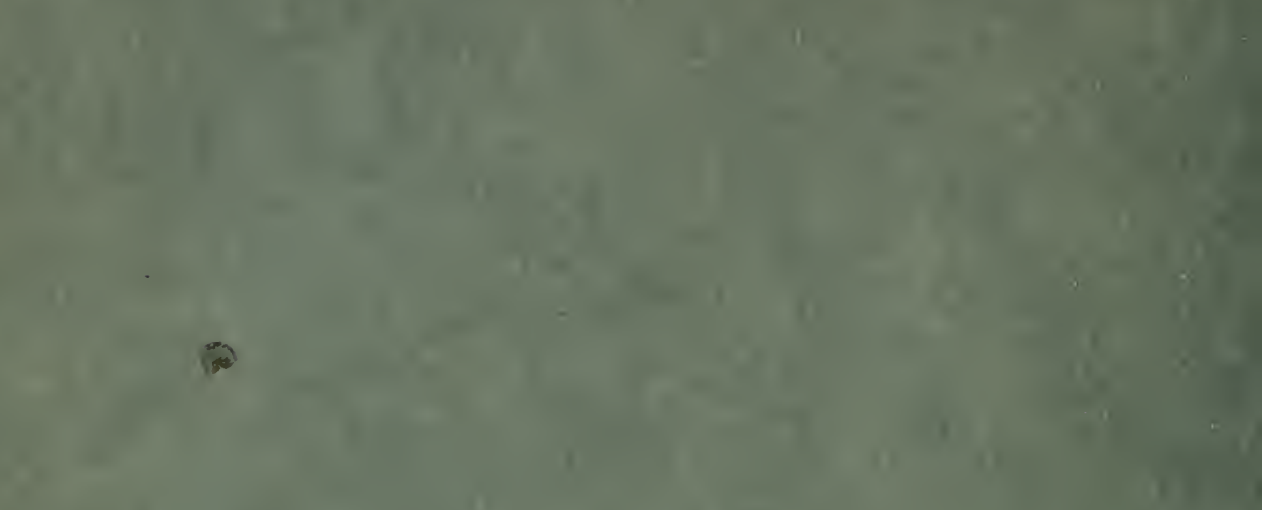

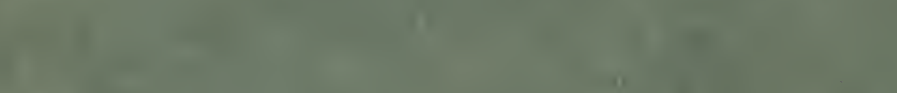

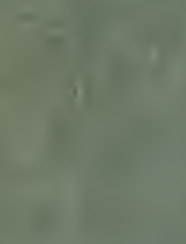
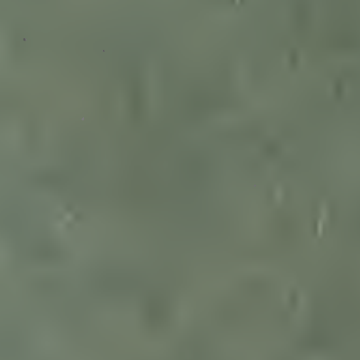
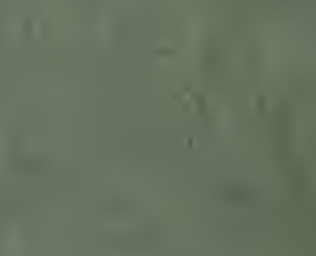

$$
\text { - }
$$


no comparison with its beauty when grown in shelter. Then it produces side shoots freely and is covered with brilliant orange-yellow flowers. (3) Amelanchier canadensis (Botryapium) and cover of Laurustinus. The Amelanchier is very pretty when clothed with white bloom in spring, and its coloured foliage and purple fruits make it ornamental in autumn. The Laurustinus is one of the most useful of small evergreens, very dense in growth, thriving on almost any soil, with bright, ornamental leaves and white flowers in winter or early spring. (4) Prunus (Cerasus) Padus, the Bird Cherry and cover of Snowberry (Symphoricarpus racemosus). The Bird Cherry blossoms abundantly in spring, when the heads are a sheet of white bloom. The Snowberry grows very densely, and becomes studded with white berries the size of marbles. (5)Laburnum, with cover of Euonymus japonicus. The Laburnum is almost too well known to need any description. The Euonymus is a good evergreen, and thrives well near the sea. Most planters prefer the golden, white-margined or yellow-margined forms, which are beautiful shrubs of dense growth, lighting up the garden beautifully in winter. (6) Lilac, with cover of Osmanthus ilicifolius. The ordinary Lilac is quite suitable for the purpose in view, although the better garden forms-which are often reserved for bush or pot culture-may be planted at will. The Osmanthus is a Holly-like evergreen with a good many garden forms, including purple-leaved and variegated. (7) The Snowball tree, or Guelder Rose, Viburnum opulus sterile, grouped with Spiræa arguta. The 
Snowball tree bears abundance of round white heads of non-fertile flowers in early summer. It does not grow to a great height. The Spiræa is one of the best of the shrubbery forms, growing to an average height of three or four feet, with graceful foliage and white flowers. (8) Prunus Pissardii (syn. cerasifera atropurpurea of botanists) with Tree Pæonies. The brown-leaved Prunus is one of the most familiar of specimen standard trees, thriving in most soils and in suburban gardens. It bears abundance of white, flowers in spring. The Tree Pæonies are among the finest of flowering shrubs, bearing immense blooms of brilliant colour. (9) Pyrus prunifolia, the Siberian Crab, with Spiræa ariæfolia. The Siberian Crab is a very hardy tree, with white flowers in spring and yellow and red astringent fruits in summer. There are several garden varieties, which may be planted instead if preferred. (ro) A large flowered garden Apple, such as Bramley's Seedling, and Mock Oranges (Philadelphus). The Apple named is one of the most vigorous of all garden and orchard varieties and will grow in almost any soil. The dwarfer hybrid Mock Oranges, such as Avalanche, Boule d'Argent and Lemoinei, are more suitable than the tall species. (II) The Mountain Ash or Rowan (Pyrus Aucuparia) and Veronicas. The Mountain Ash is particularly ornamental when in berry. One of the best of the many Veronicas is Hectori, which has lilac flowers in summer. Speciosa, violet; and Traversii, white, are also good. The last will grow almost anywhere. (I2) Pyrus spectabilis and Berberis aquifolium (Mahonia aquifolia). The 
Pyrus is one of the most beautiful of all flowering trees, bearing abundance of large rosy flowers in spring. With shelter and in good soil it may make a tree twenty feet high or more. There are several garden forms, one (magnifica) with large flowers, another double. The Barberry is the well known covert plant, which thrives in shade. The foliage is very dark in colour. The berries are purple. (I3) Almond (Prunus Amygdalus amara) and Berberis stenophylla. The Almond is one of the earliest trees to bloom and in mild winters may be in flower in February. The pink flowers are borne profusely. Berberis stenophylla is a beautiful evergreen, with long, graceful shoots laden with yellow flowers.

Other favourite ornamental trees may be planted with shrub companions on the lines suggested above. Where only one tree is planted it should be given, if possible, a bevy of three shrubs, one in front of the tree stem, the others rather farther back and forming a triangle with the tree. Each tree should have a strong stake, put in at the time of planting. It is important that the stake be firm, and if necessary an opening into the subsoil should be made for the pointed end with the aid of a crowbar after the hole for the tree has been made. The stake should then be driven down with a mallet. It is desirable that the top of the stake should come just within the head of the tree, as then the edge cannot chafe the tree stem. As a further precaution, a piece of old cycle tube may be wrapped round the stem when the tree is tied to the stake. With the hole made deep enough to cover the roots, and the soil well 
rammed in, the firmness and steadiness that are so desirable are secured.

Having accomplished two stages of our task, let us now turn to the front area. In some respects this is the most important. Here, if anywhere, will come our mounds and bays of brilliant colour. Here, too, may be planted small, choice or new shrubs, which it is important shall be immediately under the eye, and not overgrown by stronger objects.

In some cases the front area will be planted with the best of the herbaceous plants dealt with in the sister volume, "Hardy Perennials and Herbaceous Borders," but our present study is the shrubs.

In cases where Rhododendrons and hardy Azaleas are not planted in lawn beds our first task must be to provide for them in the border. The great hybrid Rhododendrons are, however, large, and it would be preferable to group them in lawn beds, whether as single specimens or massed. Under conditions favourable to them, Rhododendrons would grow to such proportions as to obscure most of the trees and shrubs in the middle area, indeed, if they are to be grown in mixed borders of shrubs it would be well to give them that zone, with no background beyond that of the large trees. Some of the species and hybrids would, however, be quite suitable for the front belt, notably hirsutum, præcox and the mauve-coloured Early Gem.

The beautiful hybrid Azaleas of the Mollis and Sinensis sections suggest themselves at once as admirable shrubs for the front zone, as they are of low, bushy growth, bloom profusely, and embrace a number 
“THE PYRUS (SPECTABILIS) IS ONE OF THE MOST BEAUTIFUL OF ALL FLOWERING TREES."

(See page 77).

The double form is here shown. Colour photo by R. A. Malby. 


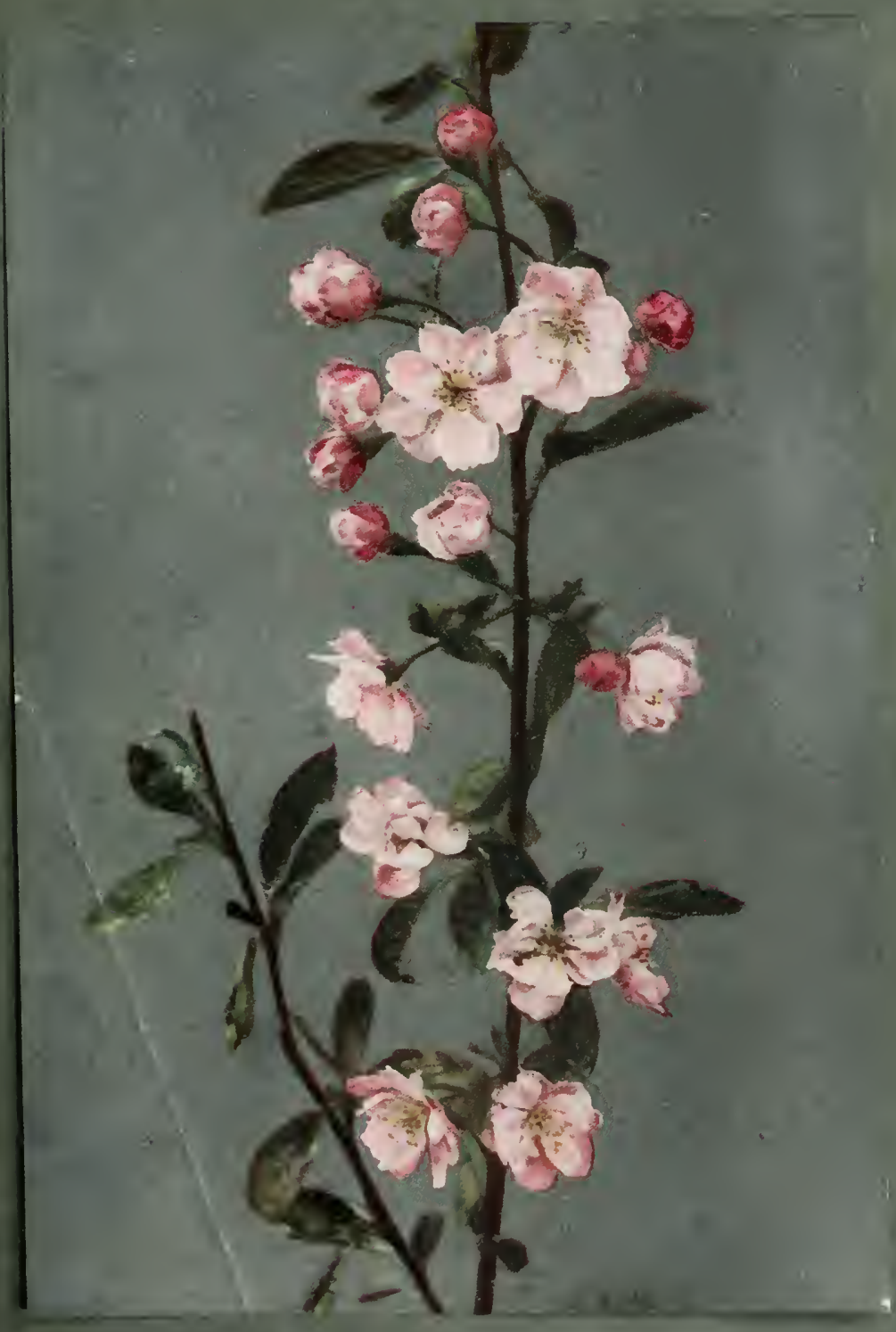




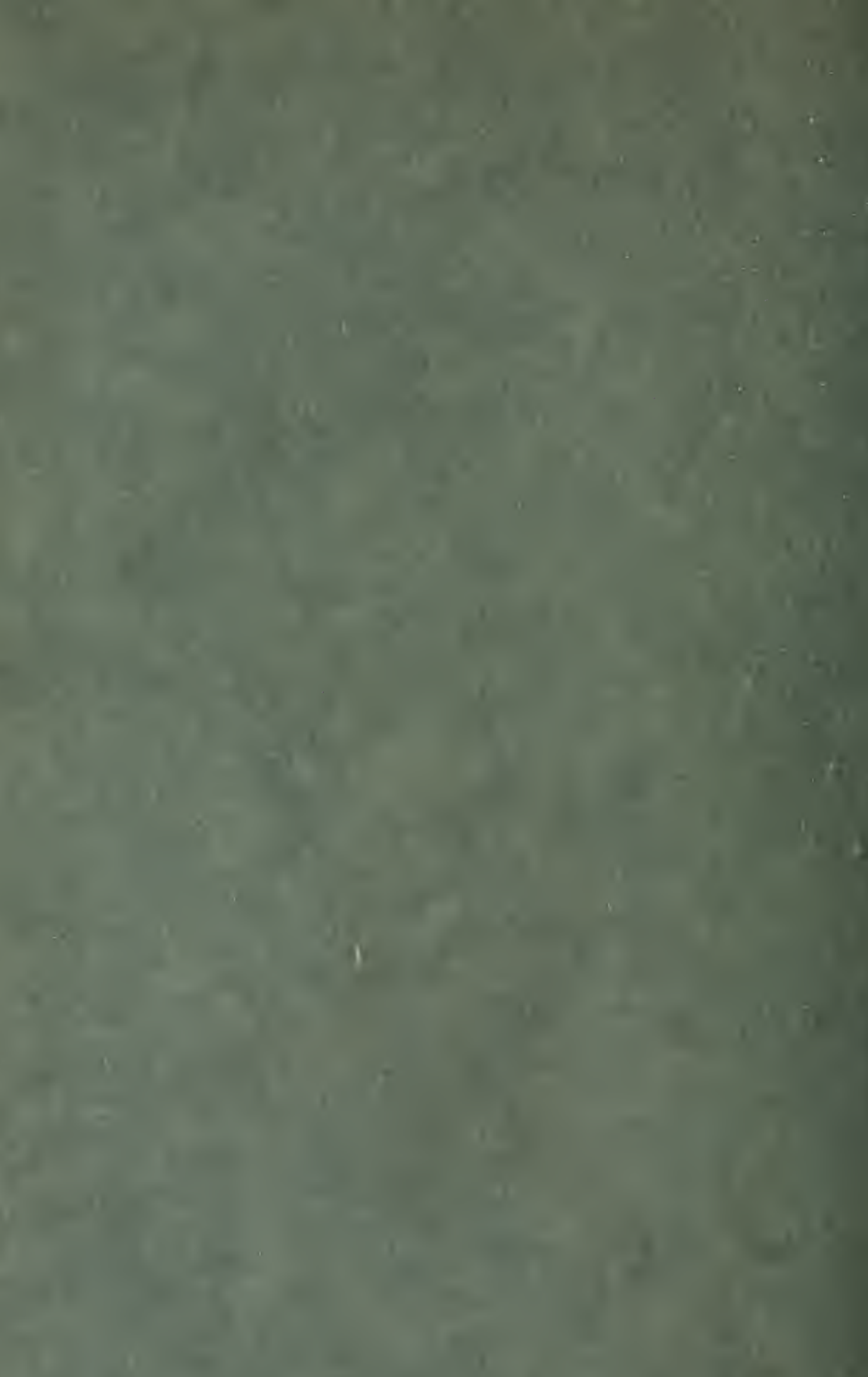


of beautiful shades not to be found in any other hardy shrub. Planted about four feet apart in a group, they will make glorious masses of colour in June and promontories of them may be formed at intervals along the border.

The Forsythias must be included, because of their abundant production of yellow flowers very early in the year in advance of the leaves.

Nothing is more delightful than a group of Daphnes, which may be placed at a point near the lawn or path, partly because of their delicious perfume, which people who walk in the garden will be constantly stooping to inhale. There are several varieties of the old dark red Mezereum, and the white may be associated with the red if desired.

A beautiful little evergreen shrub for a peaty bed (but it will thrive in loam) is Menziesia or Daboëcia polifolia, which is allied to the Heaths. Ineffective as a single plant, it is charming in a colony, the members planted two or three feet apart. The white variety should be associated with the purple, for it is equally beautiful.

The Weigela or Diervilla differs from the foregoing in being of tall, loose habit, but a place must be found for one or two of the best varieties, because it flowers profusely and is very showy. When there is plenty of young wood in the bush it may be expected to be a mass of bloom almost from the ground to the tip. It will thrive in almost any soil.

The Brooms give us a set of beautiful plants of graceful habit, the most showy of which is the brown 
and yellow variety of Cytisus scoparius called Andréanus. A group of this should be planted, if possible, for it has a very lively effect. Other good Brooms are Cytisus præcox, yellow; and C. albus, white, the former very early.

Of the brighter Spiræas, none is better for making a group at the front of a border than Anthony Waterer, which is a crimson variety of the popular species japonica. It grows about a yard high and blooms profusely in summer.

The Hydrangeas, as we have seen in a previous chapter, never look better than when mature plants are established in large tubs, stood for the summer at the waterside or in other selected places. They just lack complete hardiness; nevertheless, colonies grow naturalised in some southern gardens, and a group of some good variety of Hortensis should be planted in the border. Their duration of bloom is remarkable. The white variety of paniculata called grandiflora is hardy and looks well planted over Rubus odorata, which has dark bronzy leaves.

The Olearias are often represented by stellulata (Eurybia Gunniana), a beautiful pure white species, and this shrub is well worthy of a place at the front of the border. Haastii is also very useful, blooming freely in summer, but it requires more room.

Various deciduous Spiræas should be planted, notably Thunbergi, palmata (red) and Aitchisoni, for they are of graceful habit.

Few deciduous shrubs have been more largely planted in recent years than Buddleia variabilis 
Veitchiana, a plant of vigorous growth, which bears large panicles of lavender flowers in summer. This noble plant should have a sheltered site, and it may be given a corner position where it can develop freely, as it may grow to twelve feet high or more.

The Ceanothuses are frequently reserved for wall culture, but they look well in the border, and one of the finest forms is the variety of azureus called Gloire de Versailles.

Lavender should not be forgotten. Apart from its perfume, it is quite decorative.

The foregoing embrace but a small part of the material in the way of beautiful shrubs and trees which await the grower. Nevertheless, the suggestions given may be helpful as showing how, by proceeding on an intelligible system, representatives of the best kinds may be brought into use, not only for individual effect, but for making a collective and cumulative display. Proceeding on a similar system, the shrub-lover who has ample space may make more and more beds and borders, until he has formed a collection of the best kinds, all grown under conditions which give them an opportunity of displaying their true merits.

In addition to the kinds mentioned in the foregoing paragraphs, many beautiful shrubs and small trees not commonly met with can be worked in. The following are all beautiful ; the letter $p$ indicates that a good deal of peat is required. For descriptive details of all the kinds see Part IV. 


\section{EVERGREEN.}

$p$ Andromeda (Pieris) floribunda. Embothrium coccineum.

$p$ Andromeda polifolia.

Camellia Sasanqua (wall).

$p$ Epigæa repens.

Carpenteria californica.

Choisya ternata.

$p$ Daphne Blagayana.

Escallonia Langleyensis.

$p$ Daphne Cneorum.

$p$ Fabiana imbricata.

$p$ Pernettyas.

Piptanthus nepalensis.

$p$ Desfontainea spinosa.

\section{Deciduous.}

Cercis Siliquastrum (Judas Liriodendron tulipifera (Tulip Tree).

$p$ Chionanthus retusus.

Deutzia Lemoinei.

$p$ Enkianthus campanulatus.

$p$ Eucryphia pinnatifolia.

Exochorda grandiflora.

Fremontia californica.

Fuchsia Riccartoni.

Halesia tetraptera (Snowdrop Tree).

Hamamelis mollis (Witch Hazel.)

Tree).

Loropetalum chinense.

Magnolia stellata.

Rubus deliciosus.

Spiræa prunifolia flore pleno.

Staphylea colchica.

Stuartia pentagyna.

Stuartia Pseudo-camellia.

Styrax Japonica.

Styrax Obassia.

Tamarix hispida æstivalis. Viburnum plicatum.

Hibiscus syriacus in variety.

Hydrangea paniculata grandi-

flora. 


\section{CHAPTER X.}

\section{Moving Shrubs and Trees.}

WHEN one sees the things done in the great botanic gardens and by large nurserymen in the way of shifting trees, one wonders whether there is any limit to the powers of arboreal experts. They almost remind us of the strange deeds of American house-shifters, who transfer whole dwellings en bloc from one site to another. Little is thought of shifting a tree twenty feet high, with a bole nearly a foot through. It is merely a question of labour and tackle. A considerable block of earth is taken with the tree, and very few roots are left behind. Every gardener likes to shift with what he calls "a good ball." The ball is the mass of roots with adhering earth. Well, the ball in the case of some tree-lifting which goes on is a mass weighing, with the tree, several tons.

The great compensation for the labour involved in isolating and hoisting such a mass is that practically all the roots are secured and the tree hardly feels the shift. The labour is really considerable. A trench is cut all round when the area of the ball has been marked out. An approach is made to the cube on one side. This approach is a slope dipping from the ground level to the base of the cube. Stout planks are worked beneath. 
The ball is thus isolated. Canvas is wrapped round the mass, ropes attached, and the hoisting and swinging tackle hooked on. Provision is made for maintaining the equilibrium of the tree with guy ropes. When all this has been done it is merely a question of power for getting the mass out of the ground.

Operations of this kind have the interest that attaches to all big things, but they are not likely to come within the practical experience of most gardenlovers. Such shifting of shrubs and trees as is done in ordinary gardens is limited to moving things that are within the powers of two or three men. The main object of the present chapter is to urge that courage should be exercised when a serious mistake in shrub or tree planting has been made, and that before the owner makes up his mind that it must be permanent he should carefully, but at the same time boldly, consider the situation. Resignation in the perpetuation of an error should be the last resource of a true garden-lover.

There may be cases in which an amateur wishes to make changes when the shrubs or trees have become large. He has several things to consider. To begin with, can he expect the plants to move safely? If there is the least doubt he will be prudent to consult an expert. Assuming that an encouraging reply is received, the further question arises, will it be true economy to shift, in view of the fact that a special machine or tackle, and the services of several men will be necessary? It may help to solve this problem if the expert is prepared to give an estimate for the work. A nurseryman who is used to shifting large shrubs and 
trees can calculate the time that a particular job would take, the number of men, the character of the appliances, and the quantity of horse labour that would be needed. Thus situated, he is able to say what the whole undertaking would cost.

A reasonable limit for the powers of an ordinary garden staff might be set at trees eight feet high with boles four inches thick, and shrubs fifteen feet in circumference. The writer has not hesitated to operate on subjects of these dimensions with three assistants, with the ordinary tools of a garden and with a sheet of strong canvas. First a trench has been cut a yard from the stem all round the plant and a foot deep. This enables an idea of the rootstock to be formed. If it is compact and fibrous the problem becomes one of straightforward labour alone. If there are a great many thick, spreading roots matters are complicated. Nearly all evergreens have a fine fibrous root system, but most deciduous trees have a coarse spreading root system. Those who have the shifting of a large deciduous tree in view might cut round it a few months beforehand and ram in some good loamy soil, in order to encourage the formation of fresh fibrous roots. With these to support the tree there need be no hesitation in cutting through the stronger roots two or three feet from the stem, as the tree can do without them. If shifting has to be done at short notice, so that the tree cannot be fortified by preliminary preparation, the operator must do the best he can. He must not expect to secure all of the existing roots if the tree has been standing a few years, for they will have spread in various directions 
and some may be fairly deep; but he should try to preserve all the shorter roots near the bole, particularly the fibrous ones, and two feet or more of the others.

It will be wise to prune back the branches before replanting.

The great majority of evergreens "move" quite readily, as stated in Chapter VII. There is scarcely a period of the year when they will not endure removal, provided air and soil are moist, but one would hardly be disposed to try experiments when they were in full bloom. There is no better time to shift Rhododendrons, for example, than mid-spring, although the flower-buds are plump. That would not be the best time to remove deciduous spring-flowering shrubs, because they would be filling with young leaf; but this class can be removed with complete success in a wet spell after midsummer when the new growth for the year is complete, yet the leaves still on. One great advantage of moving in advance of leaf-fall is that a correct idea can be formed of what the shrub really is. There is a vast difference in the summer and winter aspect of, say, a Weigela. In winter the shrub is a mere framework of ribs, and does not occupy nearly so much space as when furnished with full flesh and blood. No doubt a good many mistakes are made in planting deciduous shrubs because this difference is not taken into sufficient account.

The three vital things in the success of summer shrub-lifting are: (I) moisture both of soil and atmosphere ; (2) securing a good ball ; (3) working quickly. 
Without moisture it would be difficult to get a good ball, except when operating on a very retentive soil; there would be a considerable, and perhaps disastrous, crumbling away. Given moisture, the mass of roots and adhering soil is quite homogeneous. Sure of his position, the operator may even trim the edges of the ball so as to get rid of superfluous soil, but he must do this with circumspection. The ball should not be left exposed, but wrapped in the canvas, carried away and replanted at once.

My own plan is first to make the hole of the size which I judge the ball will require, then to carry a mat or cloth to the shrub and directly it is lifted to wrap it in the cloth and carry it away for planting. At the planting site ball and hole are made to fit each other, mainly by application to the hole, possibly, however, in part by trimming the ball.

How can we get the desired "ball"? First by operating in or after a spell of wet weather ; next, by working round the shrub in a circle with the spade to a depth of a foot or so and half a yard or thereabouts from its centre, more or less according to its size, and then undermining it. The shrub will come away the more readily if one workman pulls steadily at a point opposite to the spadesman. It is well to have a chopper at hand in case any strong roots are found. The shrub will not be injured if these are severed a foot or more away from the tree. Such roots are more likely to be found on deciduous than on evergreen shrubs, most of which produce thick masses of fine fibrous roots. 

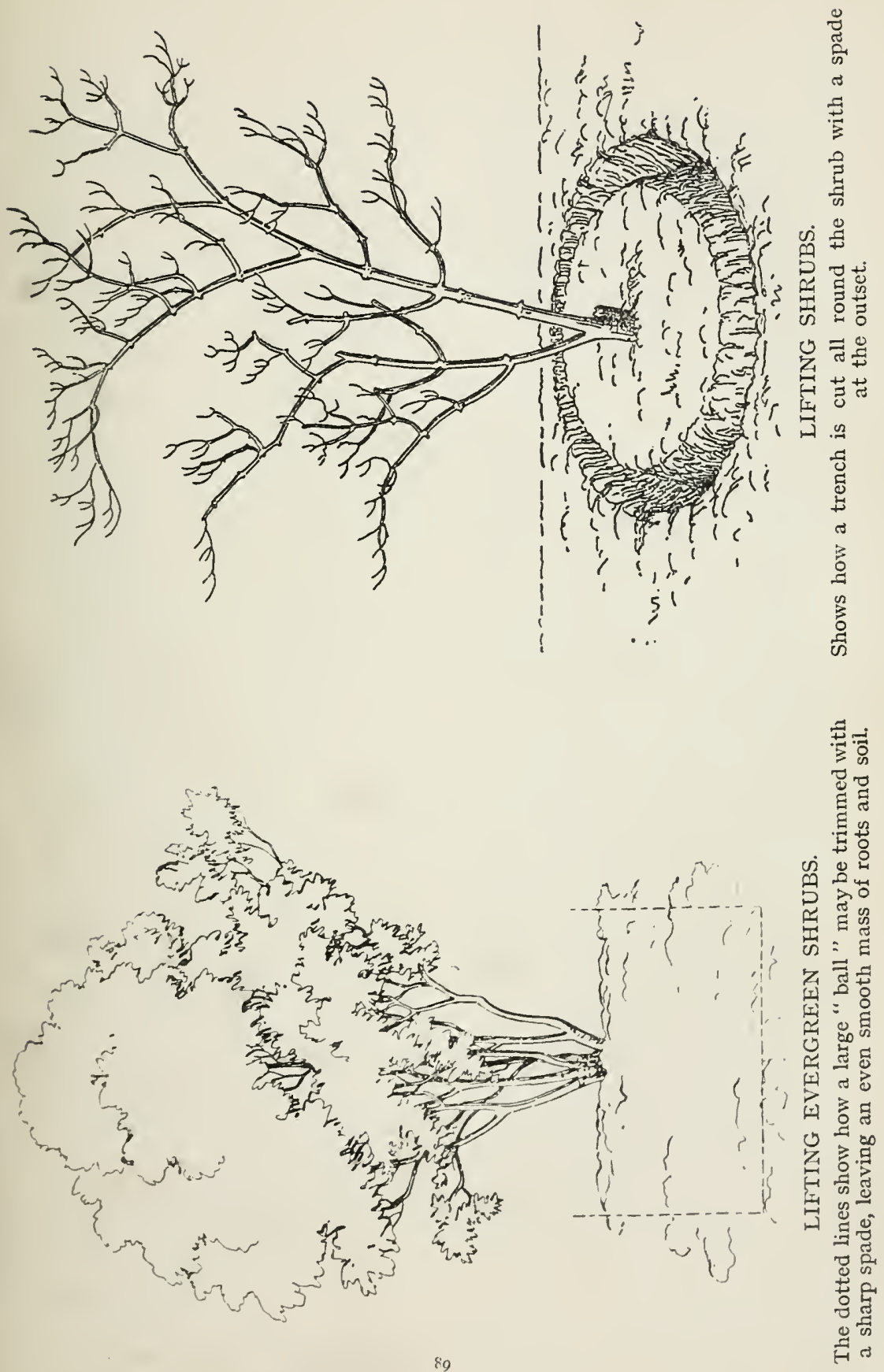
If the wet spell which encouraged the undertaking should change suddenly to a dry one, it would be wise to syringe the plants for a few days.

The general moving of shrubs and trees is done between November and March inclusive. But winter moving is not the best in retentive ground, because the soil is apt to be sticky and when trodden in (and firm soil is an advantage) binds into a close mass almost impervious to air. In such soil the grower should transplant as early in autumn as possible, or in spring, if circumstances are not favourable, or if courage is insufficient for the heroic measure of summer shifting.

Let him beware at all seasons and in all soils, but especially in winter on retentive soils, of " puddling in " shrubs and trees by turning the soil into a paste. It is not merely unnecessary, it is highly dangerous. But firm planting is good; so long as the soil is friable and crumbly there is little fear of its being made too hard.

The following is a summary of the periods of planting the principal kinds :-

Evergreens generally.-Late summer in showery weather, or mid-April.

Rhododendrons.-Mid-April to mid-May.

Bamboos.-May.

Laurels and Hollies.-September or April.

Deciduous shrubs and trees generally.-Late summer in showery weather, failing that, any time up to the end of March, but preferably November.

Magnolias._Early autumn or mid-spring. 


\section{CHAPTER XI.}

\section{Propagation of Shrubs and 'Trees.}

NEARLy all the various methods of propagation brought into play for other kinds of plants are applied to the propagation of the different shrubs and trees. Seeds, cuttings, grafts, buds and layers are all used. Division is practised a little.

Seed-sowing is the natural method of propagation, and is suitable with fixed species, but not with hybrids and varieties. The point is not that these garden forms refuse to ripen seed in every case, but that the resulting plants are not true to type. For instance, seed would be quite suitable for propagating Larch, because it is a fixed species, and the seedlings are not likely to show any important variation from the parent; but seed would not be appropriate for propagating Rhododendron Pink Pearl, because it is a garden form of which seedlings would be likely to show reversions to inferior forms. It is largely because cuttings, grafts, buds and layers can be relied on to come true that they are used.

There are different stages for cuttings. In some cases it is best to use soft wood ; in others wood that is moderately firm, but not hard, and generally spoken of as " half-ripe," in others again firm, ripe, brown wood. 
The cuttings, of whatever nature, may in some cases be inserted out of doors, but more often must be under glass, with or without heat.

As regards grafting, the method may be splice, whip, wedge or saddle grafting. The grafting may be done with or without heat.

These differences show that the subject of propagating trees and shrubs cannot be dismissed in a few words, and that it calls for detailed attention. At the same time, the fact may be admitted that there are a great many shrub lovers to whom it is not of direct interest. Those who have small places, with all the shrub area filled, may be more concerned with thinning out shrubs than with raising more.

In some cases the same kind may be propagated in different ways, and each table should be examined.

\section{A.-SEEds.}

We have seen that seed is the natural method of increase for true species. In most cases it should be sown as soon as it is ripe, but Rose hips may be laid in sand till spring.

Nurserymen and foresters raise Larch and other common trees in the open ground, but all the better things are best sown under glass, if only in a cold frame or pit. A fine bed of friable, gritty soil should be prepared. The seed may be sown in drills six inches apart. Seed approximating in size to that of a Turnip or Radish may be covered half an inch deep ; seed near the size of a Pea two inches deep. Dust-like seed should be covered with the barest film of soil or sand, 
or even left uncovered. It is an advantage to use shallow pans for sowing where the quantity is very small, as they economize soil; but boxes and pots may be used. One serious disadvantage in raising shrubs and trees from seed to the flower-lover whose glass is limited is the long time which elapses between sowing and germination. It is not in every garden that a frame or pit can be spared for several months; and the time may run to years.

In some cases seed does not ripen in this country and imported seed must be used.

Species of the following kinds may be raised from seed; see other columns for varieties :

Acer.

Alder.

Amelanchier.

Andromeda.

Araucaria.

Arbutus.

Arctostaphylos.

Ash.

Beech.

Caesalpinia.

Calophaca.

Caragana.

Carpenteria.

Carpinus.

Carya.

Caryopteris.

Catalpa.

Ceanothus.

Cedar.

Celastrus.

Celtis.
Cephalotaxus.

Cercis.

Chionanthus.

Citrus.

Colutea.

Conifers.

Cornus.

Coronilla.

Cotoneaster.

Cratægus.

Cupressus.

Decaisnea.

Dirca.

Elæagnus.

Elm.

Embothrium coccineum.

Eucalyptus.

Exochorda.

Fothergilla.

Gaultheria.

Ginkgo. 
Gleditschia.

Gymnocladus.

Gynerium (in heat).

Halesia.

Halimodendron.

Hedysarum.

Hippophæ.

Honeysuckle.

Idesia.

Indigofera.

Itea.

Jamesia.

Juglans (Walnut).

Koelreuteria.

Laburnum.

Larch.

Laurus.

Leycesteria.

Libocedrus.

Lime.

Liriodendron.

Magnolia (in heat).

Myrica.

Neviusia.

Notospartium.

Oak.

Olea.

Olearia.

Ononis.

Osteomeles.

Oxydendron.

Paliurus.
Pernettya.

Pieris.

Piptanthus.

Plane.

Podocarpus.

Polygonum.

Potentilla.

Prinos.

Prunus.

Ptelea.

Pterocarya.

Pyrus.

Rhamnus.

Rose.

Rosemary.

Ruscus.

Sciadopitys.

Skimmia.

Sophora (in heat).

Spartium.

Stuartia.

Symphoricarpus.

Taxodium.

Taxus (Yew).

Thuja.

Torreya.

Trochodendron.

Tsuga.

Vaccinium.

Xanthoceras.

Zelkova.

Zenobia.

B.-Half-Ripe Cuttings with Heat.

What the propagator calls " half-ripe" cuttings are pieces of shoot a few weeks old ; they are not green tips, 

" THE GREAT RHODODENDRONS GROUPED IN LAWN BEDS." (See page 77.) Pink Pearl at Kew.

Colour photo by R. A. MALBY. 


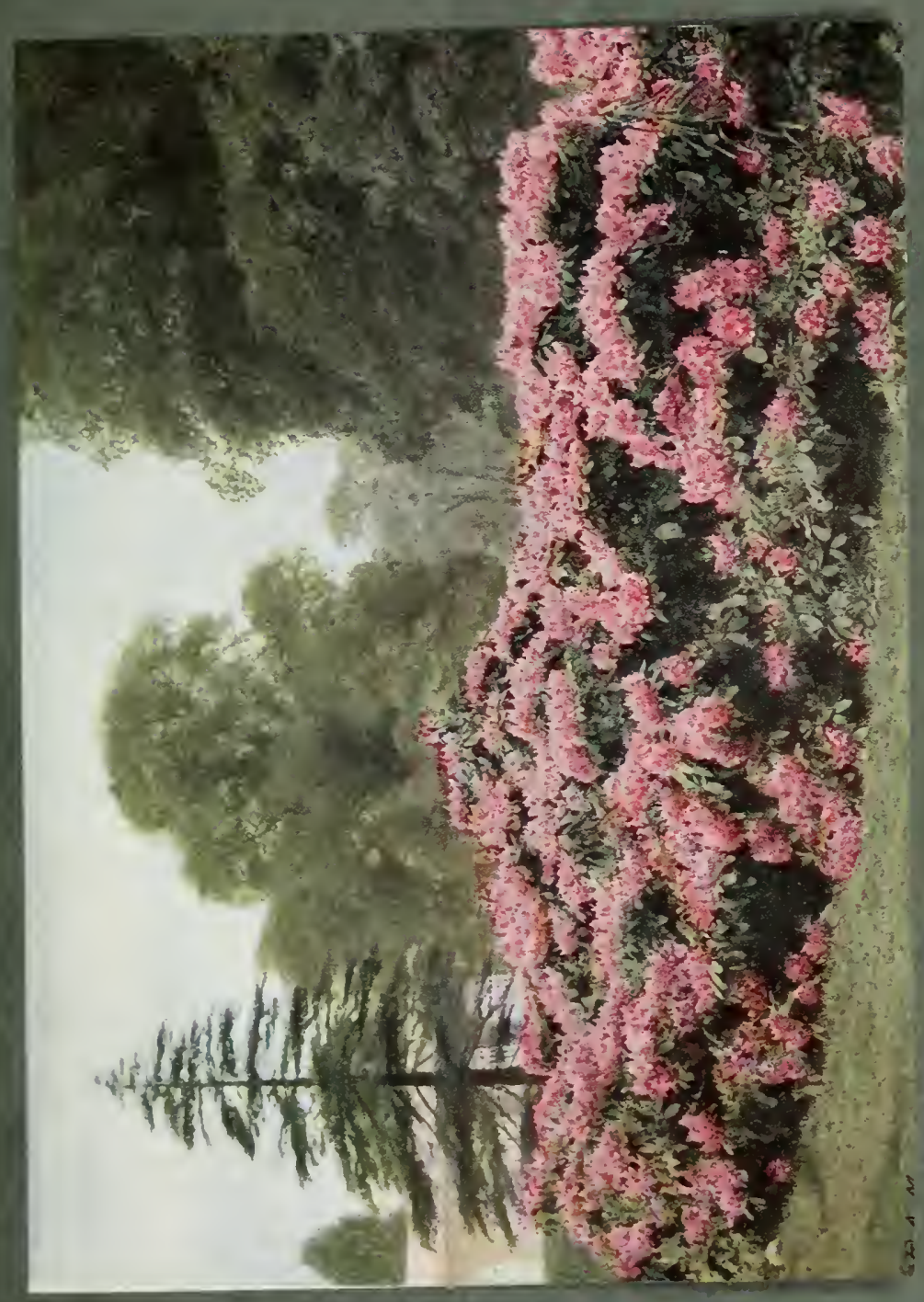




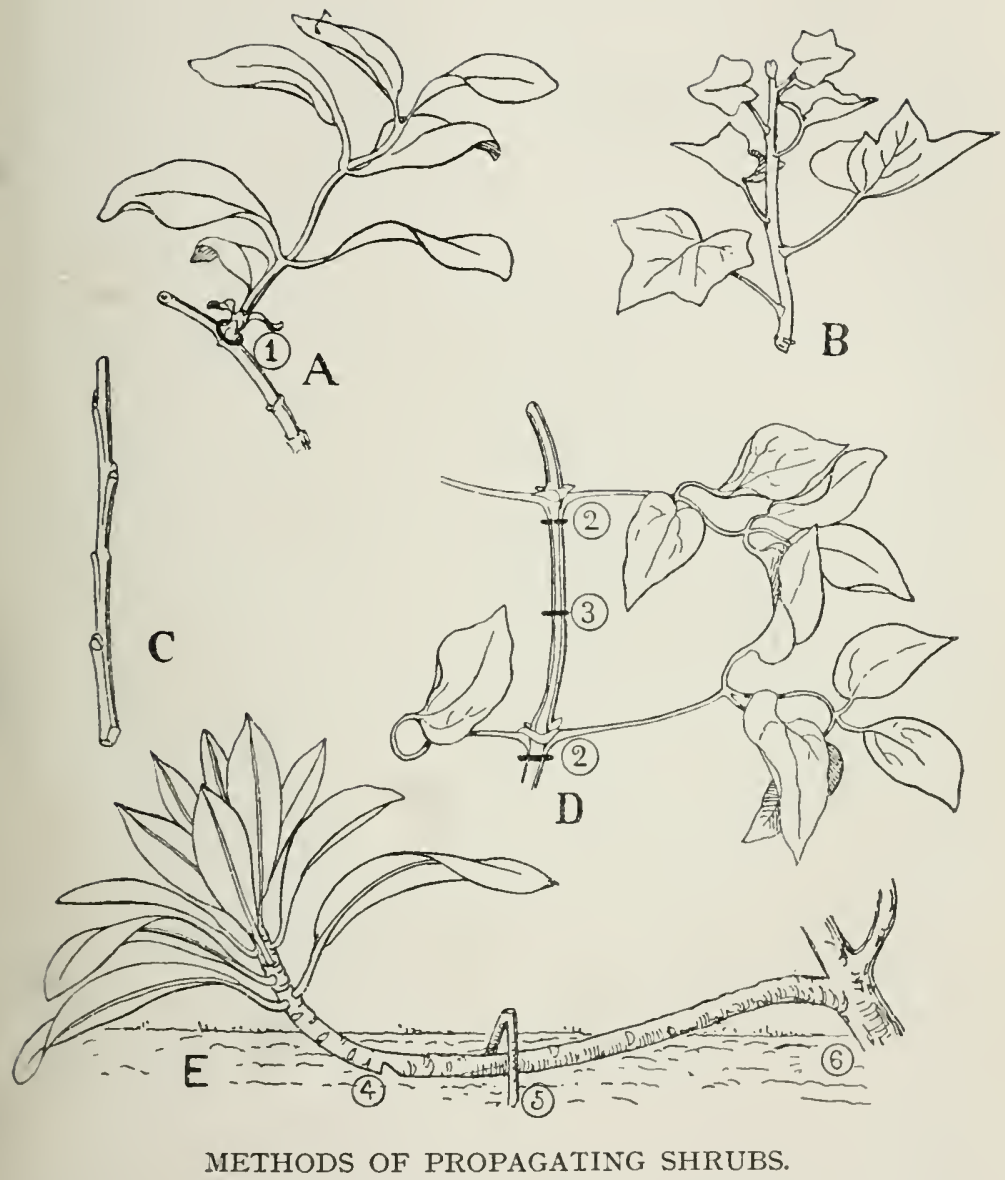

A.-A young wood cutting of Honeysuckle, (I) point of detachment with a slip of the older wood; B, a half ripe cutting of Ivy; C, a ripe cutting of Ribes or Rose; D, a shoot of Clematis showing proper point of detachment at (3) for an internodal cutting; nodal cuttings (2) are best for most plants, but not for Clematises; E, layer of Rhododendron or Magnolia (4) point of notching (5) peg, (6) stem of parent plant. 
nor are they firm woody pieces. They can be taken from leading or side-shoots and are generally made about four inches long and inserted firmly about a third of their depth in very sandy soil. Most cuttings are taken just underneath a joint or node, because it is found that roots start freely from a node, but in a few cases-and the Clematis is a conspicuous example-it is better to make what is called an internodal cuttingthat is, one severed between the joints. Clematises do not, as a rule, strike freely from cuttings, but if internode cuttings are used there will be fewer disappointments. If a cutting forms a large callus but does not root, the callus should be pared down. To ensure speedy rooting it is desirable to put certain kinds in heat. In botanic gardens and nurseries, where a good deal of propagating goes on, the heat is provided by pipes embedded in sand kept moist in propagating cases or frames. The amateur may put his few pots or pans under a large bell glass or handlight in a warm house.

Cuttings of hard wooded plants such as Heaths do not strike readily, and quite small pieces not more than two inches long should be taken.

The following kinds strike best when given close heat :

Berchemia.

Bignonia.

Bruckenthalia (peat).

Bryanthus (peat).

Calluna (peat).

Caragana.

Cassandra.
Cassiope.

Choisya.

Cistus.

Corokia.

Corylopsis.

Cotoneaster.

Desfontainea. 
Deutzia.

Diospyros.

Drimys.

Edgeworthia.

Empetrum.

Enkianthus.

Erica (peat).

Escallonia.

Fabiana.

Fremontia.

Furze.

Heaths (peat).

Hibiscus.

Holly.

Hydrangea.

Hypericum.

Ilicium.
Indigofera.

Ivy.

Kalmia.

Lespedeza (peat).

Lilac.

Myrtle.

Nandina (peat).

Notospartium.

Olearia.

Oxythamnus.

Philesia.

Polygala.

Rhododendron (peat).

Rose.

Skimmia.

Solanum crispum.

Spiræa.

When the plants have struck they should be fully exposed to the air.

\section{C.-Half-Ripe Cuttings without Heat.}

Many kinds do not require heat and root readily if put under a bell glass or handlight in a cool greenhouse or frame. Such are :

Alder.

Amorpha.

Araucaria.

Artemisia.

Azara.

Berberis.

Bupleurum.

Carpenteria.

Caryopteris.

Castanopsis.

Ceanothus.
Cercidiphyllum.

Cistus.

Clerodendron.

Colutea

Cotoneaster.

Cupressus.

Cytisus.

Decaisnea.

Desmodium.

Elder.

Eucryphia. 
Ercilla.

Forsythia.

Fuchsia.

Genista.

Gorse.

Helianthemum.

Hibiscus.

Holly.

Hypericum.

Jasmine.

Kolreuteria.

Lardizabala.

Laurel.

Laurus.

Laurustinus.

Leiophyllum (peat).

Lindera.

Loropetalum.

Menziesia (peat).

Muehlenbeckia.

Neillia.

Nuttallia.

Osmanthus (peat).

Othera.

Paliurus.

Passiflora.
Paulownia.

Periploca.

Phillyraea.

Phlomis.

Photinia.

Pittosporum.

Podocarpus.

Prumnopitys.

Punica.

Rhodotypos.

Rosemary.

Spartium.

Spiræa.

Stachyurus.

Staphylea.

Stauntonia.

Stephanandra.

Styrax.

Tamarix.

Taxodium (in water).

Taxus (Yew).

Tecoma.

Thuja.

Torreya.

Tricuspidaria (peat).

Viburnum.

\section{D.-Soft Cuttings in Close Heat.}

"Soft" cuttings are pieces of freshly formed wood, taken generally from side-shoots directly they have grown three or four inches long, inserted in sandy soil and kept close as in Class B. The following do well from this class of cutting : 

A GLORIOUS TREE TULIP, MAGNOLIA SOULANGEANA. Colour photo by R. A. MALBy. 


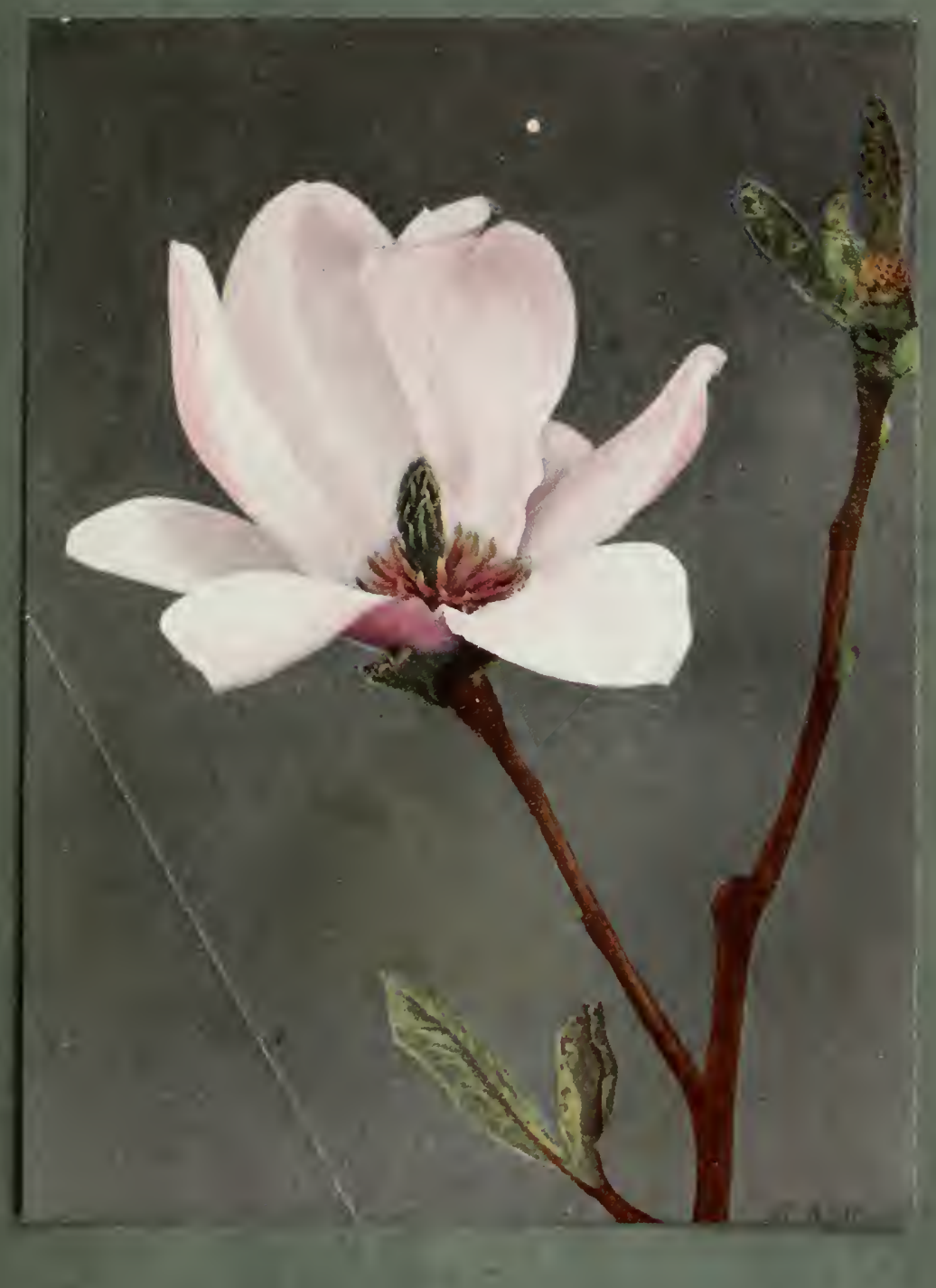




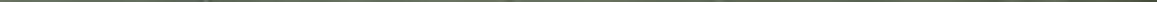


Ampelopsis.

Aristolochia.

Baccharis.

Berberidopsis.

Diervilla.

Forsythia.

Honeysuckle (some).

Hydrangea.
Hymenanthera.

Kerria.

Menispermum.

Parrottia.

Spiræa Japonica, and varieties.

Virginian Creeper.

Vitis.

Weigela.

E.--Ripe Wood Cuttings.

These are generally taken in September, from wood of the current year which has become firm. Most of them are inserted an inch or two apart, in rows just far enough apart to be hoed, in the open ground. Ribes, which include the fruiting Currants and Gooseberries, strike readily from this class of wood. They are frequently taken with a slip of the older wood, called a "heel," but it is not essential. Roses strike from ripe wood in September, but in this case the cuttings do best if inserted up to within an inch of the top. The following kinds are suitable for propagation from ripe wood, some in frames:

Ampelopsis (frame).

Broussonetia (frame).

Buddleia (frame).

Celtis.

Daphne (frame).

Deutzia.

Elæagnus.

Euonymus.

Griselinia.

Honeysuckle (frame).

Lavender (frame).

Leycesteria.
Ligustrum (frame).

Lycium (frame).

Piptanthus (handlight).

Poplar.

Privet.

Raphiolepis (frame).

Ribes.

Rose.

Rubus.

Tamarix.

Vitex (frame).

Willow. 
F.-Root Cuttings.

The experienced propagator finds that there are certain plants which strike better from pieces of root than from portions of stem. A typical greenhouse plant is the Bouvardia, and hardy sub-shrubby perennial the Anchusa. Some shrubs also come best from root cuttings. Generally it will be found best to take pieces of root two or three inches long and about as thick as a cigarette. If inserted in a shallow pan they may be laid almost flat and just covered with soil. Root propagation is particularly suited for the beautiful white Tree Poppy, Romneya Coulteri. Pieces of root two inches long and about a quarter of an inch thick may be inserted singly upright in three-inch pots, or two inches apart round the side of a larger pot in autumn. The plants may be plunged to the brim in ashes in a cold. frame. Growth will start from the top and roots push from the sides. In spring the young plants may be potted singly, and they will be ready for planting out in May. Propagation is also effected by seeds, but root cuttings give strong plants quicker. Strictly speaking, Romneya Coulteri is a herbaceous plant, although the stems frequently stand until spring, giving it a semi-shrubby habit. It is common to leave them till spring as protection and then to cut them out.

The following come well from root cuttings :

Ailanthus.

Calycanthus.

Cladrastis.

Halesia.

Maclura.
Rhus typhina.

Robinia hispida.

Romneya.

Xanthoceras. 
PROPAGATION OF SHRUBS AND TREES IOI

G.-GRAFting.

The most important shrubs commonly propagated by this means are Clematises, Roses and Rhododendrons. In the case of the first, the variety of Clematis to be propagated is attached to a piece of root of one of the commoner species, such as Viticella, Flammula, or lanuginosa. These species, raised from seed, have a tufted rootstock somewhat resembling that of Asparagus in their third year, and one plant will yield enough material for many plants, as pieces of two or three inches long suffice. A plant of the variety to be increased is grown in a pot and started in a warm house in winter and when it has made a few feet of growth the shoot is cut up into pieces between the joints with leaves and dormant buds. The soft tip is rejected. Sloping cuts are made on both root and shoot of the same length, so that they fit close together; this is splice grafting ; they are then tied and inserted in small pots of sandy soil, the tip with its leaves just above the soil. Half loam and a quarter each of leaf-mould and sand make a good compost. Some propagators slit down the centre of the root cuttings, pare down the scion into the shape of a wedge, press it into the cleft in the root, tie and pot. This is wedge-grafting. In either case the pots should be kept close in bottom heat till rooted. Although Roses are generally propagated by outdoor budding in gardens, large quantities of plants are raised by grafting in the nurseries, and this is done in heated houses at mid-winter. The varieties to be increased are grafted on to Brier stocks, generally 
seedling Briers, which are grown in pots for the purpose, because they can be put into heat and given a start at any time. They will be ready for grafting in a fortnight. The scions are small pieces of firm wood and they are attached to the side of the stock (I) by plain splice grafting, as in the case of Clematises, (2) by whip (tongue) or (3) by veneer grafting. A whip graft differs from a plain splice graft in that a tongue is raised by a second cut in both stock and scion. A veneer graft is one in which a shallow slice is taken off the stock with a small "butt" at the bottom, which takes the base of the scion. A slice is taken off the scion to correspond. Many would call this "side" grafting, as the scion is, as it were, let into the side of the stock, near the soil, not put on to the top of the stock. In each case the grafts are tied in and kept close in a warm case until the parts are united. No wax or clay is used as in outdoor grafting

With respect to Rhododendrons, they are mostly grafted on to $\mathrm{R}$. ponticum. In this case the saddle graft is often used. The stock is cut wedge-shaped, and the scion is split and fixed on. But wedgegrafting and side-grafting (see above) are also practised. If the work is done in winter it is well to put the grafted stocks in moist but not strong heat. In spring they could be put in a pit or frame without heat, and this suits all the hardy varieties. The variety Cunningham's White is used as a stock for Indian Azaleas, being raised from cuttings in moist heat in winter and grafted the following year.

It is convenient to grow stocks for grafting purposes 
in pots for several months before operating, but they need not be put in heat until about a fortnight before the work is done.

Like Roses and Rhododendrons, various conifers and Cytisuses may be grafted in late winter or early spring.

Rhododendrons may also be grafted in summer, together with the beautiful winter-blooming Hamamelis and the Japanese Maples.

The following subjects may be grafted :

Abies.

Acer.

Æsculus.

Alder.

Amelanchier.

Arbutus.

Ash.

Beech.

Camellia.

Caragana.

Castanea.

Chionanthus (on Ash).

Clematis.

Cratægus.

Cytisus.

Diospyros.

Elm.

Halimodendron (on Laburnum).

Hamamelis.

Hazel.

Juglans (Walnut).
Laburnum.

Lime.

Liriodendron.

Míagnolia.

Maple.

Oak.

Olea (on Privet).

Osmanthus.

Pæony.

Photinia (on Quince).

Picea.

Pinus.

Prunus.

Punica.

Pyrus.

Rhododendron.

Robinia.

Rose.

Sophora.

Taxus (Yew).

Most of the foregoing are cases in which garden varieties are grafted or budded on to a species. 


\section{H.-LAYERS.}

We have seen that Rhododendrons are generally grafted, but in common with many other shrubs garden varieties may be propagated by layers. A lowgrowing branch of one-year or two-year-old wood is convenient, as it can be pegged down to the soil without any trouble. It is best to cut a notch out of the shoot half way through near a joint, peg the branch down so that the cut part is embedded in the soil, and leave it for a year-two years if roots have not formed before. The soil should be light and friable. As we see above, Magnolias may also be increased in this way, but they are rather slow in rooting.

Layering may be done in the late summer or autumn, when the ground is warm and moist.

The following may be layered :

Acer.

Æsculus.

Amelanchier.

Andromeda.

Berberidopsis.

Box.

Carpinus.

Carya.

Catalpa.

Ceanothus.

Cercis.

Chionanthus.

Cistus.

Clethra.

Cornus.

Corokia.

Cotoneaster.

Cydonia.

Daboëcia.
Daphne.

Dirca.

Elder.

Erica.

Eucryphia.

Exochorda.

Forsythia.

Furze.

Gaultheria.

Griselinia.

Halesia.

Hamamelis.

Hazel.

Hippophae.

Heaths.

Jamesia.

Jasmine.

Laurustinus.

Ledum. 
Lime.

Lindera.

Liquidambar.

Maclura.

Magnolia.

Menziesia.

Morus.

Myrica.

Olearia.

Osteomeles.

Oxycoccus.

Paliurus.

Periploca.

Pernettya.

Philadelphus.

Pieris.

Piptanthus.

Plane.

Prinos.
Ptelea.

Punica.

Pyrus japonica.

Pyrus Maulei.

Rhamnus.

Rhododendron.

Rhodotypos.

Rhus.

Robinia.

Rosemary.

Rubus (tips).

Stuartia.

Styrax.

Taxodium

Taxus (Yew).

Viburnum.

Wistaria.

Zenobia.

\section{J.-Division.}

Propagation by division is not common, as shrubs and trees generally have not the habit of growth which makes this method appropriate. It will be found, however, that some shrubs, notably some of the Spiræas, form growths in the border, and these can be taken and planted. Berberis Aquifolium has a dense, tufted habit and may also be divided. Some Heaths which have a tufted habit may be divided. The work is best done just when growth starts in spring. List :

Aralia (suckers).

Arbutus.

Arctostaphylos.

Bamboos.

Berberis Aquifolium.

Box.

Dimorphanthus (suckers). Epigæa.
Heaths.

Itea (suckers).

Lilac.

Nuttallia (suckers).

Ruscus.

Spiræa (and suckers).

Symphoricarpus (suckers).

Yucca. 


\section{CHAPTER XII.}

\section{Enemies of Shrubs and Trees.}

LIKE most cultivated plants, shrubs and trees have their enemies, whether in the form of caterpillars or fungi. But speaking generally, there is not so much anxiety on this score as in the case of fruit trees. The Rose is the most harassed, and the enemies of that popular shrub are dealt with in the companion volume, "Roses and Rose Gardens."

Azaleas and Rhododendrons are, on the whole, very healthy plants. Blotches, galls and pustules may sometimes be seen on them, but rarely to the extent of seriously injuring or disfiguring them.

Occasionally branches of Rhododendrons, as of other plants in the order Ericaceae, die from canker, for which there is no known remedy.

Young trees of the softer wooded kinds, such as Willow, Chestnut, Lime, Birch, Ash and Plane, sometimes show cracks in the bark, which on being removed reveals hard, dry wood. A considerable area of the stem of a tree may be affected in patches in this way, and it may dwindle and die. This condition is often caused by a burst of sunshine after a spell of dull, damp weather. It is, in fact, a case of what the grapegrower would call "scorching," the "enemy " being the 
" VEITCH'S VIRGINIAN CREEPER IS A TRUE CLIMBER, AND ASSUMES EXQUISITE SHADES IN THE FALL."

(See page I68.)

Painted by A. C. WyatT. 


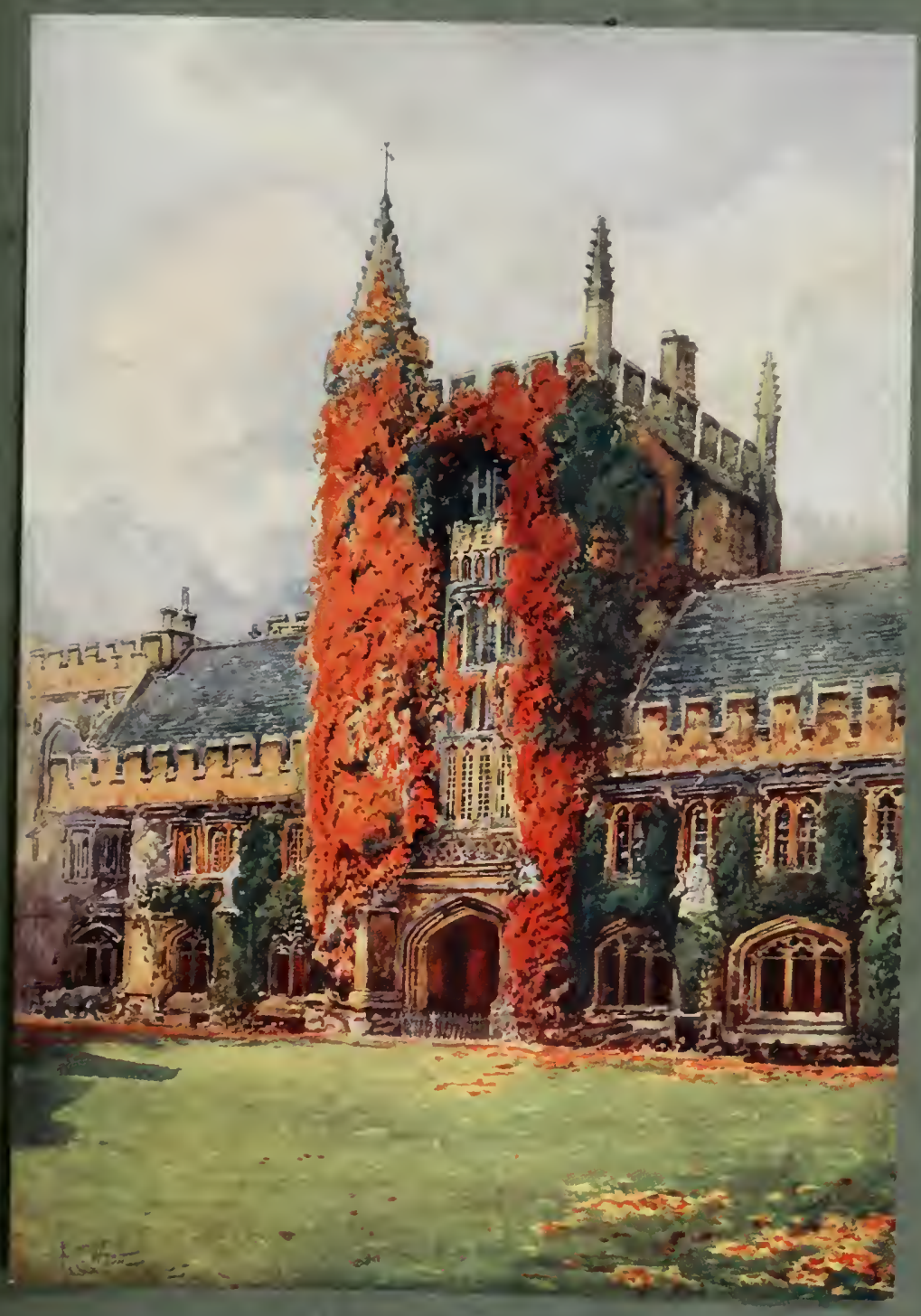




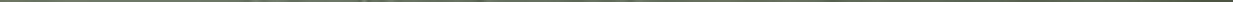


sun. It will be noticed that it happens most often in the case of trees that are quite exposed. Those of which the stems are shaded by their own foliage, by undergrowth, or by other objects, do not suffer. If a young tree should be found suffering from this cause, haybands might be made, twisted round the stem and kept moist. They are also useful when a tree has sustained accidental injury.

In case of any canker-growth, the patch should be cut out and gas tar painted on.

The upper part of a tree may sometimes break off and reveal the tunnellings of a caterpillar, such as that of the Goat Moth (Cossus ligniperda) or that of the Wood Leopard Moth (Zeuzera æsculi). The former is so called from its disagreeable odour. It makes large borings and does serious damage to timber if not destroyed. If the bark of a tree is observed to be injured in any way, it should be examined, and if any trace of wood chippings is found a hole should be searched for and a piece of wire passed in to the end, where it should be worked about so as to destroy the caterpillar. The same plan may be adopted in the case of an attack by the Wood Leopard Moth caterpillar.

One of the most remarkable diseases in trees is the "Witch-knot" of the Birch, a bundle of twigs that at a short distance might be taken for a crow's overturned nest, but which proves on a close inspection to be attached to the tree. It is due to the irritation caused by a species of gall-mite. Such mites are numerous, and their work is generally shown in swellings on the leaves; but in this case twiggy clusters develop. An 
attack should be watched, or it may spread to other Birches in the vicinity. The safest plan is to cut the bunch of twigs out and burn it.

Larches are often grown in large plantations, and the trees may suffer severely from the aphis, Chermes laricis, which absorbs sap both through the leaves and the tender bark of young trees. A simple remedy is a wineglassful of paraffin oil in a gallon of water. They are also subject to other diseases, but these troubles attach rather to the domain of the forester than the flower-gardener. The same may be said of the Pine Sawfly, the Pine Weevil, the Spruce Gall Aphis, the Willow Beetle and other tree enemies. It is rare that a few trees well grown in gardens for ornamental purposes in fertile, well drained soil, are seriously injured or disfigured.

A similar remark applies to the vast majority of evergreen and deciduous shrubs, and it is quite unnecessary to take them one by one, as would be the case with the principal fruits, vegetables and florists' flowers, and deal with individual enemies. 


\section{CHAPTER XIII.}

\section{Pruning Shrubs and Trees.}

IN referring to the common errors in the culture of shrubs and trees (see Chapter VII.) it was said that neglect of pruning accounted for many comparative failures. It was pointed out that different shrubs have different habits of growth, and that to get the best results these variations should be studied.

The true lover of shrubs and trees will never grudge the time necessary to learn their habits of growth and method of flowering. On the contrary, he will find interest and enjoyment in acquiring knowledge about them. He will see that some deciduous shrubs bloom best on entirely new wood, some on wood a year old, others on wood two years old or more.

We need look no farther than the Rose for classes typical of those kinds which do not produce their best flowers in spring, on shoots of the previous year, or on old wood, but on absolutely new shoots of the current year. With these the course is to prune the flowered shoots back to near the base, not absolutely to the old wood, but to within a few inches of it, leaving three or four buds (more or less according to the variety), from which the new flowering wood will start. It is usual to do this just as growth begins in spring. In such shrubs the old 
wood forms, as it were, a framework, a support, for the flowering wood. The old wood cannot be dispensed with altogether, as it can in the case of those shrubs which, like the Raspberry and a host of others, throw up shoots direct from the root stock. To avoid misunderstanding, it should be pointed out that although the Hybrid Perpetual, Tea-scented, Hybrid Tea and most other Roses have the habit indicated, the Ramblers and Wichuraianas have the Raspberry habit.

There are a few shrubs, of which the Rhododendron and the Camellia are popular examples, which produce shoots from the base of the flower trusses. Examine a Rhododendron in bloom and it will probably be found that growth buds are present at the base of the truss. This offers two practical hints to the cultivator: the first, that he should not cut Rhododendron blooms with long pieces of the supporting branch if he wants subsequent growth; the second, that after the bloom truss has faded on the plant it should be pinched off carefully with finger and thumb, so that the nestling buds may be left uninjured. These points are often neglected, with injury to the plant. When Rhododendrons are grown thinly they rarely need much treatment with the knife, as they develop a neat habit naturally and gradually extend their flowering wood. Should they get very crowded branches may be cut right out. When they get crowded, however, they may grow tall and lank, and so become unsightly. In such cases it is wise to attack them with a saw and prune them low. If they are happy in the soil they will 
break freely from old wood, and soon be compact bushes again.

We chose the dwarf hybrid classes of Rose as typical of the shrubs which bloom best on entirely new wood. Clematis Jackmanii might be quoted as another well known example.

The second group, that which flowers best on wood made the previous season, is a large one. The Rubus genus, of which the garden Raspberry is a familiar member, the Mock Orange, the Deutzia, the Rambler Roses and the Weigela are popular examples.

With respect to the third group, which bloom mainly on mature wood two years or more old, little annual pruning is needed, certainly there is no general cutting back as in the two other groups.

We might, indeed, form a fourth group : those which, in practice, need no annual pruning; they only require to be thinned now and then when the heads get thick.

Inasmuch as this diversity of habit exists among shrubs it follows that the same system of pruning cannot be right for all kinds, but if the grower fixes in his mind that nearly all the principal deciduous shrubs fall naturally into groups, and classifies his own plants accordingly, he will succeed. There are exceptions. Some shrubs, notably the Clematis, have no common habit throughout the species, and consequently these genera require special study; but they are not numerous.

We might usefully consider the groups one by one : 
(I) The New-Wood Group.--In this section the annual pruning consists in cutting back the flowered growths of the previous year. It is not usual to cut them out entirely, but to reduce them to a few buds, because growth starts better from buds near the old wood than from the old wood itself. Pruning may be done when growth starts in spring.

(2) The One-year Wood Group.-Here the annual pruning consists in removing the wood which has flowered, and it may be cut out the same summer, because the new wood gets full exposure to sun through the thinning of the bush, and, becoming well ripened, flowers well the following year. Certain variations will be found within this group. Some of the shrubs will throw up most of their annual growth from the rootstock itself, like a Raspberry or a Dorothy Perkins Rose. Others will produce it on the upper part of the old wood. With the former, the annual pruning of the flowered wood will be to the ground level; with the latter, to the old wood from which it breaks.

(3) The Old-Wood Group.-The annual pruning consists in cutting back the annual growth close to the old wood. It is often spoken of as spurring. It may be done in winter or when growth starts in spring.

A strong, sharp pruning knife will be found the most useful tool for pruning deciduous shrubs, but secateurs may be used on occasion with groups I and 3. A small saw will be needed on occasion.

The grower soon learns by observation the difference between new, one-year-old, and older wood. New wood is comparatively thin, flexible and green, or 


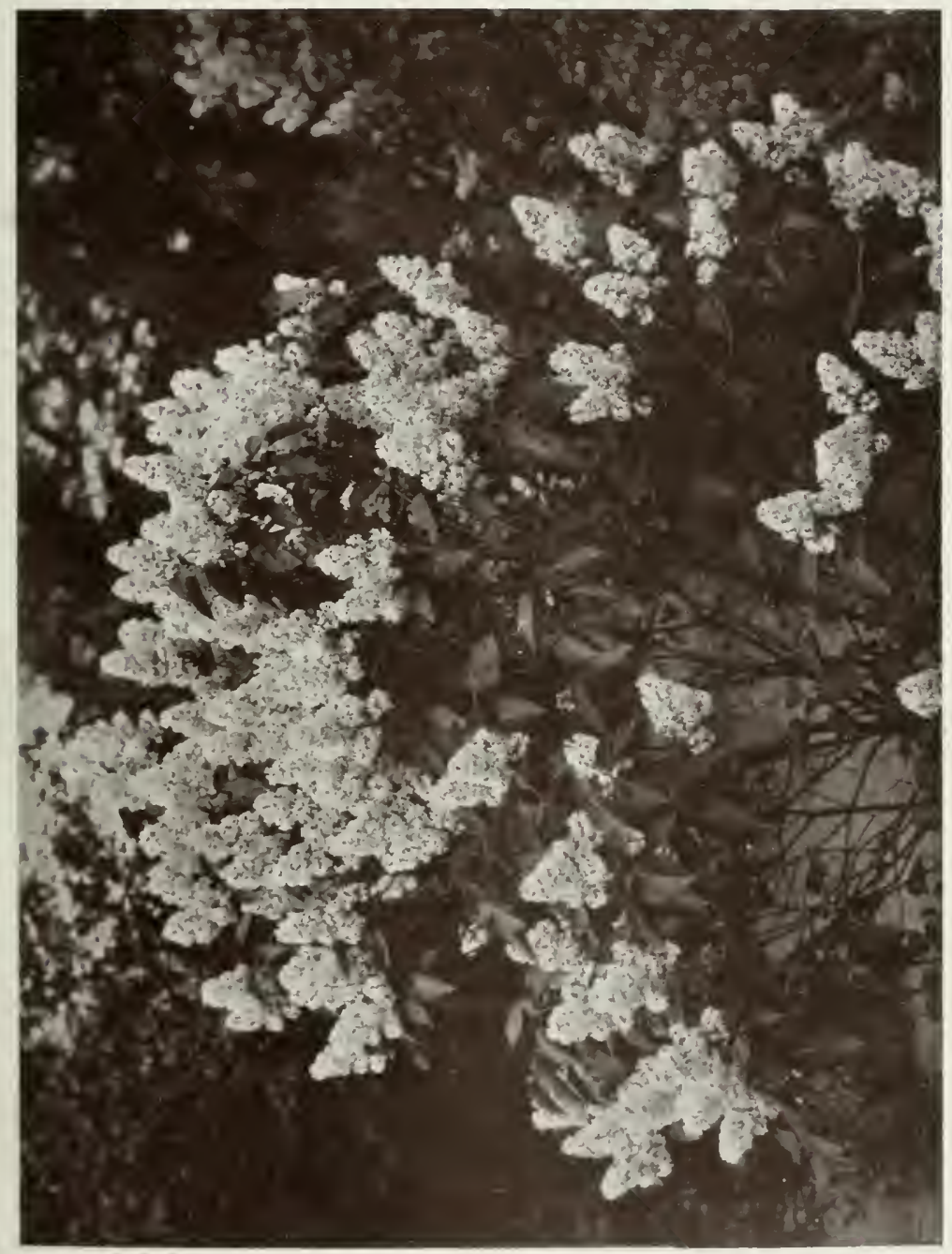

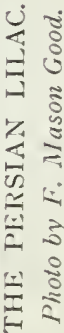




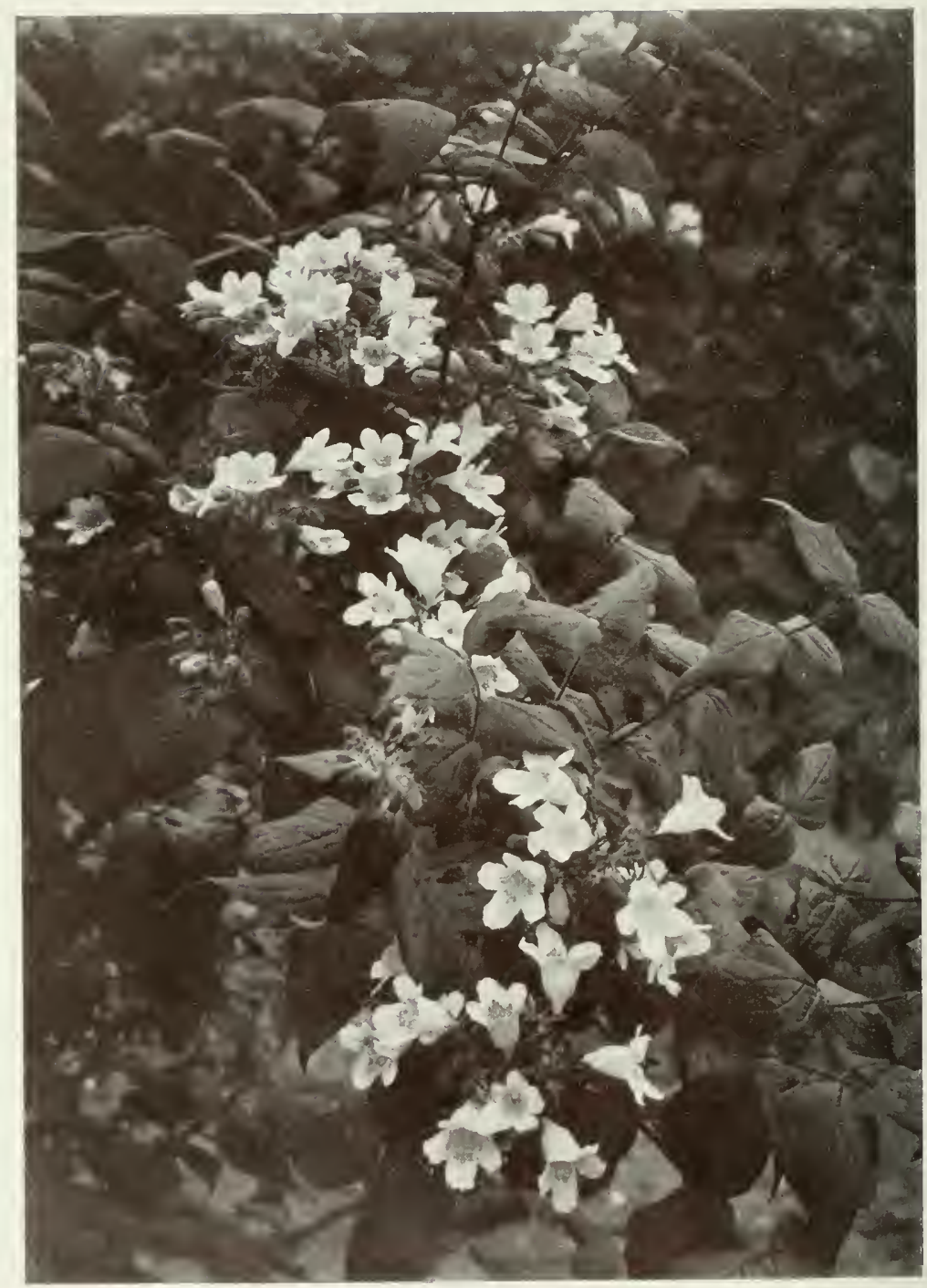

KOLWITZIA AMABILIS.

A new Shrub from the Far East.

Photo by R. A. Malby: 
greenish-brown, in colour. One-year-old wood is brown and firm, but the bark is smooth and clear. Old wood is dark and the bark is rough and dull.

Pruning may sometimes consist in cutting back a jagged stump where a branch has been broken off. The stump should be cut close back to the bole, smoothly and cleanly, and then coated with gas tar. Dead branches should also be removed promptly.

The principal evergreens require very little pruning. Sometimes a little shaping may be needed, but there is no such thing as annual pruning, except for hedges. A weak plant may be cut back.

Berberises and Hollies only need shaping. At the s?me time they will endure pruning if formal growth is wanted; and this is best done at mid-spring, because then the new growth soon hides the stumps. Laurels often require severe repression and it should be done with the knife in April. Ivy should also be clipped then.

With respect to deciduous trees, the smaller flowering trees may be shortened when young to get an open framework of branches, but afterwards they will require no pruning, unless it be to thin a much-crowded head or trim in a straggling branch. A strong leading growth is not wanted. The larger shade and shelter trees should have a clean main stem extending upwards as a leading growth, with side branches breaking from it. As a rule, it is not well to shorten the head, as advised for the small flowering trees, because a spreading, cabbage-like head is not wanted.

Conifers rarely require any pruning. A continuous 
main stem or "leader" is necessary. If a tree forks into two leaders one should be removed.

The following tables will serve as a guide to pruners :

Group I.-The NeW-Wood Group.

(Pruning consists in cutting the flowered shoots of the previous year close back in winter or when growth starts in spring).

Baccharis halimifolia.

Clematis Flammula.

Buddleia variabilis and Veitch- Clematis paniculata. iana.

Buddleia japonica.

Clematis vitalba.

Desmodium.

Buddleia intermedia.

Buddleia Lindleyana.

Genista tinctoria.

Caryopteris mastacanthus.

Ceanothus americanus.

Ceanothus azureus.

Ceanothus garden varieties and hybrids such as Gloire de Versailles.

Hedysarum.

Hydrangea.

Hypericum.

Indigofera.

Jasminum officinale.

Jasminum nudiflorum.

Myricaria.

Clematis Jackmanii and its forms.

Clematis viticella.

Ononis rotundifolia.

Perowskia.

Roses (dwarf, hybrid).

Group 2.-The One-Year-Wood Group.

(Most of these are spring bloomers, and the pruning out of the shoots which have flowered should be done in early summer, so as to give the new wood which is springing up a chance of developing freely and ripening well ; but the summer and autumn bloomers, such as the Rambler and Wichuraiana Roses and some of the Spiræas, cannot be pruned till late summer or early autumn. The new shoots will bloom the following year.) 


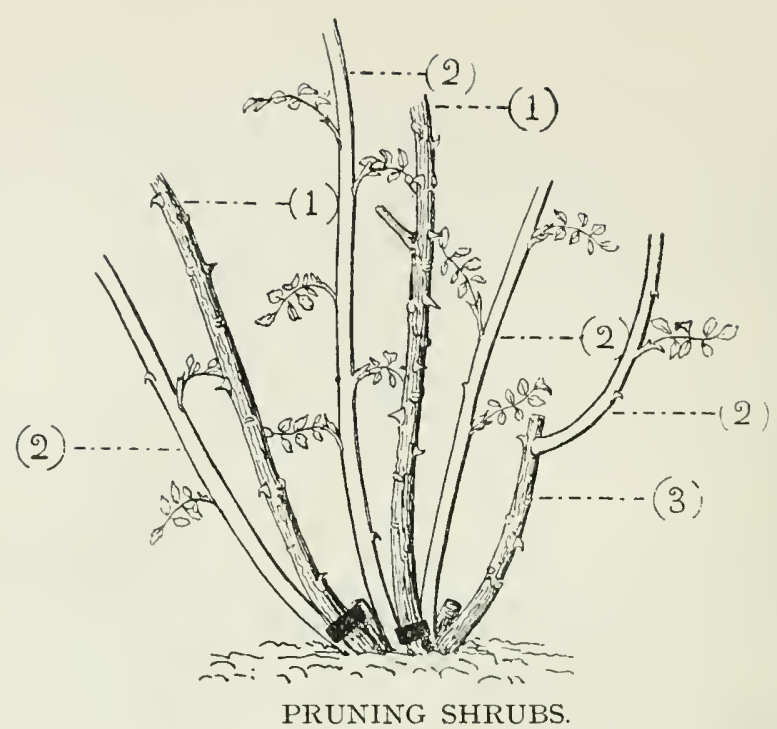

How to prune shrubs of the Raspberry and Rambler Rose habit.-(I) old dark shoots to be cut out at the base in summer; (2) young shoots to be retained for next year's flowering; (3) an old shoot shortened to allow the retention of a young shoot growing from it.

(2)

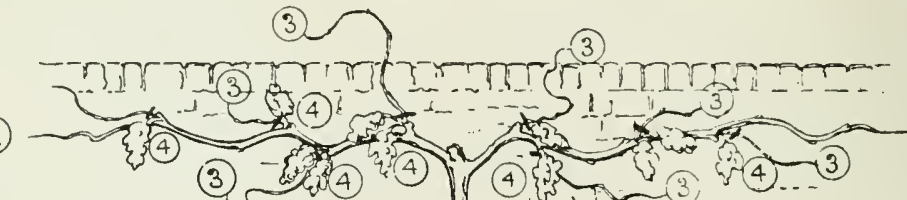
- (3) - (3) - (3)

(2)

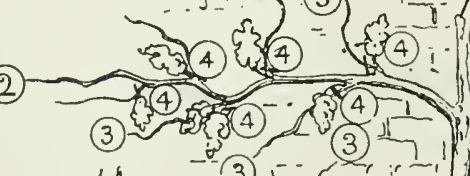

(3) $-3$

(3)
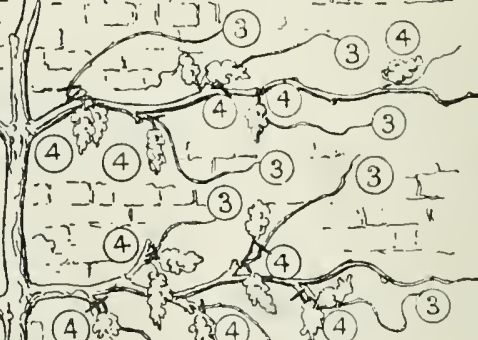

(4)

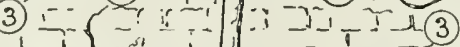

(3)

(2)
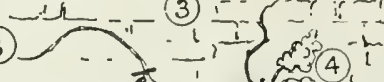

(3)

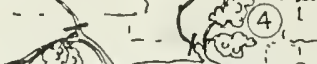

(3)

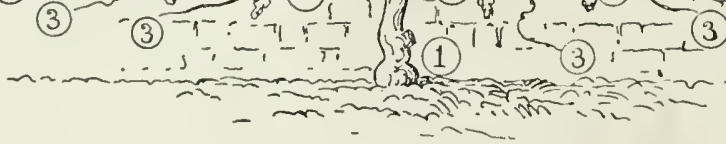

\section{PRUNING SHRUBS.}

How to prune shrubs which bloom from the old wood.-(I) a Wistaria planted against a wall; (2) side branches trained in tiers to cover the wall;

(3) young shoots pruned close back in winter or early spring ; (4) racemes of bloom springing from the mature wood. 
Calophaca.

Caragana.

Clematis montana.

Colutea.

Coriaria.

*Cornus (Dogwood).

Deutzia.

Diervilla.

*Elder, Golden.

Forsythia.

Halesia.

Jasmine.

Kerria.

*Leycesteria.

Ligustrum.

Lonicera (Honeysuckle).
Lycium.

Neillia.

Neviusia.

Nuttallia.

Philadelphus (Mock Orange).

Prunus triloba.

Prunus japonica.

Rhodotypos.

Ribes (see also group 4).

Rose (Rambler and Wichuraiana)

Rubus.

Sophora (not japonica).

*Spiræa.

Vaccinium.

Weigela.

\section{Group 3.-The Old-iWood Group.}

(Pruning consists in thinning when crowded and spurring back the young shoots to two or three inches in spring where numerous. Very little general pruning is needed.)

Akebia.

Amorpha.

Catalpa.

Ceanothus Veitchianus.

Chimonanthus.

Clematis florida.
Clematis lanuginosa.

Clematis patens.

Prunus (see also Group 2).

Pyrus.

Vitis.

Wistaria.

\section{Group 4.-No Pruning.}

(Some shrubs, in practice, require no annual pruning. The most that is likely to be needed is a little thinning

* The Dogwoods grown for their coloured stems in winter should be cut down every spring. Golden Elder the same. The beautiful purple-leaved Nut, Corylus maxima atropurpurea, should be cut down about every third year. IIost of the Spiræas respond well to cutting hard back annually, this being done in Winter or early Spring. 
and shaping every two or three years. The following come within this group):

Abelia.

Acer (Japanese).

Actinidia.

Ailanthus.

Amelanchier.

Andromeda polifolia.

Aralia spinosa.

Arbutus.

Aristolochia.

Azalea.

Azara

Bamboo.

Berberis.

Berchemia.

Bruckenthalia.

Bryanthus.

Buddleia globosa.

Calluna (Ling).

Calycanthus.

Camellia.

Carmichælia.

Cassandra.

Cassiope.

Celastrus.

Cercis (Judas Tree).

Choisya.

Cistus (Rock Rose).

Clerodendron trichotomum.

Clethra.

Colletia cruciata.

Cotoneaster.

Cratægus (Thorn, see below).

Cytisus (Broom).

Daboëcia.
Daphne.

Davidia involucrata.

Decaisnea.

Elæagnus (thin).

Erica (Heath), remove old flower heads.

Escallonia.

Euonymus.

Exochorda.

Fothergilla.

Garrya.

Genista (see also Group I.).

Gymnocladus.

Halimodendron.

Hamamelis.

Helianthemum (Sun Rose).

Hibiscus.

Hippophae.

Honeysuckle, winter flowering. Hymenanthera.

Itea.

Jamesia.

Kalmia.

Laburnum.

Lavender.

Ledum.

Lespedeza.

Leucothoë.

Liriodendron (Tulip Tree).

Liquidambar.

Lonicera fragrantissima and L.

Standishii.

Magnolia.

Myrica. 


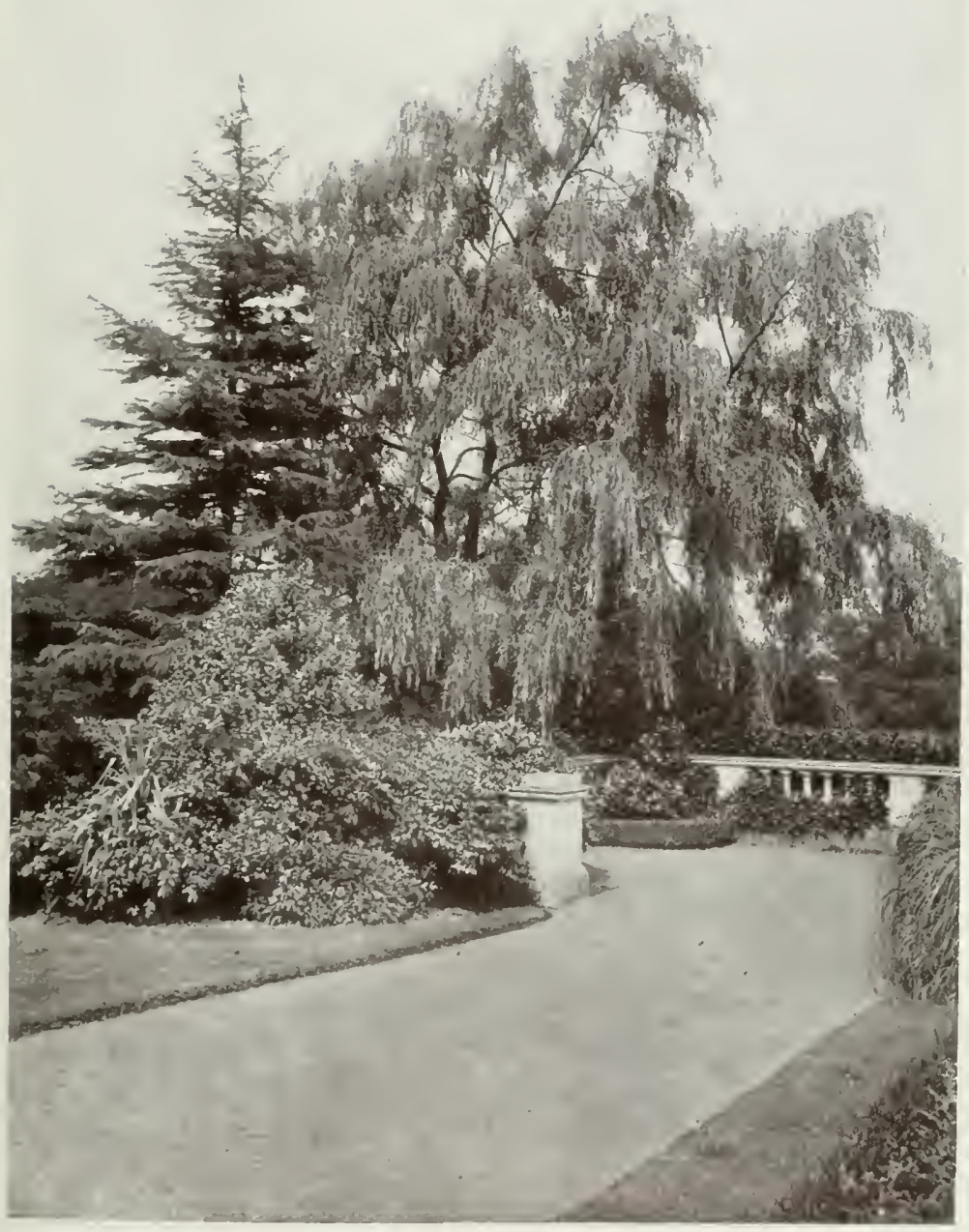

THE MIONARCH OF THE TERRACE.

A noble Weeping Willow.

For description see Chapters XIV. and XXII.

Photo by F. Mason Good. 


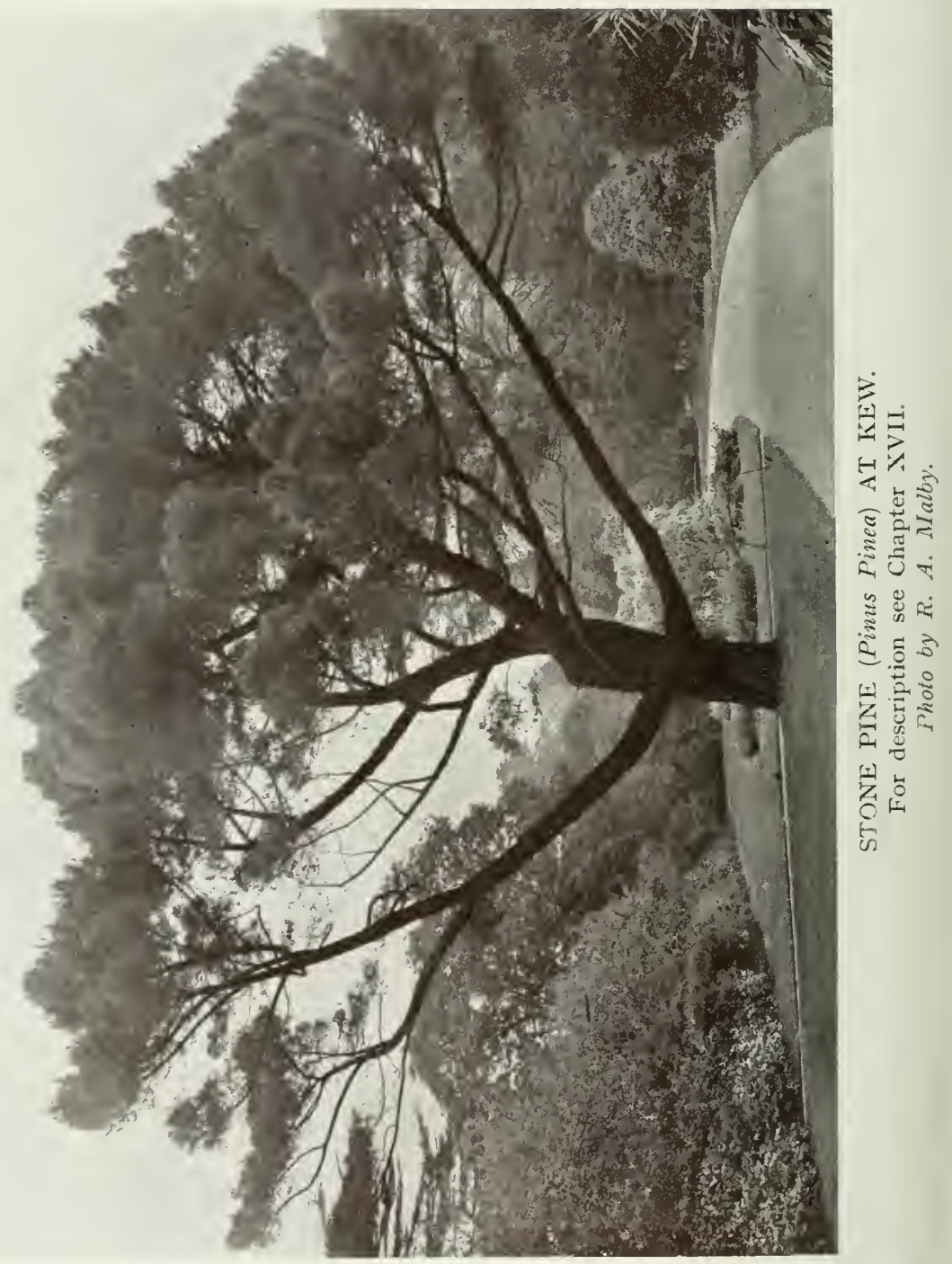


Notospartium.

Olearia.

Ononis (see also Group I.).

Osmanthus.

Oxycoccus.

Oxydendron.

Parrottia.

Periploca.

Pernettya.

Photinia.

Pieris.

Potentilla.

Rhamnus.

Rhaphiolepis.

Rhododendron.

Rhus.

Ribes.
Robinia.

Santolina.

Skimmia.

Smilax.

Spartium.

Staphylea colchica.

Stephanandra.

Stranvæsia undulata.

Stuartia.

Styrax.

Tamarisk.

Veronica.

Viburnum.

Vitis inconstans (Ampelopsis Veitchii.)

Xanthoceras.

Zenobia.

It should be understood that weakly plants of the above may be cut hard back with advantage. Crowded bushes may be thinned. Young plants may be shortened to induce new branches to break. But, broadly speaking, healthy, well developed plants need only occasional thinning.

Paulownia imperialis is sometimes used for subtropical purpeses, and is cut down every spring to get fine leaves.

The variegated and golden Elders may also be cut back annually.

Lilacs are disbudded as described in Chapter XXVI. Basal suckers should be cut out.

The Thorns (Cratægus) when grown as standards may have the heads shortened once or twice while young, but no annual pruning will be needed. 
The Winter Jasmine may be pruned severely after flowering, and strong growths will push which will bloom the following winter.

In pruning trees, due weight must be given to the consideration of getting a good bole. In nature trees are crowded, and this tends to the production of fine stems, because the trees draw up to the light and the lower side branches gradually shrink away. But the bole may be "feathered" with small branchlets.

In park planting, or any planting for distant group effect, particularly with Firs and Pines, the trees may be set close with this object in view. On a lawn or other sites near a house single planting is better. Most of the Conifers are wanted well feathered with foliage to the ground, and if uncrowded, and kept to one leader, they will be well shaped. As regards the larger deciduous trees, the desiderata are a clean bole and a large spreading head. These features may not come without assistance from the pruner in the early stages. The lower branches should be kept shortened for the first few years, but should be allowed to carry some leaves, as the foliage helps to thicken the stem. Later the lower branches can be removed altogether. There should only be one leading shoot. 
PART III.

Selective. 


\section{INTRODUCTION.}

Although all the principal shrubs and trees are described in Part IV., and their uses indicated, it is thought that selections of the best kinds, grouped for the various purposes to which they can be put, may be convenient to readers as affording a ready guide to those who have particular wants. 


\section{CHAPTER XIV.}

\section{Lawn Shrubs and Trees-Pendulous or Weeping Trees.}

WHEN the garden-maker is considering shrubs and trees in relation to the house, he cannot fail to see the value of groups and specimens on lawns; and the formation of lawn-borders is naturally followed by the planting of certain kinds, not entirely appropriate to the borders, on selected sites on the lawn itself. Such plantings have a rich and at the same time refined effect. They are good, too, for the objects planted, because the prominent positions which they occupy insure their receiving adequate attention. They have plenty of room, and care is devoted to the planting and pruning.

We have already seen that the problem of planting hybrid Rhododendrons in the border sometimes proves insoluble, and these noble plants are assigned sites on the lawn, where special beds are made for them. In prominent positions such as this, only really good varieties should be planted, and they may be selected from those described in Part IV.

The old plan of forming special peat beds is not followed now where good loam is available, as it is found that this soil suits Rhododendrons well; 
nevertheless, they are peat-lovers, and in places where, owing to a limestone formation existing, soil has to be imported to make special beds, peat may be used in a mound above ground level.

The plants grow somewhat slowly, and either thick planting with subsequent thinning must be adopted -and close-planting of modern Rhododendrons is expensive, as the plants are far from cheap-or other plants associated with the young Rhododendrons to avert a scrappy effect. Liliums are much used for this purpose. If the Rhododendrons are set six feet apart, they will meet in due course, and give the massed effect which is generally seen; but the true shrub-lover will find great delight in good specimens thinly grown, which can develop into large bushes and be seen from all sides, as in the great Cornish gardens. Thus, many will prefer single plants to groups.

One's thoughts turn naturally to Conifers when material for lawn trees is sought for. Shapely trees of the beautiful Wellingtonia gigantea, the columnar Libocedrus decurrens, the handsome Pseudostuga (Abies) Douglasi, the quaint and tortuous Araucaria imbricata, the beautiful Picea nobilis glauca and other kinds mentioned in Chapter XVII. come to mind. All these may be planted as individual trees in round beds at selected places. Others suitable for use in a similar way are Catalpa bignonioides, the Tulip Tree (Liriodendron tulipifera), Buddleia globosa, Picea pungens, and its pendulous and glaucous varieties, Taxodium sempervirens, Robinia Neo-Mexicana, Cupressus macrocarpa, Picea pinsapo glauca, Cupressus Lawsoniana, 


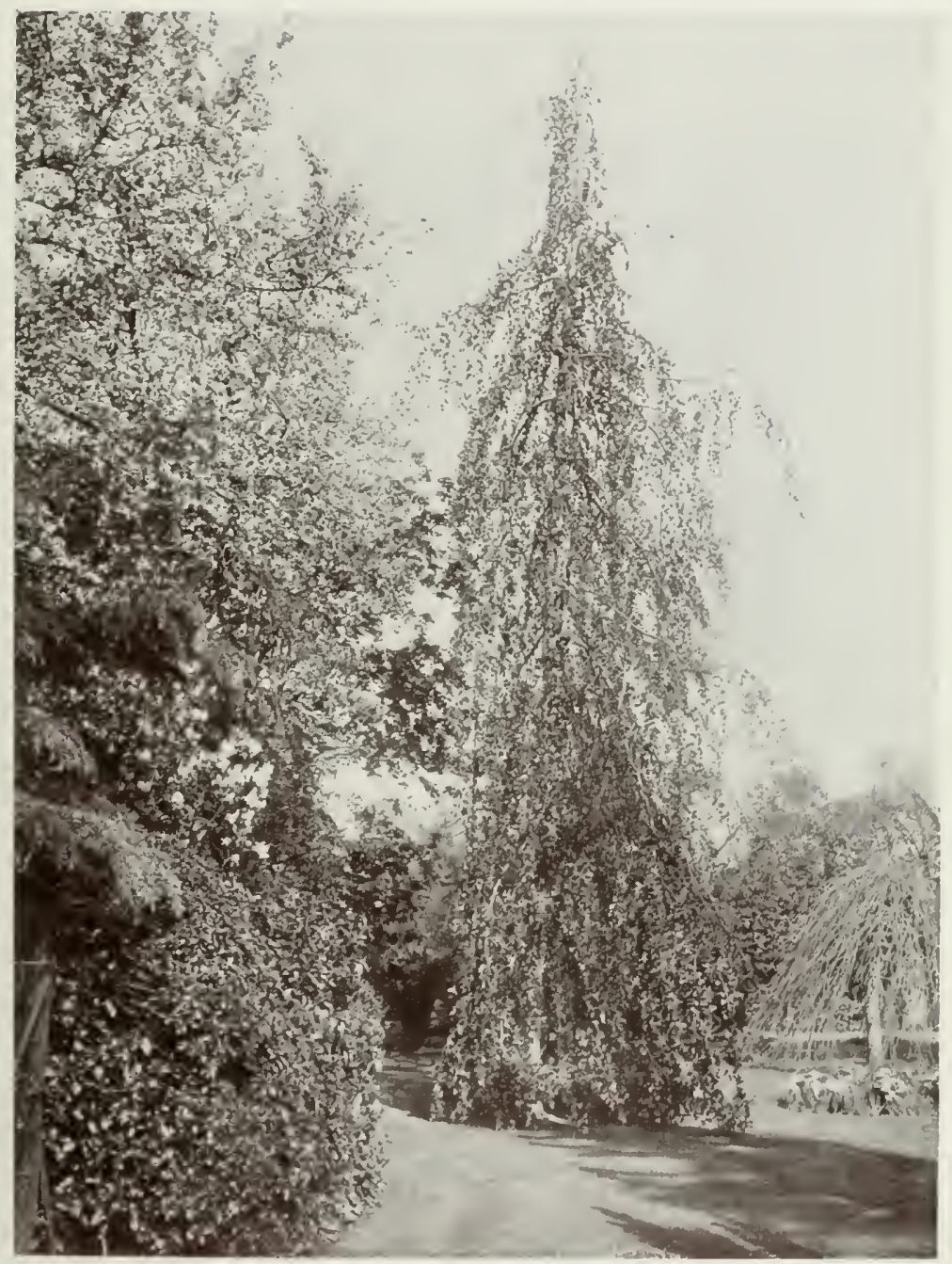

GRACE AN゙D SHADE ON THE SINTSCORCHEI RIRASS.

A good Weeping Birch.

Fior description see Chapter XIV., and Part IV., Section B. Photo by I. Mason Good. 


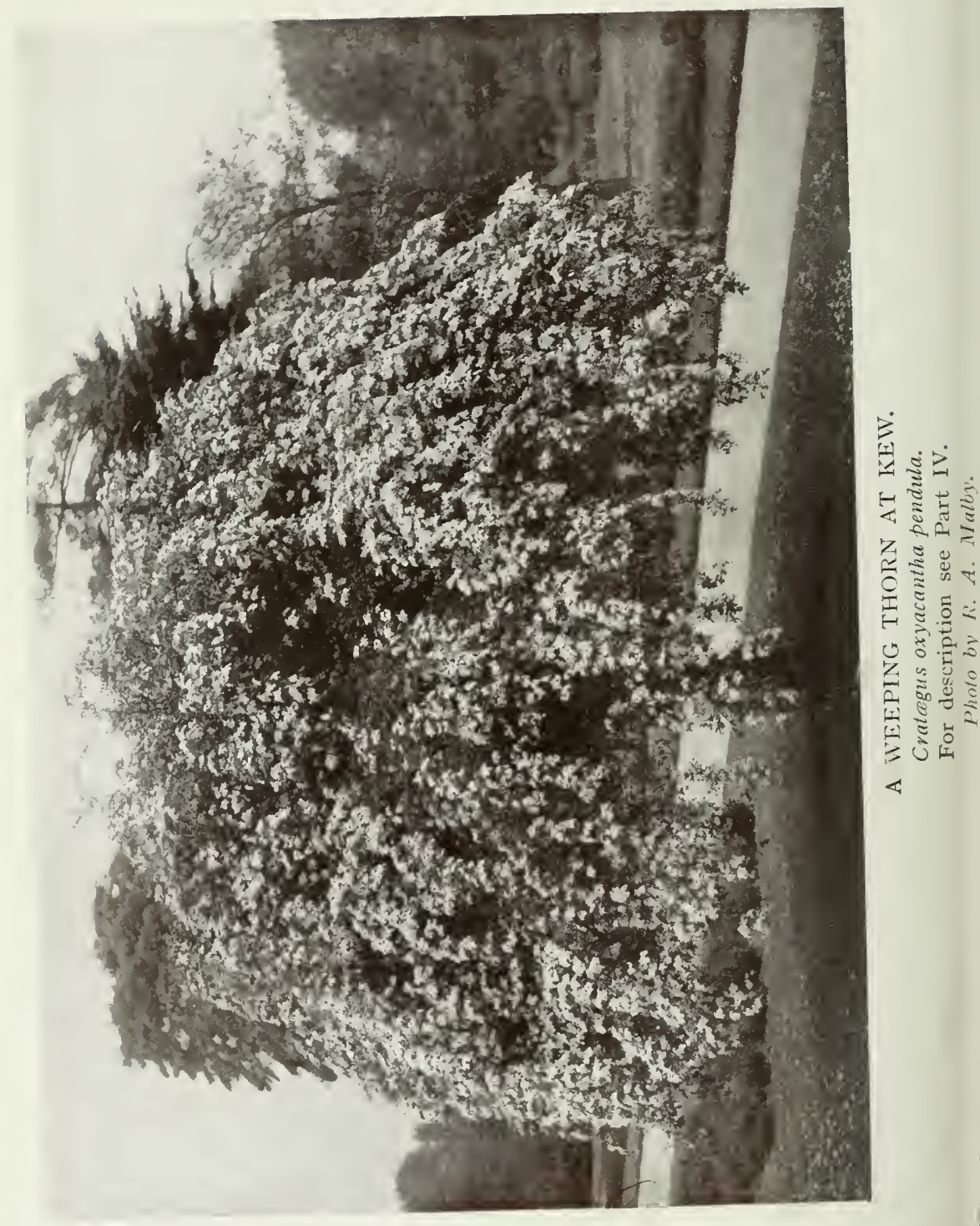


Thuja dolabrata, Pinus Cembra, the Copper Beech, and the Mulberry.

Smaller trees suitable for use on lawns are Paulownia imperialis, Ailanthus glandulosa, Retinosporas, varieties of Cryptomeria japonica, Cupressus Lawsoniana and Juniperus Virginiana.

The Pampas Grass is highly effective when well furnished with its white plumes in autumn.

Beds of hardy Azaleas will be equally as effective on the lawn as in the border.

Among the shrubs and trees used for lawns, a few kinds of pendulous habit, often spoken of as weepers, may be introduced. They have a graceful appearance, and impart a sense of variety. Nowhere in the garden do weeping trees look so well as on an expanse of turf, unless it be at the waterside.

When the tree-lover looks among the varieties of popular trees, such as the Ash, Birch, Poplar, Beech, Elm and Holly, he finds that there are many beautiful weeping forms, generally distinguished by the varietal name pendula. Thus, there is the weeping Ash, Fraxinus excelsior pendula; the weeping Aspen, Populus tremula pendula; the weeping Beeches, Fagus sylvatica pendula and F. s. Miltonensis; the weeping Silver Birches, Betula alba pendula and B. a. Youngii ; the weeping Hollies, Ilex aquifolium pendula and Perrin's weeping variety; and the weeping Elms, Alnus montana pendula and A. campestris pendula. Judgment should be exercised in lawn-planting, for it is easily overdone. There should be no planting at fixed intervals. A "spotty" effect is to be 
deprecated. The planting should be irregular. Nor should the greater part of the lawn be covered. On the contrary, there should be an effect of lawn relieved by trees and shrubs.

In the main, grouped shrubs should be in beds near the edge of the lawn, a few feet only from the path, and they should be on the part farthest from the house, so that an expanse of turf may intervene. 

"THE POPULAR PRYACANTHA; LALANDII IS A SPLENDID FORM."

(See page 134.)

Painted by A. C. Wyatr. 


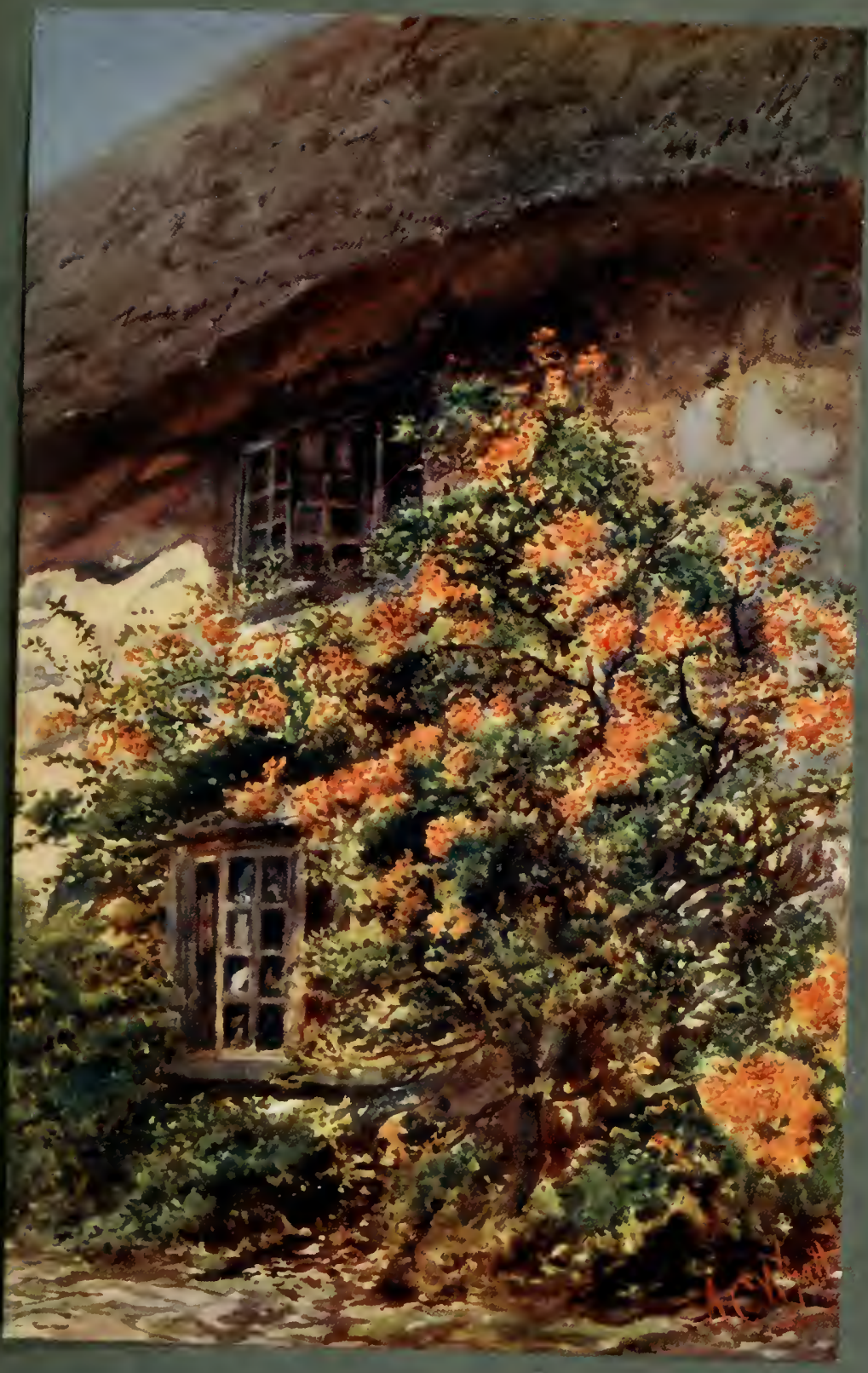




\section{CHAPTER XV.}

\section{Leaf and Stem Tints-Beautiful Fruits and Berries.}

IT may be said that all young leafage is beautiful. The early spring tint of that commonest of trees, the Larch, for example, is indescribably soft, tender and exquisite.

But there is a special beauty in the matured foliage of many shrubs and trees, and there is permanent charm in the colours of many stems.

In autumn and winter the beauty of berry and fruit must be considered.

Lest the shrubs and trees with beautiful leaves, stems and fruits should be overlooked when selections for planting are being made, it seems desirable to collect the names of some of the principal kinds into a special chapter, where oblivion cannot overtake them so easily as it might if they were scattered over many pages.

Variegation is a feature of numerous forms of cultivated trees and shrubs, and there is perhaps no more familiar example than the Holly. Variegation may be of several kinds, but in its commonest form it consists of white or yellow patches on a leaf that is partly green . Certain shrubs and trees which have or have not variegated forms have forms the leaves of which are 
wholly white, cream or yellow. There are, farther, mottled leaves, such as those of the Aucuba.

In the present chapter we may consider as special colouring all examples that depart from the normal green.

White or cream (which we may for the sake of convenience term silver) variegation is present in Ash, Elm, Maple, Beech and Holly.

The silver-variegated Maple grown under the name of Acer Negundo variegatum is one of the most useful of these, for it is a small tree admirably adapted for the middle area of a shrubbery. A very bright, clean and lively small tree or shrub of deciduous habit, it just lacks perfect hardiness, and should therefore have a sheltered place.

Another silver-variegated Maple is the form of the common Maple called pulverulentum.

The silver-variegated Hollies are among the most beautiful members of the genus, and there are several of them, notably Broad Silver and Silver Queen. The Hollies grow slowly, and it is an easy matter to keep them within the bounds of small shrubs by the use of the knife. In any case, it is some years before they get to the recognised tree stage.

Large numbers of good shrubs are distinguished by silver variegation, and perhaps the most useful are the Boxes, Euonymuses and Ivies. The Boxes are dense, low shrubs, with an adaptability to limestone soils which gives them a special value to garden-lovers operating on chalk. Sempervirens argentea is the silver form. Bought as young plants, about two feet 
high, and preferably planted four feet apart in small groups, they grow slowly into dense bushes.

The Euonymuses, which, as we have already seen, are good shrubs for the seaside, include silver forms both of the species japonicus and radicans. The variety of the latter called Silver Gem is very popular.

There are numerous silver-variegated forms of Ivy (Hedera), both climbing and tree. Variegata argentea is good.

The silver-variegated form of the well-known Kerria japonica is interesting, but not valuable. The best plant in this genus is the double yellow.

The silver-variegated Mock Orange (Philadelphus) silver-variegated Osmanthus, and silver-variegated forms of Dogwood (Cornus mas. and C. alba), will engage the attention of admirers of these genera.

The form of white Poplar called nivea has leaves wholly silvery, and so has that popular shrub, the Lavender Cotton (Santolina chamæcyparissus). Another silver-leaved shrub is Elæagnus argentea.

Turning to golden-variegated trees, we have of course the Hollies, such as Golden King and Golden Queen, a form of Acer Negundo variegatum, a yellow-margined Sycamore, and the form of White Ash (Fraxinus americana) called aucubæfolia .

Yellow-variegated shrubs include climbing and tree Ivies, Box, Dogwoods (Cornus albus Späthii and C. mas aurea elegantissima), various forms of Elæagnus pungens, and the familiar golden Euonymus (E. japonicus aureus). The dwarf Bamboo called Arundinaria auricoma, Privet (Ligustrum ovalifolium, yellow 
variegated form), yellow-variegated forms of the Winter Jasmine (nudiflorum) and the Japanese Honeysuckle (Lonicera japonica aurea reticulata) must also be mentioned.

Among golden-leaved trees the most important are Acer Prinz Handjery, the Yellow Alder (Alnus glutinosa aurea), Catalpa bignonioides aurea, the golden Poplar, (Populus deltoidea aurea), the Oaks called Quercus pedunculata Concordia and rubra aurea, and the Golden Elm (Ulmus campestris Louis van Houtte).

Perhaps the best known yellow-leaved shrub is the golden Elder, Sambucus canadensis, yellow-leaved. There is a yellow-leaved Mock Orange (Philadelphus coronarius), likewise yellow Lings (Calluna vulgaris aurea and cuprea), yellow Acer Negundo (californica aurea), and yellow Nut (Corylus Avellana aurea). Neillia opulifolia lutea may also be mentioned.

The value of these variegated and golden and silverleaved shrubs and trees lies in theircapacity for warming and lighting up the garden in periods of dull weather, and, in the case of the evergreens, in winter. The reader can hardly have failed to see in his travels the inspiriting effect of a simple hedge of golden Euonymus in a seaside garden on a grey winter day. Within reasonable limits the coloured foliage subjects have a real importance. They should certainly not be planted extensively, but in moderation they serve a distinct purpose.

The purple-leaved subjects have a different effect. They throw out into sharper, clearer relief the green and variegated plants. 

" THE BROOMS HAVE THE INTEREST OF GREEN STEMS AS WELL AS OF BIRILLIANT FLOWERS."

Cytisus Andreanus at Kew.

(See page I32.)

Colour photo by R. A. MaLby. 


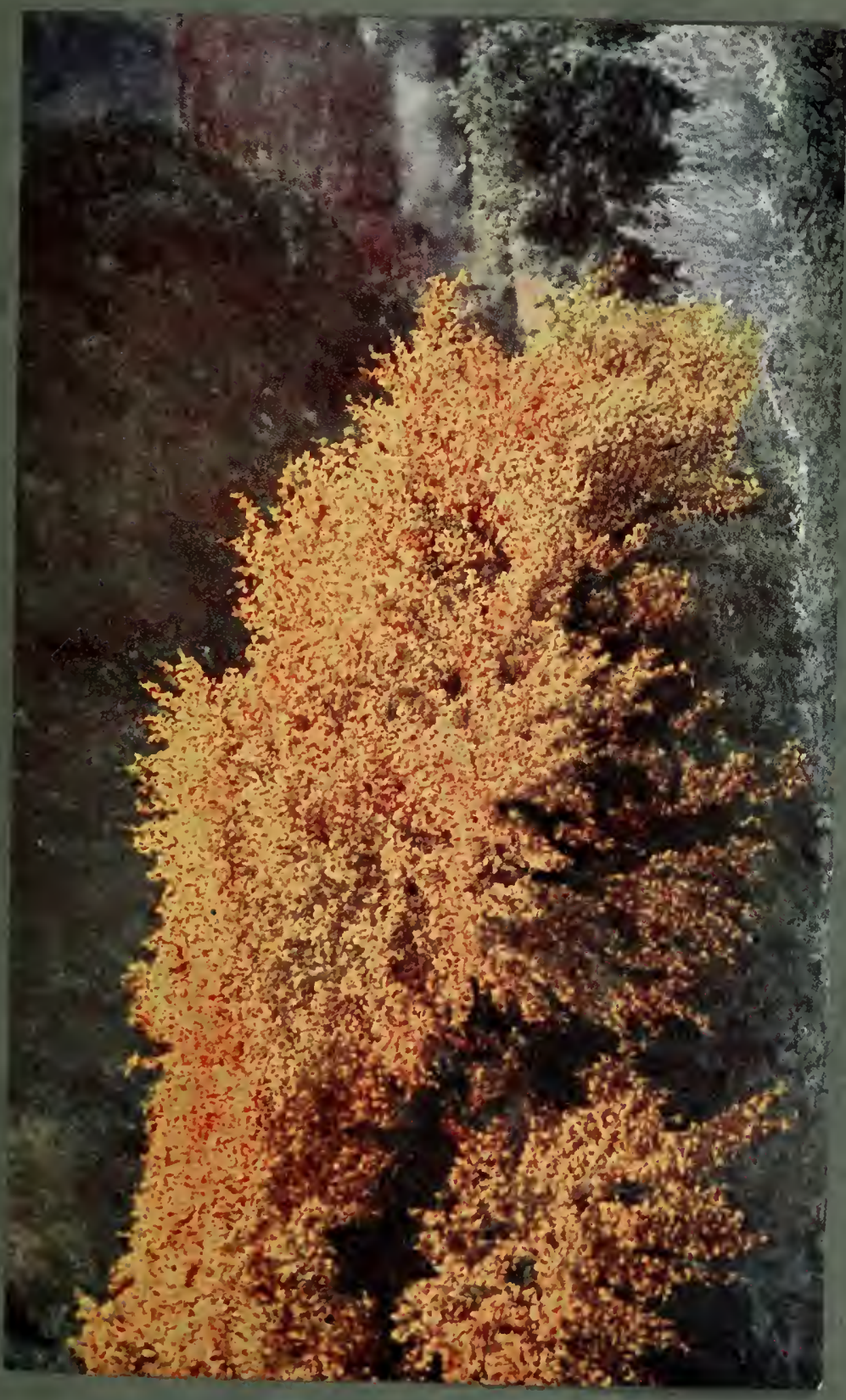



The two most popular dark-leaved trees are the Copper Beech (Fagus sylvatica atropurpurea) and the purple-leaved Plum (Prunus Pissardii of nurserymen, P. cerasifera atropurpurea of botanists). The Beech will grow into a large timber specimen, the Plum remains a small tree and may even be had in shrub form. There is a good dark-leaved Sycamore (atropurpureum).

The richest colour in dark-leaved shrubs is found in the Japanese Maple (Acer palmatum). Such forms as atropurpureum aureum, decompositum, palmatifidum, roseo-marginatum dissectum, and septemlobum purpureum are highly ornamental. Groups of these fine coloured Maples, growing in large pots or tubs, are now a feature of many large horticultural shows, and the reader is there given an opportunity of noting many forms, varying in tint and division of the rich leaves.

There is a purple-leaved form of the Common Barberry (Berberis vulgaris), but it is not important for the shrubbery, although useful for cover. More valuable is the dark-leaved Nut, Corylus maxima atropurpurea. Purple-leaved forms of Euonymus europæus and Osmanthus ilicifolius are also worth mentioning.

When planted sparingly, these dark-leaved subjects are very effective.

Stem-colour in deciduous shrubs would hardly suggest itself as a subject worthy of study by the garden-maker, nevertheless, it should not be ignored. So simple a plant as the Deutzia has a distinctly warm and lively effect with its bright, clean brown bark when the bushes 
are kept pruned, so that they are full of young wood in winter. When crowded with old wood they are not so cheerful.

A mong trees the most familiar example of stem-colour is the Silver Birch. A tree equally worthy of attention is the gold-stemmed Ash, Fraxinus excelsior aurea.

The Dogwoods are particularly valuable for the kinds they furnish with coloured stems, notably alba and Baileyi, with red bark, and flaviramea, with yellow bark.

Rubus biflorus and R. lasiostylus are often planted for their white stems, and the coloured-stem Willows, Salix vitellina, for their yellow or red stems, which are very bright.

The Brooms have the interest of green stems, as well as brilliant flowers.

The intermingling of these subjects in shrubberies has the effect of maintaining brightness throughout the year.

Another thing well worth consideration is autumn colour, and this is gained by planting a proportion of subjects, the leaf changes of which in autumn add brilliance to the border. Any reader who finds joy in the autumn woodland knows what colour-change means. There is a homely example of it on many a house in the form of the Virginian Creeper.

The Thorns give us some of the most beautiful colour among small trees, particularly the varieties of the Cockspur Thorn (Cratægus Crus-galli); prunifolia and splendens are very showy. The species coccinea also has beautiful autumn colour. 
Reference has already been made to the Japanese Maples, as subjects which provide warm colours, and their hues deepen in autumn. But many of the Maples have beautiful colour in the fall. The Norway Maple (Acer platanoides) has many good forms, and none better for late colour than that called Reitenbachii. Dasycarpum, macrophyllum, rubrum and ginnala are other brilliant leaved species of Acer.

The golden leaves of the Chestnuts add another to the already strong claims of this noble tree, and Beech colour is also an asset.

The Barberries are full of leaf-colour. The splendid B. Darwinii has charming tones when its orange flowers come towards the close of winter. Thunbergii takes on a lovely tint of orange in autumn. And the common vulgaris is not to be despised then.

The splendid Catalpa bignonioides, a tree too little used, considering that it will thrive in town gardens, and makes a beautiful lawn tree, is very bright in autumn.

The Vines (among which the Virginian Creeper already referred to is classed) give us splendid autumn leaf colour. They are grown botanically under the generic name of Vitis. The species Labrusca turns bright yellow, and the giantic Coignetiæ bronzy red. These and Veitch's Virginian Creeper (V. inconstans) are the best for late colour.

There is a charming evergreen grown mainly for its berries and foliage named Cotoneaster microphylla. The species frigida is not so truly evergreen, but it is richer in autumn colour, which is red and yellow. 
Amelanchier canadensis (Botryapium) has fine colour in autumn.

The Sumachs (Rhus) are popular shrubs, and the best for autumn colour is cotinoides, the leaves of which are marked with orange. But the commoner species, typhina, is also bright.

Two, at least, of the popular Magnolias, Fraseri and tripetala, are conspicuous for autumn colour.

The scarlet Oak (Quercus coccinea) should be remembered.

The Maidenhair Tree (Ginkgo biloba) turns yellow in autumn.

The foregoing examples show that leaf-change provides autumn tints that are of great value in the garden, prolonging, as they do, the period of beauty. We have still, however, to consider the fruits and berries, which give us a further period of beauty.

It is unnecessary to do more than name the Hollies, about which the absurd belief still persists that a free crop of berries foreshadows a hard winter.

The Thorns are also very familiar, if only through the common Hawthorn, but there are kinds which give much finer fruits than this, notably the Cockspur Thorns just mentioned for their leaf-colour, likewise coccinea (also noted for leaf-colour) mollis, tomentosa, monogyna macrocarpa, the yellow-fruited form of oxycanthoides, pinnatifida (one of the largest), the black nigra, cordata, and the popular Pyracantha. Lalandii is a splendid form of this, which fruits abundantly.

The genus Pyrus, including as it does the cultivated 
Apple and Pear, is looked to confidently for ornamental fruit, and we find it splendidly developed in the Crabs, notably the Siberian and the horticultural forms Transparent, Dartmouth, and John Downie. The beautiful Pyrus spectabilis, which, as we have already seen, is worth planting for its bloom, has handsome fruit, and so has Pyrus Ringo. One of the best known Pyruses is certainly Aucuparia, the Mountain Ash or Rowan, which has handsome foliage and scarlet fruits. There is a yellow form of it, very beautiful, but not often seen. There are many other Pyruses with attractive fruit.

The Cotoneasters must be considered. The best known is the small-leaved microphylla, which has white flowers followed by vermilion berries and evergreen foliage. Simonsii has orange berries. Frigida has already been mentioned in connection with leafcolouring in autumn; it has pretty red berries in clusters.

The Roses, so beautiful for their flowers, are in many cases fruit-bearers, and their heps are very ornamental. The Penzance Briers have real beauty in their bright fruits. The largest heps are found in the Japanese Rose (rugosa) and pomifera. Both species have red fruits, in the case of the latter species hairy. The fruit of Rosa microphylla is yellow, spiny and highly perfumed, that of $\mathrm{R}$. spinosissima black.

On the sandy foot-hills by the sea-coast, one sometimes finds the sea Buckthorn, Hippophae rhamnoides, a grey shrub, with yellow berries.

The Pernettyas are perhaps the prettiest of all low, 
berry-bearing shrubs. They are evergreens and thrive in beds of peat and loam. Small, neat, compact, with white, pink, red or purple berries, they are exquisite little plants.

The Sumachs (Rhus) have ornamental fruits. The berries of the Honeysuckle are familiar. The Yews are also well-known. The Snowberry (Symphoricarpus racemosus) is often met with. Cydonia (Pyrus) japonica and Maulei, with their varieties, have large red fruits that are often jellied. The Quince, well suited for a moist spot, is both brilliant and aromatic in fruit.

There are many other subjects which the reader may meet with in botanical gardens, in large nursery gardens and in the collections of connoisseurs. They will serve to strengthen his conviction that in forming shrubberies he cannot afford to put aside the claims of fruit and berry-bearing plants.

With subjects valuable for their leaf and stem tints, or their fruits, he can add materially to the beauty of the garden, and it is particularly gratifying to remember that with their aid colour can be maintained for a long period. One season of the year is linked with another. Pleasing and harmonious hues lighten the gloom of autumn. Brilliant berries beguile the winter. 


\section{CHAPTER XVI.}

\section{Evergreen Shrubs and Trees other than Conifers.}

SEVERAL of the preceding chapters have embraced references to evergreens, but it will not be out of place to consider the part played by this class and briefly to study the best kinds in a special chapter.

Evergreens predominated in the old type of shrubbery. We see it often enough now-a-days, with its dense masses of uninspiring Laurels, Aucubas, and evergreen Oaks, presenting the same aspect from year's end to year's end, often dull, sometimes sombre. There is no grace, no freedom, no seductive tinting in spring, no shade in summer, no glow of mellow colour in autumn. From January to December the border presents an unvarying outline and but slight change in colour.

Matters would not have been so bad in the evergreen shrubbery if some of the more beautiful and interesting plants had been used, but it almost seems as though the mind that liked evergreens liked commonness, for masses of everyday things were put in.

The shrub-lover must beware of taking guidance from the general nurseryman in respect to shrubs and trees, for that otherwise estimable person generally labours 
under the disadvantages of having no special horticultural interest in them, and of having a large stock of certain cheap kinds, which he is naturally anxious to sell. Thus situated, he is but poorly equipped for giving competent and disinterested advice. How well we know his plausible and loquacious traveller, with his tempting offers! He has the "stock" articles of all sizes, like boots and shirts, and his prices are low. We buy, we plant, and somehow, in a few years, we awaken to the fact that the best parts of the garden are full of coarse, aggressive, uninteresting things, which serve no purpose except to fill space.

Sometimes the general nurseryman has a few plants in his nursery of better things, which he will supply if pressed; and in any case, there are firms which make special cultures of good kinds, and indeed grow them to the exclusion of the commoners. These firms should have preference.

There has come to be an understanding that evergreens are the only suitable shrubs for town gardens. From more than one point of view they are the least suitable. Those who look at town evergreens with a discriminating eye note that they are often in poor health, and that they are unusually sombre and gloomy. This is due to the deposit of smuts on their foliage. People who plant evergreens in town gardens might at least give them a drenching now and then in order to keep them clean.

Lovers of evergreens should refuse to be contented with Laurels and Aucubas, but should make themselves acquainted with the Barberries, the Arbutuses, the 

"CYDONIA (PYRUS) JAPONICA AND MALLEI, WITH THEIR VARIETIES, HAIE LARGE RED FRUITS THAT ARE OFTEN JELLIED."

(See page I 36.)

Painted by A. C. IVyatt. 


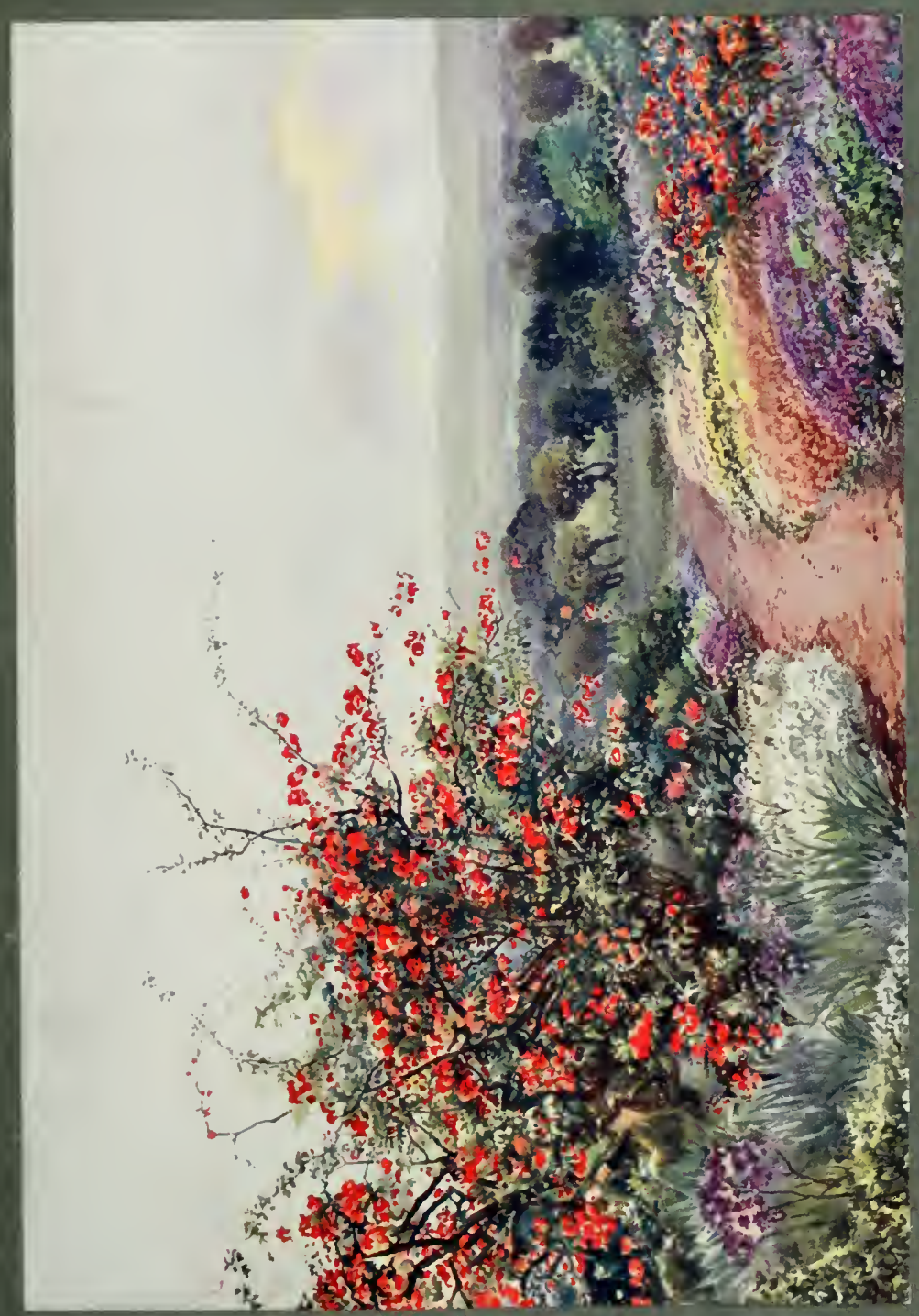



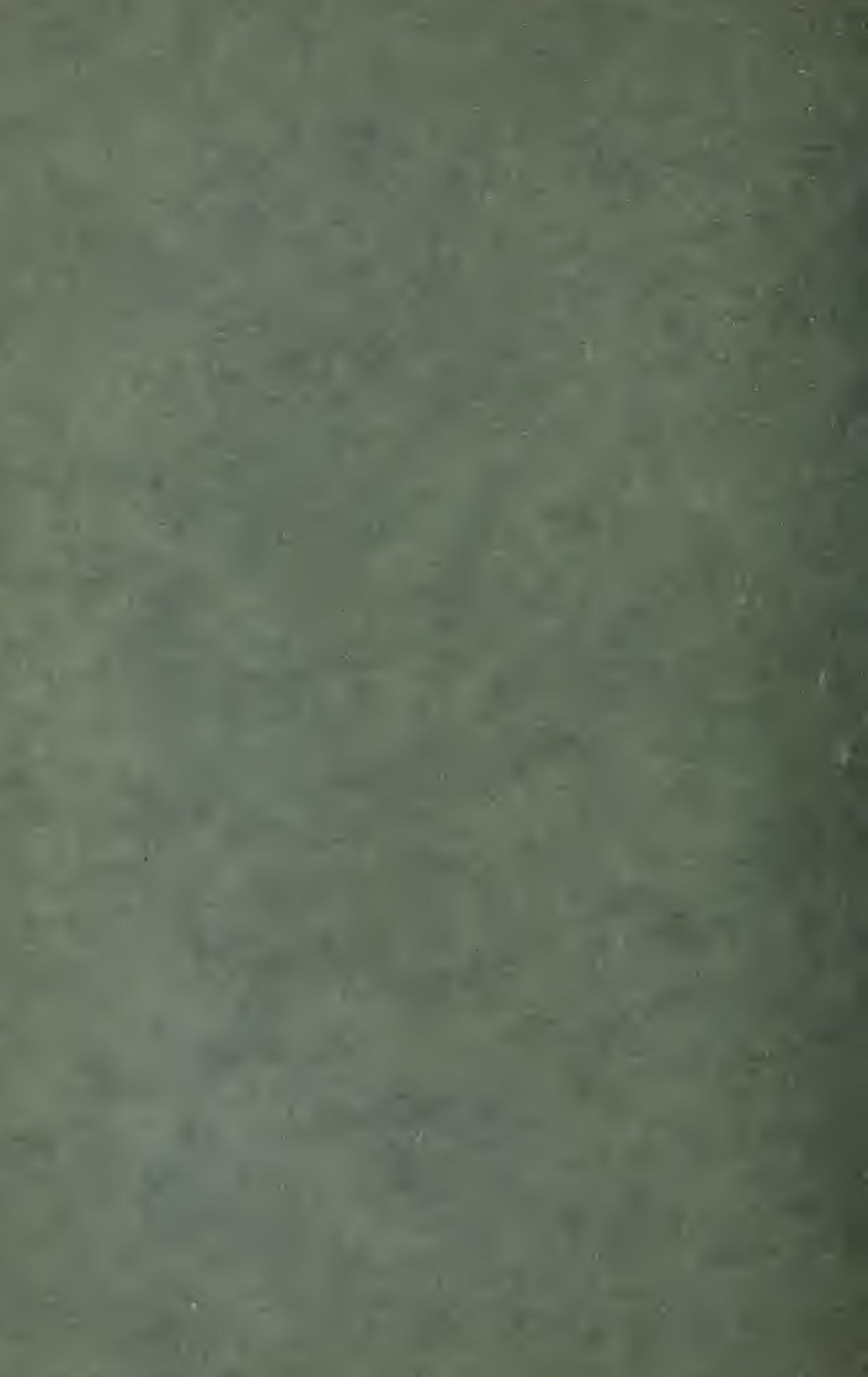
Boxes, the Cotoneasters, the Daphnes, the Escallonias, the Euonymuses, the best of the Ivies, the Cistuses (Rock Roses), the Helianthemums, the Hypericums, the Pernettyas, the Rhododendrons, the Veronicas, and other important kinds. The Laurels and Aucubas undoubtedly have their uses, and so far as the latter shrub is concerned it is really ornamental when properly grown, for iis berries are large and brilliant ; but neither it nor the Laurel should be planted in dense masses to occupy a great deal of valuable space.

It is desirable to indicate the importance of the class by drawing the readers' attention to the principal genera of evergreens. The Bamboos, which comprise the three genera of Arundinaria, Bambusa and Phyllostachys, are beautiful for sheltered places. They are dealt with in Part IV.

The Barberries include such fine plants as Berberis Darwinii, B. stenophylla and B. Wallichiana, as well as several others. B. Darwinii likes sea air, and one may sometimes see it forming a hedge in a seaside garden; but the finest effect is produced when it is given room to grow into a fine individual specimen in a sheltered place.

The Box genus gives us the many forms of Buxus sempervirens, some of which are variegated.

The Cistuses are splendid shrubs for the rock garden, and the best kinds for growing there are described in Chapter XIX. The same remarks apply to the Helianthemums or Sun Roses.

The Cotoneasters are admired for their bright foliage and charming berries. C. microphylla is the best known_species, and is well worth planting. 
The well-known Thorn, Cratægus Pyracantha, should be remembered, especially when shrubs for planting against walls are required. The variety Laiandi is splendid.

The Daphnes include several attractive species, particularly Cneorum, but the deliciously sweet Mezereum is not evergreen.

The Elæagnuses are conspicuous for handsome foliage.

The Lings and Heaths, species of Calluna and Erica, will receive the particular attention of garden-makers who operate on sandy peat. Another great evergreen particularly adapted to this soil is the Rhododendron.

The Escallonias are attractive both in leaf and bloom. Although the foliage is small, it is very bright and cheerful. E. macrantha ought certainly to be planted, particularly in mild places near the sea.

We have already seen how bright and inspiriting the Euonymuses are in sea-side gardens, but it is not to be inferred that they are unsuitable for culture inland.

One of the finest of the St. John's Worts, Hypericum calycinum, is an evergreen.

The Hollies, with their beautiful foliage and bright berries, come naturally to mind when one thinks of evergreens in winter.

Kalmia latifolia is a good evergreen and the Ledums are worthy of attention.

Several of the most interesting and beautiful of the Magnolias are deciduous, but in the gigantic grandiflora with its broad leaves, so often seen on lofty walls, we have an evergreen species. The new Delavayi is also evergreen. 
The Evergreen Oak, Quercus Ilex, is a serviceable tree

Ruscus aculeatus, the Butcher's Broom, is not a striking plant, but comes in useful for shady places.

Many good Veronicas are not hardy, but the genus remains important, for the species thrive on chalky soil. Traversii is particularly useful. The Laurustinus (Viburnum Tinus) will thrive on almost any soil.

Such handsome Yuccas as angustifolia and gloriosa may be mentioned as good representatives of a useful genus.

In addition to the foregoing, the reader may consider Andromeda polifolia, Arbutus Andrachne and A. Unedo, Arctostaphylos Uva-ursi, Azara microphylla, Cassinia fulvida, Castanopsis chrysophylla, Empetrum nigrum, Eucryphia pinnatifolia, Gaultheria Shallon, the Sweet Bay (Laurus nobilis), Leiophyllum buxifolium, Olearia Haastii, Osmanthus ilicifolius, Phillyreas, Pieris floribunda, Rhamnus alaternus, the Rosemary (Rosmarinus officinalis), the Lavender Cotton (Santolina chamæcyparissus); and the various special shrubs named in Chapter IX.

The Periwinkles (Vinca major and V. minor) are of trailing habit, with pretty foliage and large flowers.

The Laurel and the Portugal Laurel are respectively the Prunus Laurocerasus and P. lusitanicus of botanists.

The best of the foregoing shrubs for shady places are the Butcher's Broom, the Aucuba, Gaultheria Shallon, the Periwinkles and Ivy. The best of the larger evergreens for shady places are Laurels and Hollies. Berberis Darwinii does not dislike some shade, on the 
contrary, in a sheltered, partially shaded corner, it will generally grow into a fine specimen. But the best Barberry for dense shade is aquifolium (syn. Mahonia aquifolia). See also Chapter XXV.

In the partial shade and shelter of woods one sometimes sees the grand old Rhododendron ponticum thriving. With years it grows into a most effective object. All Rhododendrons, indeed, love a measure of shade. While they are not at home when quite under large trees, the umbrageous shadow of the tops of large trees is comforting to them.

That well-known hedge shrub, the Privet (Ligustrum ovalifolium), is one of those useful subjects which will thrive either in sun or shade. Single plots in shade grow to a considerable height, and assume a tree-like habit which is somewhat surprising to those who have only seen Privet as a clipped hedge plant. 


\section{CHAPTER XVII}

\section{Conifers}

For the same reason that a chapter has been given to the evergreens, in spite of many incidental references, one may be devoted to the Conifers. They are in every way worthy of special study. We have seen what splendid objects selected Conifers are for lawns. They are also beautiful for avenues and for groupplanting.

A garden-like aspect might be imparted to many meadows near large houses by devoting a little money to the formation of groups of conifers, and so long as the trees were fenced in the fields could be grazed. Thus inexpensively could ornament and utility be combined.

A further use for Conifers is to plant on the edges of drives, for example, in large parks.

Every tree which bears its flowers in a woody bract is a Conifer. The majority are evergreens, but not all. A well-known example of the deciduous Conifers is the common Larch, Larix europæa. The Wellingtonia is a familiar example of the evergreen Conifers, which include most of the Firs and Pines, as well as the Junipers and Cedars.

The cones of this class vary as greatly as the fruits of domestic trees such as the Apple, Plum and Cherry. 
A judicious planting of Conifers adds distinction to the garden. These trees are never wild and unkempt.

It is rare to see healthy, well-developed Conifers with an out-of-place look. If such an instance occurs, it is when they are planted freely close up to a small, low house. Distance and a groundwork of turf show them to the greatest advantage.

The different kinds vary a good deal in rapidity and vigour of growth. None attain in Europe to the dimensions of the giant trees of California, which are a species of Sequoia (Wellingtonia); but in suitable soil they will make good specimens up to sixty or seventy feet high, in the course of years. The majority thrive in a deep loamy soil. Shelter from cold winds helps them at all stages and is particularly important when they are quite young.

The trees should never be crowded. Even when planted in groups, those of pyramidal habit should be far enough apart, say ten feet, to make their characteristic circular growth. If ample space is not provided, the contour of the trees will be broken, and there will be bare, hollow patches where branches, grown into by others, have died back.

While some of the finest of the Conifers will, as stated, make good trees, there are others of slow growth and low habit which are shrubby, and are more suitable for mixed planting in the borders than for specimens on lawns or for meadow or park groups. There are even kinds which are of such stunted growth as to be suitable for small rock gardens. See Chapter XIX. 
The principal genera of Conifers, whether in number of species or distinctive kinds, are Abies, Araucaria, Cedrus, Cryptomeria, Cupressus, Ginkgo, Juniperus, Larix, Libocedrus, Picea, Pinus, Pseudostuga, Sequoia or Wellingtonia, Taxus and Thuja.

We use the popular names "fir" and "pine" in connection with certain of these Conifers from childhood, and often never pause to ask ourselves their meaning.

The Firs are not members of one particular genus and the Pines of another. For example, we speak of the Austrian Pine and the Scotch Fir ; both, however, belong to the genus Pinus.

Fir derives from the Anglo-Saxon word fuhr. Compare the German fohre, a pine tree.

There are two great groups of Firs, of which the principal economically is the Spruce Fir or Norway Spruce, a tree hardy enough to thrive in latitudes far too cold for most of our Conifers, and yielding in its timber the deal of commerce. It grows at an elevation of 3,000 feet in Norway, and at I,000 feet in Lapland. This tree also yields the Burgundy pitch of commerce. It has pointed, rounded ("tetragonous") leaves and drooping cones. It is the Picea excelsa of botanists. It is not important as a garden tree, but some of its stunted forms, such as dumosa and pygmæa, are grown in rock gardens and elsewhere. "Pine-needles" are the rounded, fallen leaves of the spruce.

The Silver Firs are grouped under the botanist's name of Abies, and A. pectinata is the typical species. The Silver Firs differ from the Spruce in having flat leaves and upright cones. 
The word "Pine" comes from the Latin pinus (picnus). Note pix and picis and the Anglo-Saxon pic, from which our common word pitch derives. Pitch is of course the solid black substance obtained by boiling down tar, and tar is the dark resinous substance obtained from pine trees. Thus we come "full circle."

One would use, as far as possible, the old names Fir and Pine, but they will not suffice for a garden collection of Conifers, as some handsome species have no popular name. Thus in Abies we find such kinds as cephalonica, concolor, grandis, nobilis, nordmanniana, Omorica, Pinsapo and Veitchii, which embrace Grecian, American, Crimean, Japanese, Balkan and Spanish trees having no recognised popular names. The foregoing are all handsome. A. nobilis has a variety named glauca which is more frequently grown than the type as a border tree.

Some important nurserymen sell under the generic name Abies certain species which botanists put under Picea and Tsuga, indeed, these dealers almost ignore the two last names. Thus, where some call the Spruce Fir Picea excelsa others will call it Abies excelsa. It is necessary for the amateur to know this, when consulting catalogues, and he is advised to bear it in mind in considering the names in the present chapter.

The lover of Conifers who is driven to the conclusion that he must use the botanists' names if he is to obtain a proper grasp of the order will find other pitfalls in the trade catalogues, which do not follow modern 
"LAWN PLANTINGS HAVE A RICH, AND AT THE SAME TIME REFINED EFFECT."

(See page 123.)

Painted by Josephine Gundr:. 


\section{Q1)}

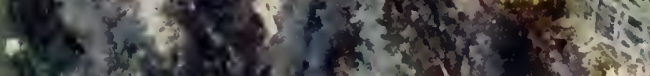

S r I I P.

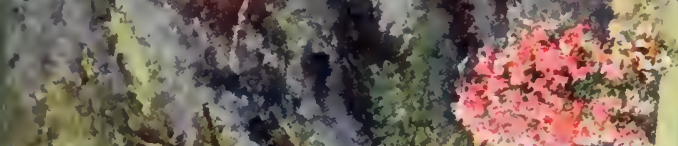

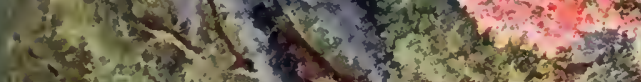

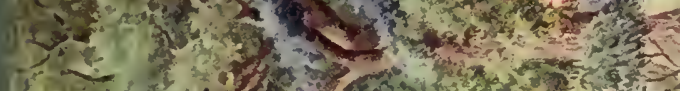
I 120

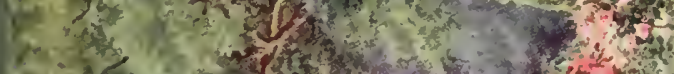

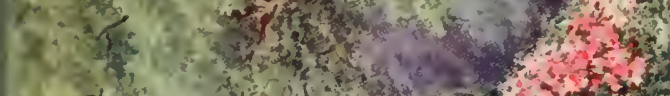

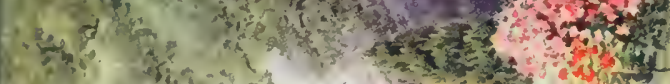
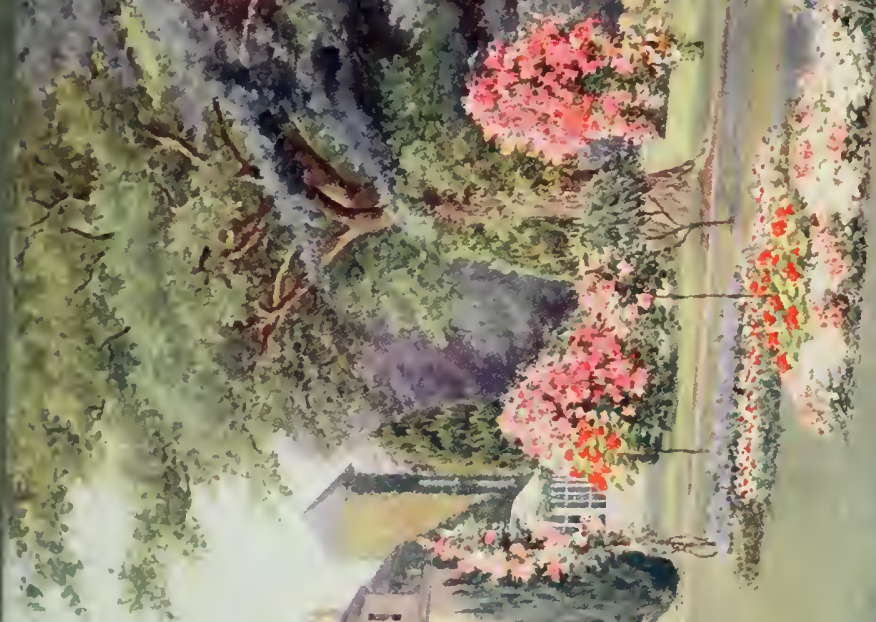

4 ing 1.1. औै $x$ ?

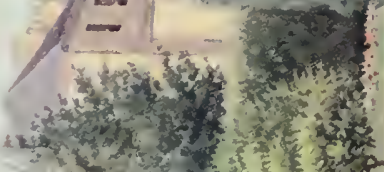
-

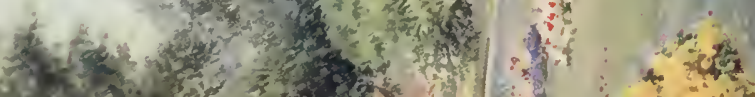

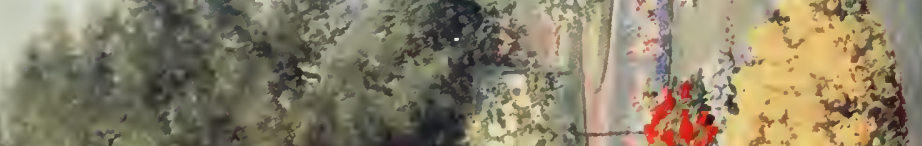

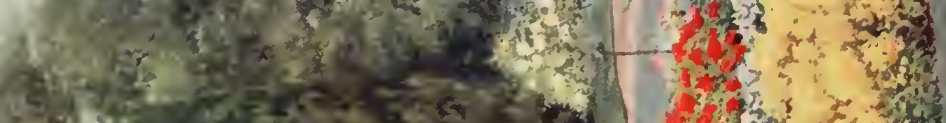

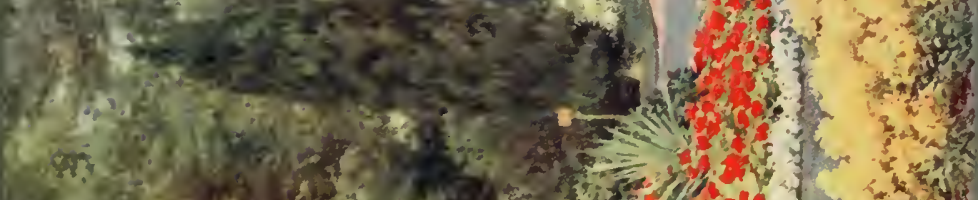

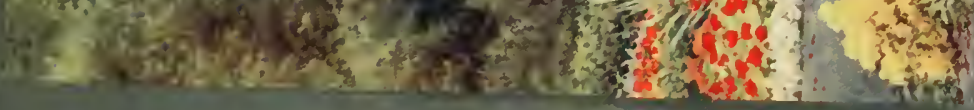




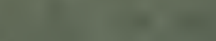

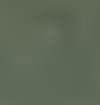

1.1.
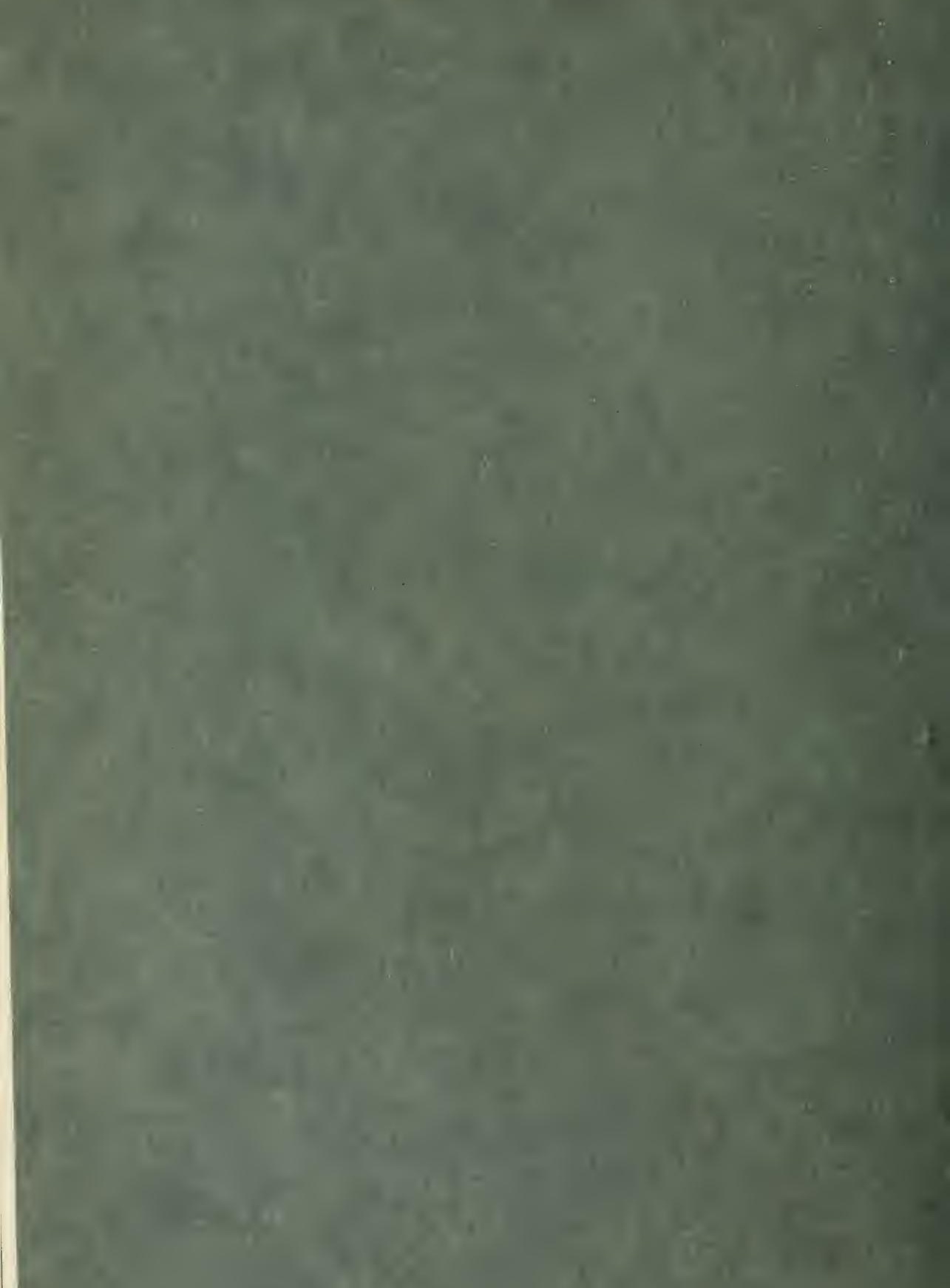
botanical nomenclature in every case. The principal of these will be pointed out in the present chapter.

The genus Araucaria is important to gardeners from the possession of one hardy species, imbricata, the familiar "Monkey Puzzle." This remarkable Chilian tree is entirely distinct.

The genus Cedrus gives "us the Cedar of Lebanon (C. Libani), the Indian Deodar (C. deodara), and the Atlas Cedar (C. atlantica), of which there are popular forms called aurea and glauca.

There are many forms of deodara, notably argentea (silvery), aurea (golden), crassifolia, robusta and viridis. C. atlantica is the most generally useful of the Cedars. It is beautiful both as a young and a mature tree, the habit being good and the colours rich without being sombre. There are some splendid examples near Reading in Berkshire.

The Cedars will thrive in most good loamy soils, in fairly sheltered places, and never look better than on the farther confines of a large lawn.

The Cryptomerias, forms of the Japanese timber tree, C. japonica, which is popularly known as the Japan Cedar, are graceful small trees, suitable for shrubberies. One sees many varieties in the nurseries, differing more or less widely in habit. Some of the best of these are elegans (syn. Veitchii), Lobbii, araucarioides, nana and spiralis. The planter should pick out from a collection in the nursery the forms which he likes the best. Deep fertile soil and a sheltered site are necessary to get fine specimens; but they will thrive on chalk, merely growing more slowly. 
The genus Cupressus gives us the popular Cypresses, of which Lawson's (C. Lawsoniana) a Californian species, is by far the most popular. This upright, columnar tree, with its dense green foliage, is largely planted. In quantity, it is monotonous, but individual trees, whether on the lawn or in the border, are pleasing. Few Conifers have produced more forms and some of the varieties are more popular than the type. The planter, seeing a collection in a nursery, can make his choice from such forms as erecta viridis (bright green), Smithii, Alumi (blue), Fraseri, alba-spica (white-tipped), filifera (thread-like), gracilis aurea and g. pendula, nana glauca (dwarf) and lutea. These prettily tinted forms of Lawson's Cypress are admirably adapted for planting in shrub-borders. They could be associated with flowering shrubs, or used as components of Coniferbeds, which can be made extremely attractive features of a garden. They will thrive on most soils, and do not at all object to chalk. In such soils they grow slowly, and a nice collection can therefore be formed in a limited space, for they do not quickly crowd each other, even when planted as close as four feet apart. They make a surface net of fibrous roots, and can be shifted with balls at almost any period of the year, provided the soil is moist. Another use for these pretty little Cypresses is to grow them in large window boxes for winter ornament.

Macrocarpa, a strong upright grower, is a fine Cypress ; Crippsii and lutea are forms of it.

A less popular, but still desirable species of Cupressus is nootkatensis, a weeping form of which called pendula 


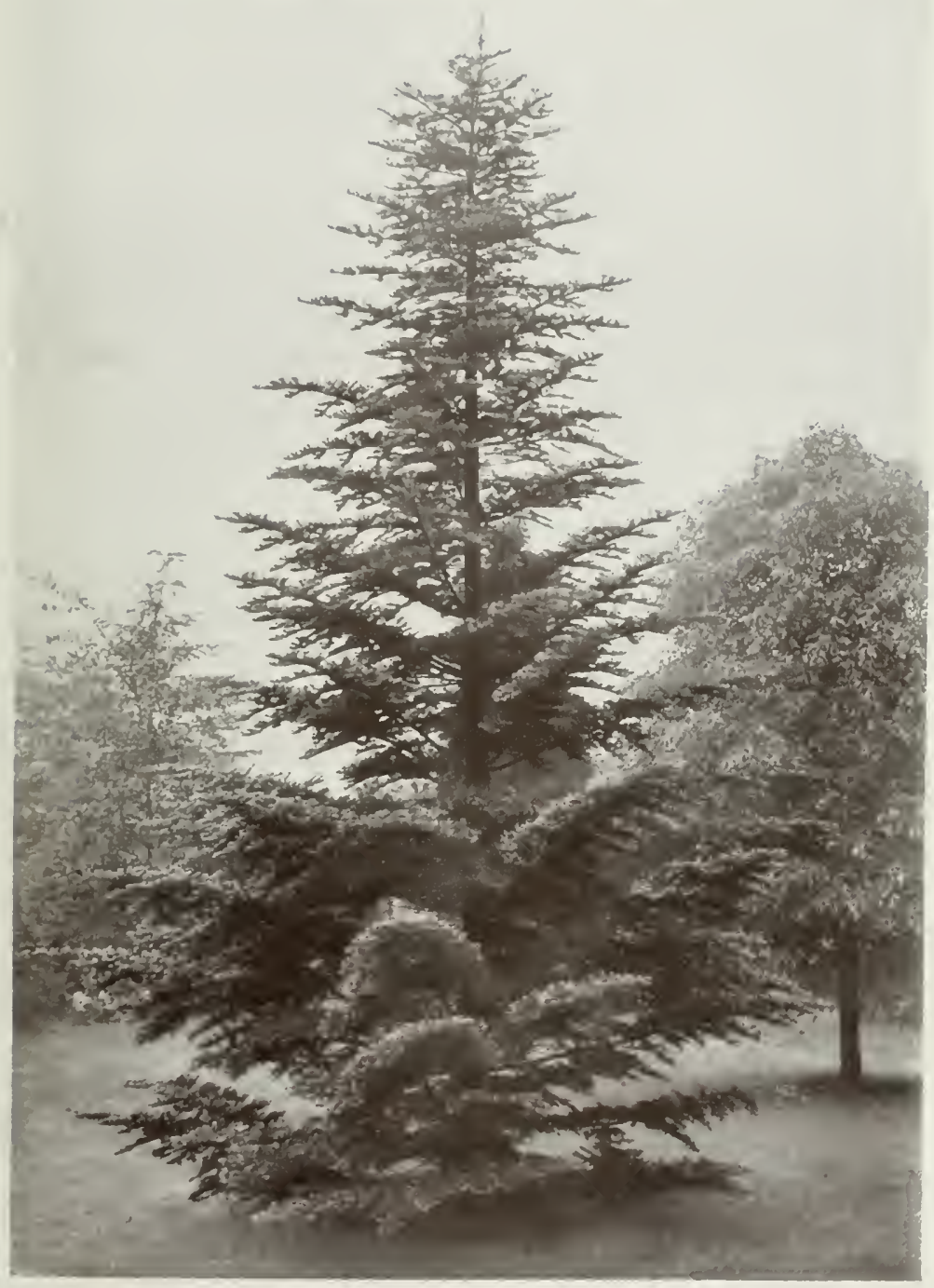

THE SHORT-LEAVED, SILYER-LINED FIR.

Abies brachyphylla.

For description see Chapter XVII. Photo by R. A. Halby. 


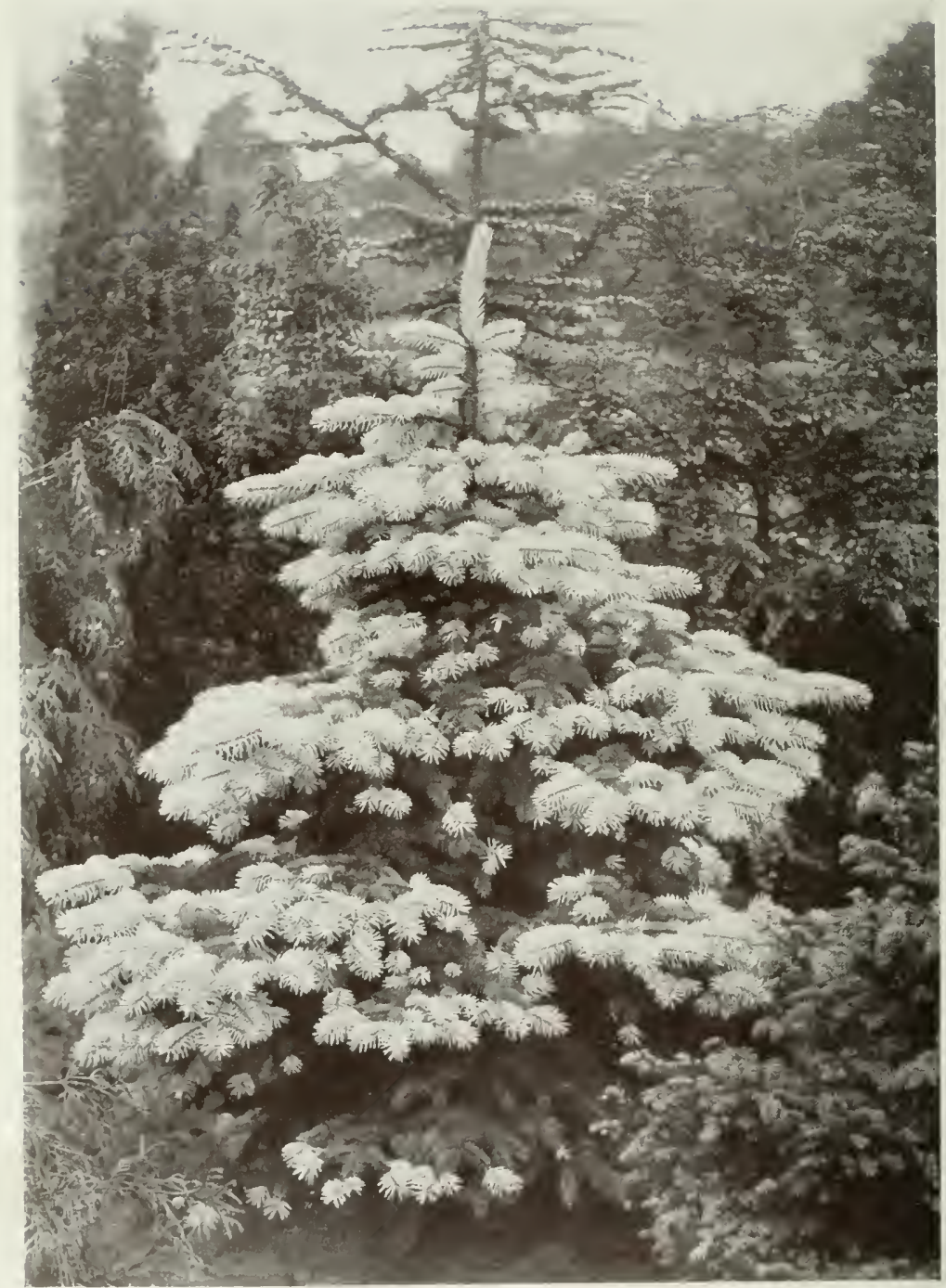

THE SILVER-FROSTED GARDEN FIR. Picea pungens glauca.

For description see Chapter XVII. Photo by R. A. Malby. 
is good for lawn-planting. There are several other forms.

Several of the Cupressuses, notably obtusa and pisifera and their varieties, are grown in nurseries and gardens under the generic name Retinospora. This has become so well established, as to defy the efforts of botanists, who seek to merge Retinospora in Cupressus. C. (or R.) obtusa is a Japanese tree, most often represented in gardens by some of its forms, which are very popular. Obtusa aurea, alba spica, compacta, filicoides, nana aurea and pyramidalis are a few of those muchplanted forms of obtusa. As regards pisifera, which is also a Japanese species, filifera and the feathered forms plumosa, p. aurea and p. argentea, also squarrosa, and s. sulphurea, are the most popular. They are beautiful little shrubs, and may well be associated with the forms of Lawson's Cypress and other small, neat Conifers in special beds. They seem to be quite at home on chalk and move well. Retinospora ericoides is a low dense grower suitable for the rock garden.

The genus Ginkgo is important only in connection with the species biloba, which is popularly known as the Maidenhair Tree, because of the resemblance in shape which the flat-lobed leaves bear to the wellknown Adiantum. It is a handsome Chinese tree, quite good enough for a lawn specimen, and suitable for the mixed border. It does not soon attain to a great size, consequently is valuable for small gardens, more particularly because it will thrive in towns. It is not evergreen. The Maidenhair Tree is not very particular as to soil, and might well be regarded, in view of 
its distinct and graceful appearance, as one of the most important of garden Conifers. The yellow, cherrylike fruit is worthy of note.

The Junipers (genus Juniperus) include several more interesting kinds than the common species (communis) which is a native of Britain, and yields berries that are made use of for flavouring gin. Thus, there are the Chinese species, chinensis and its varieties; sabina, a North American tree; and Virginiana, the Red Cedar. The varieties of chinensis include aurea, albo-variegata, glauca and Smithii. Fastigiata is a pyramidal variety of communis and glauca a glaucous form. There are many forms of Virginiana, of which the most popular is perhaps the drooping variety pendula. Light, loamy soil suits Junipers better than heavy ground, but however well provided for in this respect, they remain of low stature, and are therefore suitable for small gardens.

The Larch, Larix europæa, is hardly worth planting as an ornamental tree for the garden, although useful for its tall, straight timber. A Japanese species named leptolepis is found to grow faster than the common Larch.

The genus Picea gives us, as we have already seen, the Spruce Firs. Two of the pitfalls alluded to in connection with nomenclature occur in connection with this genus and that of Abies. The nurseryman has a tree which he calls Abies Smithiana. He may also have one called Abies Morinda. These are both the same as the botanist's Picea morinda. It is a beautiful species from the Himalayas, and is not only handsome 
but very hardy, so that it may be planted for shelter. The Japanese species Alcockiana and Maximowiczii are ornamental.

The garden forms of excelsa, the Norway Spruce, comprise several very prettily tinted trees, well suited for a bed or border of mixed evergreens. Argenteospica, Clanbrassiliana (good for rock gardens) aurea, diffusa, pygmæa, dumosa and compacta are cases in point.

The species pungens, the Rocky Mountains Blue Spruce, often listed as Abies pungens, is very handsome and distinct, and has several garden forms, such as glauca, argentea and pendula.

Picea polita is a handsome Japanese Fir. Omorica is a Balkan species with flat leaves.

The genus Pinus gives us fewer garden subjects than the Picea, nevertheless it is by no means without use. In large places the Stone Pine (Pinea); the Weymouth Pine (Strobus) and such species as ponderosa, Pinaster, montana, Laricio, insignis, excelsa, Cembra, Lambertiana, and monticolor may be planted. Where large tracts are to be planted in heathy districts, on peat soil, the Scotch Fir (P. sylvestris) will prove its value. This tree is very common in parts of Surrey. There are few better known Pines than the Austrian (austriaca), which thrives on chalky land, and is very hardy. It should not be planted in large groups except for shelter, or it will give a gloomy aspect to the surroundings. The Corsican Pine (Laricio) is a hardy forest tree, and is not much planted in gardens; but there are some useful garden forms of it, such as 
pygmæa, which is of compact, shrubby habit. A new Chinese species called Armandii belongs to the Cembra section; it has yellow bark.

The genus Pseudostuga gives us the Douglas Fir, which is often grown in the nurseries under the name of Abies Douglasii. It is a handsome tree and should be considered one of the best Conifers for garden planting. Beautiful specimens develop with shelter on deep loamy soils. There are drooping (pendula) and glaucous (glauca) forms of it, in addition to others that the tree-lover may meet with in the nurseries and botanic gardens.

Sequoia or Wellingtonia gives us, in the species gigantea, one of our best Conifers.

This is the tree which attains to such enormous dimensions in California. It becomes a noble and beautiful tree in gardens, when given a sheltered place, fertile soil and plenty of room. Silvery, goldtinted and drooping forms are grown in the nurseries. Although sempervirens, the Red Wood, is much less familiar than gigantea it is equally ornamental and horticultural forms are available; alba-spica (whitetipped) is very pretty.

The genus Taxus gives us the familiar Yew (T. baccata) regarded in olden times as the peculiar ornament for churchyards. The common species is 'generally left to that habitat, unless it is wanted as an inner garden hedge, the Yews planted in gardens as specimen trees being selected from tinted forms such as Washingtoni and Dovastoni. The former has a yellow tint. The drooping form, gracilis pendula, 


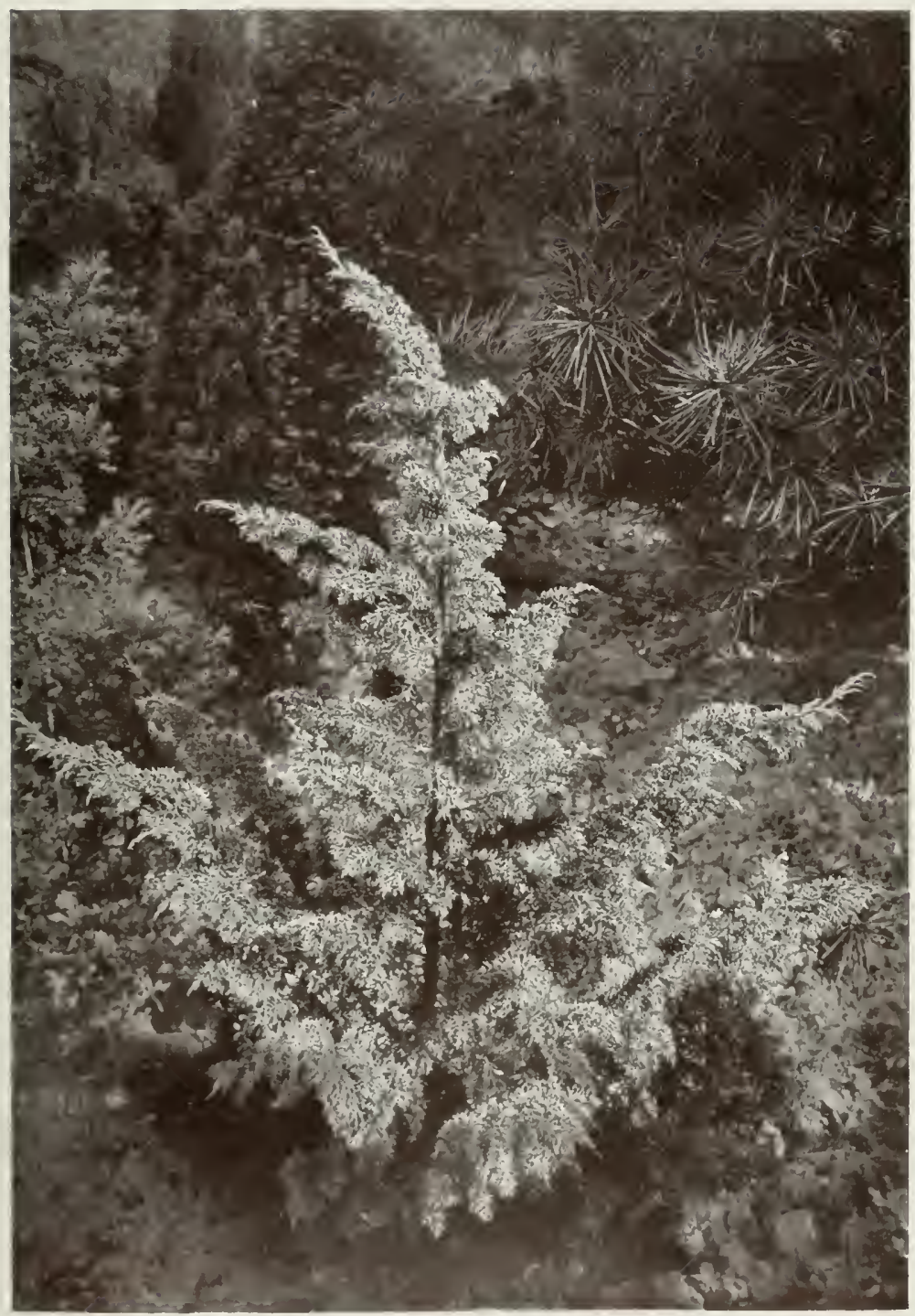

THE GOLDFN JAPANESE JUNIPER. Juniperus japonica aurea.

For description see Chapter XVII. Photo by R. A. Malby. 


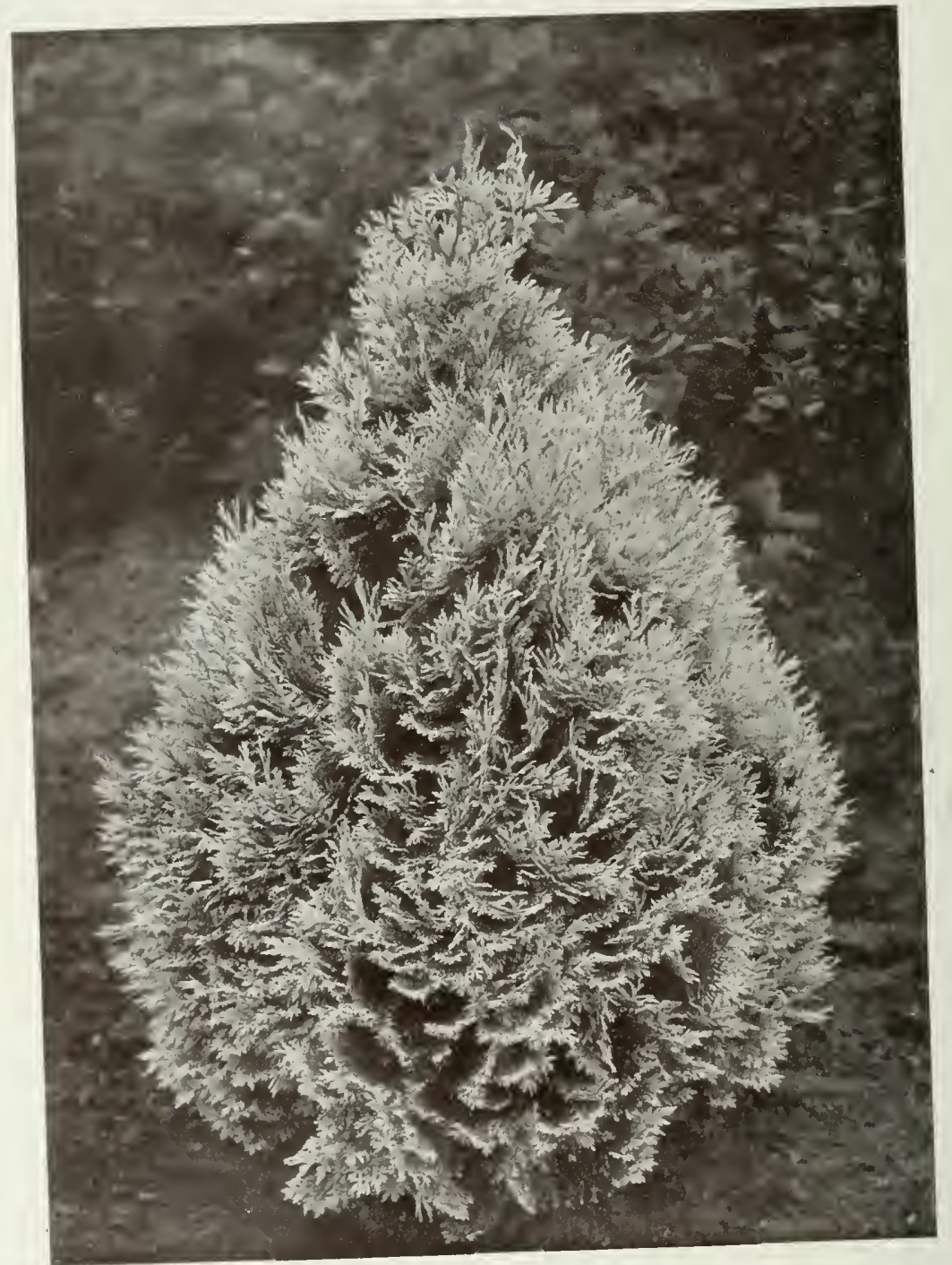

THE GOLDEN CYPRESS.

Cupressus Lawsoniana lutea.

For description see Chapter XVII. Photo by R. A. Malby. 
may also be planted. The Irish Yew is a pyramidal form of the common called fastigiata, and there is a yellow form of this. There is an interesting yellowfruited Yew named fructu-luteo.

In the ranks of the Thujas we find those popular Conifers, the Arbor-vitæs. The American Arbor-vitæ, or White Cedar, T. occidentalis, is perhaps the best known, although the Eastern, T. orientale (syn. Biota orientalis) which comes from China and Japan, is also familiar. A more ornamental kind than either is T. dolabrata, from Japan; it makes a nice small lawn tree, and its form variegata is well suited to the same purpose. There are many garden forms of the Arborvitæs, of the American there are silver-variegated and yellow variegated, drooping (pendula), dwarf (nana), and so forth. Similar forms of the Chinese are also met with in the nurseries, filiformis, aurea and elegantissima are beautiful little plants. The large species gigantea is worth mentioning; it is the same as the nursery tree T. Lobbii; aurea and pyramidalis are forms of it.

The genus Tsuga is almost ignored by nurserymen, most of whom call its best species, Mertensiana, Abies Albertiana or Abies Mertensiana. Again, T. canadensis, the Hemlock Spruce, is often listed by dealers under the name Abies canadensis. There are several garden forms of this popular tree, including a whitetipped, a dwarf, and a drooping variety. T. Hookeriana, T. Pattoniana, and $\mathrm{T}$. Sieboldii are sometimes met with.

While the foregoing lists include the most important of the Conifers, they exclude several interesting plants 
to which a brief reference may be made. There are, for example, Athrotaxis cupressoides, the Tasmanian Cypress; the Cephalotaxuses, of which drupacea and Fortunei are perhaps the best known ; Cunninghamia sinensis; Dacrydium Franklini, Libocedrus decurrens, a handsome and distinct American Conifer; the Podocarpuses; Prumnopitys elegans, the Chilian Plumfruited Yew; Pseudolarix Kaempferi, the Chinese Golden Larch; Saxe-Gothæa conspicua, Sciadopitys verticillata, the Japanese Umbrella Pine; Taxodium distichum, the American Deciduous Cypress, which is good for the waterside ; there is a drooping form of it ; and the Torreyas.

Athrotaxis cupressoides is not quite hardy.

Sciadopitys verticillata is one of the most beautiful of the less familiar Conifers, and should be planted more. When frequently transplanted in the nurseries, while young, it will form a fibrous root system and bear shifting when of large size. Its fine leaves are borne in large bunches.

The smaller Conifers, such as the forms of Cupressus Lawsoniana and Thuja orientalis, the Irish Yew, the Retinosporas, the Cryptomerias, and the garden forms of Picea excelsa and P. pungens, are suitable for the smallest borders and even for window boxes in winter. They are beautiful in a very small state, and grow slowly except when planted in very rich soil. 

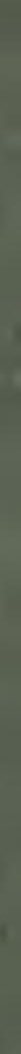

$x$

1

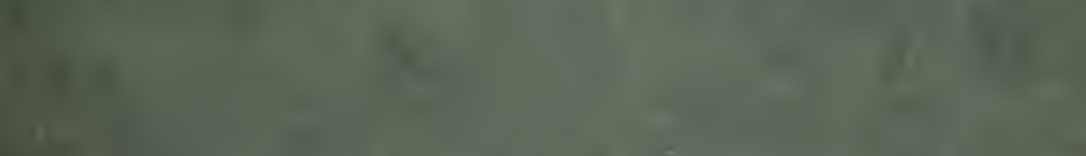

1

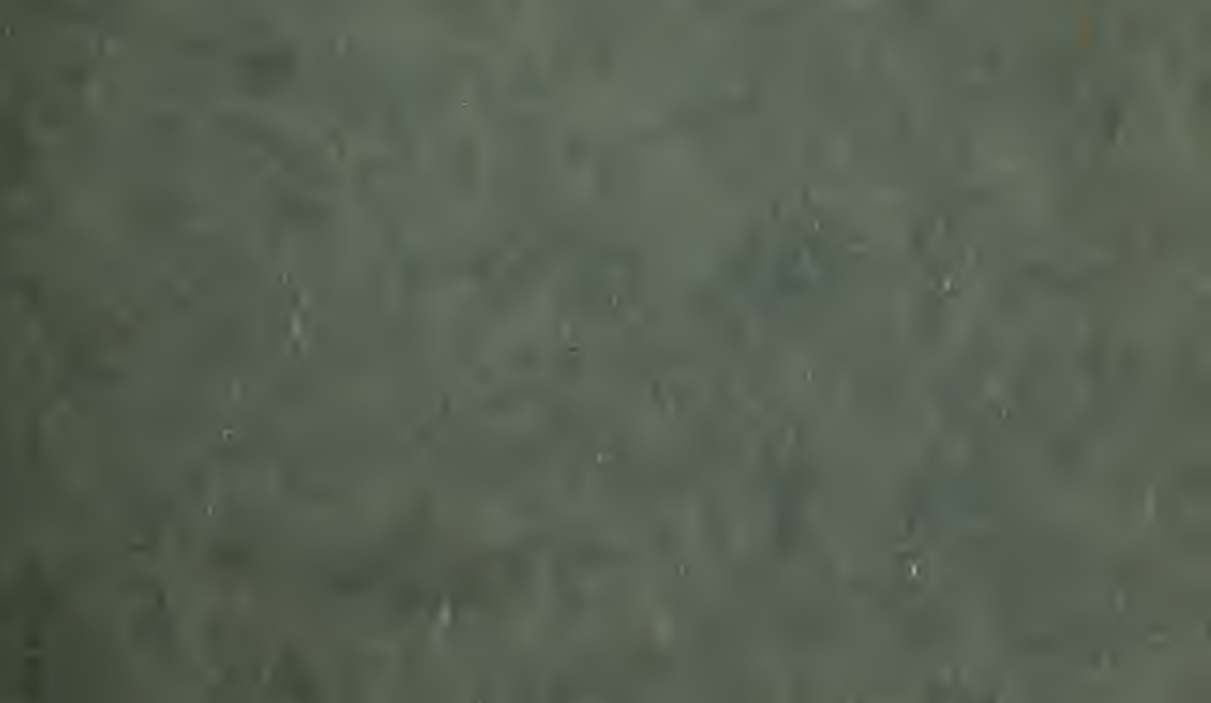




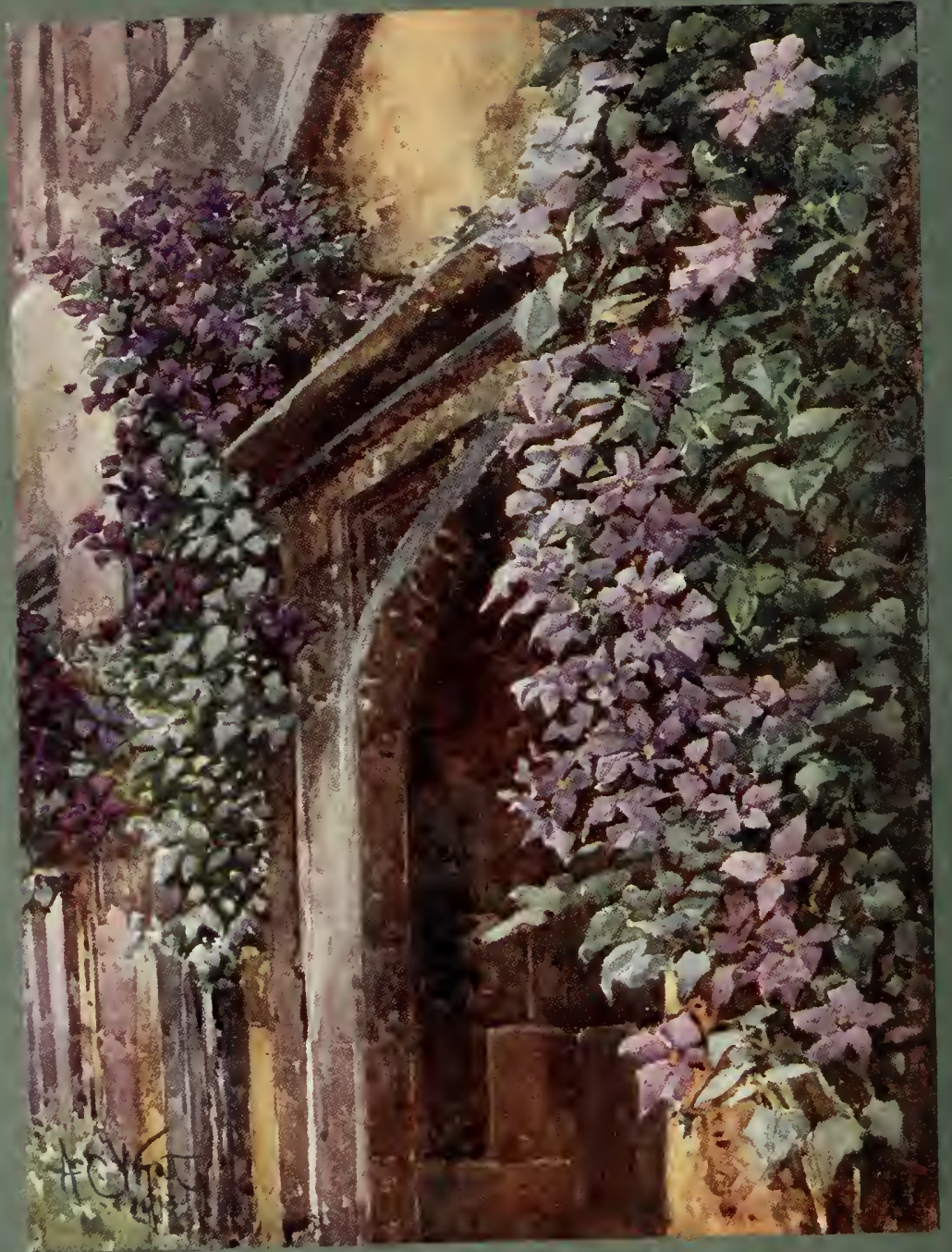


"ALL THE FORMS OF CLEMATIS JACKMANII ARE BEAUTIFUL." (See page I $_{5} 8$ ).

Painted by A. C. WYatT. 
. 


\section{CHAPTER XVIII \\ Climbing Shrubs}

A PURIST might object to the term " climbing " as used in connection with certain shrubs which are often grown on walls or other supports, and indeed, there are few plants that really climb by means of special processes such as those employed by the Virginian Creeper and the Ivy. Nevertheless, the term is permissible, because it implies a class available for the same uses as those to which the climbing plants are put.

Many hardy shrubs, deciduous and evergreen, are suitable for covering walls, and there are other kinds which, lacking perfect hardiness, are only safe on walls in climates where severe winters prevail. We may fairly, for the sake of ${ }_{\text {r }}^{\mathrm{r}} \mathrm{ready}$ comprehension and convenience, refer to all these as climbers. We could hardly speak of Cratægus Pyracantha as a climber; it is, however, an excellent wall shrub. The same remarks apply to the Honeysuckles and to the Cydonias.

Let us not, however, by the repeated use of the word "wall" imply a limited use to these free-growing shrubs. There are arbours, arches, summer-houses, fences, pillars, tree-stumps and pergolas to consider as well as walls. Perhaps more particularly pergolas. This is the day of the pergola. Thousands of garden-makers 
are coming to realize what a charming and interesting feature of a garden a pergola is. Forming a distinct break in the outline of a garden, it likewise affords support for a number of beautiful plants which might not otherwise find accommodation.

Flower-lovers who note the exquisite effect often produced in nature when the Traveller's Joy rambles over the tall thickets, or when the Honeysuckle fastens its tight grip on the hedgerow, may learn a lesson for their gardens and set in appropriate places piles of old tree stumps and gnarled branches to serve as a support for rambling plants. With a little scheming, many a rough waste corner could be made bright, interesting and beautiful.

Let us consider some of the best of the climbing shrubs in alphabetical order.

Actinidia chinensis, a modern species from China, is the best of its genus. It has heart-shaped leaves covered with reddish hairs. The flowers are yellow, about the size of a half-crown piece, and are followed by plum-like fruits in the case of the female plant.

Akebia quinata, which bears purple flowers in spring, has not the merit of brilliant flowers, but is worth including in a large collection for its quaint form. A. lobata is also grown.

Much the same may be said of the "Dutchman's Pipe," Aristolochia Sipho.

The Ampelopsis is referred to under Vitis.

Berberidopsis corallina is a typical example of a really beautiful shrub which requires a wall in cold climates. It is an evergreen, flowering in spring, with 
coral-red flowers near the tips of the shoots. In mild places it may be planted on the pergola or arbour.

The Bignonias, most brilliant of climbers, includē one species, capreolata, which may be grown on an outdoor wall in a mild district. Its scarlet flowers are very showy.

We have seen elsewhere that the Buddleias include some beautiful plants for the mixed shrubbery. In cold districts they might be considered for walls, particularly the two magnificent forms of variabilis, Veitchiana and magnifica, which producelong, dense, mauve or purplish flower-spikes in summer. They do best when pruned hard, like Roses, in spring, for the best spikes are produced on the new wood. Colvilei has lovely rose campanulate flowers; it should have a warm wall.

The Allspice, Calycanthus floridus, is worth growing for its perfume. The brown flowers, which appear in June, are deliciously scented. It might be grown in the angle of a wall, and such a position would also be suitable for the exquisitely perfumed Chimonanthus fragrans (syn. Calycanthus præcox), which blooms on bare wood in winter or spring, and likes a south or west aspect.

The Ceanothuses are beautiful deciduous shrubs for walls, and the finest spikes are found in the forms of azureus, such as Ceres, Gloire de Versailles, Croix du Sud and Marie Simon.

The species Veitchianus, blue, is also very good. They thrive in any well-drained, fairly fertile soil, and will do on chalk. They should have a south or west aspect. 
The Clematises are among the most beautiful of all climbing shrubs. Nothing is more charming on the autumn countryside than masses of the silvery achenes of C. Vitalba, the Traveller's Joy, which remain for many weeks a delight to the discriminating wayfarer. The flower-lover may elect to plant varieties of greater intrinsic beauty of bloom in the garden, except in semiwild places, where he may establish C. Vitalba and let it grow at its own sweet will. C. Flammula may have a place, for it is fragrant as well as pretty. Room must be found, too, for C. montana and perhaps for the new forms rubra and Wilsonii. C. montana is truly a charming plant for a wall, arch, or arbour, blooming profusely in late spring. Its flowers are white, and are not, therefore, showy; nevertheless, it produces a beautiful effect. The new Wilsoni is larger. Rubra is red and makes a splendid pillar. There are many lovely Clematises grouped under the names of well known-species or hybrids, such as Jackmanii and lanuginosa. The former is too well-known to need description, but it may be noted that many growers fail to get the best out of it, by neglecting to prune it ; only when the old flowered shoots are kept under ( $p$. II5) and young wood encouraged does the gardener see this splendid plant in its true beauty. It might well be pruned every spring with the dwarf Roses, and with a similarity of method, in as much as the wood which bloomed the previous year could be cut back. All the forms of Jackmanii are beautiful. There are large deep violet (superba); white (alba or nivalis); and red (rubra or Madame Edouard André). These are 

"THE CEANOTHUSES ARE BEAUTIFLL DECIDUOUS SHRUBS FOR WALLS."

(See page I 57.)

Colour photo by R. A. MaLby. 


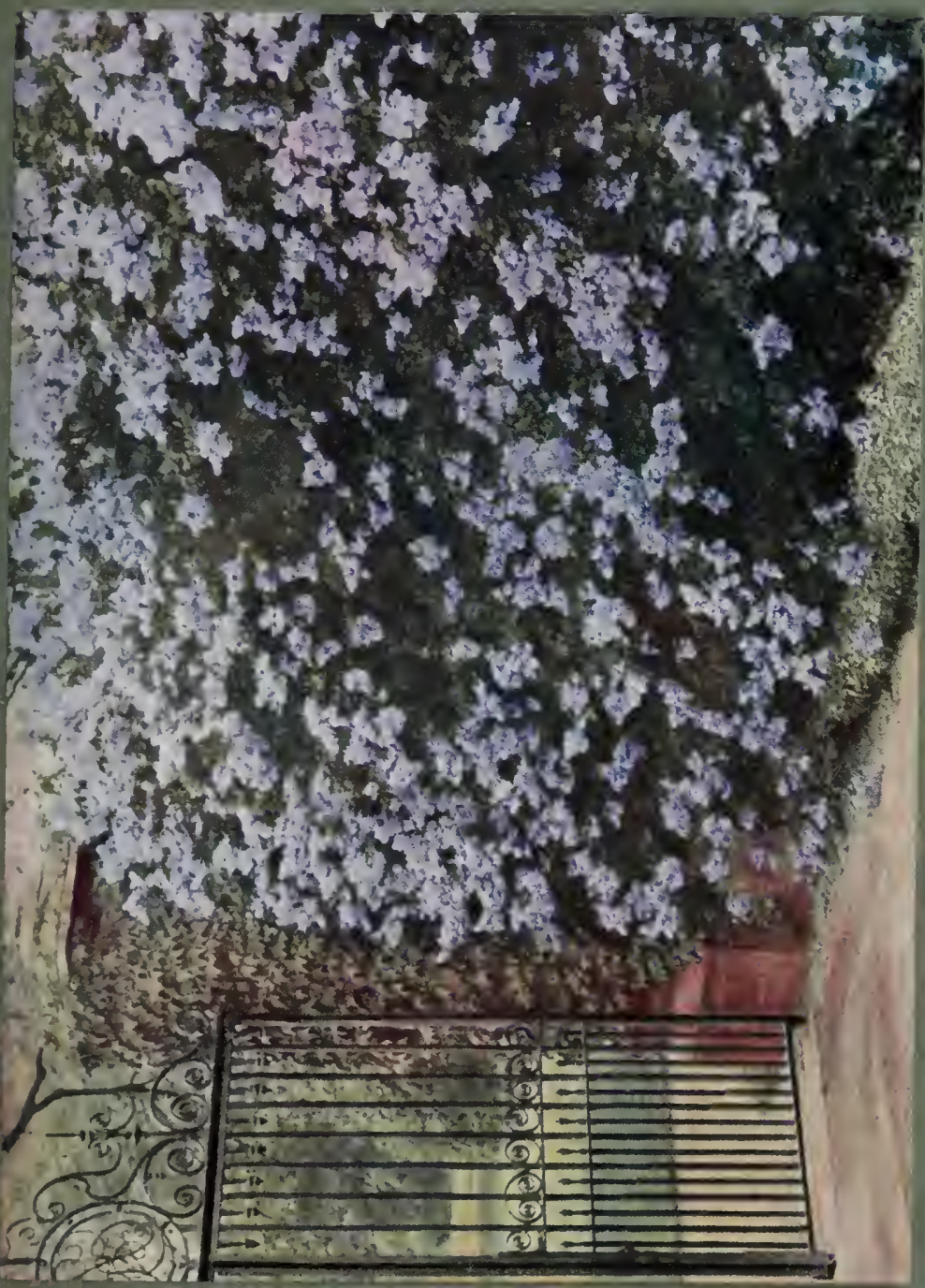


"THE CEANOTHUSES ARE BEAUTIFUL DECIDUOUS SHRUBS FOR WALLS."

(See page I 57.)

Colour photo by R. A. MaLBY. 


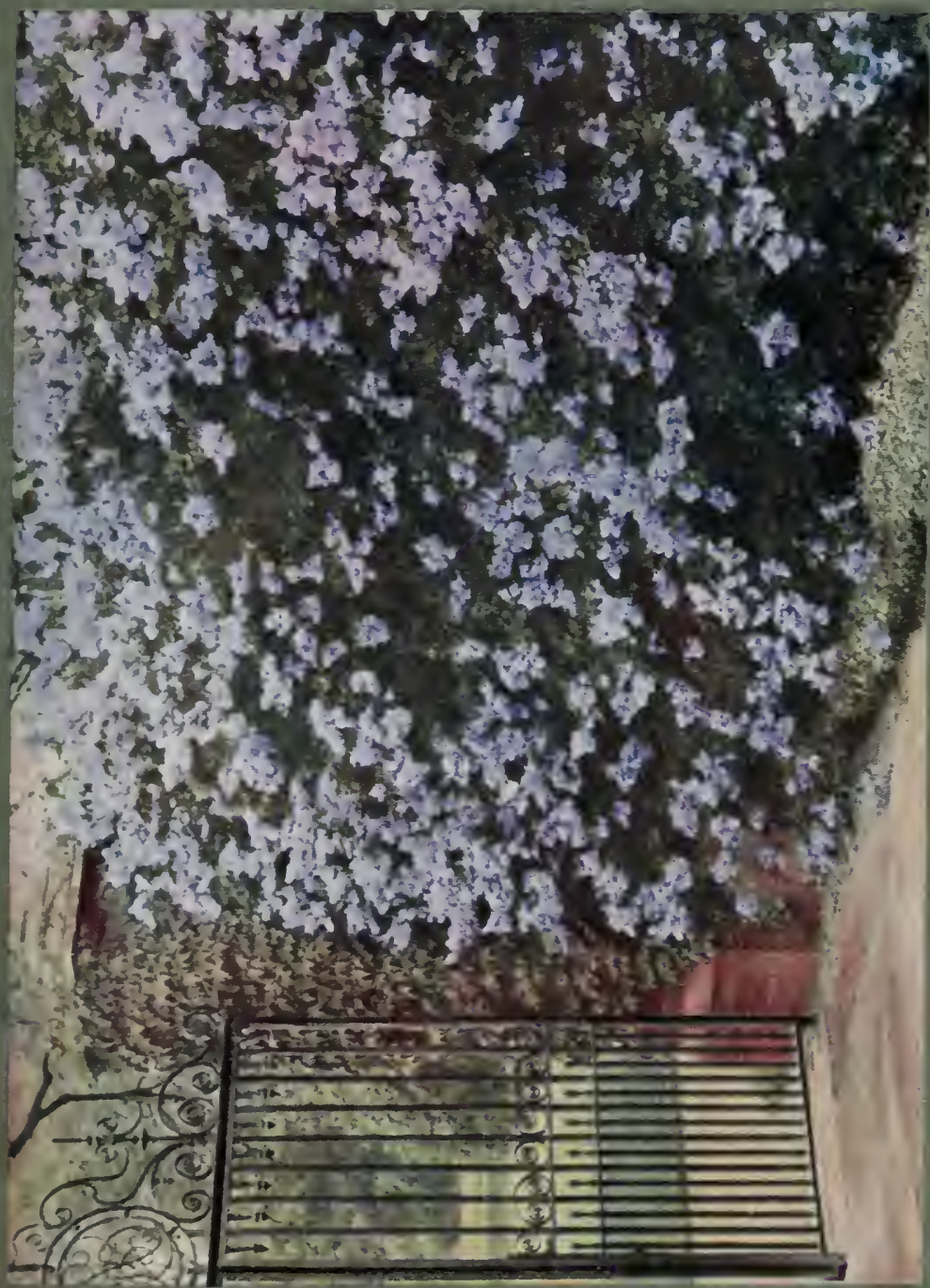


suitable for walls or pillars. Of varieties associated with the species lanuginosa there are Enchantress, double white, flushed with rose; Candida, grey; Venus Victrix, pale lavender; and Beauty of Worcester, blue-violet, all with very large and beautiful flowers. The type has lavender flowers. These are among the most showy of all the Clematises and make splendid pillar plants, so that they could be used for the pergola. They do not want much pruning, and the flowered wood should not be cut back as with the Jackmanii set, but thinning should be practised if the plants are crowded. Another beautiful set, admirable for the same purposes as the lanuginosa group, equally large and brilliant, and suited by the same system of pruning, are those associated with the species patens. The Queen, lavender, is one of the best of these. Fair Rosamond, blush ; and Miss Bateman, white, are also good. These large and beautiful Clematises can be planted to drape old trees, which in themselves are past the ornamental stage, but may make the best of supports for younger rivals.

The foregoing is but a tithe of the material awaiting the Clematis-lover if he cares to make a study of the genus. He will admire æthusifolia, with its small narrow-lobed leaves and white, bell-shaped flowers borne in early autumn. The coccinea hybrids, with flowers shaped like urns, will attract him by their distinctness. He may prune them in the same way as the lanuginosa and patens sets. Cirrhosa, an evergreen species, with white flowers; grata, bluish white, sweet, an autumn bloomer; paniculata, white, fragrant, 
another autumn bloomer; and Viticella, purple, with its white and red forms, will all attract him. The varieties of Viticella have the same flowering habit as Jackmanii.

The Cotoneasters, which were described in the chapter on evergreens, may be used with advantage for walls.

For a wall of moderate height, with a north or east aspect, few things can be better than that beautiful Thorn, Cratægus Pyracantha, and its form Lalandii. The importance of the Pyracantha lies in its brilliant berries. It will thrive in town and surburban gardens, and hold its berries right through the winter.

Cydonia (Pyrus) Japonica and C. Maulei, with their varieties (Simoni is splendid), claim attention, especially where brilliant shrubs are wanted for a low wall. The Japanese Quince has large and brilliant flowers, which sometimes expand in late winter and are followed by fruits suitable for jellying. The varieties differ mainly in hue. Thus there are purple (atropurpurea); white (alba); rose (rosea); scarlet (coccinea) and others. C. Maulei and its form superba are also good.

In mild, moist, sheltered places, no shrub is more vivid and beautiful in June than Embothrium coccineum, an evergreen which produces its glorious scarlet flowers in clusters. In colder districts it might be tried on a south wall in a compost of peat, loam and sand, with good drainage. It is worth an effort.

The Escallonias may have walls or wall shelter except in mild places near the sea, where they thrive in the 
open. The best known species is macrantha, with pink flowers in early summer; but the hybrid Langleyensis, with its long sprays of charming pink inflorescence, is a precious plant. It need not be placed actually on the wall, if there is shelter from cutting winds, but may have a wall border.

Garrya elliptica is a yellow-flowered evergreen which is much at home on a south or west wall.

The Ivies (Hedera) are, of course, among the most important of wall plants. Some people plant them with an uneasy mind, fearing that they will do injury to the walls. There need be no apprehension on this score, Ivy rather benefits than impairs masonry. It is true that a problem is sometimes presented when an Ivycovered house has to be re-decorated, but the painter will generally be very fluent in assuring you that he can not only remove the Ivy, but replace it intact and in the end be able to point to a qualified triumph.

Practically all the many forms of Ivy which we see in nurseries are variations, more or less strongly marked, from the common species, Hedera Helix. They differ in size, form and colour of leaf. Some of the most distinctive types, such as the Irish (canariensis) have sub-forms; there are large spotted and large variegated forms of the Irish. There is, too, a variegated form of the gigantic dentata, the largest leaved of all the Ivies, and it is very beautiful.

The following are a few of the best garden Ivies: algeriensis, argentea rubra, azorica, Caenwoodiana, and its form aurea, canariensis and its forms, chrysophylla, dentata and d. variegata, digitata and 
d. aurea, Emerald Green, maderiensis variegata, palmata and p. aurea, Rægneriana and rhomboidea ovata. The Ivies are apt to move slowly when young, and the Irish is perhaps the quickest grower. They can be stimulated by good soil and abundant moisture. The stronger growers can be bought in pots with several strong shoots twined round a stake and upon each other. Disentangling them is sometimes a tedious process, but it should be done and the shoots fastened to the wall with nails and shreds. When fairly established the plants will make their own supports. When the Ivy has grown into a dense mass on the wall, it should be clipped in spring just before growth starts. The new leaves will soon hide the marks of the shears.

Ivy is useful for covering shady trunks as well as for clothing walls. Another pleasing use to which it can be put is to plant it to cover tree stumps, which may be set in selected places.

The Tree Ivy, Hedera arborea or arborescens, grows without support, and is a useful evergreen for shady places. Like the climbing Ivy, it will thrive in towns. Chrysophylla, aurea and elegantissima are forms of it.

Two Hydrangeas are suitable for growing on walls, and indeed must have shelter except in very mild districts ; these are petiolaris, which has white flowers in spring; and quercifolia. Petiolaris clings naturally, and is good for a high wall; it soon covers a wide area.

Two of the commoner Jasmines are hardy, namely, nudiflorum and officinale. The former is the wellknown plant which bears yellow flowers spasmodically, 

CLEAIATIS IIONTANA IS A TRLLI CHARIING PLANT FOR A WALL, ARCH OR ARBOUR."

(See page I58.)

Painted by A. C. WYatT. 


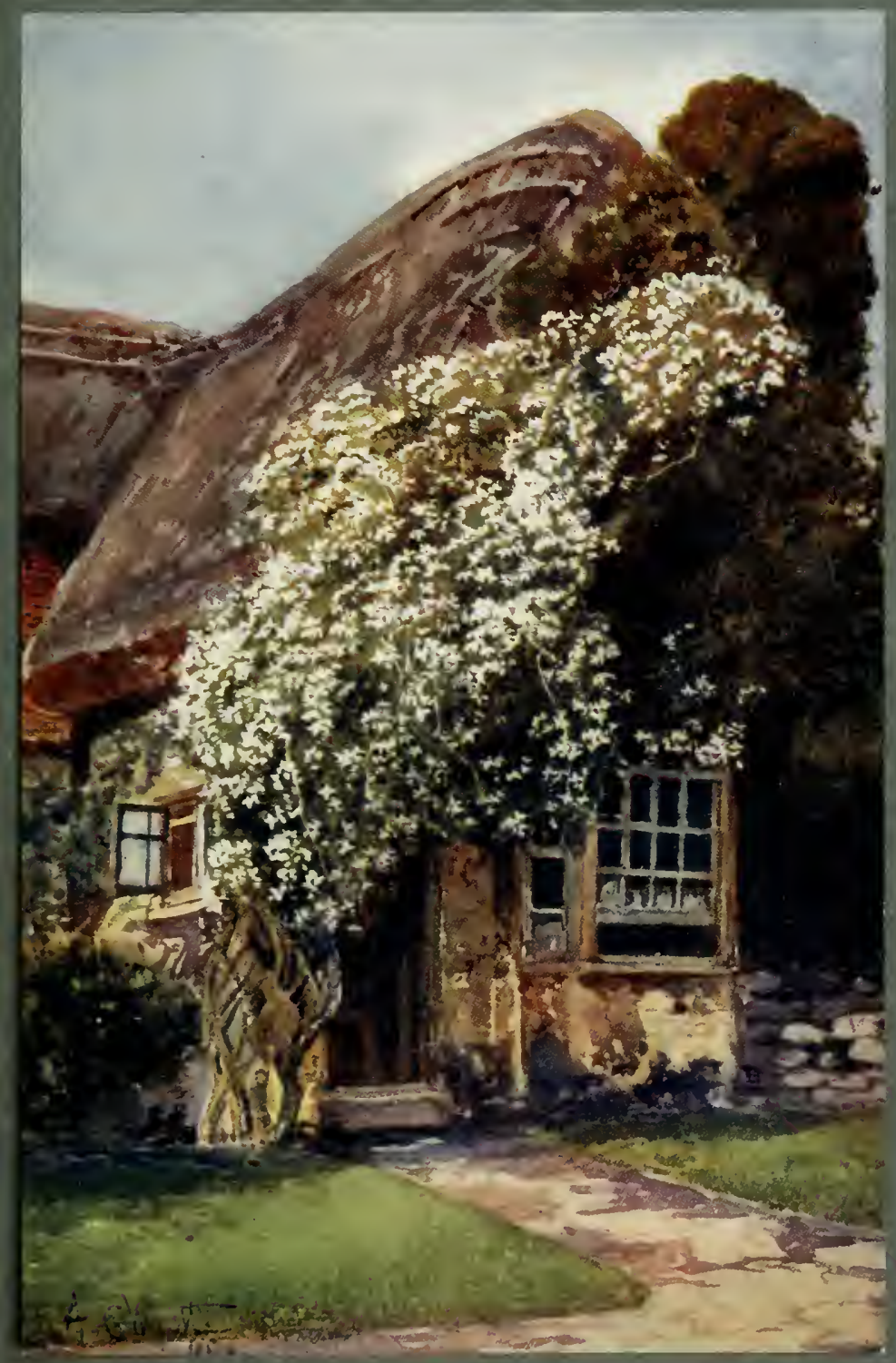




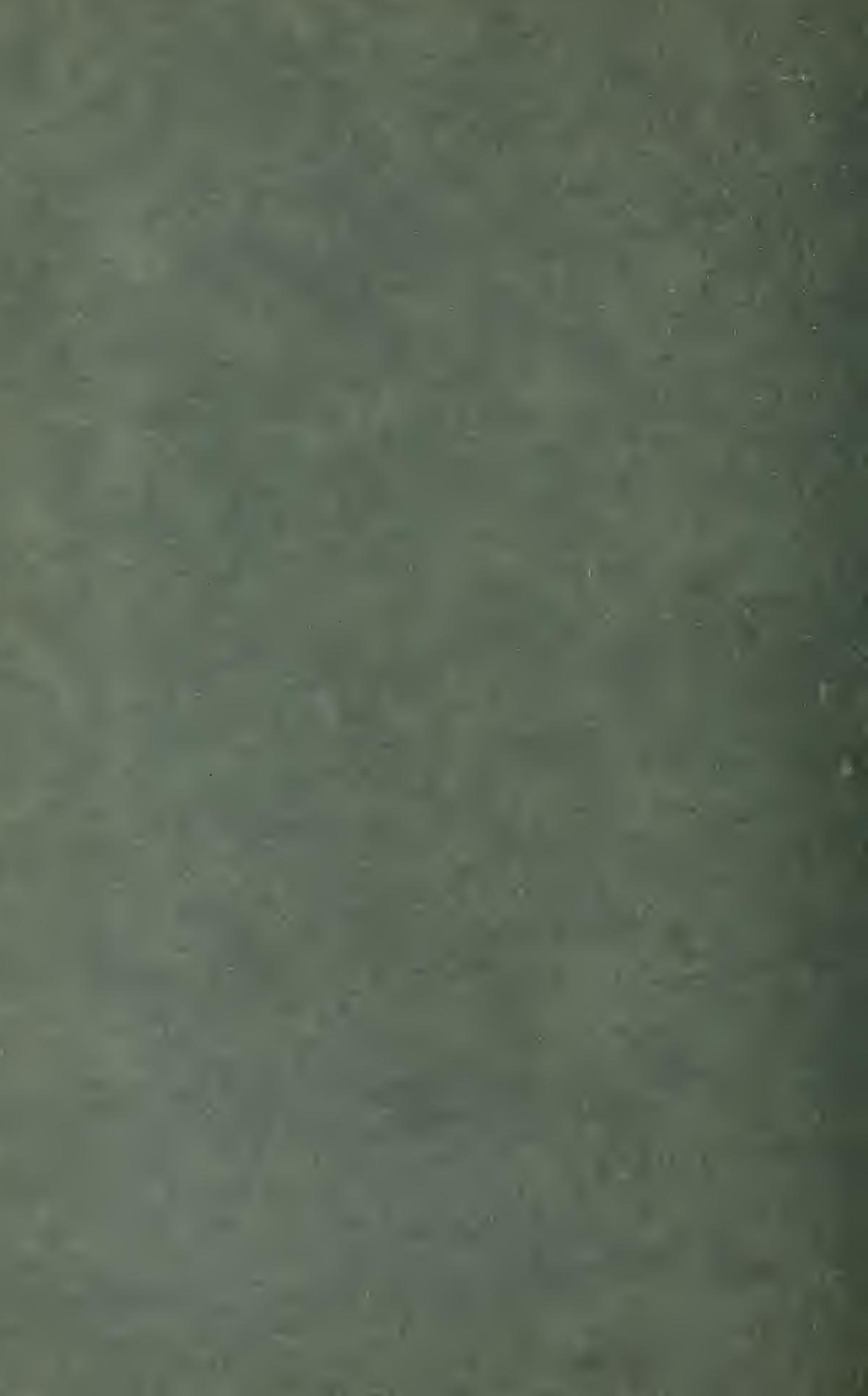


in winter, in advance of the foliage; there is a yellow leaved form of it. The Winter Jasmine grows well in towns. Officinale is the common white scented Jasmine. Primulinum, revolutum and Wallichianum may all be grown on outside walls, in mild districts, but they are not hardy. Primulinum is a very attractive Jasmine, with flowers much larger than those of nudiflorum. Like the Clematis, and indeed many other hardy climbers, the Jasmine often suffers from want of pruning. Much crowded plants do not bloom well, and if they were thinned freely, and the young wood cut back, the bloom would be the finer.

More popular even than the Jasmine as a fragrant climber is the Honeysuckle, the twining branches of which will bind themselves round a fence, over a tree stump, among the "lattices " of trelliswork, and round pillars. The common Honeysuckle is known to botanists by the somewhat formidable name of Lonicera Periclymenum; there are several garden forms of it, such as Early Cream, Early Dutch and Late Dutch. Flava is the yellow trumpet Honeysuckle. Flexuosa and brachypoda, with pale very fragrant flowers, are the same species, and the gold-netted (aurea reticulata) is a garden form of it. Sempervirens is the scarlet trumpet Honeysuckle. There are two winter-blooming species with white flowers, fragrantissima and Standishii. The Honeysuckles will grow in almost any soil if the site is not very hot and dry. The only pruning which they need is thinning when crowded.

Kerria japonica, double form, is good for a north wall. 
The Magnolias give us some of our noblest shrubs and trees, and the large-leaved grandiflora is generally grown on a wall. Those who think of planting this fine evergreen should endeavour to get the Exmouth variety, which is finer than the common. Ferruginea is another form of it. They should not be planted on a cold aspect; a south or west wall is desirable. Magnolias conspicua, Lennei, Soulangeana and stellata (syn. Halliana) are beautiful deciduous Magnolias that may be planted in shrub beds and borders.

The Myrtles have a body of faithful admirers, who love the plant for its perfume. One could hardly deal with it appropriately among climbing shrubs, but for the fact that it is often planted against walls for the sake of shelter; it does not grow up the wall like a climber, but gains vigour from the protection which it receives. Even with the wall-shelter, provision should be made for protecting the plant in severe weather. The common Myrtle is Myrtus communis, and there are several varities of it, including a narrow-leaved, (angustifolia) and a variegated.

The Passion Flower (Passiflora cærulea) is one of those plants which tantalize their admirers by just falling short of that perfect hardiness which enables one to plant them anywhere without fear, but they will live in the open in sheltered places, and after all, the plant is so interesting and beautiful that it is worth a risk. The white form, Constance Elliott, may also be planted. These Passion flowers will serve to give diversity to the furniture of a long pergola, and variety adds interest and charm. 


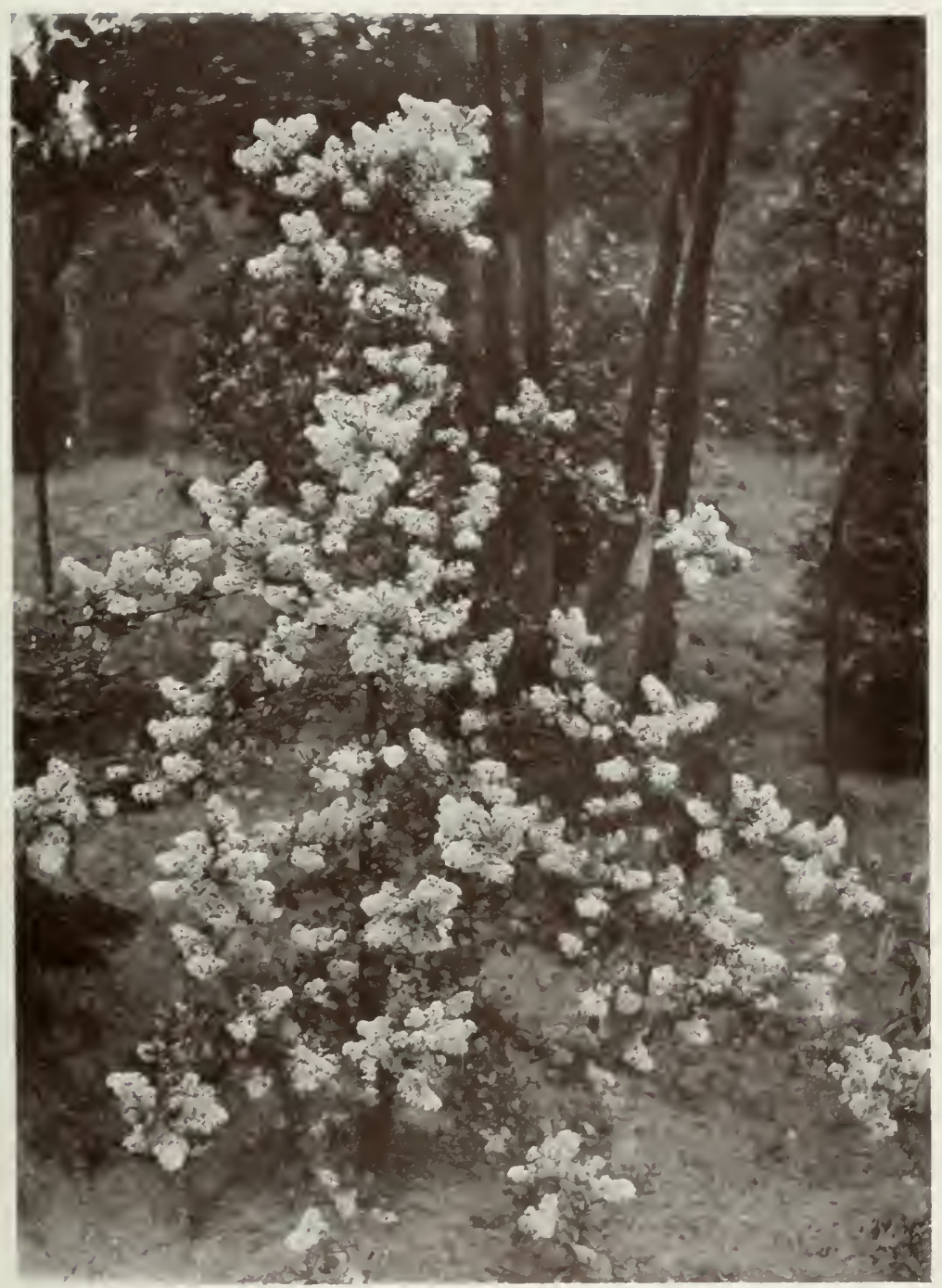

ALL BLOOM, ALL BLUE.

Ceanothus thyrsiflorus grisens.

For Ceanothuses see Chapter XVIII.

Photo by R. A. Mally. 


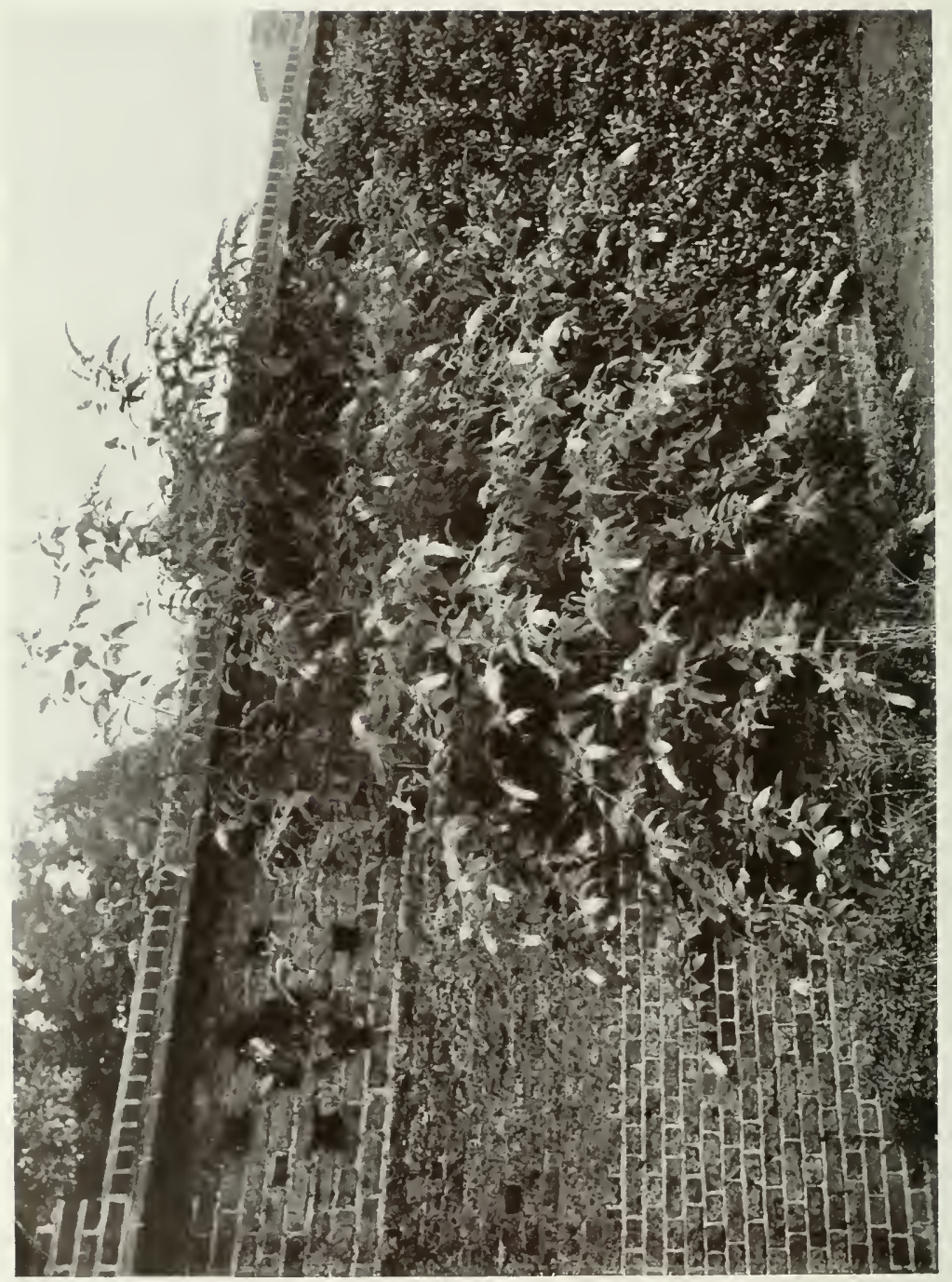

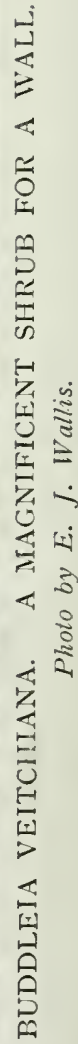


Periploca græca may be planted to vary the interest of a collection of climbers. Although it is not showy, its greenish purple flowers are quaint. It will do for the pergola.

Polygonums comprise a large number of species, but few are suitable for climbing, and the best by far is Baldschuanicum, which grows very fast and twines its stems round any object. The white flowers are produced in panicles from early summer to September, and it is often at its best, a fleecy cloud of bloom, in early autumn. The plant is hardy, and it grows so fast and blooms so profusely that it is a splendid subject for covering arbours, arches and pillars. It may also be used for the pergola.

Roses must, of course, be included in any collection of climbing shrubs. They are the most beautiful of all plants for covering arches, arbours, pillars, pergolas, fences, walls and banks. It may here be explained that in passing references to Rose-pruning in the present chapter, the pruning of dwarf and standard Roses of the Hybrid Perpetual, Tea and Hybrid Tea classes, which bloom on the current year's wood, was referred to. The best of the climbing Roses belong to the multiflora, polyantha and Wichuraiana sections, and these flower best on long canes made the previous year, so that they come within the ranks of the majority of flowering shrubs in respect to pruning. In brief, they do best when the flowered wood of any particular year is pruned out after blooming, giving room to the young canes which spring up from the base. As with many shrubs, it is sometimes desirable to retain the 
lower part of an old rod for the sake of a strong young cane which is growing on it, and which is better placed, or more vigorous, than canes from the rootstock.

It would not be possible to deal fully with the pruning, general culture and varieties of so important a shrub as the Rose in a general work. These matters are dealt with, alike as regards climbing and dwarf Roses, in the sister volume, "Roses and Rose Gardens." It is desirable, however, to point out the beauty and value of what are called climbing Roses in connection with the subject of the present chapter. The varieties are constantly changing, new coming into the catalogues and old dropping out every year ; but there are certain sorts of such outstanding merit, that it is difficult to improve on them; and they are likely to stand for many years. Such are the beautiful Wichuraianas Dorothy Dennison, Excelsa, Jersey Beauty (for banks), Dorothy Perkins, Lady Gay, Alberic Barbier, Lady Godiva, and White Dorothy; Crimson Rambler and Blush Rambler, Carmine Pillar, American Pillar and Shower of Gold. All these have the elements of long-continued favour. All are good for pillars, arbours, arches and pergolas. All the Wichuraianas are good for banks, Jersey Beauty and Alberic Barbier particularly so. In mild winters they are evergreen. If the varieties as a whole are weak, it is as wall plants. None of the Wichuraianas and Ramblers are quite at home on a wall. For this purpose the planter should choose Madame Alfred Carrière. For a lofty wall, especially with a cold aspect, there is probably nothing better than William Allen Richardson. For low walls 
Gloire de Dijon, L'Ideal, Cheshunt Hybrid and Alister Stella Gray may be considered. If a few more Roses are wanted for pillars or pergolas, the claims of Felicité-et-Pérpétue, René André, The Lion (not the Lyon), Mrs. F. W. Flight, the Penzance Briars Lucy Ashton, Meg Merrilees, Rose Bradwardine and Anne of Geierstein, Tausendschön, Leuchtstern, Tea Rambler, Dundee Rambler, and Trier may be considered. It will not be practicable to prune all these wall Roses quite the same as the Wichuraianas and Ramblers, because they will not throw up so much wood from the base. The best course is to shorten the side branches hard when they get crowded, and new flowering wood will break up to take its place. All Roses love a deep substantial soil ; but the Wichuraianas will thrive in poor, chalky land where few of the other sections would grow, and this will be a strong inducement to plant them in the case of many garden-lovers.

The genus Smilax gives several plants suitable for climbing, but this does not include the plant commonly grown under the name of Smilax in greenhouses, for that does not belong to the Smilax genus, and is really an Asparagus. Aspera and its variegated form and rotundifolia are perhaps the best of the hardy kinds.

Veronica Hulkeana is suitable for a south wall, and has long lilac spikes in spring. It is very beautiful.

Considering the Vitises as including Veitch's Virginian Creeper (and the name Vitis inconstans has been substituted for Ampelopsis Veitchii by botanists) the genus is very important, inasmuch as this is perhaps the most popular of all wall plants. It should 
always be planted in preference to the common Virginian Creeper, Ampelopsis quinquefolia (syn. hederacea), which is a coarse plant and does not give such beautiful autumn colour as Veitch's. The latter is a true climber and assumes exquisite shades in the fall. Vitis Coignetiæ is the largest of all the Vines, its huge, thick leaves often being nine inches in diameter. They are deep green above, yellow beneath, and become highly coloured in autumn Heterophylla and its varieties are worth considering A series of new kinds will attract the attention of novelty-lovers. These comprise armata, Veitchii, Henryana, Leeoides and megalophylla. Veitchii is a beautiful form of armata and colours exquisitely in the fall. The Vines are free-growing plants and need not be given a rich soil. The species of Vitis named vinifera is the wellknown Grape Vine.

The Wistaria is one of the oldest favourites among wall plants, and certainly few ramblers are more beautiful when it is well established. One has to wait for it, especially in poor soil, but when it grows into full beauty it is glorious. The old mauve species is sinensis (chinensis); there are white, variegatedleaved, and double forms. To get a wall well covered with Wistaria the branches should be trained in parallel, horizontal tiers a yard or so apart, and the young growths which spring from them will give fine racemes. The shoots which have bloomed may be cut away in winter, and fresh flowering growths will break the following spring. This pruning routine gives much finer bloom than one gets when the plants 


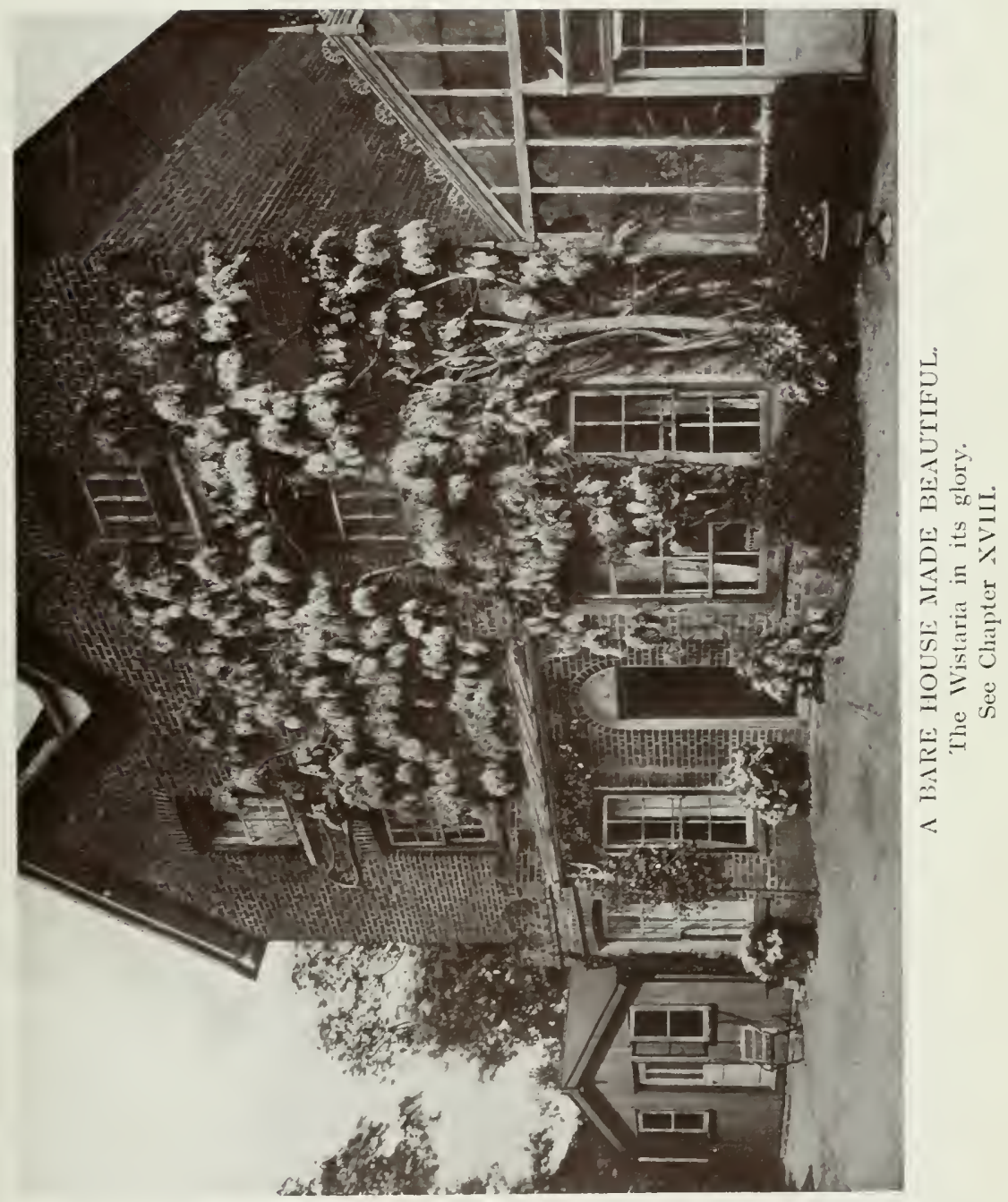




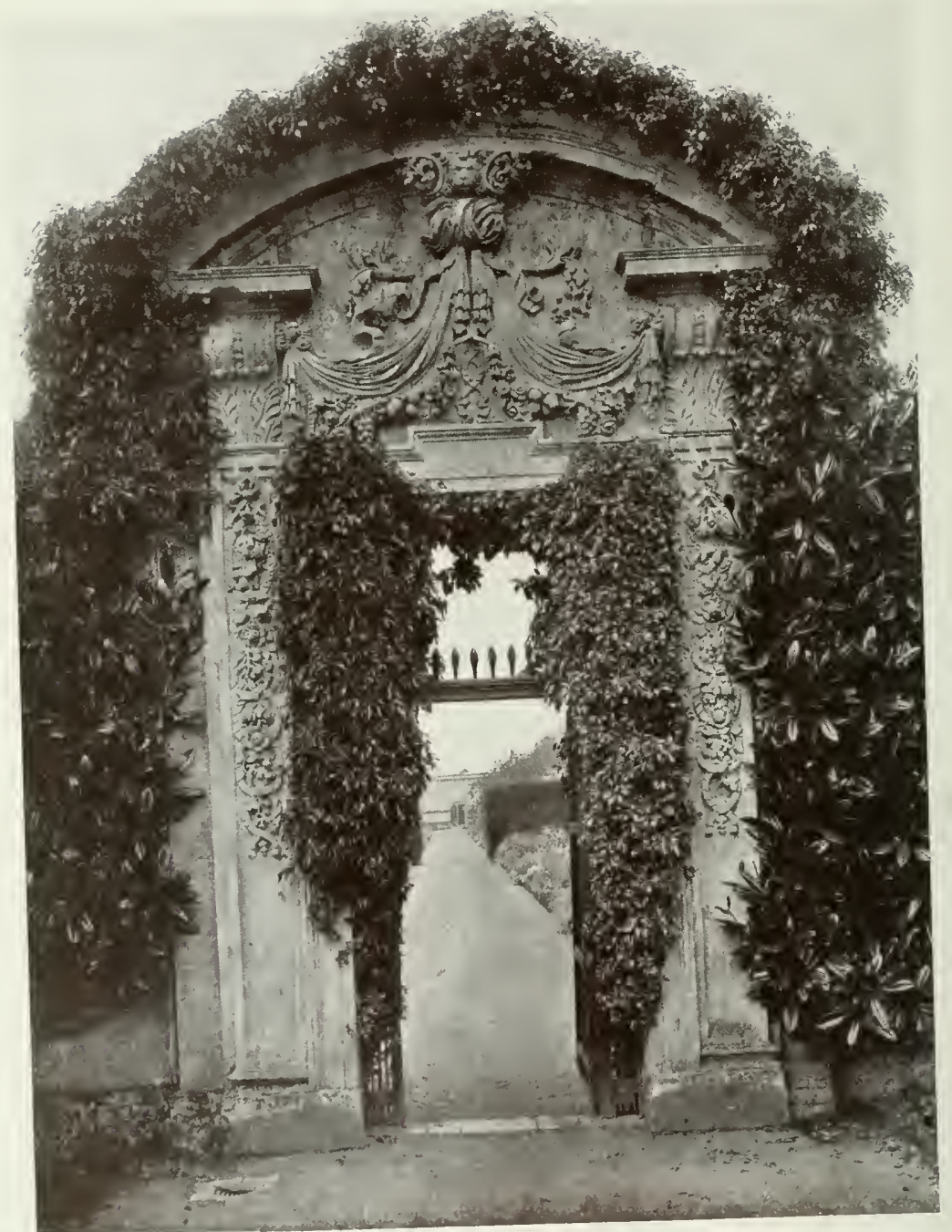

ITALIAN ARCH WITH CLIMBING SHRUBS AT SIVALLOWFIELD PARK.

Photo by F. Mason Good. 
are allowed to remain crowded and unkempt from year to year.

We see that the number of good climbing shrubs is not limited; on the contrary, there is an almost embarrassing amount of material to choose from. However, in modern gardens there is generally a considerable area provided for climbers. In this connection it may be suggested that the smaller the garden the greater the space above ground that should be provided for plants. It is true that the indiscriminate use of arches, pillars and pergolas might lead to a crowded and packed appearance, and that it is desirable to avoid this; still, there are other important considerations. Apart from the fact that in small gardens the ground area is limited, there is the fact that small gardens often have near neighbours, and the desire for privacy alone urges the flower-lover in the direction of putting up a greater proportion of plantsupports than would be called for in a larger place. Pillars, fences, arbours, pergolas, and the like are not only plant-supports but screens. These are points that must have due weight in planning gardens. 


\section{CHAPTER XIX}

\section{Shrubs for the Rock Garden}

THE lover of Alpines is so much the better placed in one respect than his brother amateur who specializes in herbaceous plants that he has some vegetation, and not infrequently bloom, to show even in the winter months. The rock gardener is generally weakest when the herbaceous lover is strongest-from July to October inclusive.

In every department of flower gardening there ought to be prolonged interest. In many cases specialistic plant growing is not gardening, because it merely aims at making particular plants grow, and does not consider them in connection with other subjects, or with the garden generally. Every plant that is put into the ground ought to be planted with these things in mind.

Shrubs should be considered for the rock garden: (I) because they enter into harmonious relations with other occupants ; (2) because they serve as permanent furniture for the garden ; (3) because they give beauty of bloom or foliage at a period when the majority of Alpines are ineffectual. The smaller Rhododendrons, the Cistuses, and the Helianthemums-to mention only three genera-will provide bloom practically 

" THE BROOMS COMPRISE SPECIES OF WIDEIY VARYING HABIT ADMIRABLY ADAPTED FOR THE ROCKERY."

(See page $\mathbf{1 7 7 . )}$

Cytisus pracox and C. Kewensis are here shown.

Painted by G. SOPER. 


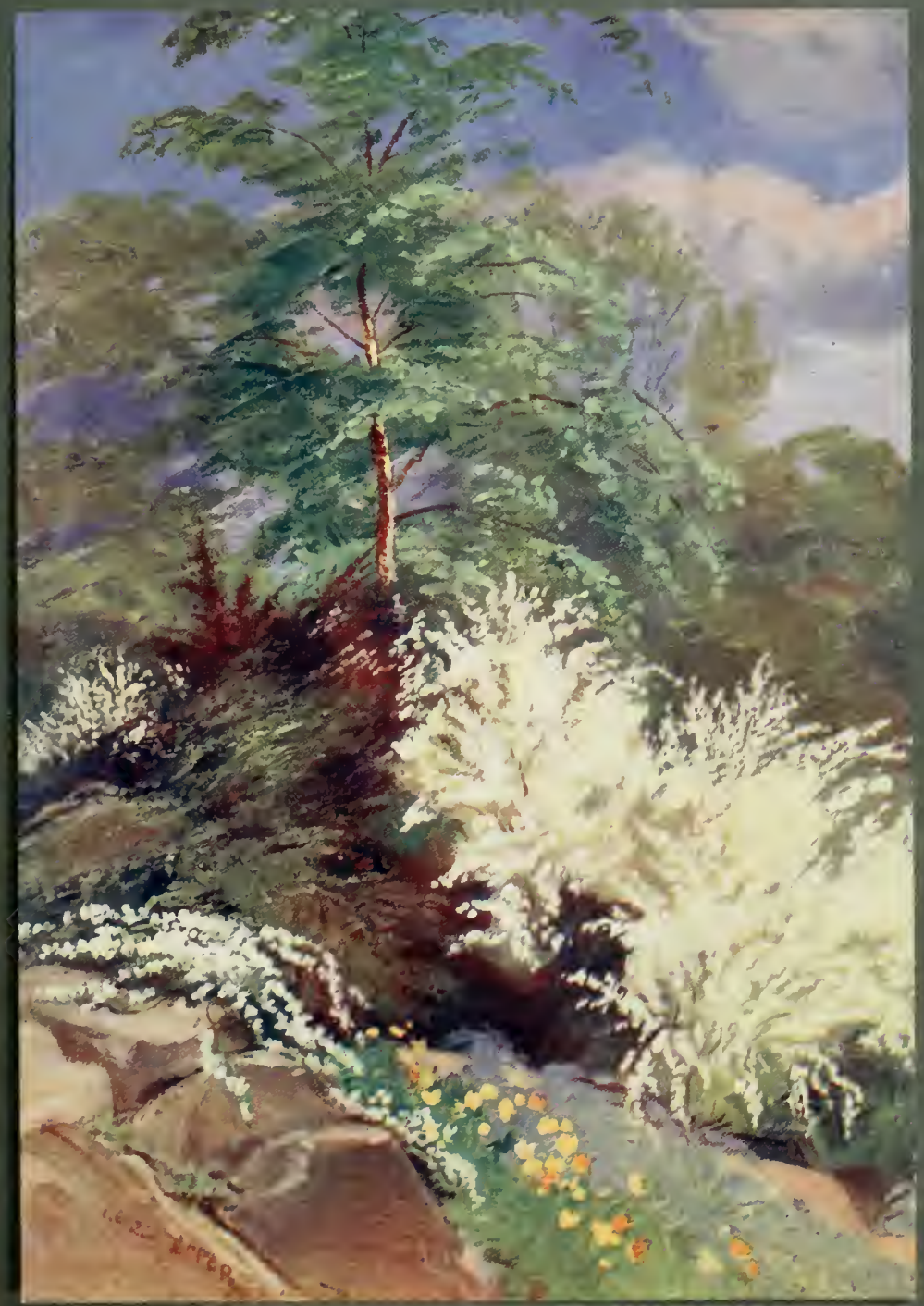




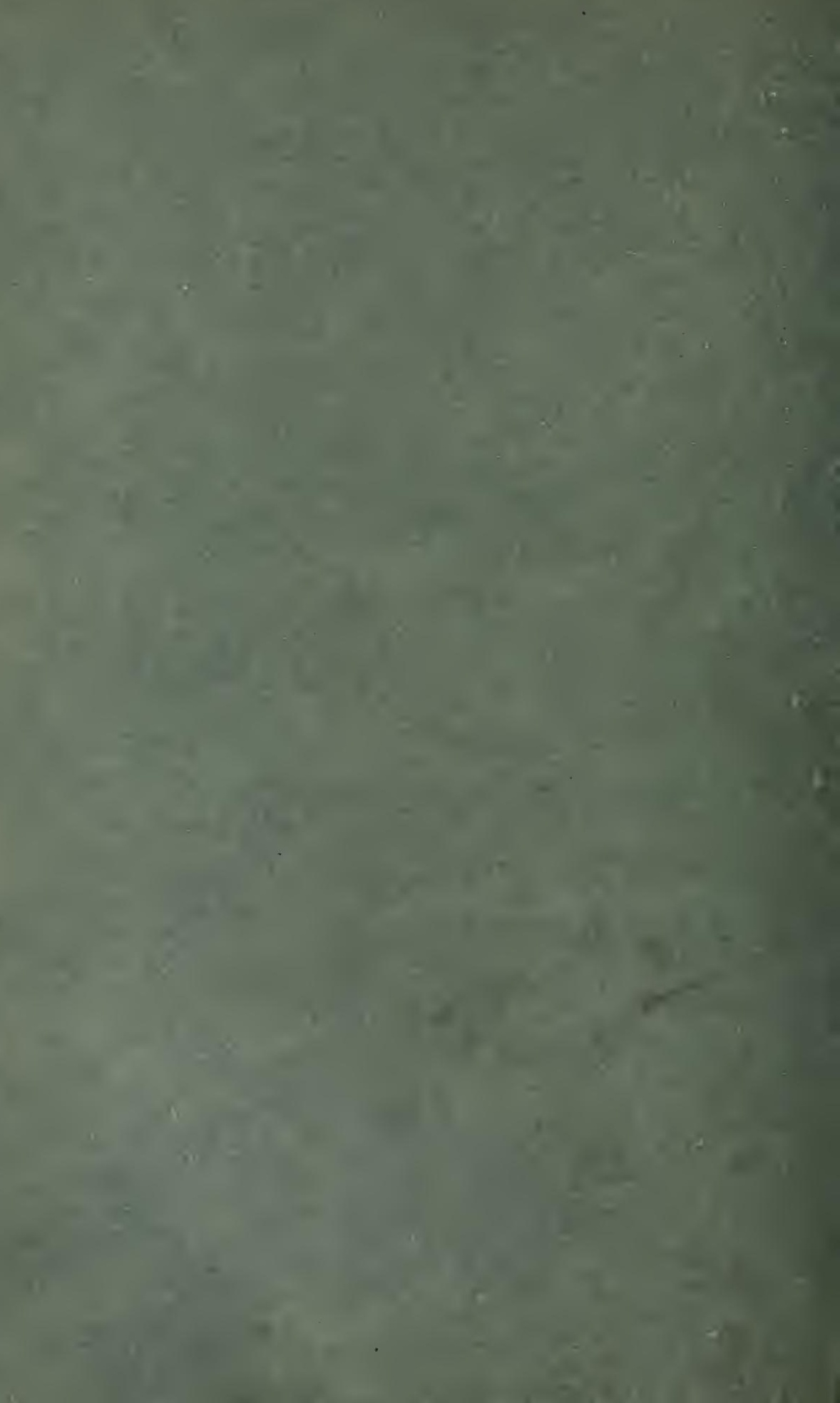


throughout the summer, and there will be no period of the year when they are other than ornamental.

The rock-gardener is apt to overlook shrubs because they are associated in his mind with bulky blocks of uninteresting evergreens. $\mathrm{He}$ does not realize the wide range of shrub-habit and beauty. He does not consider that many shrubs are truly Alpine in character, and are never better placed than among stones. The common coarse evergreens have nothing in common with these subjects, except the mere physical fact that they bear their stems throughout the year.

In a garden that is planned with real art the shrub and rock gardens will be so interwoven that they cannot be separated. Groups of shrubs will be planted at the approaches to the garden, and also on the mounds within it. They will be in character with their surroundings. They will bear a proportion in size and habit to the conformation of the ground and the mounds and stones.

We may very well consider some of the shrubs best suited to the purpose in view.

Visitors to Switzerland will be familiar with the Alpine Rose, Rhododendron ferrugineum, coloured figures of which appear in the sister volume, "Alpine Flowers and Rock Gardens." This beautiful little evergreen grows about a foot high, and has foliage resembling Box. It bears small umbels of tubular rosy flowers. There is a white form called alba or albiflorum.

Another Alpine Rose is R. hirsutum, which is likewise a dwarf evergreen, with hairy leaves, and red, 

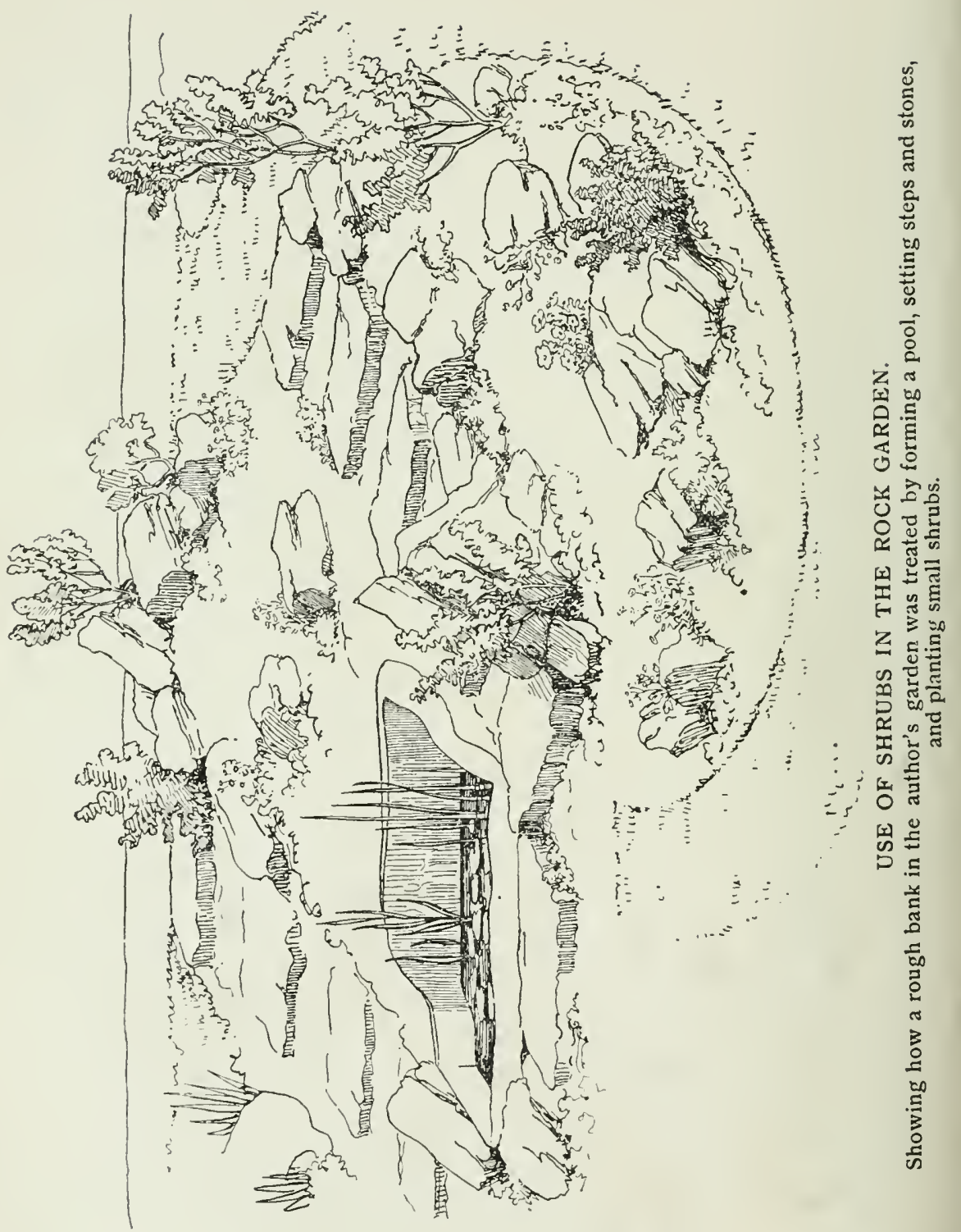
funnel-shaped flowers in umbels. A coloured plate appears in "Alpine Flowers and Rock Gardens," showing the plant growing below Pinus Cembra, the bright umbels of bloom admirably displayed by the greygreen foliage of the Pine. There is a white form.

There is considerable interest in $\mathrm{R}$. intricatum, an evergreen species introduced from Yunnan by Wilson, as recently as I907. It has very small scaly leaves on much crowded branches. It is often seen bearing its small mauve flowers when no more than six inches high, and is not likely to grow over two feet. It is not, however, hardy enough to be planted in cold districts.

Another modern species from China and happily more hardy than intricatum, is $\mathrm{R}$. flavidum (primulinum) a dwarf evergreen with Myrtle-like leaves and pale yellow, bell-shaped flowers in clusters. This plant must not be confused with $\mathrm{R}$. flavum (Azalea pontica).

R. Przewalskii is a Chinese evergreen species, compact in habit, with white bell-shaped flowers.

$R$. racemosum is a deciduous shrub from Yunnan, dwarf and compact, with white or pale rose flowers in clusters along the branches.

Among the hybrid Rhododendrons Early Gem is one of the most suitable, for it is dwarf and blooms freely. The colour is rosy lilac. This plant is often forced in pots. R. compactum multiflorum could be planted. R. arbutifolium, myrtifolium, and Wilsonianum, all with rose flowers, are other dwarf hybrids well suited to the rock garden.

The shrub-lover whose soil is free from lime should 
endeavour to plant a selection of these dwarf Rhododendrons in his rock garden. They will serveadmirably for the upper parts of rock beds. Although they love peaty soil they must not be planted in wet, undrained bog, as they dislike stagnant moisture at the roots.

The Heaths and species of Erica will serve the same purpose as Rhododendrons and thrive under similar conditions-that is, in peaty soil on elevated, welldrained sites. In districts where the natural soil is peaty Heaths should be planted freely on the upper part of sloping ground which is set with stones for alpines. Sharply-sloping ground forms a natural place for rock gardening, as with stones partially embedded in tiers to give an approach to the appearance which stones have when lying in their natural strata all semblance of artifice is done away with. Ericas carnea, ciliaris, codonodes and mediterranea may all be planted; the last two will sometimes tolerate lime. $\mathrm{E}$. carnea forms a dense carpet and is beautiful in early summer.

The allied plant known as St. David's Heath, Daboëcia (or Menziesia) polifolia, may also be planted with advantage. This beautiful little plant looks charming in a peaty bed near the base of a rockery, but the site must not be wet. It is essentially one of the things that should be planted in some quantity. Single plants have interest, of course, and better one than none; but the planter who can make a little colony of them will enjoy them most.

Similar remarks, alike as to interest, soil, site and planting, apply to the exquisite Pernettyas, the 

"THE THREE BEST DAPHNES, BLAGAYANA, CNEORUM, AND MEZEREUAI ARE ALL SUITABLE FOR THE ROCK GARDEN." (See page 176. )

Colour photo of D. Cneorum by R. A. Malby. 


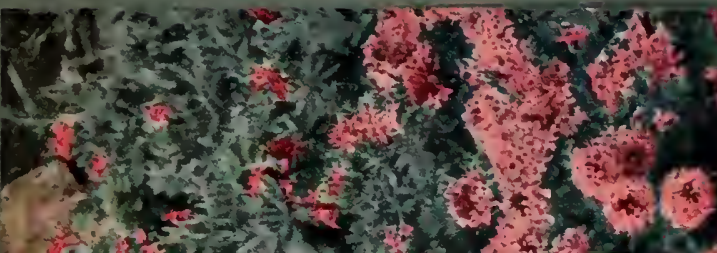

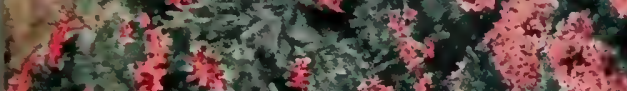

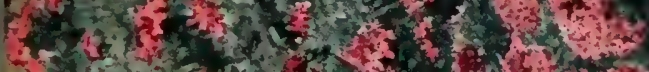

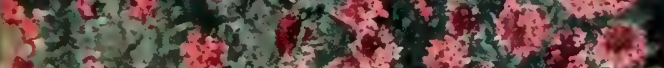

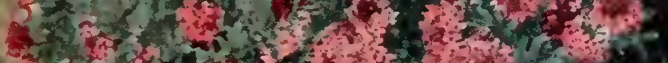

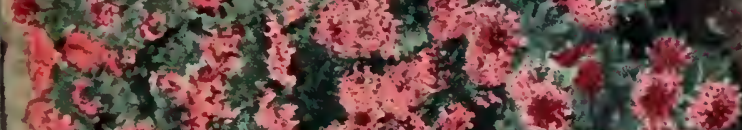

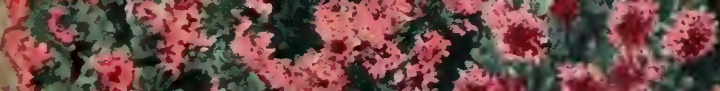

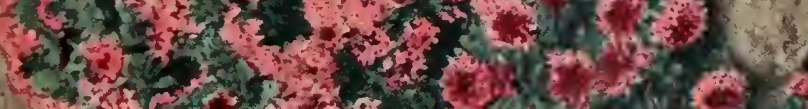

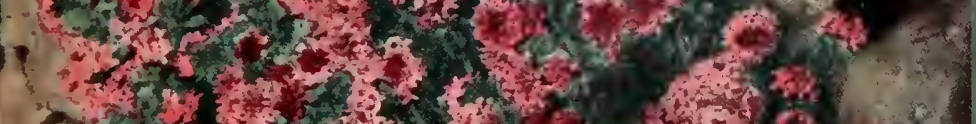

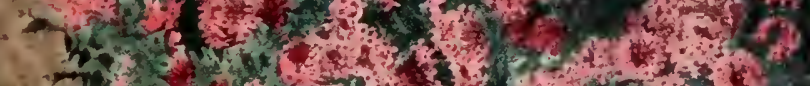

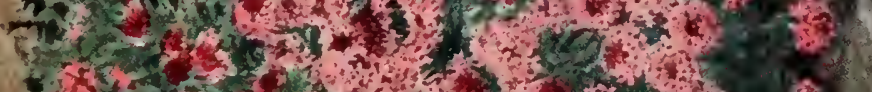

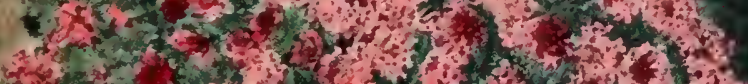

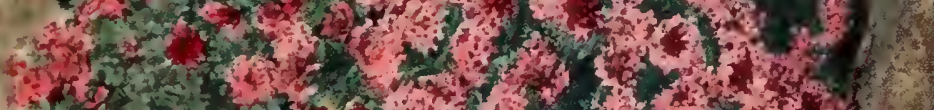

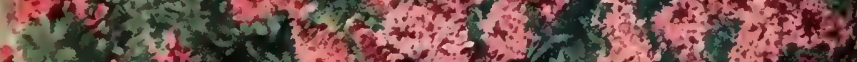

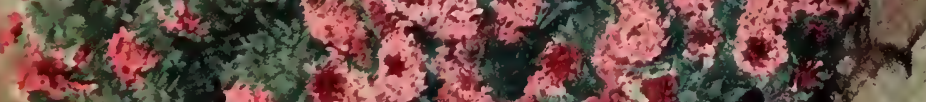

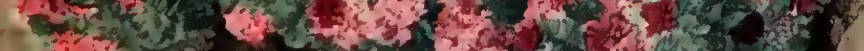

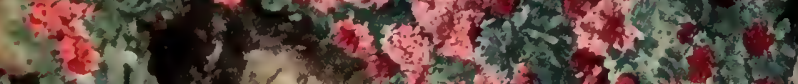

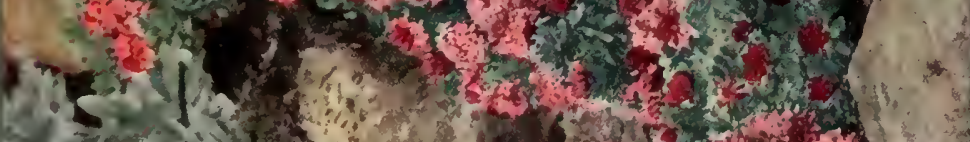

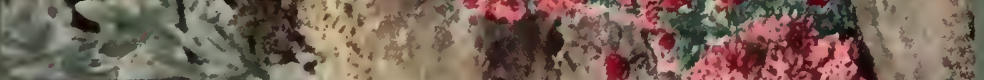
कासी intaril - 1.

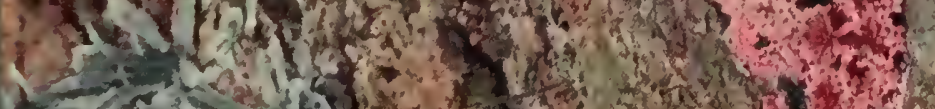
Ler. 


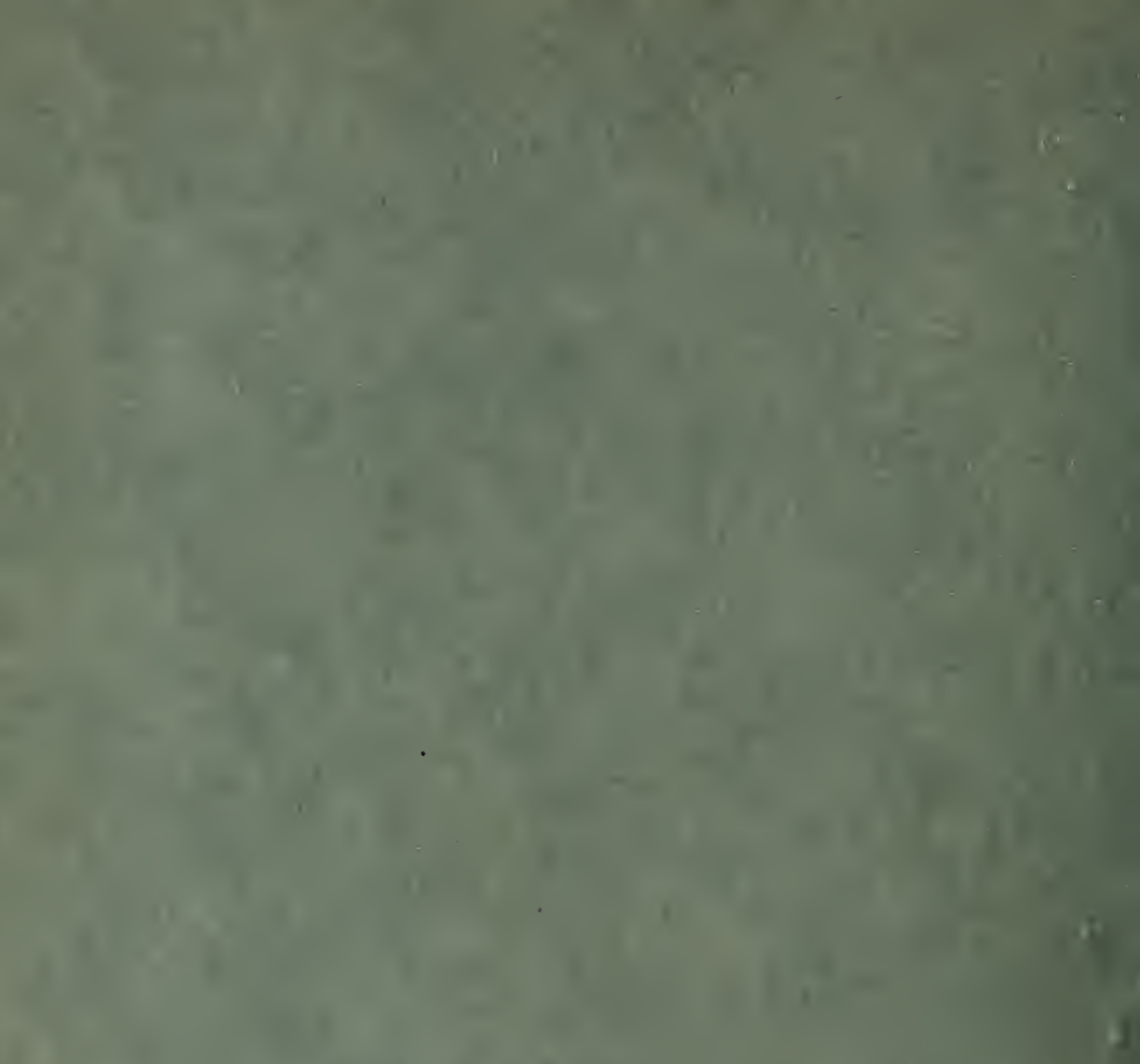

$-5$

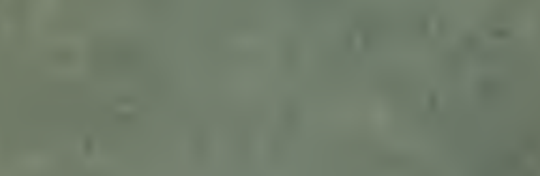

to
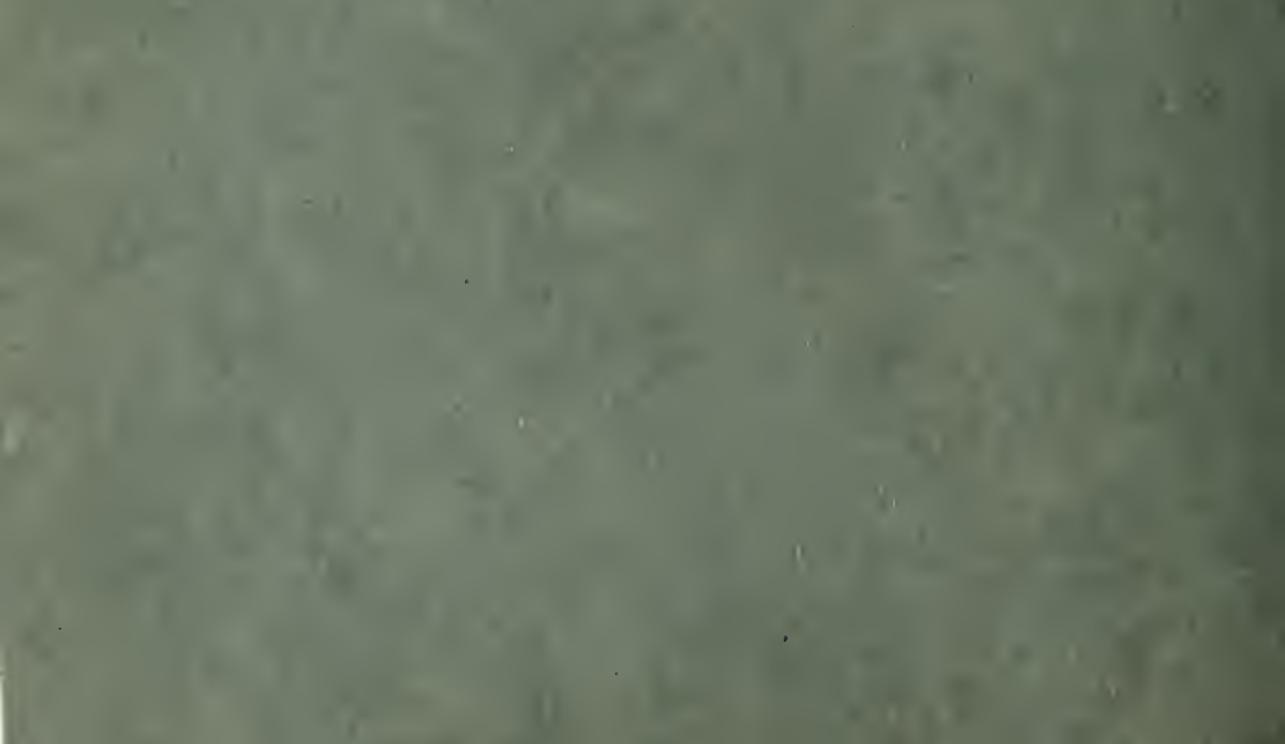
main interest in which lies in their pretty berries. These shrubs are also admirable for the rock garden.

A shrub which likes lime as much as the Rhododendron resents it is the Cistus or Rock Rose ; moreover, it is evergreen. It is the limestone garden-lover with hot, dry sites to furnish who will feel the deepest gratitude towards the Cistus. Vain is it to look towards the Ericacæe (an order, be it noted, that includes the Rhododendron as well as the Erica) when a parched southern slope on chalk has to be furnished. Wherever it can establish a foothold, be it only in a handful of soil on a limestone bank, the Cistus will thrive. The fact that its flowers only last a few hours need not repel the planter, for he will find that a long succession of bloom is produced, and more often than not when he examines the plants, throughout the summer, he will find flowers. The blossoms are as beautiful as great single white Roses, or Japanese Anemones. The species differ a good deal in habit. The nomenclature of the genus appears to be straightforward enough, but when one sees the plants in the large nurseries, it becomes apparent that great confusion exists, and a reference to Sweet's old work on Rock Roses shows that the same trouble was experienced many years ago. Salvifolius and corbariensis are sold indiscriminately; the former has a rounder leaf than the latter; both are grey-leaved, and comparatively dwarf. Still worse, cyprius, a quite different species, is sold for both the foregoing; it has a bronzy green leaf. 
Ladaniferus and longifolius florentinus are relatively tall. All those named have white flowers, but a form of ladaniferus, called maculatus, often sold as the type, has chocolate blotches. Crispus has purplish magenta flowers.

In poor limestone soil, on a hot dry site, none of the species is likely to grow more than three feet high, and they will not make large bushes, as they will do on better ground; it is a question, however, if they are not longer lived. Where the plants prove to he shortlived, it is prudent to put in a few cuttings annually, and they may be inserted in gritty soil in May.

A plant belonging to the same order as the Cistus, and likewise a hardy evergreen that will luxuriate on hot dry limestone soils, is the Helianthemum or Sun Rose. It is even more valuable than the Cistus, because it is lower and more spreading in habit and produces a profusion of brilliant flowers over a longer period. It is rarely out of bloom in summer, and the double forms are particularly lasting. The planter need not trouble about species here. He should get florists' named forms, such as Kitty, Primrose Dame, Pink Beauty, Fireball, Jubilee and Garibaldi.

The three best Daphnes, Blagayana, Cneorum and Mezereum, are all suitable for the rock garden. These little plants should have the special attention of the smallgardener, for they are neat and compact in growth. They give, too, delicious perfume.

Azaleas of the mollis and sinensis sections and hybrids between these species are, as we have seen in previous chapters, particularly adapted for beds on 
lawns, or for "bays " along the front of large shrubberies; but they may also be used in the rock garden, and they will be particularly at home in peat beds at the base of a large rock bank.

The Brooms comprise species of widely varying habit, and while Cytisus scoparius and its beautiful forms Andreanus and sulphureus, C. albus, C. præcox, and C. Dallimorei are perhaps best suited for borders and beds, dwarfer and prostrate kinds like C. Ardoini, yellow ; C. hirsutus, yellow ; C. kewensis, cream; C. purpureus, purple, and its forms albus, versicolor and incarnatus, and C. decumbens, yellow; are admirably adapted for the rockery. The last named species is often found under the name Genista prostrata, and an early yellow form called præcox (not the same as Cytisus præcox, which is a cream-coloured hybrid growing several feet high) is offered by florists. Of the Genistas proper, hispanica and its variety nana; tinctoria and its double variety ; germanica, sagittalis, and pilosa are suitable. G. tinctoria flore pleno is an excellent small yellow shrub.

The mountain Avens, Dryas octopetala, with white flowers, is a good plant.

The Magnolias are in the main too bulky for ordinary rock gardens, but there is one deciduous species that produces its glorious pure white flowers in advance of the leaves, which is of slow growth and compact habit; this is stellata. The rock-gardener should seize upon it as upon a gem of purest ray.

Among the species of Rose, which are a sealed book to many people who claim a considerable knowledge of 
Roses-natural species, be it understood, not nurseryman's varieties of hybrid origin-there are many beautiful and interesting plants, some of which can be brought into use for the larger rock gardens, especially where there are arid banks to cover. For this purpose Wichuraiana and its garden forms are admirably adapted. Rosa arvensis, the Ayrshire Rose, is also a straggly creeper. Of upright growers, cinnamomea and its varieties; sericea, an Indian species with white flowers; spinosissima and its forms altaica (white) and lutea (yellow); the dwarf alpina and its beautiful carmine form pyrenaica; likewise pimpinellifolia and xanthina, are all interesting. These Roses might be planted on the summits of mounds, the faces of which were planted with Alpines. Their light, free, graceful growth and abundance of pretty single flowers give a delighífully pleasing and natural effect.

A few selected Spiræas may be introduced with advantage. Decumbens (syn. procumbens) is a natura] trailer with white flowers.

The Veronicas comprise species suitable alike for their flowers and their foliage. V. cupressoides is grown for its habit and foliage ; it is quite cypress-like, and evergreen. V. Hectori, also an evergreen, has a pretty buff tint in the foliage in autumn and has attractive lilac flowers. Incana, repens and Teucrium are good carpeters, but these are herbaceous. Epacridea, with a buff tint in autumn, not quite hardy, pinguifolia, decumbens, and Traversii are all good.

Yuccas, such as filamentosa and gloriosa, will serve. Several of the smaller Conifers may be made use of 

"IN DISTRICTS WHERE THE NATURAL SOIL IS PEATY, HEATHS SHOULD BE PLANTED FREELY."

(See page I74.)

Erica carnea and alba.

Colour photo by R. A. Malby. 


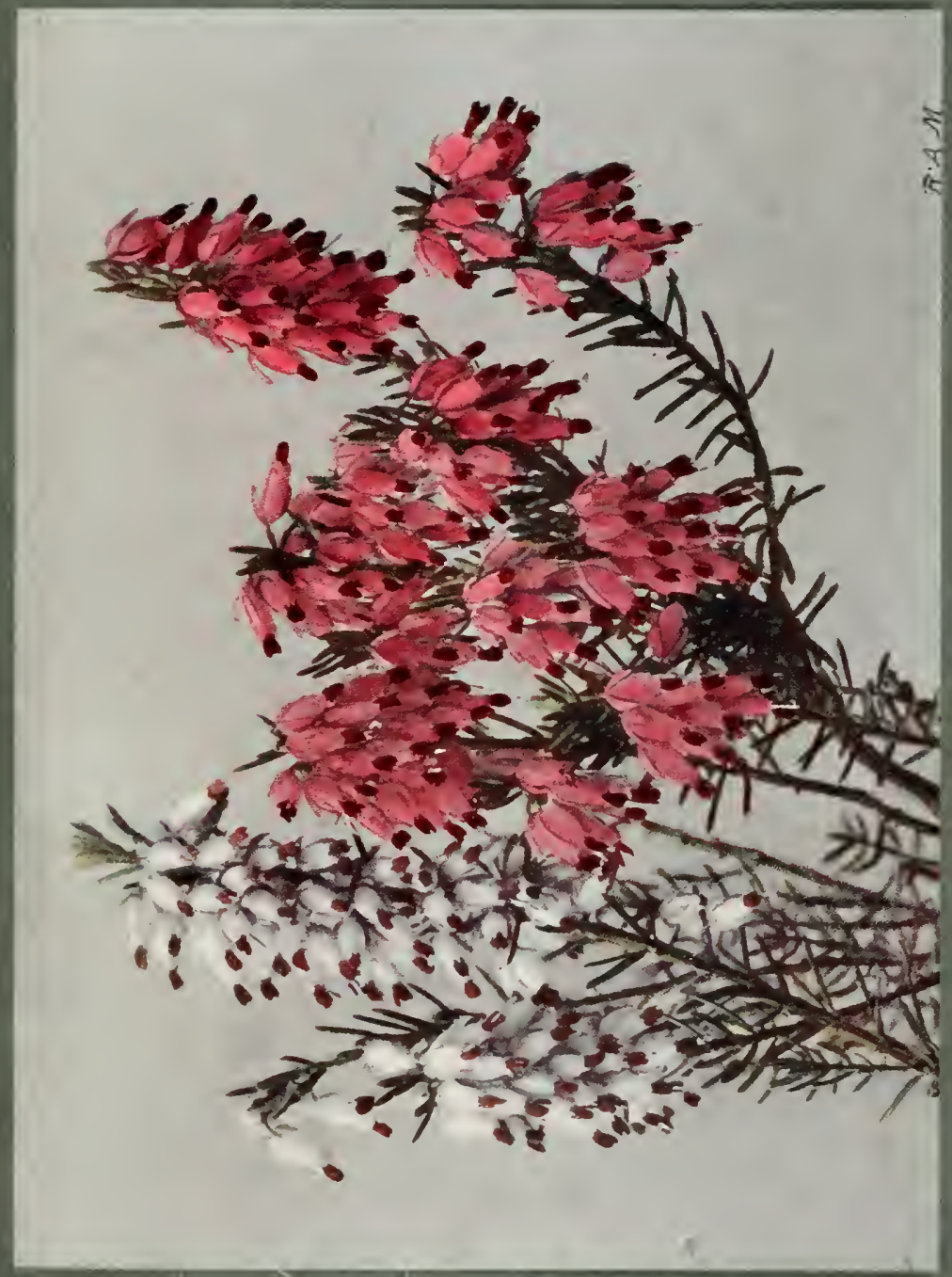



in the rock garden. Admirers of Japanese gardens will not fail to observe the way in which these evergreens are pressed into service. The smaller the garden the more cunningly are these little shrubs used to give an effect of space and distance. A proportion is carefully maintained between them and the other occupants of the garden. Picea (or Abies) clanbrasiliana, P. pumila, and its form glauca, P. pygmæa, Cupressus (or Retinospora) obtusa and its forms aurea, Crippsii, lycopodioides, and gracilis aurea, C. ericoides, C. pisifera and its form aurea, Juniperus Sabina and its forms, particularly tamariscifolia; J. hibernica compressa and Podocarpus alpinus are all well adapted for the purpose in view.

The creeping Cotoneasters, such as horizontalis and Dammeri, are admirable for rock gardens. They are close growers and have pretty berries.

Those who wish to practise Alpine gardening on poor soil, and whose means do not permit of importing better soil, should draw largely on small shrubs. They will be particularly useful in the early days of the garden, before the Alpines have become thoroughly established. 


\section{CHAPTER XX.}

\section{Shrubs and Trees for Town and Suburban Gardens and for the Garden City.}

THE Plane and Lime have long been regarded as the best trees of the town, but it behoves us to remember that several trees much more valuable than these for flower or leaf beauty-trees such as the many forms of Prunus, including the Almond, the Gean or Wild Cherry and the purple-leaved Plum, the Catalpa, the Mountain Ash, the False Acacia or Robinia, the Tree of Heaven (Ailanthus) and the Paulownia-will thrive in town gardens.

Those who learn their gardening from the civic authorities become wedded to the Plane, but it is more particularly a street tree. It certainly has its value, for it will endure impure air and flourish in ordinary soil. Moreover, it will bear a good deal of cutting. This is par excellence the London street tree. In Berlin, the Lime or Linden is favoured. This tree has a strong odour when in bloom, which some people find disagreeable; the point should be considered when selecting trees for positions near houses.

The Wych Elm will thrive in town gardens, and the Lombardy Poplar and Horse Chestnut are quite at home in the suburbs of the largest towns. It has been 
mentioned elsewhere that the Lombardy Poplar may be used as a kind of glorified hedge, for if planted about six feet apart and beheaded at eight feet, it will throw out a dense thicket of shoots from bottom to top of the main stem, thus forming a thick screen. It is a tree for utility rather than ornament.

The Horse Chestnut ought to be planted much more freely in the larger suburban garden than the Plane, the Lime, or the Poplar. It is neither columnar nor cabbagy; on the contrary, its habit is well balanced and symmetrical. It spreads sufficiently to give valuable shade and shelter. Of the beauty of its flowers nothing need be said.

The Sycamore and the Maple will thrive.

The Mulberry might be thought of as a distinct and interesting tree for the gardens of suburbs, small towns and garden cities.

The Laburnum and the double red and white Thorns may be planted in the suburbs and in garden cities where small flowering trees are wanted.

The Aucuba occupies the same position as a town shrub which the Plane fills as a town tree. It will grow almost anywhere, and it will thrive in shade.

As commonly seen, that is, in its variegated form and without berries, it is apt to look "tame." When well berried, however, and particularly if intermingled with the green-leaved berry-bearing form, it loses its monotonous effect. Planters should order both variegated and green-leaved berry-bearers or female trees, and also male trees to plant in the neighbourhood, for in this shrub the sexes are on different plants. 
Another good suburban and garden city shrub is the Euonymus, which will thrive quite close to the largest town. It is a lively and exhilarating shrub. The Japanese form should be chosen, because this is evergreen, and one of the brightest varieties of it is latifolius aureus, which is as good as a burst of sunshine on a winter day.

The Golden Elder, which botanists know as Sambucus nigra foliis aureis, is a good suburban shrub and may be grown as a hedge if desired.

There is nothing better for a low wall in a suburban or garden city enclosure than Pyrus (Cydonia) japonica ; for a pillar than the yellow winter Jasmine, nudiflorum; and for an arbour or arch than Clematis montana.

As flowering shrubs for the border, the following may be used: Amelanchier canadensis, Berberis aquifolium (B. Darwinii, B. stenophylla and others thrive splendidly at Kew and would do in the garden city), Colutea arborescens, the Bladder Senna; Daphne Mezereum (this will do in surburban gardens, near the largest towns and is deliciously scented), Deutzia crenata flore pleno, Forsythia suspensa and F. viridissima, Hypericum calycinum, Kerria japonica flore pleno, Lilacs, Philadelphus grandiflorus (large Mock Orange), Potentilla fruticosa (a low shrub that could be used for the rock garden), Rhus Cotinus, Ribes aureum, R. sanguineum and its forms (atrosanguineum is particularly rich in colour), Skimmia japonica, Weigelas and Yuccas.

A little consideration of the foregoing will serve to 
show that there is a much wider range of choice for the town, suburban and garden-city planter than is generally known. There are, of course, towns and towns. There are acid towns like Widnes, coal towns like Dudley, foundry towns like Lincoln, factory towns like Sheffield, residential towns like Winchester and Canterbury, garden-towns like Bournville, Letchworth and Port Sunlight. Very few shrubs or trees will succeed under the walls of huge works from the chimneys of which volumes of gritty smoke and smuts or noxious fumes are poured. But the largest of towns may be harmless to most vegetation if factories are few and well scattered.

The old kindly practice of planting trees for shade along town streets is reviving. In the new type of town we may expect to see wider thoroughfares than in the old, and not only that, but a liberal provision of corner sites and squares kept open for trees and shrubs. In fact, there is a movement-a noble and wholly beneficent movement-for wide streets and green corners in towns instead of narrow streets and tavern corners.

New communities have opportunities which the old did not enjoy. Urban authorities have a large and increasing mass of enlightened public opinion behind them, and there should be no such evils either in the towns or suburbs of the future as those which grew up in the old, and which still throw their evil shadow over the homes of the poor. 


\section{CHAPTER XXI.}

\section{Shrubs and Trees for Seaside Gardens.}

THE garden-wanderer who finds himself by the sea in winter never fails to note the cheerful colour of the Japanese Euonymuses, the bright glow of the Hollies and the healthful tint of a shrub which in mild spells may be full of bloom, the Laurustinus. Looking farther, he may see that sturdy evergreen Escallonia macrantha happy. These are lessons for him.

Before spring opens another beautiful evergreen, Berberis Darwinii, may be in bloom; and when it attains its full beauty there will be nothing to vie with it. Two things are important to the seaside gardener in connection with this shrub: that it will thrive on chalky soil, and that it will bear sharp shearing back. Some early pruning is good for it. Without that, it may tend to become gawky. One sees it sometimes tall, freely branched and tree-like. It is far from being without beauty in that state when in bloom, but as a pyramidal shrub eight or ten feet high, perfectly symmetrical, densely clothed in foliage, and in its season a mass of brilliant orange yellow flowers, it is in its most imposing garb. To secure that end, knife or shears must be brought into play, for short branches 
will be thrust out from the mass, and after (or before) blooming they should be shortened.

Other of the Barberries also love the sea air.

With liberal planting of the four splendid shrubs named, the seaside garden will be bright in winter and spring; but there are many other kinds to draw upon.

The Cotoneasters are charming, alike in leaf, flower and fruit. We have seen that microphylla is evergreen, and frigida partially so. These shrubs love the soft saline air of mild seaside places.

The Cistuses and Helianthemums, which, as we have seen in Chapter XIX., are invaluable for hot sites and shallow soils, will grow in perfection, and give flowers off and on throughout the summer.

The Ceanothuses will succeed, especially if planted near walls.

That beautiful Broom, Cytisus scoparius, and the still more beautiful hybrid form, Andreanus, will thrive.

All the Ivies will be happy, and in poor sandy soil there will be nothing so comfortable as the Sea Buckthorn, Hippophae rhamnoides, with its abundance of pretty berries.

Roses will thrive if the soil is good, but as a class they do not care for the light, sandy and gravelly soils which are often found in seaside gardens. The likeliest to thrive under such conditions are the hybrid Wichuraianas, which will be at home on banks, pillars and arches; and the great rugged Japanese Rose, Rosa rugosa, which forms dense clumps.

Of the smaller flowering trees none will be more 
contented than Thorns, Crabs (most kinds of Pyrus indeed), Bird Cherry and other Prunuses, Laburnum, Lilacs and Thorn.

One of the interesting features of summer will be the Tamarisk, whose graceful, charmingly tinted plumes grow in close masses - a harmony of brown and olive. This beautiful plant loves sea air, and if planted a yard apart will form a splendid garden hedge. It should be protected on the most exposed side with wattles in cold districts during winter.

Here already we have a wide range of material to choose from, but it can be still extended to bring in less familiar things: Atriplex Halimus, Baccaris halimifolia, all the Boxes, Coronilla Emerus, Elæagnuses of sorts (including bright varieties such as aurea marginata, Simoni variegata, glabra aurea, the silvery microphylla, and larger ones such as multiflorus and microphylla), the Forsythias, Halimodendron argenteum, the Junipers, the Laurels, Leycesteria formosa, the Lyciums, the Mock Oranges, the Olearias, the Honeysuckles, the Phillyræas, Rhamnus alaternus, Rhododendron catawbiense, the Ribes, the Willows, Shepherdia argentea, the Spanish Broom, the Snowberry (Symphoricarpus), Ulex europæus (Gorse), the Veronicas and the Yuccas. The hardy and vigorous Veronica Traversii will grow in the poorest limestone soil.

As a protecting Conifer there is nothing more useful than the Austrian Pine, which can be planted in thick belts on banks of poor soil, and will endure almost any degree of exposure. Pinus montana and the variety Mughus, P. Laricio, P. Pinaster, Cupressus Lawsoniana, 

ABUTILON VITIFOLIUM. A FREE FLOWERING SHRUB FOR A SHELTERED CORNER.

Colour photo by R. A. MALBY. 


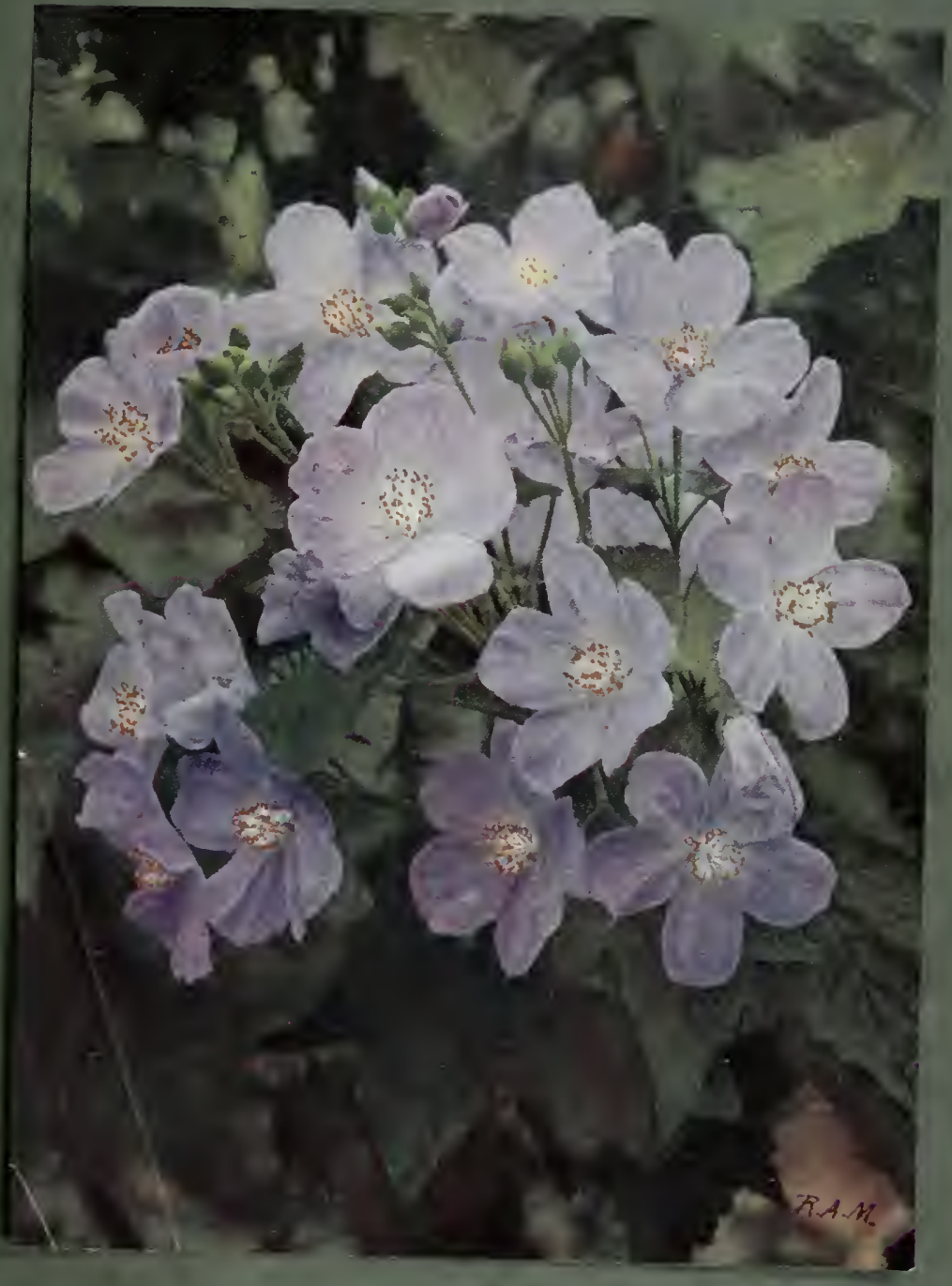



and its forms, and C. macrocarpa (the Monterey Cypress) will thrive.

Clematis Flammula will prove one of the best of creepers.

The Birch, the Beech, the Hornbeam, the Sycamore, the Ash, the Poplar, the Evergreen Oak and the Wych Elm will serve where large trees are wanted.

On very bleak, exposed places the list of trees must be restricted. The Austrian Pine, the Larch, the Corsican Pine and the Norway Spruce are good Conifers. The Beech and Hornbeam are useful trees, holding their brown leaves through the winter; seaside nurserymen often use the Beech for a hedge. The Ash, Poplar, Birch and Wych Elm are also good. The Thorns, the Hollies, the False Acacia (Robinia) and the White Willow will endure great hardships.

The shrubs that will best endure rude buffeting are Atriplex Halimus, the Aucubas, the Barberries, the Laurel, the Bladder Senna (Colutea) the Cotoneasters, the Brooms, the double Deutzia, the Euonymuses, Gorse, Halimodendron argenteum, the Junipers, the Privet, Lycium europæum, the Mock Orange, the Phillyræas, the Spanish Broom (Spartium junceum), the Ribes, the Snowberry, the Guelder Rose (Viburnum opulus sterile) and Veronica Traversii. The last named has remarkable tenacity of life, and will survive the roughest handling on the poorest, driest bank. 


\section{CHAPTER XXII.}

\section{Shrubs and Trees for the Waterside.}

THERE are subjects, such as the Willow, which become particularly associated with the waterside, because their love of moist places causes them to grow luxuriantly there. The Willow itself is not only well suited by such conditions, but possesses forms which droop gracefully over the water. There are, however, many other shrubs and trees besides this.

The water in a garden may be pool, lake or streamlet. There are cases where it is impracticable to drain a garden except by collecting the water in some low-lying part. If this is done, a pool, large or small, according to the size of the place and the rainfall, is formed.

Should a garden be drained? It depends upon the soil and situation. A garden-maker who has to operate on heavy, retentive soil, on a low-lying site, will find it much to his advantage to drain. Without drainage, it may happen that the surface soil is waterlogged for many weeks during winter, and this is as bad for most shrubs and trees as it is for most other kinds of plants. Such a soil, in such a situation, would certainly be improved by laying drain pipes or "tiles" in trenches about a yard deep, and five yards apart. 
It is not uncommon to drain land, but it is less common to retain the water which the drains collect. The general idea is to get rid of it by the simplest plan available, such as to turn it into the nearest ditch. But the garden-lover should think twice before deciding to get rid of the water. He should think during a dry spell in summer, as well as during a wet period in winter. If, in the latter, he is inclined to get the water off the place as quickly as possible, in the former he is likely to think only of how he can keep it.

When drain-pipes are laid, it is easy to arrange for them to converge on a low spot, and discharge their water into a prepared pool instead of into a ditch. The bottom may be puddled with clay or lined with concrete in cases where there is a doubt about sufficient water gathering to hold through the summer; but where it is reasonably certain, from the retentive nature of the subsoil, the size of the place, and the rainfall, that a good body of water will remain, no special provision need be made.

The one serious drawback to a pool which is fed merely by surface water, is that it tends to become stagnant and foul. There is not the constant change of water which occurs when a stream runs into and out of the pool. The true garden-lover will never permit such a pool to become a nuisance and an eyesore. He will plant it with water-lilies, and clean it out every few years, so that it is a feature of interest and beauty.

Another way of getting a pool or small lake in a garden, is to take advantage of the passage of a stream. At a selected point or points the bed may be widened. 
It may be possible, in some cases, to split a stream into two, taking the sections round an island mound.

There are, of course, instances where an area of swampy ground exists, which cannot conveniently and economically be drained. But the garden-lover is not helpless. He has it in his power to make what might be a "dismal swamp" or "slough of despond" an interesting feature of the garden by judicious treatment with proper plants.

We see, therefore, that "waterside" has a rather wide meaning for the gardener. It may be still or it may be running water. It may be a self-contained pool or it may be a lake with inlet and outlet. In any and every case, we can find means of dealing with it. Whatever it may be, we can seize upon it and convert it into a source of beauty and interest from the gardening point of view.

To deal with all the plants suitable for the waterside would be outside the scope of this work. Many of the best are Alpines or hardy herbaceous plants, and these have been dealt with in the sister volumes: "Alpine Flowers and Rock Gardens," and "Hardy Perennials and Herbaceous Borders." But there are many beautiful shrubs and trees which will supplement the good effect of the other classes, and these we may appropriately consider.

Of the larger trees one of the best is the White Poplar, or Abele, Populus alba, which attains to its finest proportions on a moist site. But practically all the Poplars will thrive in moist soil. The Aspen, Populus 


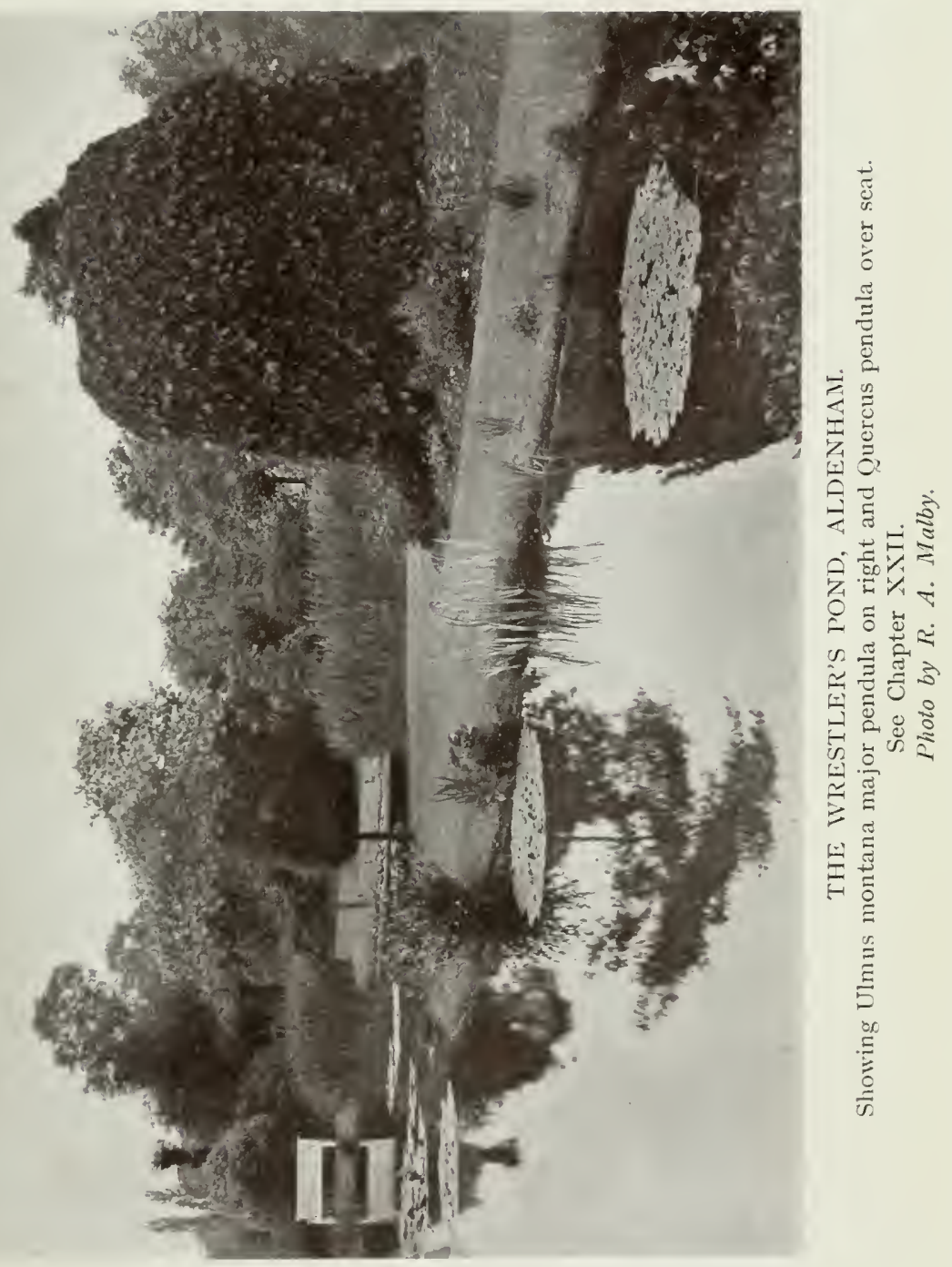




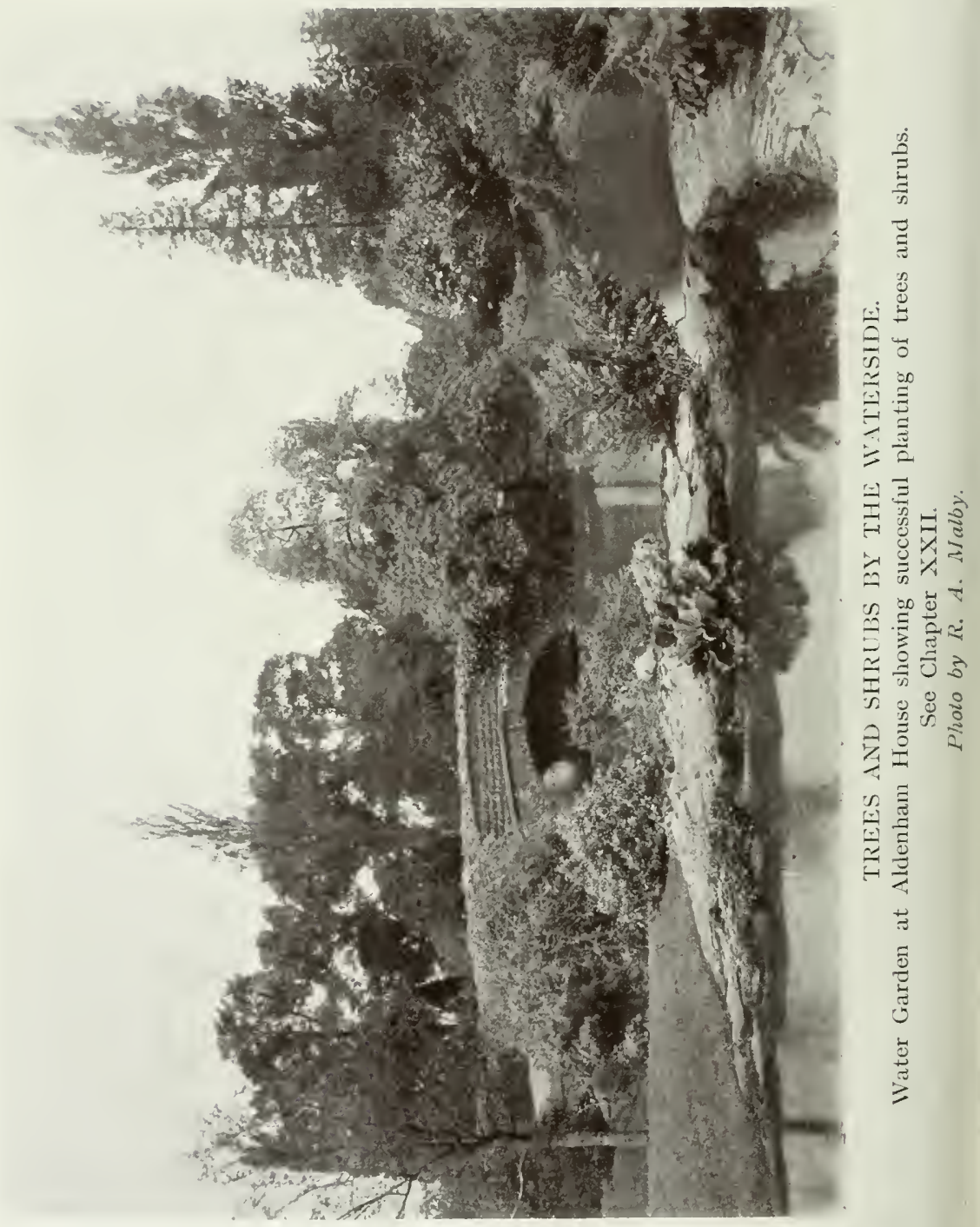


tremula, becomes a magnificent tree in a moist clay soil ; and its flickering leaves are never still.

The various Alders (Alnus) will also thrive, indeed, they naturally inhabit moist places. The yellowleaved form is bright.

The Ash, the water and swamp Oaks (Quercus aquatica and $Q$. palustris) and the Elder will succeed. Elders are fond of damp spots, and on such sites one may sometimes see thickets spring in a few years from bird-sown seeds if there is shelter.

Of the smaller trees, one of the best is the mountain Ash. Prunus Pissardii does not dislike a moist site, and its brown leaves are very telling.

Many of the Conifers will thrive, notably Abies Menziesii, the Cypresses, Austrian Pines, Tsuga canadensis, Thuja gigantea and Taxodium distichum. The last, the Deciduous Cypress, browns over in autumn.

As regards the Willows, there are two forms of the variety of White Willow (Salix alba) called vitellina, which are worth planting for their coloured stems, one yellow, the other red; they are sometimes called respectively the Golden Willow and the Cardinal Willow. There are several Weeping Willows. Perhaps the best known is Salix Babylonica, but the Kilmarnock Weeping Willow, which is a form of the Common Sallow, Salix caprea, called pendula, is very popular. There is a yellow-stemmed form of Babylonica called ramulis aureis. The Willows with coloured stems should be particularly considered, because they are so bright and cheerful in winter when the leaves are down. A line of Willows may often be planted with 
great effect to overhang a section of a stream. It may also be remembered that they may be planted in swampy spots. Here the Sallow comes in very useful. Its catkins are conspicuous in early spring.

With respect to flowering shrubs, few are likely to do better than the Viburnums, including the Guelder Rose, V. opulus sterile, and plicatum, the Dogwoods, Halesia tetraptera (the Snowdrop Tree), the Sweet Gale, Kalmia glauca, Berberis Darwinii, such Brambles as Rubus biflorus (with white stems), R. laciniatus and $\mathrm{R}$. fruticosus, the Cotoneasters, Ledum palustre, the Tamarisk, the red-berried Elder (Sambucus racemosa) and its forms such as laciniata and plumosa aurea, Spiræa Douglasi with red and S. Lindleyana with cream flowers (and of course the herbaceous meadow-sweets) and the fine Reed (Arundo donax) which is second only to Gynerium argenteum in beauty of white plume.

The stronger Bamboos, such as Arundinaria japonica, A. Simoni and Phyllostachys viridi-glaucescens, should be planted, for they will make noble clumps.

An idea for using the Bamboos is to set them in a series of isolated clumps alongside the approach to the water. For this purpose such imposing herbaceous plants as Rheum palmatum and Gunnera manicata will also be useful ; they produce gigantic leaves.

Elæagnus macrophylla is a handsome shrub for the margin of water. 


\section{CHAPTER XXIII.}

\section{The Clipped Trees of the old Dutch Garden.}

THE astute garden-lover will always make a point of paying periodical visits to the larger nursery-gardens, for not only will he be able to select plants there from many growing together of the kinds he wants, but he will also learn what is in favour with the public. The nursery is a true reflection of current taste in plants.

During recent years, the visitor to these places will have seen a feature that he did not see in them ten years previously, and that is a colony of clipped shrubs, mostly Confers, reminding him of the quaint figures seen in pictures of old Dutch gardens. Prim are they, and yet with an odd air of perky make-believe about them, like a dog with a shaven back and tufted tail-selfimportant, but humorously unreal. Grouped together in the nursery, they form a strange conglomerate, for some are cut into the shape of animals or birds and others into the form of domestic articles. They have a bizarre, almost a ludicrous, appearance. But in the garden they are not huddled in this way; on the contrary, they are put in selected places, to vary the interest of the garden.

The revival of topiary has caused heart-searchings to the Nature school of gardeners, who are oppressed 
by forebodings of a return to the stiff garden of past years. There is no more fear of this than of a general return to ruffs and wigs. Gardening is now so popular that every phase of it receives attention. The ripples of the wave have spread into remote backwaters, but they are only ripples.

Mural decoration, called topia, was practised in the houses of ancient Rome, and topiary is the adjectival form of the word applied to the clipping of trees and shrubs. Like topic and topical, the words come from topos, a place. Topiary work is certainly very old, and it reached the highest stage of popularity in the sixteenth and seventeenth centuries. The Yew was always the favourite subject, but the Box and Holly were also treated. All these shrubs will bear cutting with impunity.

When the reader reviews the extremes to which topiary went, he cannot wonder that a reaction set in against it. Examples are on record of dogs, fowls and pigs, as well as bottles, boats, seats, spirals, pyramids, tables, birds, jugs, crosses, umbrellas, wigwams, swans, lions and letters of the alphabet cut in Yew or Box.

It is quite likely that topiary first began in the clipping of trees to make them uniform with the architecture of houses among the ancient Greeks. From that to a peacock was not so long a step if we consider that that resplendent bird has long been given a place of honour on the terraces of great mansions. It is beyond doubt that the Romans practised topiary largely. 


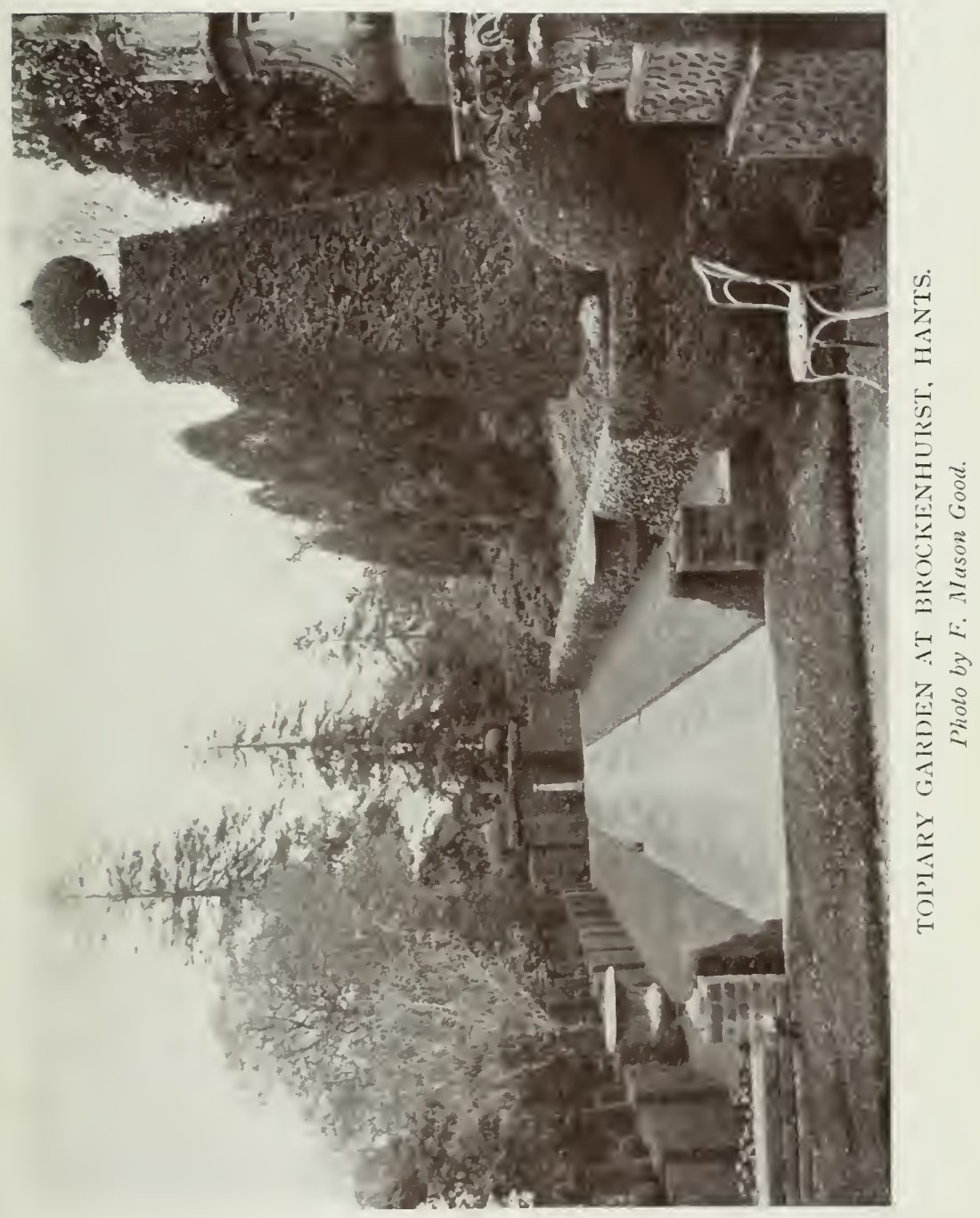




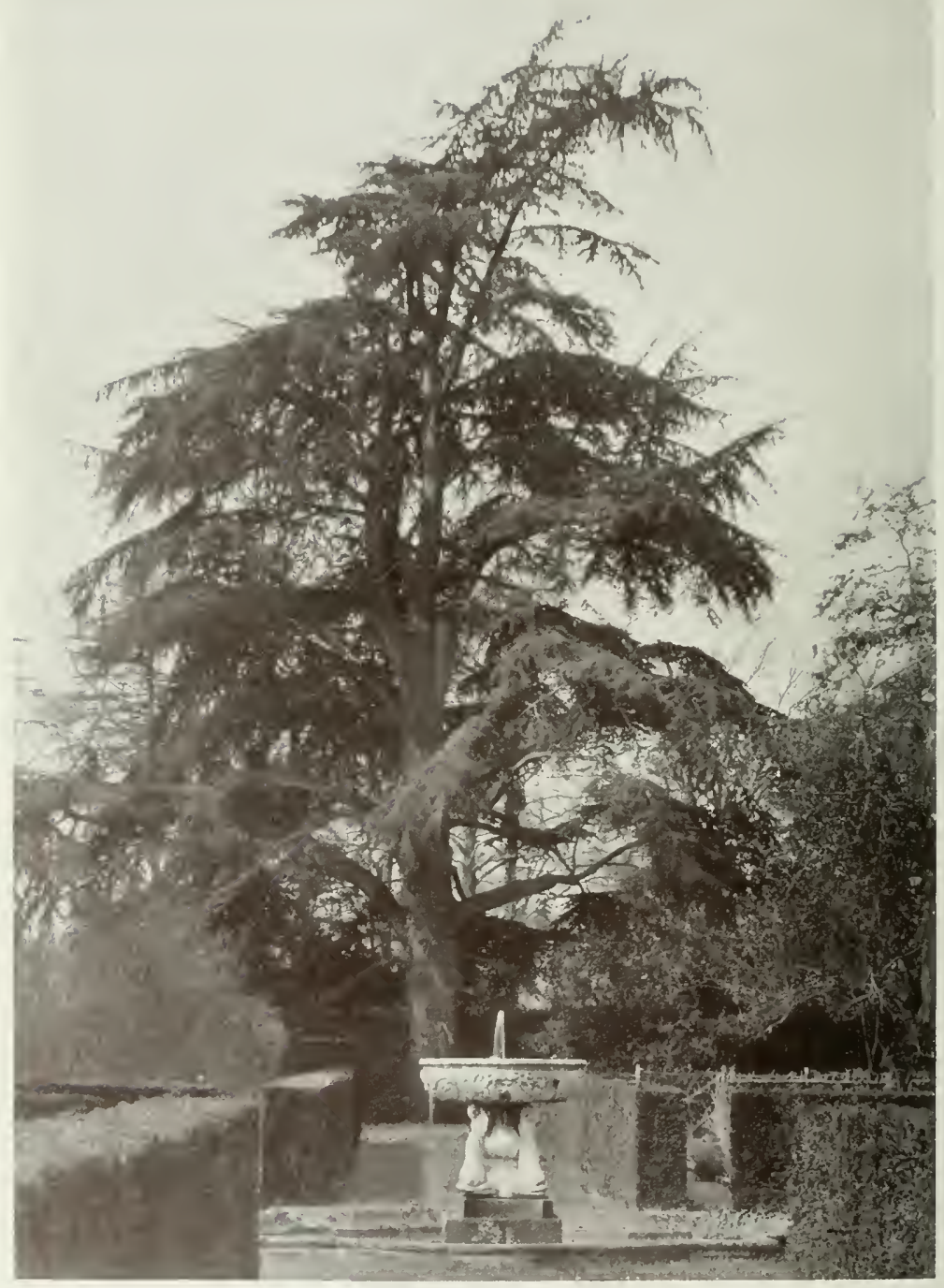

GARDEN SOLITLDE.

A Cedar dreaming by the fountain. For description see Chapter XVII. Photo by R. A. Malby. 
It established itself firmly in England in the sixteenth century, and was highly popular in the seventeenth, when Charles II. brought over the famous maker of the gardens at Versailles, Le Notre. Levens Hall, the most famous centre of topiary in England to-day, was given its great feature by Beaumont, who was gardener to James II., and who had studied the methods of Le Notre.

Inasmuch as topiary work was very popular in Holland, it is not surprising that it was given a fillip in England when James II. made hasty way for William of Orange. "Little Hooknose" loved the clipped Yews of the Netherlands, and encouraged their spread in his new kingdom. The result was that topiary ran riot, and men of taste began to revolt against it. About the middle of the eighteenth century a reaction set in, and in a few years clipped trees all but disappeared from gardens. It was not only landscape gardeners like Kent, Bridgeman and Brown, but prominent writers such as Pope and Addison, who attacked them. One can believe that it was the pen which finally vanquished the shears. Topiary still flourished in Holland, and when, towards the end of the nineteenth century, there was something in the nature of a revival, it was from the Netherlands that our traders got their most striking examples. They brought together collections at the large shows, and people paused to gaze in curiosity. Here and there a person bought, and there were just sufficient customers to make the trade fairly lucrative to two or three firms. 
Remarkable examples of topiary work still exist in some of the larger English gardens. Levens Hall, Westmorland; and Elvaston Castle, Derby, are two of the most complete, but examples may be found at such places as Compton Wynyates, Mentham Court, Sussex ; Montacute, Somerset ; Heslington, Yorkshire; Ascott, Buckinghamshire; Wiťley Court, Worcestershire; Friar Park, Oxfordshire; and in many other gardens. Almost every village shows some specimen or another, if only in the form of a pyramidal Yew or dome-shaped Box. And we must remember that in every one of the many gardens in which we see a Yew hedge we see an example of simple topiary.

What can be said in favour of clipped trees? A well arranged rock garden gives pleasure because it shows beautiful Alpine plants growing in a natural way. In herbaceous borders plants are grouped for colour effects at various seasons of the year. Beds of flowering shrubs give pretty leaf tints in early spring and in autumn, flowers in spring or summer, and in some cases brightly coloured berries in winter. The Rose garden shows the Queen of flowers in beds and on arches, chains and pillars. What does topiary work give us in the way of garden beauty and interest ?

The answer must be that topiary is not in any sense gardening as we understand it to-day, and it can only serve a special and quite limited purpose in gardens. It can form one of many features in a large garden. There are garden-lovers whose tastes are catholic, whose means are ample, and who have a wide circle of friends. One can imagine a member of this favoured 
class who opens his garden freely to his acquaintances (and perhaps, on occasion, and for a particular purpose, to the public) adding a collection of clipped trees to the attractions of his garden, as much to interest his visitors as to please himself. He has an Alpine garden, he has herbaceous borders, he has a Rose garden, he has a Shakespeare garden ; to those and other features he adds a topiary garden.

Or there may be a person who loves to recall the sense of old-time peace, seclusion and deliberation. His mind is in the stately, slow-pacing past. He dislikes modern flare and clangour. He sighs for the quietude and perfume of the serene, placid, mellow, old-world garden. The upbuilding of rock gardens impresses him as rather tawdry mal:e-believe, springing from the modern Swiss conducted tour at so many guineas per head. He looks on the herbaceous border as assertive and even violent. Such a person would be happiest in a garden surrounded by tall, thick hedges of Yew, with perhaps a collection of soft-tinted Tea Roses, or of border Carnations, by way of flower-beauty.

There is, perhaps, a suspicion of primness, as certainly there is much of dignity, about such a personality. The mind is composed, reflective, and orderly. One can well imagine it clinging to tradition. It will love the mellowness of old architecture. It has a rich, ripe conservatism. It communes with the old poets and essayists.

There is a suggestion of permanence, of discipline, of substance about an old clipped Yew. It is not an ephemeral thing. It is of the old order. It is a piece 
of solid architecture, like a weather-stained building that has withstood the tempests of centuries. It is not of the giddy modern generation. And because of its suggestions and associations, it presents a strong appeal to the type of mind indicated.

The reader may have walked among carven trees in some great garden. Has he not found himself overtaken by a hush, a sense of repose? Has not his step lagged involuntarily? Has not the pungent smell of the Box taken him back into his own past? From the moment that he walked under the Yew arch at the entrance of the garden he found himself in another atmosphere. His mood became subdued, almost reverential. He felt himself in commune with the spirits of the mighty dead.

Let us not, then, dismiss topiary in all cases as freak gardening. It is not in a freakish spirit that clipped trees are planted and tended in many places, but out of a genuine respect for the spirit of a past age. 


\section{CHAPTER XXIV.}

\section{Shrubs and Trees for Hedges.}

THE modern gardener has a laudable wish to combine ornament with utility, and even in the case of so plain a thing as a hedge, he seeks to bring in the garden spirit. There are, however, certain practical considerations. Boundary hedges may line public roads, and county surveyors do not care to see hedges grow tall and loose, because of the shade they throw on the road and the check to drying which they cause. Or the hedges may bound fields in which stock feeds, and in this case the planting is governed by the habits of the animals. Horses have no protective instinct which will stop them from eating Yew; although it is poisonous to them. Sheep will desert grass for Privet, and play havoc with a young hedge of that popular shrub if they can gain access to it.

The tall, tangled, mixed hedge of many waysides is a thing of joy. It way be a compound of Hawthorn, Dog Rose, Bramble, Wayfaring Tree, Hazel, Sloe, and Sweetbriar. There will be bloom on it from the earliest days of spring, when

The first green shoots of tender corn

Show on the plough; when the first drift of white

Stars the black branches of the spiky thorn. 
Throughout the summer it will be alive with bloom and fruit, and in the autumn it may be sprayed over with the profuse feathery achenes of the Traveller's foy.

These wild and riotous old hedges linger along the countryside, where roads look after themselves, and farming is not keen. They are the development of a century or more, and successive generations of farmers tolerate them. The birds love them. The village children delight in them. Nuts, Elderberries, Blackberries, and Sloes are gathered from them.

Can we have these grand old hedges in our gardens? We can, with time; but they can never be forced like mushrooms. Even a plain Quick hedge will take ten years to grow into a thick mass four feet high and capable of barring heavy stock. Quick (Hawthorn) is certainly the best all-round boundary hedge. It requires to be protected from cattle while young, but when it has thickened and stiffened it will be hedge and fence in one. A Quick hedge should never be hurried. A good way of dealing with it is to plant it nine inches apart, in a double row, shorten the plants to a foot high, and each subsequent year to shear the annual growth back to nine inches in winter. A hedge thus taken by stages or tiers will thicken at the base and become dense and hard in every part. The farmer's man generally prunes a Quick hedge annually either with a billhook or with a "bagging hook." In the former case, he uses both hands to the tool, in the latter, he has the "hook" in one hand and a hooked stick in the other.

When the Quick is planted, Brambles, Wild Roses, Sloes and other things may be put in with it if desired. 
There is nothing in any way picturesque about a Privet hedge. Its great value lies in its rapid growth and great sheltering powers. Even if it does not retain its leaves through the winter (and in hard winters the oval-leaved variety will cast most of its foliage, in spite of the fact that it is nominally evergreen) it will, if well managed, afford a good deal of shelter, because it will be full of twiggy growth. Good management here means hard and regular cutting back, as with Quick. Privet is generally cut twice-in June and in September-and a pair of shears are used. Plant a foot apart. Even in poor chalky soil, a good hedge of Privet may be built up in six years, so that it has at least one advantage over Quick. But it is never really fence and hedge in one, like the latter, for stock are fond of it, whereas Quick, when well hardened, is obnoxious to them on account of its abundant thorns. Animals may nibble at its soft green tips, but will never eat much of it.

The most useful of hedges for giving quick dense shelter is certainly Laurel, for on almost any soil it will be a dense mass five feet high in four or five years, unless the site is very much exposed to cold winds; but it is not suitable for a boundary hedge, because cattle eat it down relentlessly. It has great vitality and growth will spring from hard wood when old bushes are pruned; but it is an advantage to clip it while the growth is young: because the work can be done quicker with the shears than the knife. Young plants about two feet high could be put in four feet apart ; they need not then be cut back. In the second 
year, at the most, they would begin to interlace, and in the third would give appreciable shelter. From this time shearing may begin and the hedge outline formed. Afterwards there will be no difficulty for Laurel is nearly always growing and fresh shoots follow rapidly on the cutting. Prune in early summer.

Yew is suitable for garden, but not for boundary hedges. It grows slowly while young, and ten years will be required to make anything like a hedge. But if Yew is deliberate it is lasting. The plant is both very hardy and very long-lived. And a dense, thick hedge of it, four feet or more through, is a splendid shelter. It should be clipped in late spring. It is poisonous to animals.

There are many other hedge materials. The Myrobalan Plum is excellent, and is largely used as a substitute for Quick and Privet. It has one advantage over Quick in its more rapid growth. It should be treated in the same way.

Beech and Hornbeam are both used, more particularly by nurserymen, who esteem them because they make excellent tall shelter hedges in a few years, and, although deciduous, hold their leaves so thickly and so long as to have almost the value of evergreens.

When inner garden hedges-or even boundary hedges so long as there is protection - are considered, the names of several interesting plants arise. What more beautiful hedge could there be than one of Berberis Darwinii ? This splendid evergreen is always attractive, and in spring it is glorious in its mantle of orange bloom. It thrives in most soils, does well near the sea, and bears 


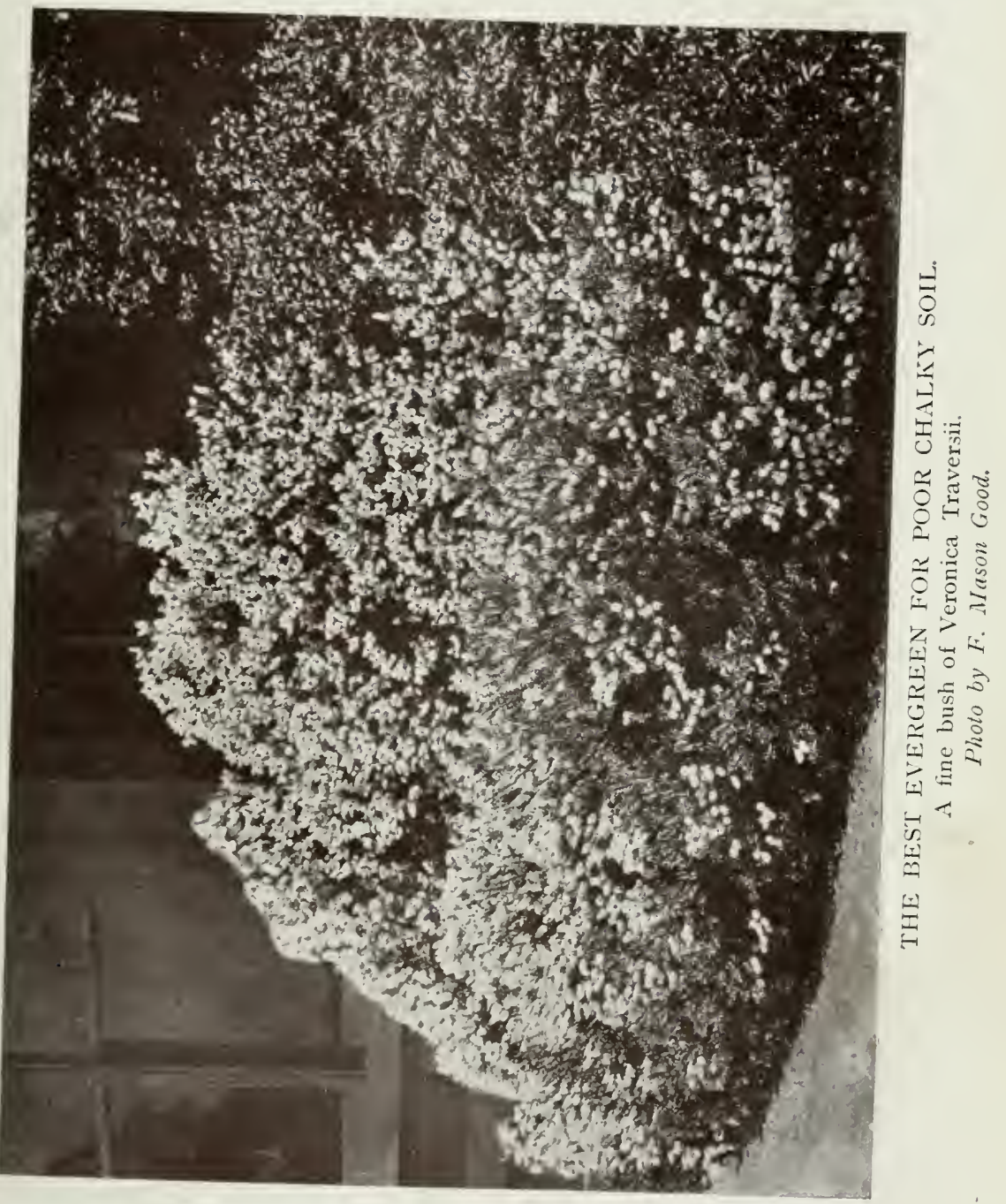




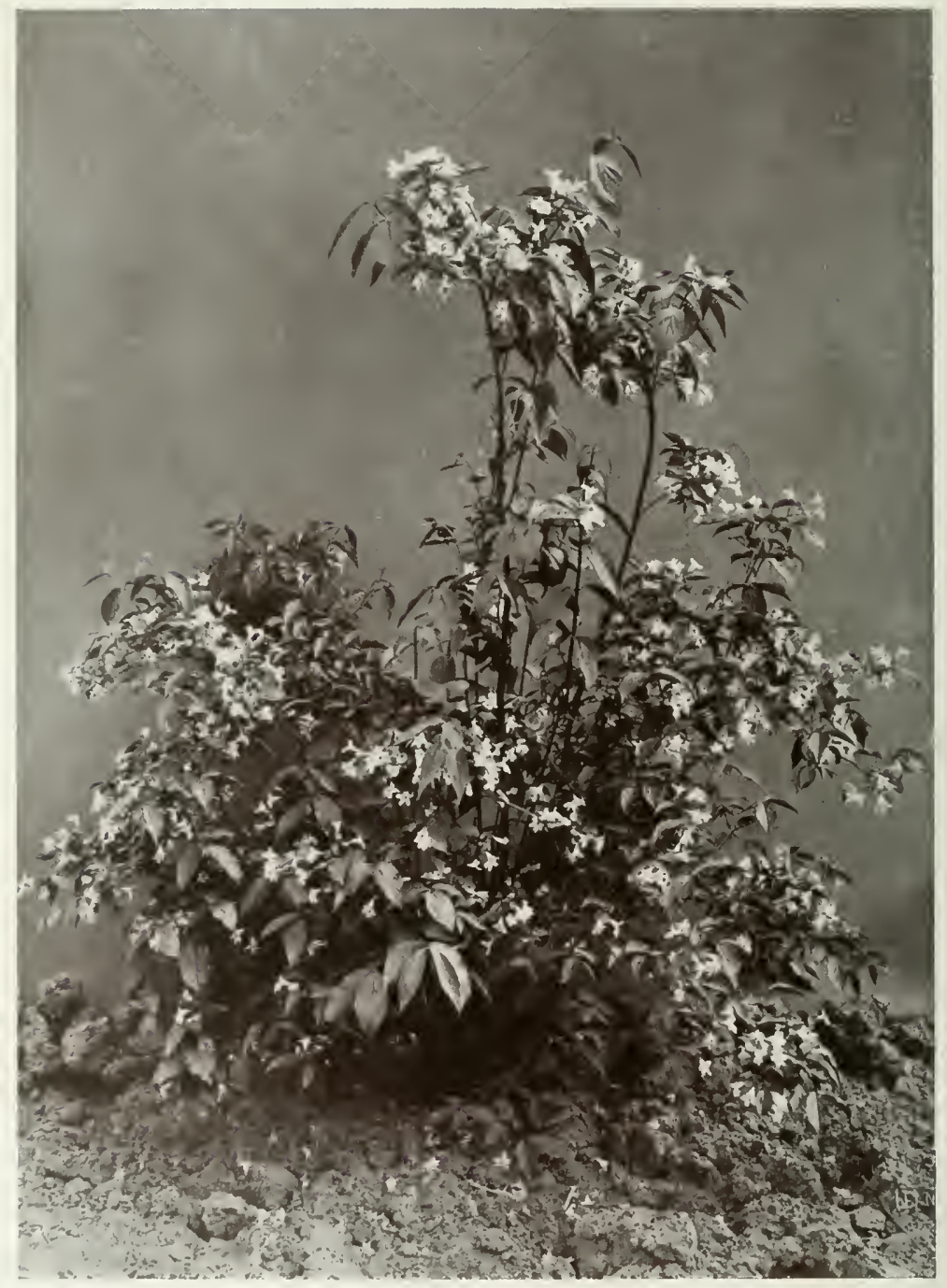

DIPELTA FLORIBUNDA $\triangle T$ KEIV.

Photo by E. J. Walls. 
cutting. And a hedge of Sweetbriar is worth thinking of, because, apart from its intrinsic beauty, it is delicious after rain. The Snowberry (Symphoricarpus) and Lavender are also available.

We must not forget Holly, which makes a splendid hedge in its own good time. It will move very slowly for the first four or five years, afterwards much more quickly. Early autumn is a good planting and late summer a good pruning time. Quite small plants, about two feet high, should be put in eighteen inches apart.

We have seen good hedges of the American Arborvitæ (Thuja occidentalis) produced by sharp cutting back for a few years. By thus pruning them while they are young, before the wood has time to get hard, they can be induced to make dense bushes. Cupressus Lawsoniana is also excellent.

Box is perhaps more used as an edging than a hedge, but for a low inner hedge there are few things better ; there will be no dulness if a yellow tinted form is chosen. The Golden Japanese Euonymus also makes a bright, cheerful low hedge. Plant both of these a foot apart.

As between a square-topped and a conical hedge, there is this practical point - the former will hold a great deal of snow and the latter will not. Hedges are generally cut into a conical form. They widen gradually from the bottom to the middle, and then narrow again towards the top. This is merely a matter for judgment in pruning. But there need be no hesitation in having a square-topped Yew or Laurel hedge, for 
these plants are not easily broken down. When buying Yew stipulate for iransplanted stuff.

There is also a practical matter to consider in planting. When plants are to be set fairly closely, say eighteen inches apart or less, it will be better to cut a continuous trench for them than to make separate holes. This may be a foot or more wide and deep, according to the size of the root-ball; but in all cases the under soil should be broken up and manured after the top soil has been cut out and laid in a ridge at the side. In cases where the plants are to go two feet apart or more, holes may be made.

Beyond the annual pruning, there is not much cultural routine with hedges. Such subjects as Privet, Laurel, Beech, Hornbeam, Myrobalan Plum and Yew can fend for themselves. Every two years a dressing of manure may be given to Sweetbriar, Berberis, Box and Arbor-vitæ. Quick is benefited by annual digging along it. Privet should not have this treatment, Holly may be dug and manured until well established, after which it will look after itself.

We have seen the monotony of a hedge of common Holly broken by taking up shoots at every twenty-five feet or so, and budding them with a good variegated sort.

The garden-maker who wants a miniature hedge or glorified edging might plant the pretty silvery shrub Euonymus radicans variegata.

It has been mentioned in another chapter that when the Lombardy Poplar is planted closely and headed at about eight feet high, it throws out a mass of side shoots and becomes practically a tall hedge. 


\section{CHAPTER XXV.}

\section{Shrubs for Shady Places and Undergrowth.}

SHADE is grateful in hot summer weather, and in planting trees the fact that they will break the fierce rays of the sun in the dog days is a strong consideration with many garden-lovers.

A garden without shade is as incomplete as a garden without shelter, but there is this difference, that shade pertains rather to the comfort of human beings than that of plants. To the latter, shelter means much benefit, while shade may be inimical to them. Alpine plants, herbaceous perennials, Roses, flowering shrubs, indeed the vast majority of the most important plants, love and are benefited by sunshine.

As a rule, it is quite easy to arrange a garden in such a way that the larger trees shall not, when developed, overhang the principal plants. The point is of great importance, because the drip from trees acts adversely as well as the shade. And this raises the consideration, What plants could bechosen when existing areas under trees are bare and some ornamental planting is desired? Not every tree will need to be thus underplanted. One, at least, will be kept clear for seats, perhaps for hammocks. But there certainly are many 
tree-shaded places in gardens that the owner would gladly plant if he could feel certain of success.

It must be confessed at once that the number of good subjects is not great, nevertheless, it can be made to suffice. There are two really ornamental yet inexpensive evergreens which have no objection either to shade or drip : the Aucuba and the Barberry called variously Berberis aquifolium and Mahonia aquifolia. The fact that the Aucuba is often overdone, being planted in quantity on good sites to the exclusion of various beautiful subjects, must not blind us to the fact that it is a distinctly handsome plant. If it had possessed no intrinsic worth, it would never have attained to such popularity as it now enjoys. People who like variety. in their gardens tend to become irritated by the repetition of one particular plant, and this may grow until it becomes an unreasonable prejudice. The Aucuba has had to endure many harsh criticisms in consequence of this feeling. It is the variegated form which is so much overplanted. The female green forms are not overdone, indeed, many people do not recognise them at sight. The habit is good, the leaves large, glossy and handsome, the berries brilliant and making a rich contrast with the leafage. Plants eighteen inches or two feet high may be planted six feet apart at any time when the weather is open from October to April, inclusive, and they will require no pruning or other cultural treatment.

As regards the Barberry, while a smaller plant than the Aucuba, it is little less ornamental, except when a winter comparison is made with an Aucuba in full 


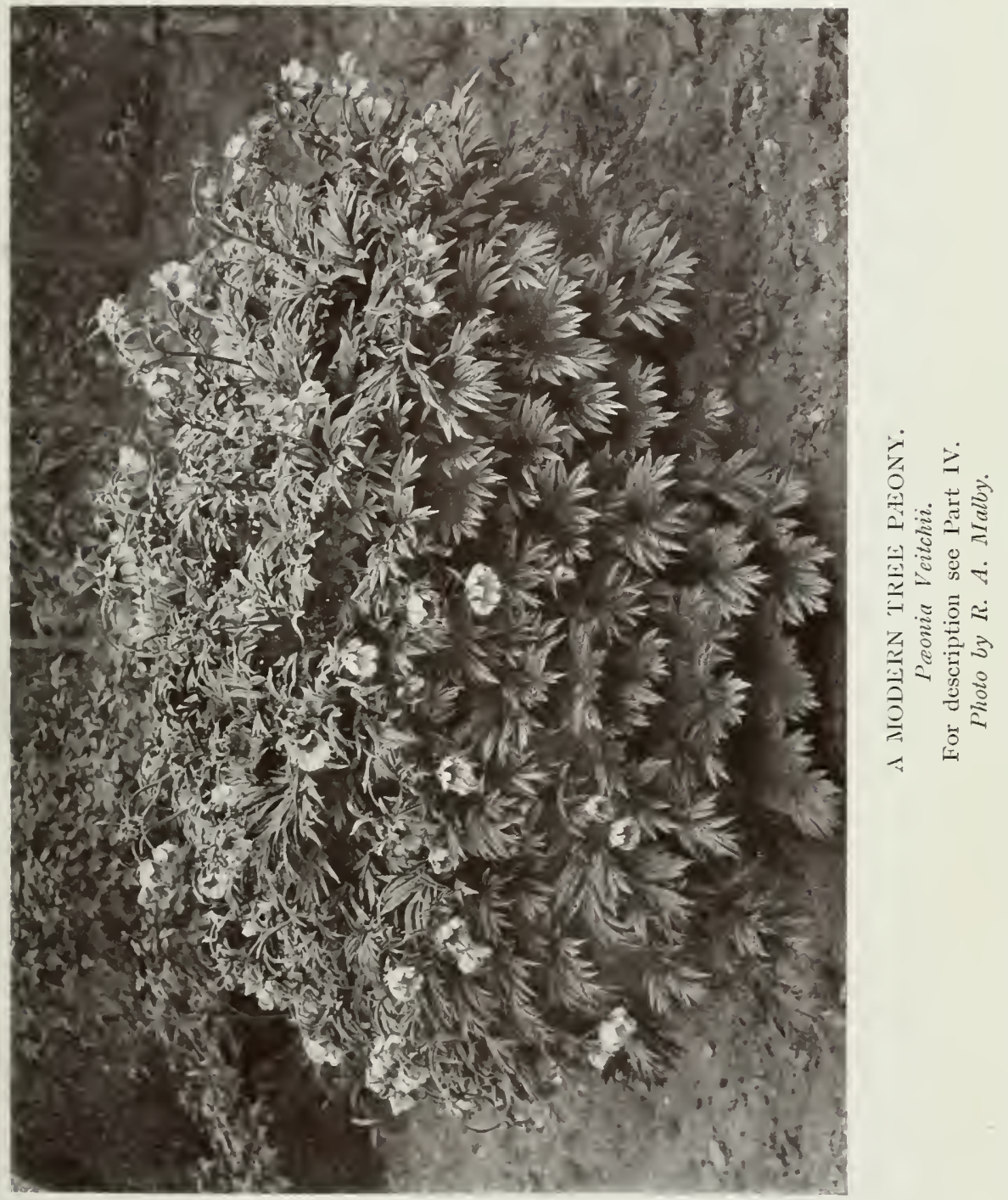



berry. The habit is dense and the leaves are broad; they are deeply serrated, giving the plant a somewhat prickly appearance. The flowers are yellow and generally appear in April ; they are followed by small Plum-coloured berries. The foliage becomes brownish in autumn. Owing to its dense habit and suitability for shade this plant is often planted by landowners for their game coverts, and special quotations for large quantities are made by the principal nurserymen. Those who want it as a garden plant, and have a good deal of shaded ground to cover, might vary it by using some of the forms, such as fascicularis, Moseriana, rotundifolia Hervei (or Herveyi), and undulata nana; the last is dwarf ; all of these can be got from the larger nurseries. The Barberries might be planted four feet apart.

Rhododendron ponticum is a fine old species that may be planted under the lee and partly under the shade of trees. One sometimes sees large belts of it on the great estates, and remarkably effective they are in early summer, when well furnished with their massive corymbs of mauve flowers. It is, of course, evergreen, its habit is excellent, and it is very hardy. It may be planted eight feet apart. The dislike of Rhododendrons for lime must be remembered in connection with this noble evergreen.

Thenext most important plant for shade is the Holly. If small plants are put in four feet apart, either in early autumn or late spring, they will generally establish themselves and thrive. They may not grow into such handsome specimens, nor berry so freely, as in the 
open, but they will be ornamental. There are many beautiful garden varieties of Holly, but none is better for shade planting than the Common.

Privet is so largely used as a hedge plant that a suggestion for using it singly or in groups may surprise the reader, nevertheless, it is by no means a bad shrub. When grown in a hedge and left unshortened it is gawky and ugly, as the plants "draw" up and become bare at the base, but this is not likely to occur when it is given room, and in any case can be corrected by pruning back once or twice. The oval-leaved species, known botanically as Ligustrum ovalifolium, should be chosen. An advantage of this shrub is its liking for poor limestone soils.

The foregoing will probably meet the wants of most readers as far as the larger shrubs are concerned.

One of the best of the smaller kinds is the Butcher's Broom, Ruscus aculeatus. It is not a strikingly handsome plant, but it will grow almost anywhere and is evergreen. Another good small shrub is Gaultheria Shallon, an evergreen belonging to the Ericaceæ, but fortunately not so exacting for a peaty soil as most of the members of that order are. It will thrive in sandy soil, or indeed in any fairly fertile moist garden soil. It bears white flowers in spring and berries follow. There is a garden form called acutifolia. Both the Butcher's Broom and the Gaultheria may be planted two feet apart.

The two best running plants for carpeting ground under trees are the Periwinkles, Vinca major and V. minor, and common house Ivy. The Periwinkles are 
generally preferred, because their large blue flowers are attractive. There are several garden forms of Vinca minor, one with white flowers (alba) and another with double blue flowers (cærulea flore pleno), one with silver variegated and another with yellow variegated leaves. The silver-variegated form is particularly pretty. The Periwinkles may be planted a foot apart.

The new Chinese shrubs Sarcococca ruscifolia and humile will prove an excellent addition to the shrubs which thrive in shade. S. ruscifolia is the better of the two. It is a vigorous shrub of good habit with green leaves. Pachysandra terminalis is aso a good shade shrub. 


\section{CHAPTER XXVI.}

\section{Hardy Shrubs and Trees for Forcing.}

THE departments of a garden are to some extent interwoven, and on occasion a subject which belongs to the open air finds its way into the greenhouse. This is particularly the case with certain shrubs, and one has only to mention the Rose to present a shining example.

With the increased attention which is given to hardy plants in these days, there is less disposition on the part of many to go in for glass, nevertheless, there may be some readers who are not only shrub-lovers, but have greenhouses and conservatories to furnish. Can they draw on the resources of their shrubberies with advantage at any period of the year?

The reply is that many shrubs may be lifted from the open ground and forced into early bloom under glass. Moreover, they will suffer no injury in the process ; provided that the simple precaution is taken of giving them a brief interregnum in a cool house before returning them to the open ground. If a shrub were put direct out of a warm house into the open air it might be injured, however nominally hardy it might be, in a spell of cold weather.

There could be no more convincing proof of the value of shrubs and trees for indoor decoration than the 

" DOUBLE CHERRIES AND PEACHES . . . BLOOM PROFUSELY WITH VERY GENTLE FORCING, AND THE FLOWERS ARE EXQUISITE."

(See page 215 .)

Prunus Pseudo-Cerasus Yoshino, a Japanese variety. Colour photo by R. A. Malby. 


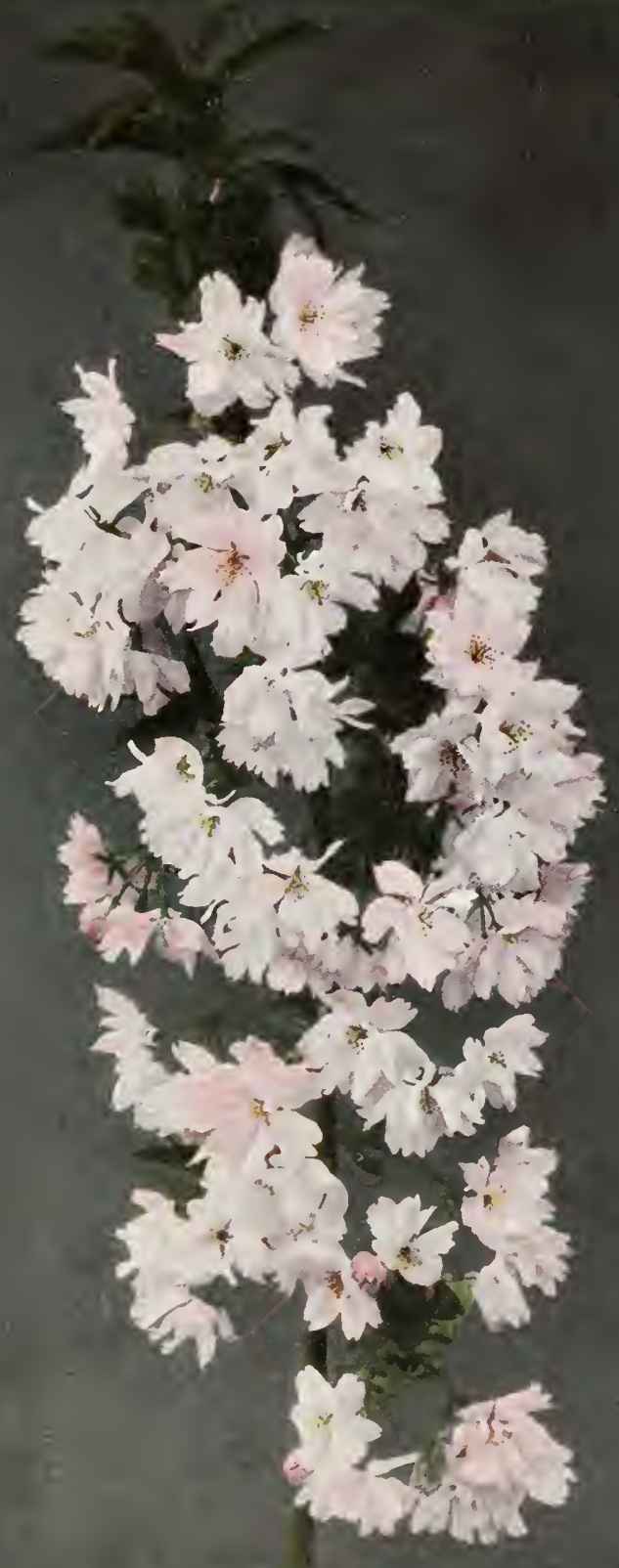


$-1$
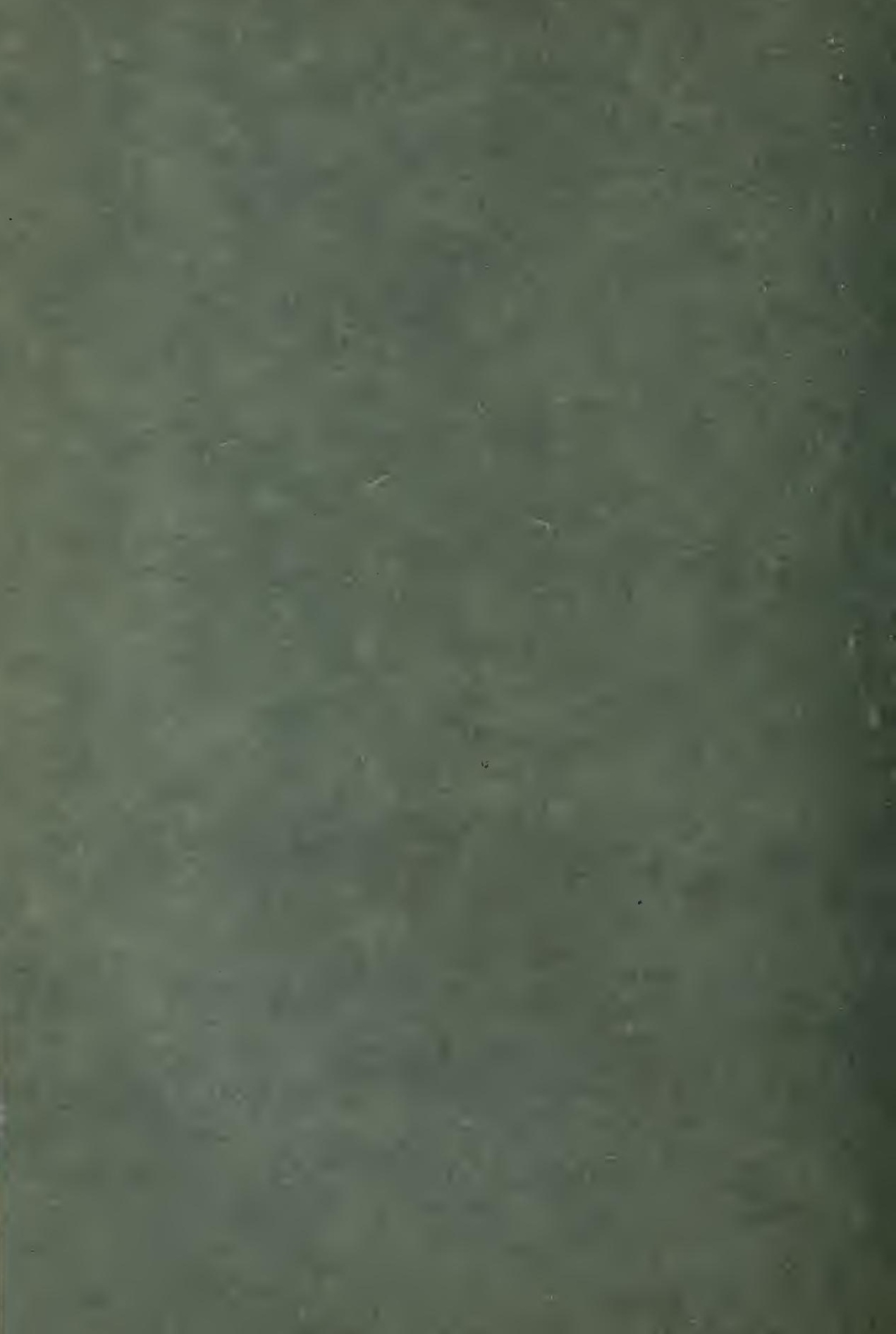
groups in pots and tubs which are set up at late winter and early spring flower shows. The exhibits begin in February; they grow more numerous in March; in April they are abundant. One sees many members of the great genus Prunus, including Almonds, Apricots, Cherries and Peaches. There are Pyruses, notably, perhaps, Scheideckeri. Lilacs are prominent. Tree Pæonies are represented. There are Azaleas and Rhododendrons in rich variety. Magnolias are seen. And there are less important but still beautiful things: Wistarias, Spiræas, Deutzias, Ribes, Laburnums, Ceanothuses, Viburnum., Thorns, Japanese Maples, Amelanchiers, Staphyleas, Forsythias, and Kerrias.

The forcing of shrubs and trees may be either casual or systematic. It may consist of merely taking up a few things from the borders, a choice being made where the plants are getting crowded, and planting them out again in a fresh place after forcing; or it may consist in setting apart a certain number of plants specially for forcing purposes, treating them at all periods of the year for the one particular purpose. Plants so grown will not be kept under glass the whole year; they will be outside part of the time, but they will have special quarters.

It is particularly trade growers who cultivate shrubs systematically for forcing, but some owners of large gardens do it with the help of their staff of trained gardeners. With respect to smaller private places, it would probably be hardly worth while; but that is a matter for individual judgment. The systematic forcing of shrubs and trees is not a light and cheap 
process. Large pots, a considerable quantity of suitable soil, a reserve ground and a not inconsiderable amount of labour are called for. These things arise out of the size of the various plants. Shrubs and trees are bigger things than Primulas and Cyclamens, thus they call for larger pots. With larger pots more soil, more space and more labour are required. There is also the question of pruning to consider.

The issue once freely and fairly stated, we may go on with a clear conscience to point out the great beauty of certain shrubs and trees when forced into bloom in winter and early spring. The most beautiful of all, perhaps, are the double Peaches, of which a typical variety is Clara Meyer, with its lovely pink flowers that stud the branches closely. This can be had in bloom in March. The double variety of Pyrus spectabilis is another delightful subject, and makes a charming companion for Scheideckeri. Both of these can be flowered in March, several weeks in advance of their natural season in the open air.

Lilacs are among the greatest favourites, because apart from their beauty and perfume they force well. The modern forms such as Marie Legraye, single white; Maréchal de Bassompierre, double reddish lilac; Arthur W. Paul, double red; Alba grandiflora, single white; Madame Lemoine, double white; Souvenir de Louis Spath, deep brownish red, single; Miss Wiilmott, double white; President Carnot, double lilac; Grand Duc Constantin, double soft lilac; and La Ville de Troyes, purplish red single; are beautiful. The old variety Charles $\mathrm{X}$., with purplish red single 
flowers, that come white when it is forced in the dark, should also be mentioned, as it is cheap and forces well. These are all varieties of the common Lilac, Syringa vulgaris ; but the Persian Lilac also forces well. Lilacs grown for forcing are kept to about four shoots, all side growths being removed at an early stage. The routine for early winter bloom is to plant out in rows, in spring, disbud as required throughout the summer, chop round the plants in August, lift and pot in September, force in a dark, hot place, harden after flowering, plant out again, give a year's rest and repeat the forcing a second season. To force into bloom in late winter or early spring is a much simpler process, as only gentle warmth is required and the plants may be grown in a light house with other subjects.

For steady forcing to give bloom in late winter and early spring, Lilacs and other shrubs and trees need not be put in heat until the New Year, and then they should only have a mild warmth of about $50^{\circ}$ for the first two or three weeks. After that, if convenient, $55^{\circ}$ to $60^{\circ}$ may be allowed. If greater heat than this is given, the bloom will be earlier, but it will not last so long, unless indeed, there is a second and cooler house into which the plants can be shifted when they come into flower. There is the further objection to hard forcing that a greater strain is put on the plants. A moist atmosphere, induced by syringing, is desirable while the plants are swelling their buds, but a drier air is desirable when the bloom opens.

After flowering, the wood which has bloomed should be removed, and about half a dozen new branches 
allowed to develop. With a limited number, the wood will ripen well and there will be good bloom the following year. This applies to most of the deciduous flowering shrubs. Evergreen Rhododendrons will not, of course, be cut back in this way. If the plants have to be put out before the middle of May they should be stood in a sheltered place, where they will not be subjected to late frosts and cold winds.

Shrubs and trees that are to be kept in their pots through the summer should be plunged up to the rim of the pot, as this will save a good dea! of watering. Plants that have been lifted and potted for a casual forcing may be planted out in May.

Two types of Azalea are largely forced: the socalled Ghent Azaleas and the varieties and hybrids of A. Mollis. The former are the little plants, with bare stems a foot or so high, and dense heads of bloom, which appear in florists' windows at mid-winter; they are prepared for forcing in milions by Belgian florists, and exported to nearly all parts of the world. They need only be brought into bloom in the way already advised, and they are so cheap that it is hardly worth while growing them after flowering. They are undeniably pretty, but they do not yield the beautiful salmon, orange, buff and fawn shades which are found in the Mollis type. Some of these are varieties of A. Mollis, but the best are hybrids between Mollis and pontica or Mollis and sinensis. Oswald de Kerchove, salmon-pink; Floradora, orange ; Anthony Koster, rich yellow; Prince of Orange, orange; Betsy de Bruin, yellow-crested; Duchess of Portland, cream 
and rose; J. C. van Thol, orange; Alphonse Lavallée, orange; J. C. van Thol Imperial, flame colour; Glory of Boskoop, dep yellow ; Clara Butt, rose flame; and Louis Endz, orange yellow, are examples. They force quite readily under the treatment indicated.

The double Japanese Cherries known botanically as Prunus Pseudocerasus and P. Pseudocerasus James $H$. Veitch have beautiful rosy flowers. Avium, the wild Gean, with single white flowers; Cerasus Rhexii flore pleno, double white ; and serrulata, double white ; are also beautiful members of the Cherry section of the great genus Prunus which force well. As regards the Peaches, Prunus Persica flore pleno, white; the crimson and rose forms, and the semi-double carmine form called Persica flore pleno magnifica, are alı splendid. They bloom profusely with very gentle forcing, and the flowers are exquisite. Clara Meyer has already been mentioned and is equally good. Turning to Apricots, there are Prunus triloba, silvery rose, and its double form flore pleno.

Pyrus floribunda, with rosy flowers, its double form, flore pleno, of the same colour, and the variety or hybrid Scheideckeri, blush changing to white, are all forced; the last, a lovely Crab Apple, that blooms profusely, is particularly good.

Two of the most beautiful white Magnolias are conspicua and stellata, and both force well.

Cunningham's White is one of the best Rhododendrons for the purpose, but the magnificent Pink Pearl may also be used. The small dwarf blush-coloured species ciliatum and racemosum can be flowered in March. 
Deutzia gracilis has long been a favourite for the purpose and other Deutzias may be used.

Of Spiræas, arguta, prunifolia flore pleno and Thunbergii are excellent.

Hydrangea paniculata grandiflora is a splendid plant for forcing towards the end of winter.

Staphylea colchica, a very pretty white flowered shrub blooming in the ordinary way in spring, forces well.

There would be no trouble in adding considerably to the list of shrubs and trees suitable for forcing, but it is only desired to name the best. There are, of course, hundreds of subjects of shrubby habit which, coming from warm climates and not being hardy, have to be grown under glass in cold countries all the year round. But tender plants do not come within the scope of the present work.

The Japanese dwarf trees are a class apart. They are not tender, but they are grown in the greenhouse. They are hardy kinds, but they are not forced. What can be said of them but that they are "freak" trees, produced by a remarkable yet unnatural method of treatment? They are, of course, expensive, and can never enter into the real economy of a garden. But these trees have interest, alike as a tribute to human patience and skill, and as a proof of the wonderful adaptability of plants. There are trees in existence only a yard or so high at upwards of fifty years of age, which in nature rise to fifty feet high. And some of the dwarf trees are more than half a century old.

The Japanese habit of making miniature landscapes 
created a demand for the dwarf tree. When a complete garden is made in a space less than that of an average town back-yard, there is little room for trees of any kind, moreover, the methodical and correct Japanese make a point of maintaining proper proportions. In a landscape there must be trees. Where the garden is small the trees, to be in proportion, must be small also.

In course of time, these trees aroused the interest of European and American garden-lovers, and the astute Japanese developed a trade in the West. But garden-making in Britain and America is rarely on so restricted a scale as to make such material fitting in the open air. The trees, therefore, were not planted out, but grown in ornamental pots or other ware. As a rule, they are grown together in a large, cool, airy greenhouse. They form an item of interest under glass corresponding with a collection of clipped trees out of doors. They are not really gardening. They are "collecting."

Root restriction and branch twisting both play a part in forming the dwarf trees, but as no Western gardener is likely to practise it, there would be no advantage in devoting space to the matter. 


" SHRUBS SHOULD BE CONSIDERED FOR THE ROCK GARDEN, BECAUSE THEY ENTER INTO HARMONIOUS RELATIONS WITH OTHER OCCUPANTS."

(See page I70.)

Spiræa arguta is here shown.

Painted by George Soper. 


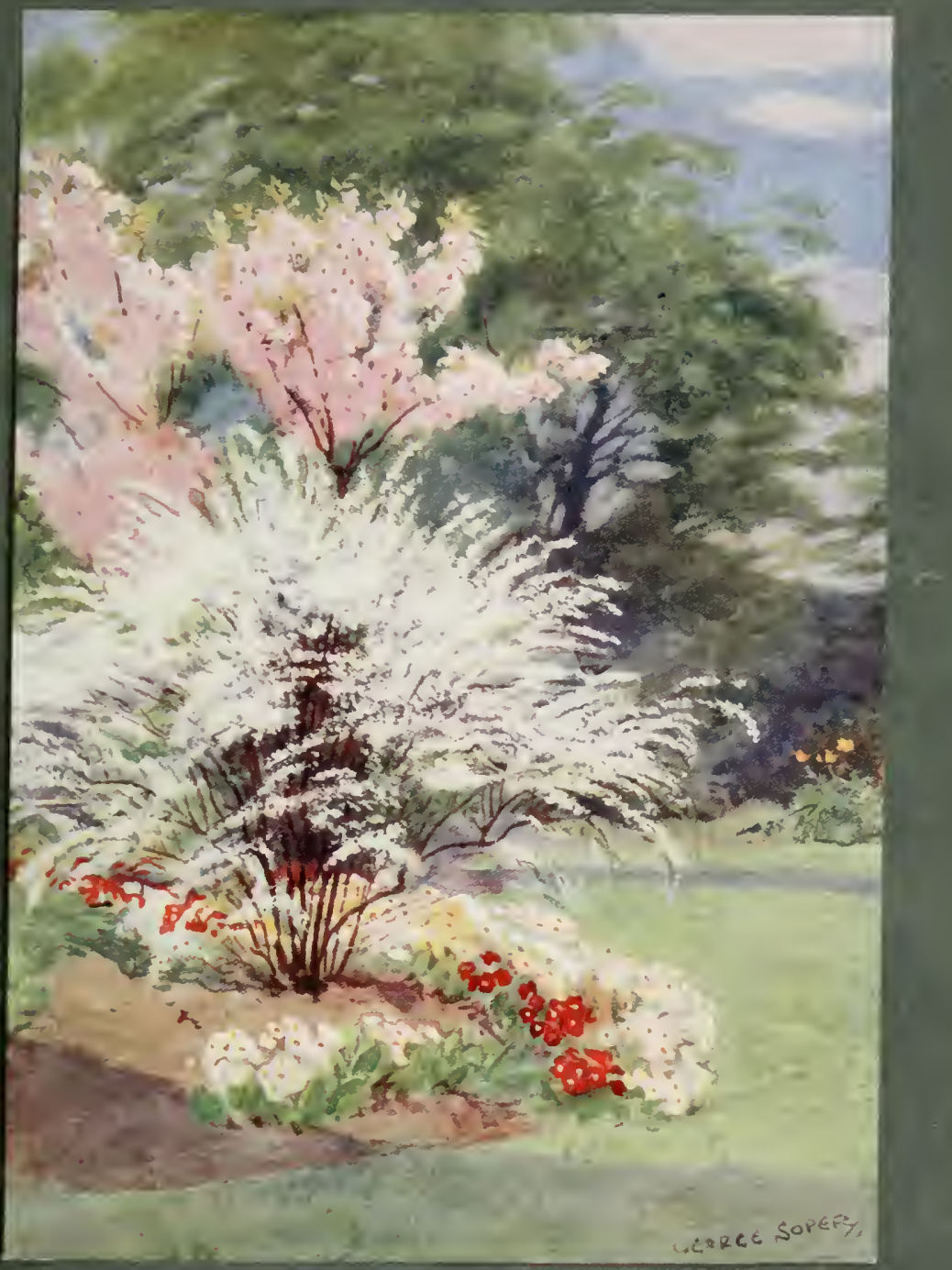




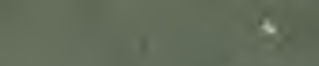




\section{PART IV. \\ Descriptive.}

SECTION A.

Modern Shrubs and Trees, chiefly Chinese.

AND

SECTION B.

Notes on the Best Shrubs and Trees in Alphabetical Order. 



\section{SECTION A.}

\section{Shrubs and Trees of Modern Interest, chiefly Chinese.}

As there may be many readers of the present work who are well acquainted with the older genera and with what may be called the "standard" species and varieties of shrubs and trees, it has been thought desirable to group the principal kinds of modern interest in a chapter to themselves, in spite of the fact that in some cases the genus to which they belong is treated in other parts of the work. Any risk of confusion which might arise from this arrangement is obviated by a system of cross references and a complete index.

The majority of the kinds named are new, but there are a few cases in which a plant long known to botanists has come recently into commerce and is new to most amateurs.

The most remarkable of the new shrubs and trees have come from China. Many were collected there by Mr. E. H. Wilson, Abbé Delavay, Dr. Henry, and Abbé Farges; others have been raised from imported seed by various connoisseurs.

The travels of Wilson have been attended with almost startling success. Ground hitherto untouched by plant collectors has been explored, and genera and species 
of entirely unsuspected beauty and interest have been brought to light.

It would be no exaggeration to say that, great as the developments in every phase of gardening have been in modern times, there is none in which more remarkable progress has been achieved than in shrubs and trees, particularly Chinese. Before becoming attached to the Arnold Arboretum in America, Mr. E. H. Wilson explored Western China in the interests of a British firm of nurserymen, James Veitch and Sons, Ltd., and it was through this great firm that the best of his early introductions were put before the public.

The successes of Wilson entitle him to rank with the greatest of plant collectors, such as Douglas, Fortune, Thompson, and Maries. It is probable that many of his discoveries will find permanent places in the gardens of shrub-lovers in Britain and America, although some are of botanical rather than garden interest.

We are far from being at the end of this wonderful stream of new shrubs and trees. An enormous collection of seedlings in being raised and tested by the Hon. Vicary Gibbs and others, while the present work is in the press. Many of these are entirely new and, judging by their appearance in the young state, are both distinct and valuable.

Meantime, the following are notes of the principal new and special kinds :

$A C E R$. - Two interesting additions have been made to the Maple genus by the introduction of Acer Davidii and A. griseum, both deciduous trees, growing up to 


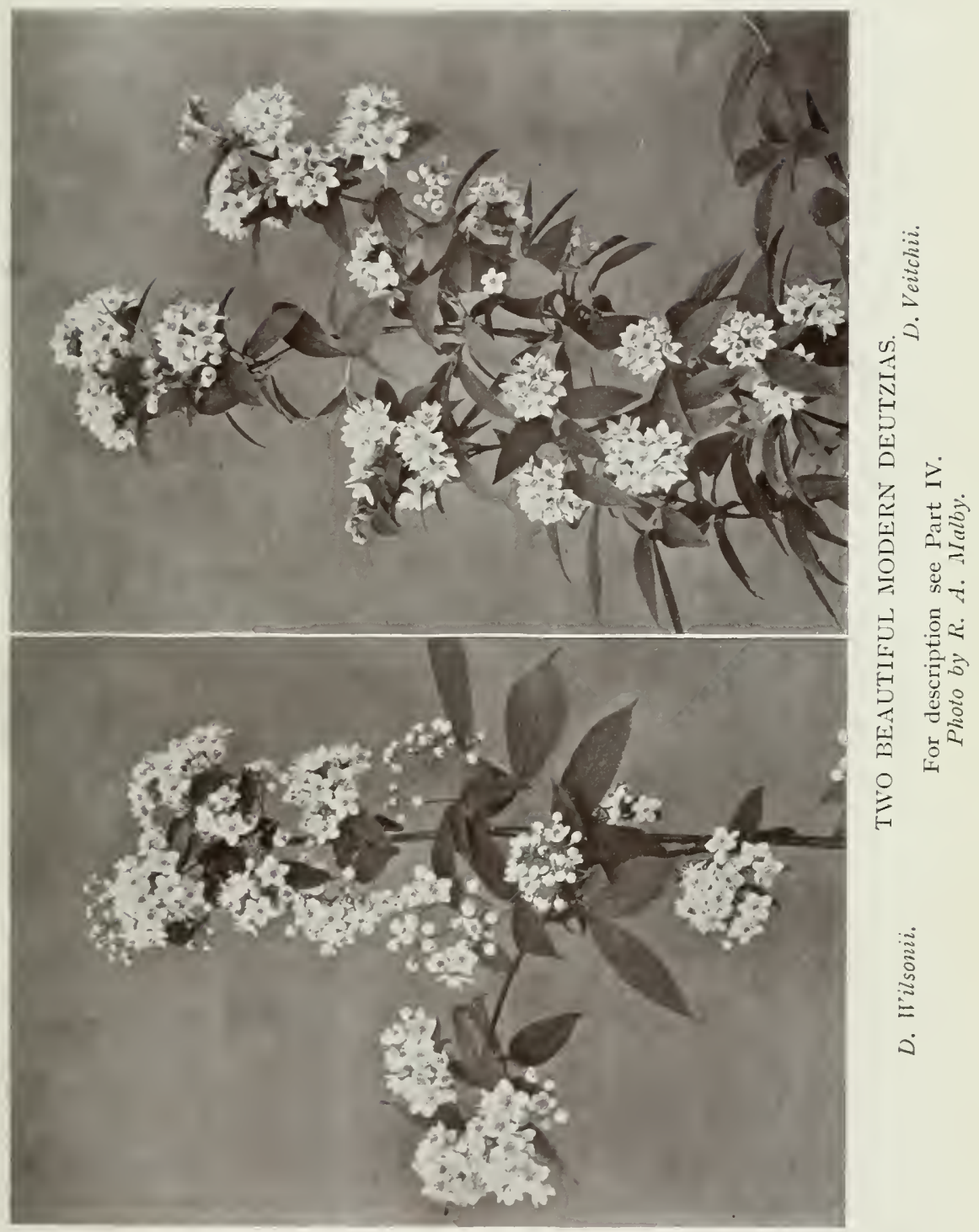



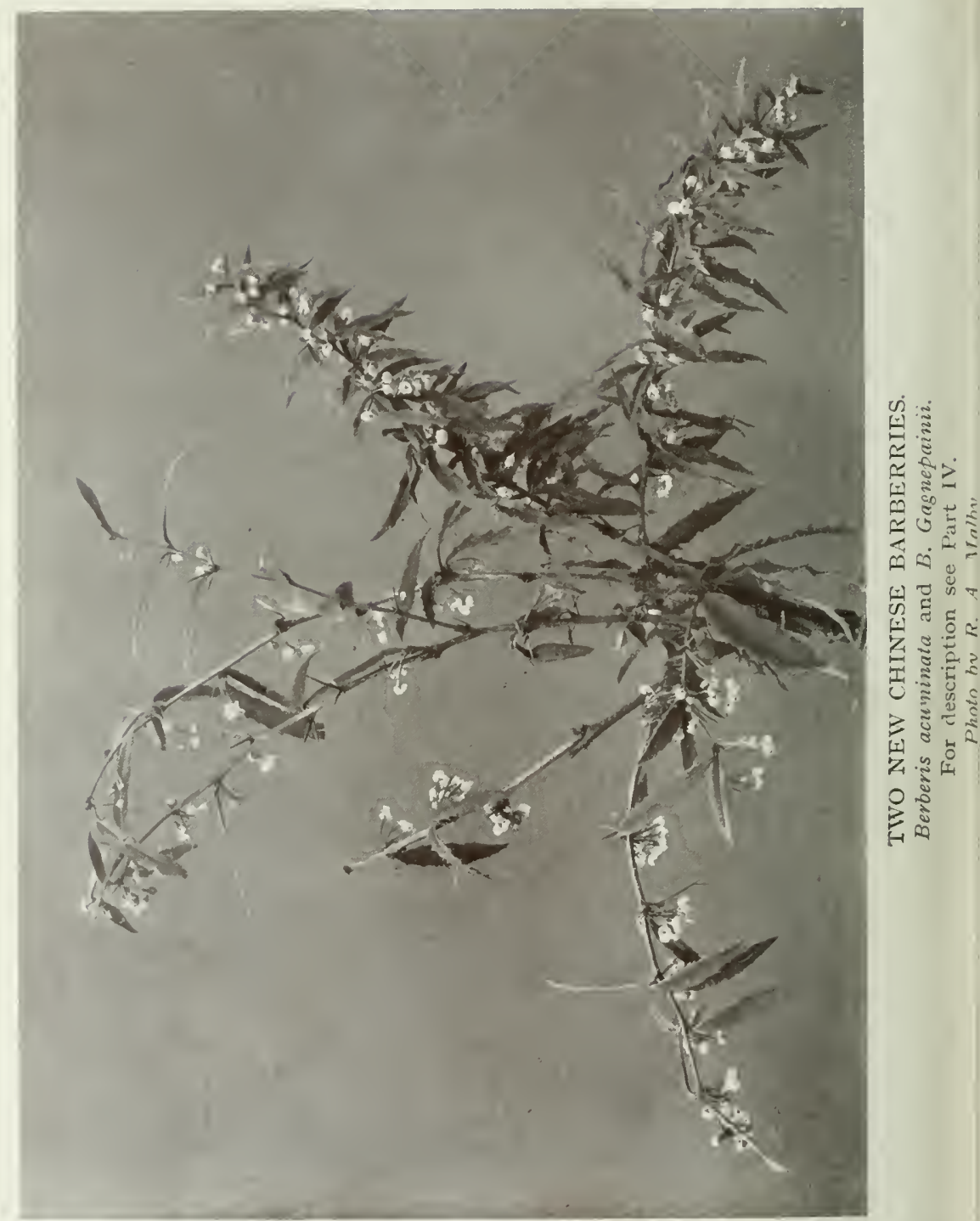
twenty-five feet high. A. Davidii is distinguished by the fact that the bark is streaked with white on a dark green ground. The toothed foliage is bronzy red when young and shining green when mature. The bark of A. griseum is brown and peels off in the fall. The toothed trifoliate leaves are rosy when young. A fine form of A. campestre, the common Maple, called Schwerini, has been introduced.

$A C T I N I D I A$.- The species chinensis is a deciduous climber with heart-shaped leaves and yellow flowers. The female form, more recently introduced, proves to have deeper coloured flowers than the male. Henryi, a new species introduced from China by Wilson, has evergreen, coriaceous, toothed leaves, which have rich colour in autumn.

AMPHIRAPIS ALBESCENS.-A compact shrub from the Himalayas; whitish leaves, violet flowers.

ARISTOLOCHIA. The species moupinensis is new. It is a deciduous climber of rapid growth, well suited to the pergola. The tubular flowers are of a greenish yellow tinge, marked with purple.

BACCHARIS PATAGONICA.-This is much superior to $B$. halimifolia, the Groundsel tree. It is a small, free-growing evergreen tree with dark green foliage and whitish flowers in June.

$B E R B E R I S$.- Striking additions have been made to this important genus, already of great importance with such popular and valuable members as Darwinii, stenophylla and aquifolium. Acuminata has yellow flowers, the young wood is red and the branches are arched. Brevipaniculata is a dense upright deciduous 
species growing up to six feet high, with obovate leaves clustered on red stems, panicles of yellow flowers, and rosy berries ; the bark of the young shoots is red. Dictyophylla has serrate leaves in clusters of four to six, dark green, on stiff upright stems, of a grey colour when young, fruits coral red. Gagnepainii is an evergreen with pale yellow flowers and glaucous purple berries. Polyantha is deciduous, height up to six feet; yellow flowers and coral-red fruits. Stapfiana is dense in habit, deciduous, and with yellow flowers and small red berries. Verruculosa, a dwarf evergreen, with small, thick, spiny leaves, has yellow flowers on arched stems and purple fruits. Wilsonæ has scarlet berries. Bealei is a form of aquifolium. It is not new but is little known, and in the collection of the Hon. Vicary Gibbs is remarkable for its beauty. It is an evergreen with pinnate foliage, and bears lemon-coloured flowers scented like Lily of the Valley at Christmas time. Fremontii (syn. Mahonia Fremontii) is a glaucous evergreen with yellow flowers and red berries.

$B E T U L A$. An addition to the Birches has been made in alnoides pyrifolia, a small deciduous tree with Pyrus-like leaves.

BROUSSONETIA.-Cucullata is a hooded form of B. papyrifera, in the collection of the Hon. Vicary Gibbs.

BUDDLEIA.-Hemsleyana and nivea, the former with lilac flowers in erect terminal spikes; the latter remarkable for the leaves being covered with white fluff, are new Chinese species. 
CAMELLIA.-An addition to this great genus is cuspidata, a dense bush with narrow leaves and single white flowers. It was given an Award of Merit by the Royal Horticultural Society.

CARAGANA AURANTIACA.-A dwarf species with yellow flowers.

CATALPA.-There is a new species called Fargesii, a deciduous tree growing up to forty feet high, with five-lobed glabrous leaves and pale purple flowers. Duclouxii is a Chinese species with glabrous, cordate, three-lobed leaves, and pink flowers in clusters.

CELASTRUS.-There are two new species: hypoglaucus and latifolius, both deciduous.

CLEMATIS.-The importance of this genus is so great that interest attaches to any additions, and certainly the newcomers are worthy of the attention which they have received. The red form of montana, rubens, and the late blooming white form Wilsonii, are both great acquisitions. Other new Clematises are Armandii, an evergreen species with white flowers, which appear early in April ; there is a figure of it in the Botanical Magazine, T. 7897 ; nutans, with creamy bell-shaped, drooping, fragrant flowers in summer; akebioides, a deciduous species with trifoliate toothed leaves and small pale yellow flowers; and Gouriana, deciduous, with compound leaves and small, fragrant, creamy flowers in dense clusters.

CLERODENDRON.-Fargesii, a species of spreading habit, with large acuminate leaves, sweet white flowers in panicles and dark blue fruits, is said to share the hardiness of $\mathrm{C}$. Trichotomum. 
COCCULUS.-Most of the known members of this genus are hothouse evergreens. The two new species heterophyllus and Thunbergii are hardy enough to be grown on pillars and pergolas in mild districts. The former is deciduous, the latter evergreen.

CORIARIA HIMALAYENSIS.-An evergreen species with black fruit. Its hardiness has to be proved.

CORYLOPSIS.-Multiflora and Veitchiana are interesting additions. Both bear yellow flowers in pendulous racemes like Hazel catkins in winter, before the leaves devlop. Veitchiana is the more vigorous of the two. They received Awards of Merit from the Royal Horticultural Society in I9I2.

COTONEASTER.-The new Cotoneasters are numerous. Humifusa is an evergreen trailer, useful for covering banks; the growth is vigorous but dense; scarlet berries are borne in autumn. Prostrata has orange berries and is good for the rockery. Adpressa is deciduous, and is well suited to the rock garden. Dammeri is a dense creeper with scarlet berries, excellent for the rockery. Divaricata is an evergreen of low, free-branching habit, with dark green leaves and scarlet berries. A First-class Certificate was awarded to it by the Royal Horticultural Society. Bullata is a vigorous species with clusters of shining red berries. Salicifolia rugosa is a loose bush with red berries on drooping shoots. Zabeli has dull red berries. The last three received Awards of Merit from the Royal Horticultural Society in IgI2. Fontanesii, red berries, grows three feet high. 

" THE LABURNUM MAY BE PLANTED IN THE SUBURBS AND IN GARDEN CITIES."

(See page I 8 r.)

The Laburnum is here shown growing in Kew Gardens. Colour photo by R. A. MALBY. 


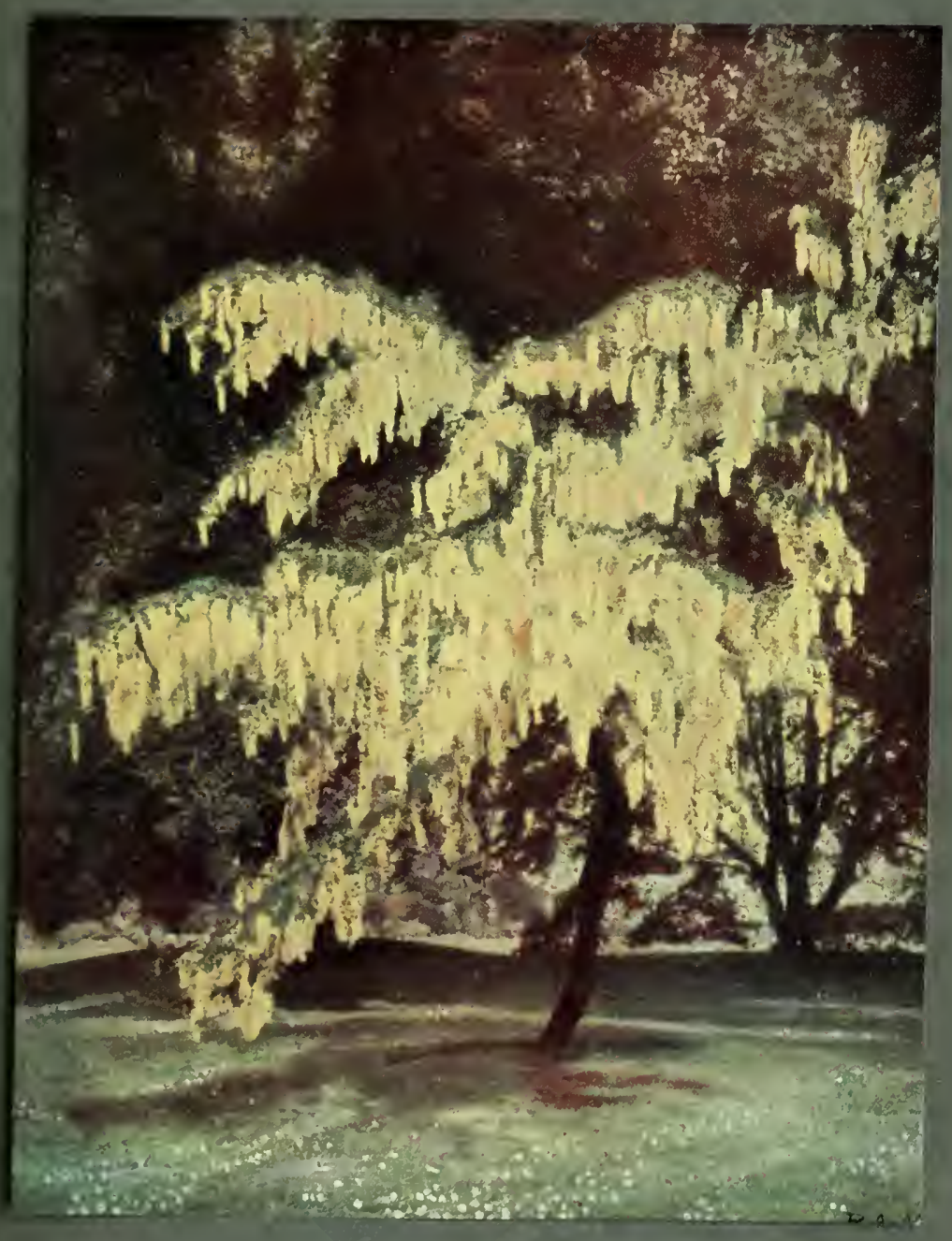


8
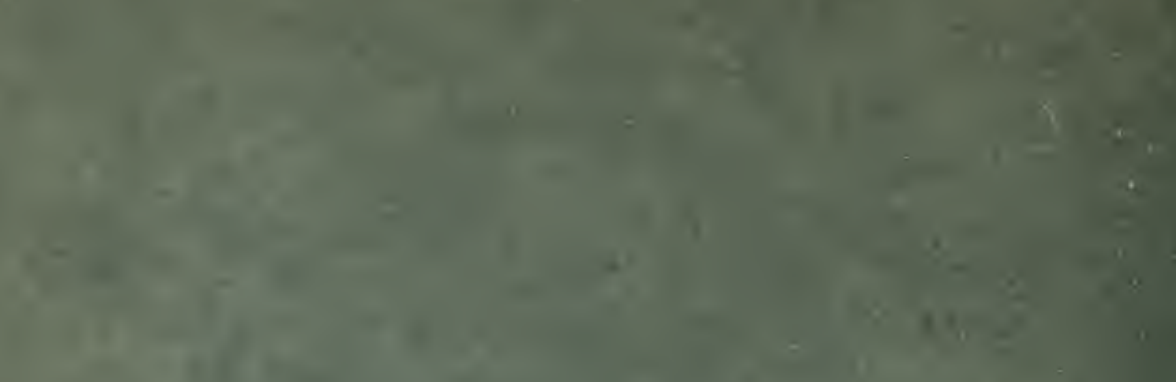

,

$=1$

$2=$

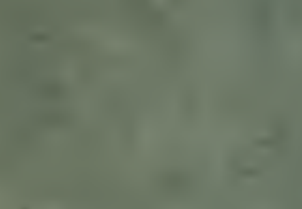

$=$

S.

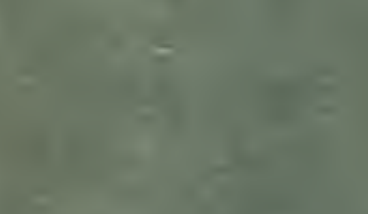

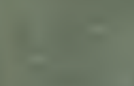
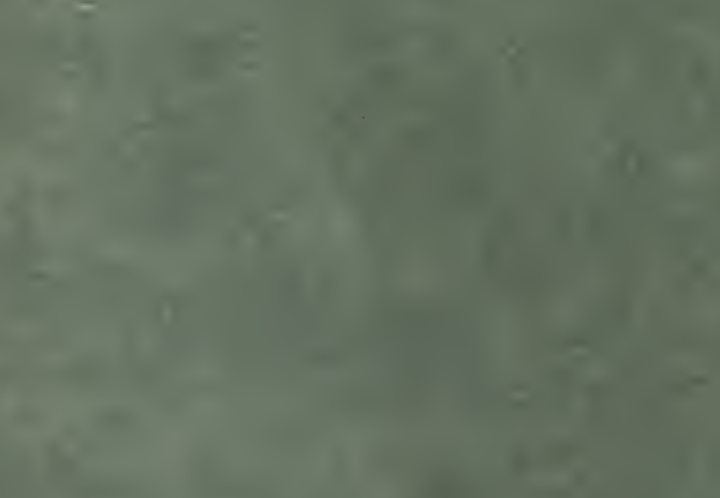

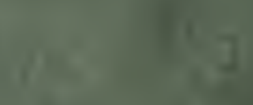
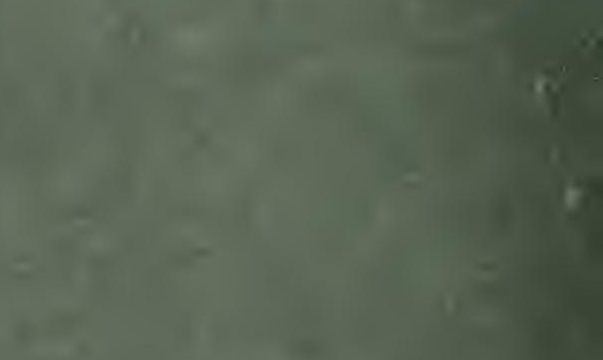

$=$ 2
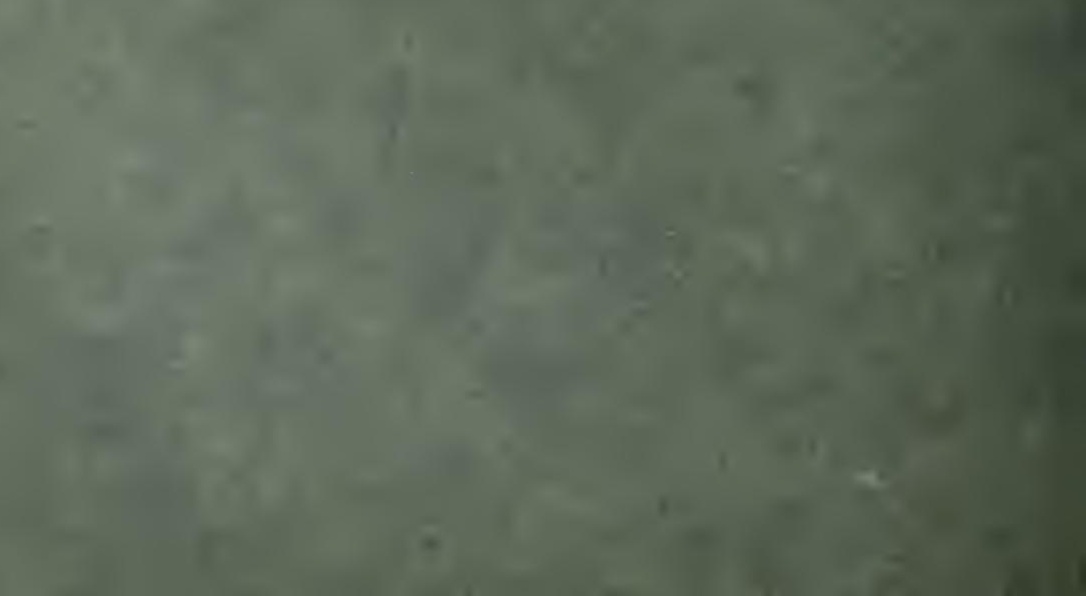
Pannosa is a low evergreen with slender spreading branches, white flowers and red berries. Rugosa Henryi is evergreen, with clusters of brownish berries. Applanata is deciduous, with leaves grey below, and scarlet berries. Francheti is an erect shrub with white flowers and orange berries. Angustifolia has spiny stems and red berries.

CRATAEGO-MESPILUS DARDARI.-This is a graft hybrid between Cratægus and Mespilus, sometimes reverting in growth to one of the parents. White flowers.

CYTISUS.-The interesting hybrid Dallimorei, raised by crossing C. albus and C. scoparius Andréanus at Kew, was put in commerce in the autumn of Igra. It is of dense habit, has small trifoliate leaves, and is covered with rosy mauve flowers in late spring. C. Beani is of rambling habit with yellow flowers. The modern forms of scoparius, such as Butterfly, which may be succinctly described as a pale Andréanus; and Daisy Hill, chocolate on blush ground, will not be overlooked by shrub-lovers. All make good standards, in common with most of the Brooms.

$D A P H N E$.-A dwarf evergreen species named retusa, with shining leaves and fragrant white flowers suffused with rose in terminal umbels in May, has been introduced. See the Botanical Magazine, T. 8430.

DAVIDIA.-Involucrata, a Chinese tree with Limelike dark green serrate leaves, growing up to thirty feet high, ornamental by reason of its white bracts, flowered for the first time in England in IgII from 
seed sent from China by Wilson and sown in Igor. It bears round fruit about as large as a walnut. The inflorescence is drooping and comes from side spurs. Of the two large bracts, one is nearly double the size of the other. In China the trees grow up to fifty feet high. It is quite hardy.

DEUTZIA.-This important genus has been revolutionized, as much by the work of hybridists-most prominent of whom is Lemoine of Nancy-as by explorers. As regards new species, longifolia, Veitchii, Vilmorinæ and Wilsonii are all notable additions. Longifolia has large blush flowers tinged with mauve. Veitchii has corymbs of rosy flowers on arching shoots in May. Vilmorinæ, which was found on the mountains of Setchuen, is a vigorous species, with large panicles of white flowers in June. Wilsonii has toothed leaves and white flowers. Both longifolia and Veitchii have received Awards of Merit from the Royal Horticultural Society. With respect to the hybrids and their forms, they are so interwoven with the older species from which they have sprung that it seems desirable to deal with them in the section B., although many are quite new.

DIPELTA VENTRICOSA.-An interesting deciduous shrub with Peach-like foliage and small brown tubular flowers with white lip and cream throat. A peculiar feature is the Acer-like seed wing.

DRIMYS AROMATICA.-A Tasmanian evergreen which requires the protection of a wall in northern climes. It bears small white flowers in spring. ERIOLOBLIS DELAVAYI.-A Pyrus-like tree. 
ELEUTHEROCOCCUS HENRYI.-A deciduous shrub with compound leaves, grey spiny stems and globular heads of bloom. It bears dark purple fruit. Two other Chinese species are offered: senticosus and Simoni; they are rare shrubs with palmate leaves.

EUCOMMIA ULMOIDES.-A Chinese shrub with large glossy leaves from which gutta percha can be made; but the seeds yield more. It is of little garden interest.

EUONYMUS.-Sanguinea is a deciduous species with toothed leaves which become rich crimson in autumn. Alatus, the winged Euonymus, is remarkable for its beautiful tint of rose in autumn.

EUPTELEA.-Davidiana is a small deciduous tree growing up to twenty feet high. The foliage colours well in autumn. Francheti and polyandra are also offered; they are rare shrubs.

EXOCHORDA GIRAL.DII.-A new Chinese species with white flowers about two inches across in spring, the petioles, leaf-ribs and young growths are rosy purple.

FORS YTHIA.-Europæa is a vigorous, free-growing shrub of erect habit with yellow stemless flowers which open in April. It was discovered by Dr. Von Degen in Albania. It differs mainly in leaf from the Forsythias previously described by botanists.

FRAXINUS.-Bracteata is an addition to the Ashes with pinnate leaves.

GLEDITSCHIA DELAVAYI.-A species from Yunnan, with strong thorns and pinnate leaves 
composed of numerous leaflets. The fruits are used for making soap by the Chinese, as are those of $\mathrm{G}$. sinensis.

GYMNOCLADUS CHINENSIS.-This interesting plant differs from the North American species canadensis, the Kentucky Coffee tree, in having violet flowers and short pods; the latter are used for soap by the Chinese. When ripe the seeds are hard and black, and are used for making rosaries.

HYDRANGEA.-Aspera is a deciduous species with large cut leaves and pale mauve flowers in corymbs in summer. As with other Hydrangeas, the outer florets are sterile. The height is about three feet. Xanthoneura is a somewhat taller deciduous species, with cut leaves and creamy heads of white flowers in summer. Sargentii is quite distinct from other Hydrangeas; it has large velvety leaves and bluish flowers in broad heads, the outer florets sterile; it received an Award of Merit from the Royal Horticultural Society.

ILEX.- Pernyi and Veitchii are striking additions to the Hollies. Fargesii is also noteworthy. Pernyi is distinct from the popular Hollies, forms of Ilex Aquifolium. The habit is neat and dense, the leaves small and pale green on the young wood, dark green on the old wood. It was awarded a First-class Certificate by the Royal Horticultural Society. Veitchii resembles it, but is larger and more vigorous, with very spiny leaves, thoroughly hardy and suitable for a lawn specimen. Fargesii, with its narrow, lanceolate, spineless leaves is a very distinct Holly. Another interesting Ilex is corallina, which has slender drooping branches, 
dark green coriaceous toothed leaves three to four inches long and coral red berries.

JASMINUM.-Beesianum is a new species from China with bright red flowers, suitable for rambling over stones on a rockery. It is vigorous and hardy.

JUGLANS.--An addition has been made to the Walnuts in Cathayensis, a handsome species with black fruit.

LEPTOSPERMUM.-The species scoparium, the Australian and New Zealand Manuka, is a beautiful small-leaved shrub, growing up to five feet high, with white flowers in June, but of such doubtful hardiness that it is generally grown under glass ; it may, however, be cultivated outside in mild places. A larger form called grandiflorum has been known, but a remarkable new variety named Nicholli has appeared, in which the flowers are carmine red and the leaves tinted with purple. A First-class Certificate was awarded by the Royal Horticultural Society. Another new variety is Boscaweni, white with red centre. The Leptospermums like a compost of peat and leaf mould with sand.

LIGUSTRUM--Henryi is an evergreen species with glossy green leaves. Walkeri has light-green shining leaves. Delavayanum is a small-leaved evergreen from Japan.

LIQUIDAMBAR.-Formosana is the Chinese Feng Tree. It is perhaps rather of botanical interest than garden value.

LIRIODENDRON.-Chinense is described as quite distinct from the well known Tulip Tree, L. tulipifera, mainly in its flowers, which are much smaller and 
differ in structural details, but are of the same colour, greenish yellow. It may be expected to be quite hardy in great Britain and America.

LONICERA.-One of the most interesting additions to the Honeysuckles is the evergreen bush species nitida, a beautiful little plant, as dense in habit as Box, indeed a mass of small shining leaves. The flowers are cream-coloured and fragrant. Pileata is a low spreading grower well suited to the rock garden, also an evergreen. Henryi is an evergreen climber, with chocolate and orange flowers followed by purplish fruits. A figure appears in the Botanical Magazine, T. 8375. Prostrata is a deciduous species of trailing habit, and therefore suitable for a bank. The creamy flowers are borne in summer. Spinosa (syn. Alberti) forms a straggling bush with clusters of lilac flowers in early summer. Heckrottii has carmine flowers, yellow on the interior. Belgica bears its yellow fragrant flowers with carmine tube on red stems ; it is an evergreen. Tragophylla is an evergreen with long yellow tubular flowers, very beautiful, but not strongly scented. Giraldii has bronzy velvety leaves and violet flowers-a colour new in Honeysuckles.

MAGNOLIA.-Delavayi is a remarkable evergreen species, with very large massive leaves and creamcoloured flowers. Like grandiflora, it is suitable for a lofty wall, but is possibly less hardy and had better be planted on a sheltered wall.

OSMANTHUS.-Armatus is an evergreen with large toothed leaves, which are bronzy green when young and deep green when older. The flowers, which 
are cream-coloured and fragrant, are produced in Autumn. In this respect it resembles the well known ilicifolius, but the leaves are much larger. Delavayi is an evergreen from Yunnan, with ovate, acuminate, toothed leaves and sweet white tubular flowers in terminal clusters in early spring.

PACHYSANDRA TERMINALIS.-This makes a useful addition to the limited number of shrubs which will thrive under the shade of trees. It is a dwarf spreading evergreen from China and Japan. It may be grown on the rockery. The white flowers are borne in spring. There is a variegated form.

PAULOWNIA. - Fargesii, large white flowers; Duclouxii, white, and imperialis alba, white flowers and large velvety leaves, have been introduced from China. PHILLYREA ROSMARINIFOLIA.--A neat evergreen with small linear leaves a little more than an inch long, good for the rockery.

POLIOTH YRSIS SINENSIS.-A tree introduced by Wilson from China, with large ovate leaves and greenish flowers in erect panicles. It bears a dry, capsule-like fruit.

POPULUS.-Lasiocarpa is a new Poplar with enormous ovate, cordate, bright green leaves. The species is distinguished by the red tint of the leaf stalk and midrib. It should have a moist place. Another new Poplar is Populus alba Richardi, a variety with a golden tint on the upper surface of the leaves, making it quite distinct from the familiar white Poplar.

POTENTILLA.-Veitchii is a sub-evergreen growing up to four feet high, with sprays of white 
flowers produced in succession from spring to autumn Vilmoriniana is a shrub three feet high, with small silvery leaves and yellow flowers.

PRUNUS PSEUDO-CERASUS.-A magnificent blush coloured form named Shirofugen is worthy of ranking with the splendid James $H$. Veitch. The colour is paler. The flowers are larger and even more abundantly produced.

PYRUS.-This great genus shows an addition in Veitchiana, a tree of rapid growth, with ovate toothed leaves and large dull red leaves. An Award of Merit was made to it by the Royal Horticultural Society in IgI2.

RHODODENDRON.-The modern species comprise several plants which, if not of the highest importance, nevertheless are of much beauty and interest. Dealing mainly with the hardy kinds, and these in alphabetical order, we take furst Augustinii, which was named after Dr. Augustine Henry. It is abundant in Western China, where it grows up to twenty feet high. The leaves are lanceolate ; the flowers are about two-and-ahalf inches across and vary from pink to pale purple; there is a white form. Chartophyllum, from Southern China, is an erect evergreen with white, spotted flowers about one-and-a-half inches across; it resembles an Azalea. Flavidum (syn. primulinum) is a small evergreen shrub with Myrtle-like leaves and pale yellow flowers. Harrovianum is an evergreen about three feet high with mauve flowers in clusters. Keiskei is an evergreen from Japan, six feet high, with pale yellow flowers in clusters. Mucronulatum is 

RHODODENDRON YUNNANNESE.

Colour photo by R. A. MaLby. 


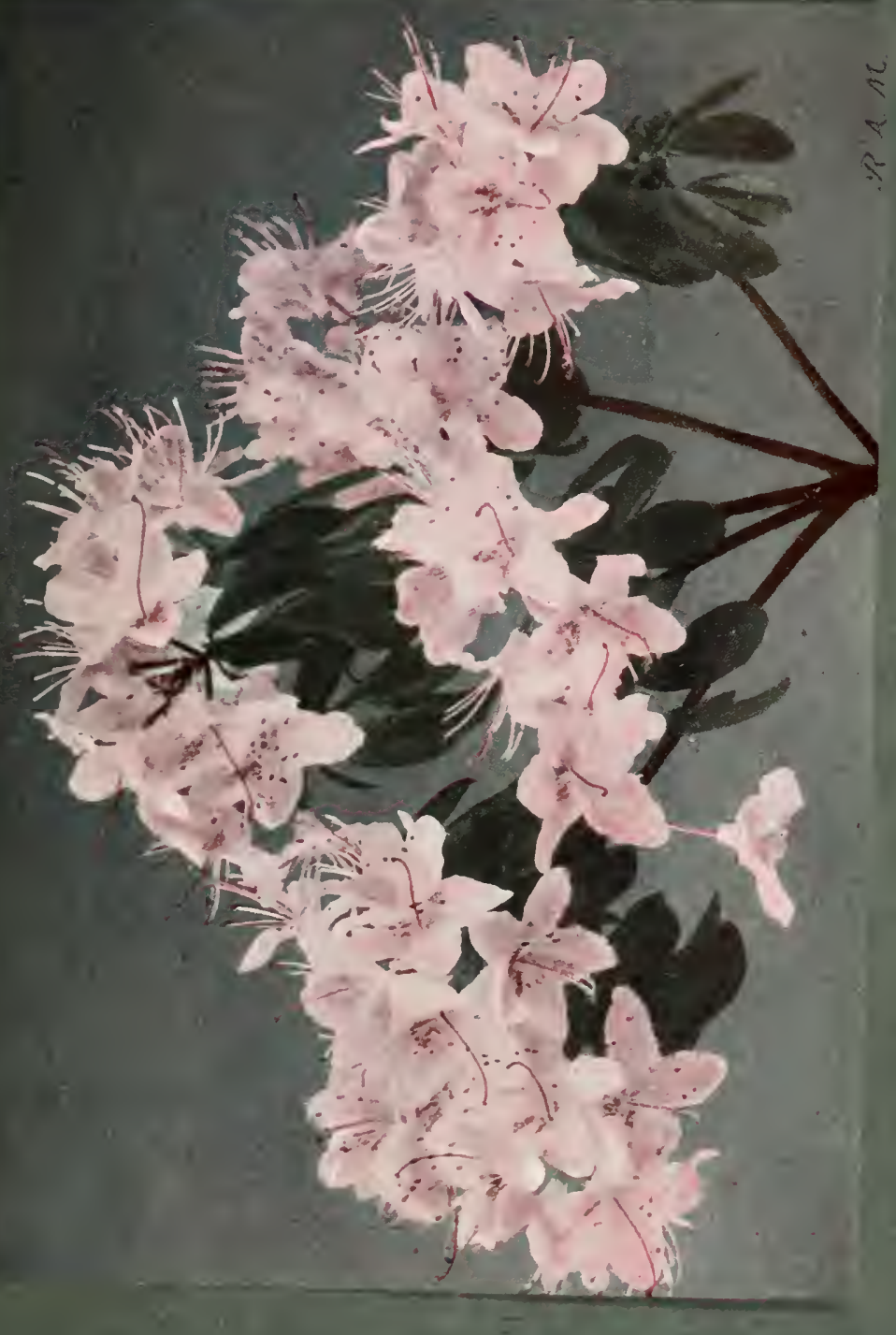




$$
=-
$$
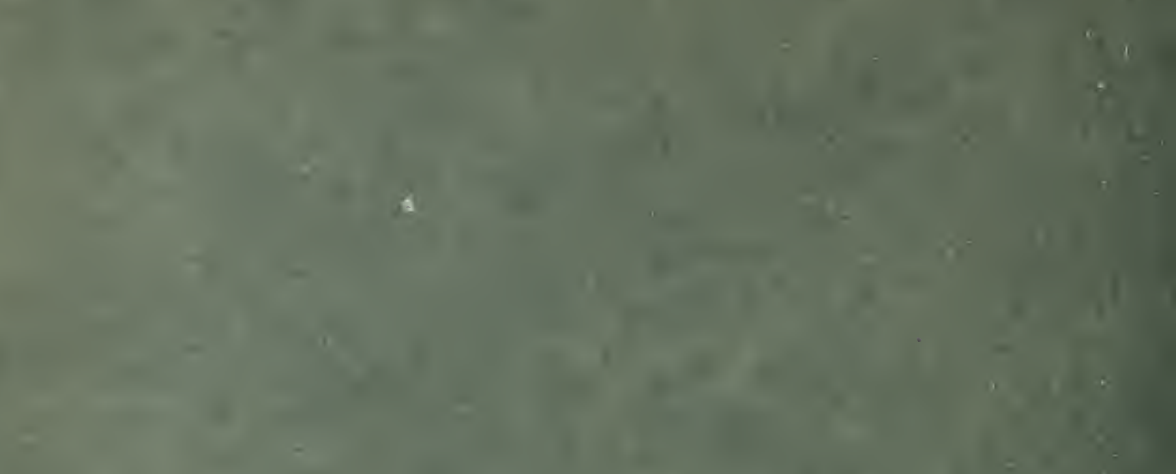

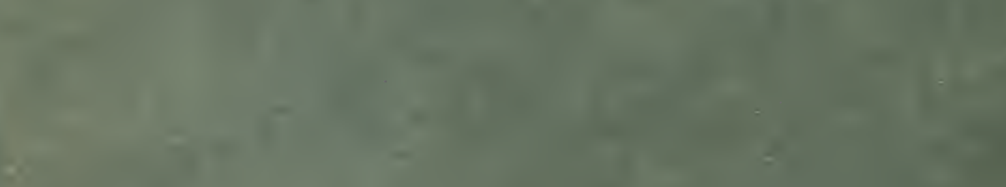
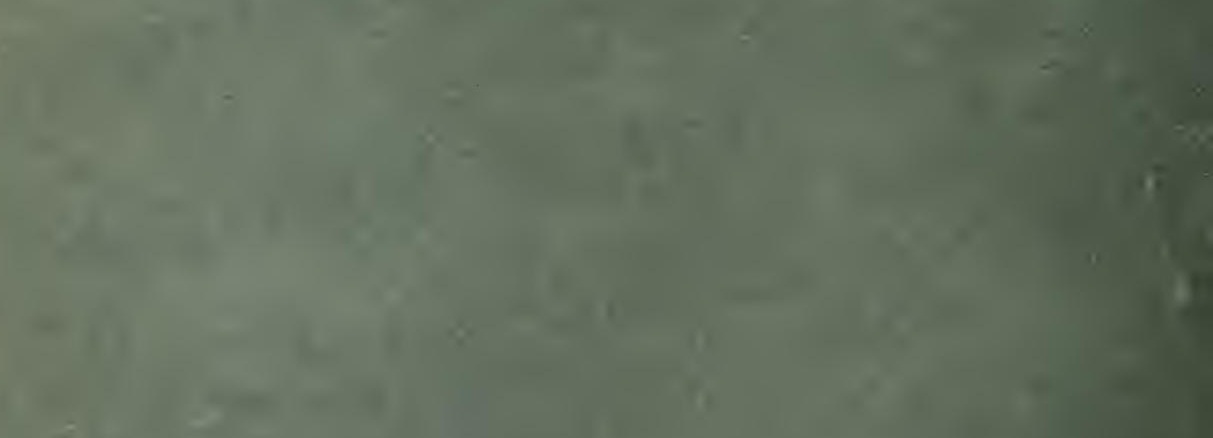

$=x^{3}=$

y 
from Central Asia, it is a low deciduous species with rose flowers in clusters. Przewalskii is an evergreen from China, with white flowers in corymbs. Racemosum is a distinct deciduous species from Yunnan, two to three feet high, with small white or pale rose flowers in clusters from the leaf-axils; useful for the rock garden. Rubiginosum is an erect evergreen from Yunnan four to five feet high, with small trusses of rosy flowers spotted with crimson. Yunnanense is an erect evergreen shrub six feet high, with flowers in open heads like an Azalea, white spotted with crimson. The following should have sheltered places if grown outside, as their hardiness is questioned : auriculatum, from Hupeh, Central China, a tall evergreen, large and beautiful white or rose funnel-shaped flowers. Benthamianum, China, evergreen, violet flowers in threes. Ciliicalyx, Yunnan, resembles formosum, bristly stalks, flowers four inches across, white flushed rose, in large clusters; very beautiful. Decorum, China, large leaves and fragrant flowers but of poor habit. Delavayi, China, an evergreen resembling arboreum, which is a Himalayan species; dark red flowers two inches across in a round head. Fordii, China, flowers white, tinted pink, red spots, in corymbs, a compact evergreen. Intricatum, a smalı dense evergreen from Yunnan with small violet flowers in clusters of five. Irroratum, China, an evergreen six feet high, white spotted with rose. Lacteum, China; bell-shaped flowers in a close truss, white, blotched with purple; resembles Falconeri, a Himalayan species. Micranthum, China, small white bell-shaped flowers in 
racemes. Scabrifolium, a small evergreen, with white or pink bell-shaped flowers in umbels; from Yunnan. Pink Pearl and Alice are the two outstanding garden varieties of recent introduction.

RIBES.-Laurifolium, a species with drooping racemes of greenish yellow flowers, received an Award of Merit from the Horticultural Royal Society in IgI2. It is an evergreen. Leptantha is also an evergreen species with velvety green leaves. Giraldii has drooping branches and greenish flowers.

ROSA.-Two interesting species have been introduced in Moyesii and Willmottiæ, the former bright red, the latter rosy carmine. $R$. Willmottiæ is illustrated in the Botanical Magazine, T. 8r86; it has small foliage, principally in nine leaflets, and brown stems.

RUBUS.-Several new species have been introduced notably Henryi, an evergreen with grey stems; chroosepalus, with deciduous, simple leaves resembling the white Lime, Tilia alba; Veitchii, a deciduous shrub with pinnate leaves and pubescent stems; bambusarum, a graceful trailer with trifoliate leaves downy on the under side in common with the young wood; ichangensis, an evergreen with whitish shining leaves; and polytrichus, thornless branches covered with red hairs, light green plaited leaves.

$S A R C O C O C C A$.-Humile and the larger species ruscifolia are evergreens with glossy leaves that are important because they will grow under the shade of trees. Ruscifolia is a vigorous but compact grower, bearing white scented flowers. 
SCHIZOPHRAGMA.-Integrifolia is a deciduous climber with white bracts. S. hydrangeoides is a Chinese and Japanese species with white flowers which climb by means of aerial roots and is suitable for the pergola; this was introduced as far back as I879. The Schizophragmas are very well described as climbing Hydrangeas.

SPIREA.-Henryi, mollifolia, Veitchii and Wilsonii are all worthy of attention. Henryi bears white flowers in corymbs on long arching shoots in late spring. See the Botanical Magazine, T. 8270. Mollifolia is of creeping habit and is suitable for the rock garden. Veitchii is a fine species blooming in July in white terminal corymbs. It is illustrated in the Botanical Magazine, T. 8383. Assurgens is worth growing for its prettily-tinted foliage alone, but the inflorescence, in rosy panicles, is beautiful.

STRANV ESIA.-Undulata is an interesting evergreen shrub, the principal beauty of which lies in the corymbs of orange fruits. The flowers are white. Glaucescens has glaucous leaves and white flowers.

STYRAX.-Wilsoni is a new Chinese species with slender branches, ovate toothed leaves, brown stems and small white single flowers with cream anthers, produced abundantly inspring, even on quite young plants. An Award of Merit was given to it by the Royal Horticultural Society in May, I9I3. Officinale has sweet white flowers in clusters. Height twelve to fifteen feet.

SYCOPSIS SINENSIS.-An evergreen growing up to fifteen feet high, with ovate lanceolate coriaceous dark green leaves, two to three inches long. 
TETRACENTRON SINENSE.-A native of Central and Western China, where it is a forest tree with alternate, ovate and acuminate deciduous leaves and small yellow flowers in slender spikes.

TILIA OLIVERI.-A Lime with heart-shaped leaves, the under side of which is covered with white down and the upper glabrous.

VERONICA CANTERBURYANA.-A dwarf evergreen species, growing about a foot high, with pale green foliage and white flowers; free and early; a good rock shrub.

VIBURNUM.-Important additions have been made to this genus, notably in coriaceum, an evergreen growing up to fifteen feet high, with creamy flowers; Davidii, a dwarf evergreen with ovate coriaceous greenish brown leaves, white or blush flowers in corymbs and small oval blue berries ; Henryi, an evergreen with glossy lanceolate leaves. which produces panicles of coral fruit in autumn; phlebotrichum, deciduous, white flowers in corymbs in spring, scarlet fruit in autumn; rhytidophyllum, a noble evergreen with magnificent foliage, dark green above, downy below, yellowish flowers in corymbs and dark red berries, First-class Certificate from the Royal Horticultural Society; theiferum, resembling phlebotrichum, but larger throughout ; utile, an evergreen with corymbs of white flowers in early spring; see the Botanical Magazine, T. 8I74; buddleifolium, long wrinkled leaves; Sargentii, remarkable for its very large leaves; and Carlesii, white or blush fragrant flowers, one of the best of the newer kinds. 


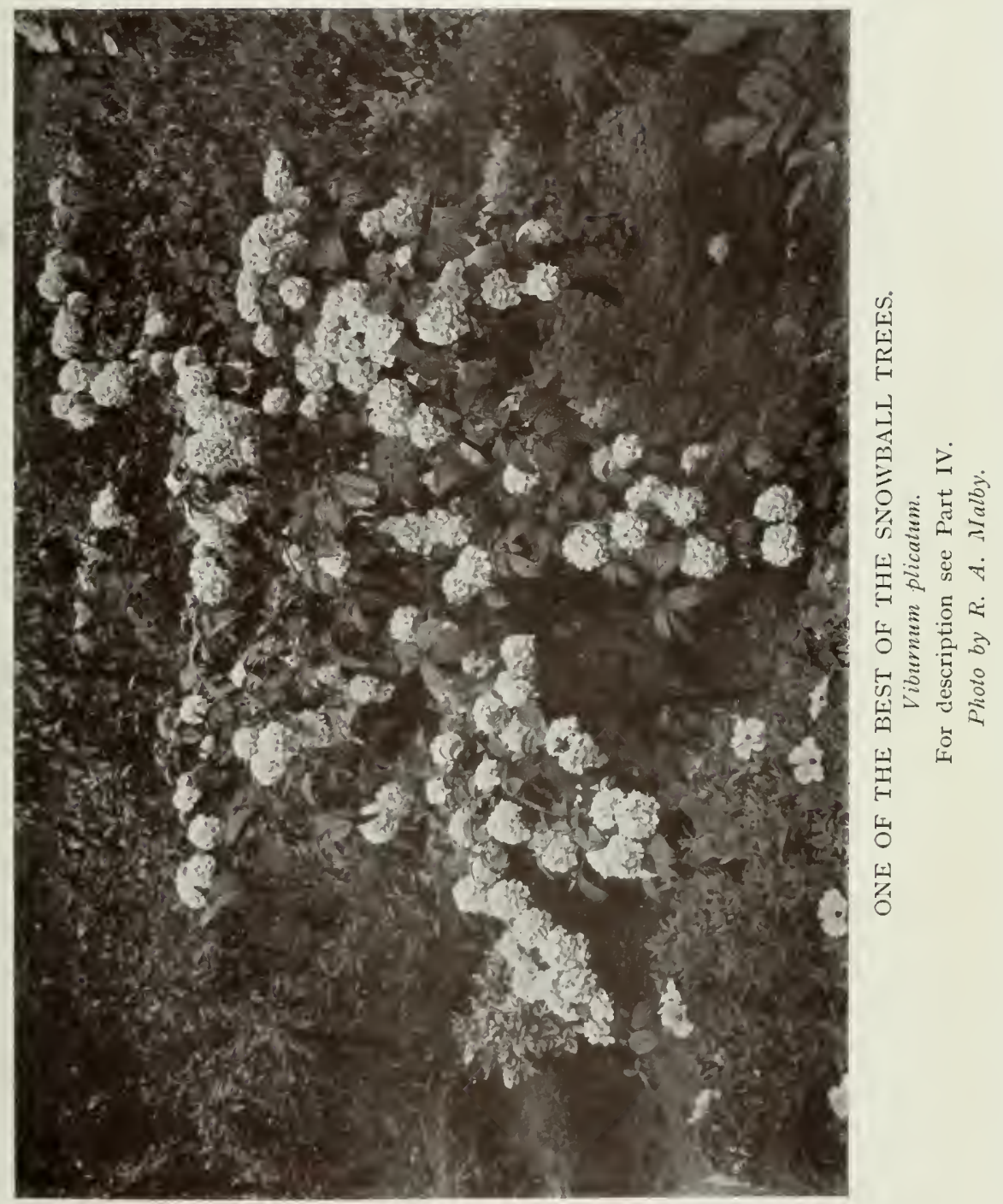




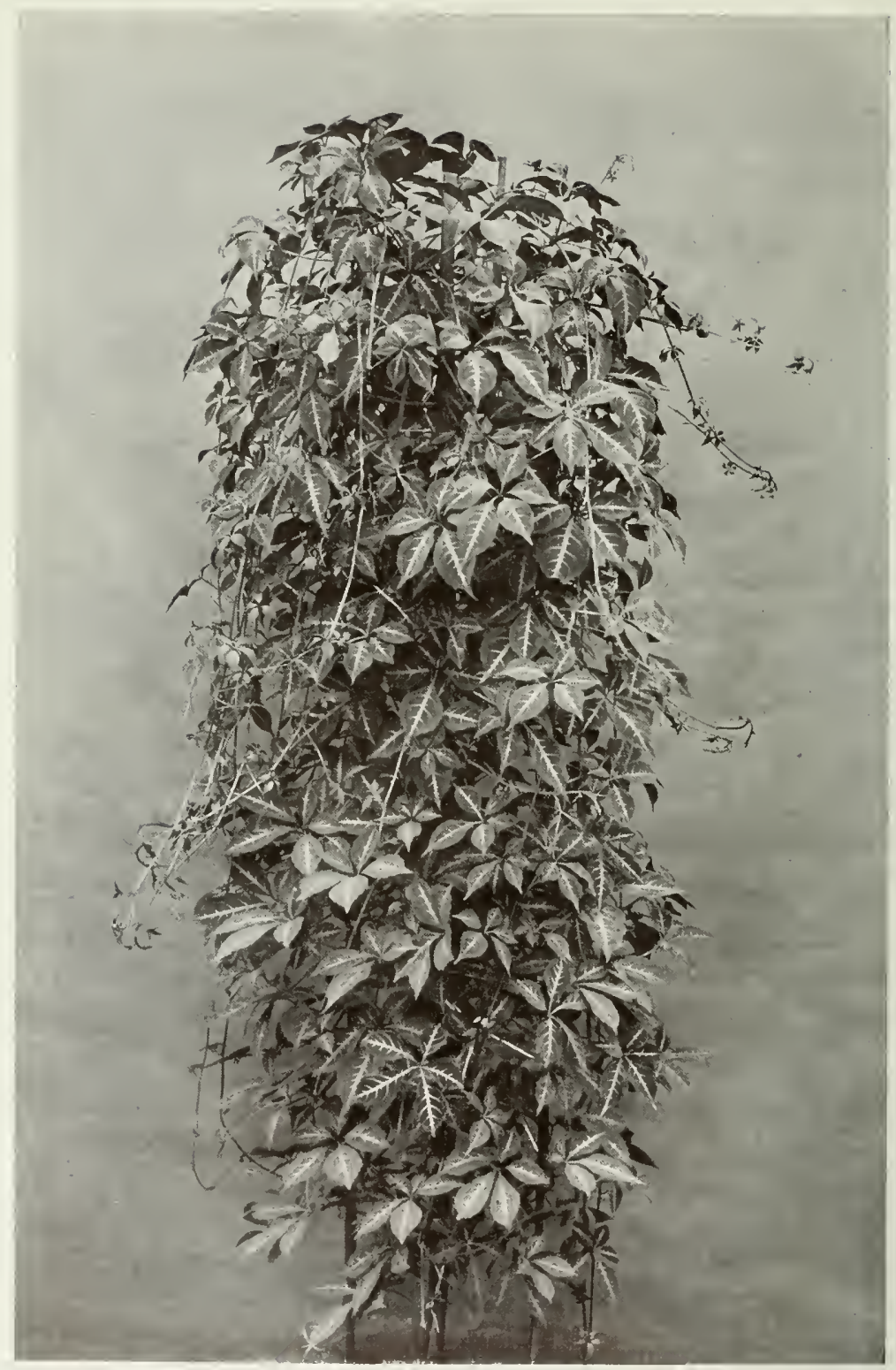

A REMARKABIE NEW VINE. I'itis Henryana.

For description see Part IV. Photo by R. A. Malby. 
VITIS.-The vines are supplemented by armata, a dense grower which colours well in autumn; armata Veitchii, a splendid variety of brilliant colour ; flexuosa Wilsonii, bronzy foliage, crimson on the under surface; Henryana, green leaves (red in autumn) with white veins and midribs; leeoides, pinnate leaves, red above, green below; megalophylla, a rapid grower with enormous leaves; and sinensis, a species with bright green leaves that vary a good deal in form.

\section{ADDENDUM.}

KOLWITZIA AMABILIS.-An interesting hardy shrub, with small, oval, acuminate, opposite leaves, chocolate-coloured stems, and pinkish-white, yellowthroated flowers resembling the Weigela (see photograph). 


\section{SECTION B.}

Notes on the Best Shrubs and Trees, in Alphabetical Order.

ABELE. - The Abele is the white Poplar, Populus alba, and is dealt with in Chapter IX. A good tree for moist spots.

$A B E L I A$.-Generally included in lists of hardy shrubs, but as a matter of fact not quite safe in cold districts in Northern climes. The flowers are in drooping clusters. Floribunda, an evergreen, rose flowers in spring; rupestris (syn. chinensis) sweet blush flowers); serrata (syn. uniflora), an evergreen, pale red, sweet, spring, tender ; and triflora, cream, are generally offered. They should have light soil containing peat and leaf mould, and a sheltered place near a wall.

ABIES.-As stated in Chapter XVII., where some of the best of the Spruce Firs are described, this genus is connected with Picea and Pseudotsuga. The synonyms are stated in the chapter referred to.

$A B U T I L O N$.-One species, vitifolium, is hardy enough to be grown outdoors in mild districts, but most of the Abutilons are greenhouse subjects. Vitifolium bears pale blue flowers in July and grows up to 
ten feet high. There is a white form called album. The silvery foliage is an additional attraction to this species, which is shown in one of the coloured plates.

$A C A C I A$.- See Robinia.

ACANTHOPANAX.-See Aralia.

$A C E R$.- Inasmuch as this deciduous genus includes the Maples, the Sycamore, and the variegated Negundo, it is one of considerable value. The Japanese Maples described in Chapter XV., where some good varieties are named, are very popular, as the foliage is in many cases prettily cut as well as richly coloured. For Acer Negundo variegata see Chapter XV., for the Sycamore, Chapter IX. The best Japanese Maples are forms of Japonicum and palmatum, particularly of the latter. A. campestre is the common Maple. A. platanoides is the Norway Maple, and of the several varieties, Reitenbachii, Schwedleri and Walderseei are popular. A. Pseudo-Platanus is the Sycamore; there is a particularly beautiful variety of this named Prinz Handjery; the foliage is of an exquisite bronzy salmon shade in spring, and colours brilliantly in autumn; it is one of the most conspicuous objects in a border in spring; another good variety is Leopoldii. A. rubrum is the scarlet Maple. A. saccharinum is the Sugar Maple. A. dasycarpum is the Silver Maple. A. rubrum is the only one of the Maples which should be chosen for a damp site. A form of A. pictum has attracted some attention during recent years, and is offered by some nurserymen under the name of colchicum aureum. The golden tint of the foliage is noteworthy. Colchicum or Colchicum rubrum is simply 
a synonym of pictum. Carpinifolium is the Hornbeamleaved Maple.

ACTINIDIA.-Deciduous climbers which might be used for pillars and pergolas. Kolomikta is an interesting and uncommon plant. Volubilis and polygama are the best known. All these have white flowers in summer. Chinensis has heart-shaped leaves on hairy stems and yellow flowers, which it bears freely on ripe wood in summer. The female form has deeper coloured flowers than the male.

ADENOCARPUS.-A small genus, not entirely hardy, all with yellow flowers. Anagyrus, foliolosus, hispanicus and intermedius are the principal species. Sandy loam.

ESCULUS.-This is the botanists' genus for the Chestnut. The Horse Chestnut is Hippocastanum; see Chapters IX. and XX. Album flore pleno is a double white form of it. Carnea (syn. rubicunda), with pink flowers in June, is a beautiful small species; there is a good variety of it called Briotii. Neither of these is likely to grow more than twenty feet high. A still smaller species is parviflora (syn. macrostachya), which has white flowers in late spring, and should not be expected to grow more than eight or ten feet high. Californica, a newer species, has narrow, glossy leaves. AILANTUS.-The species glandulosa, the Tree of Heaven, is a small deciduous tree grown for its handsome foliage. It is hardy, but strong, cold winds may impair the leaves and consequently it should be planted in a sheltered place. It does well in towns. Where sub-tropical gardening is practised the Ailantus 

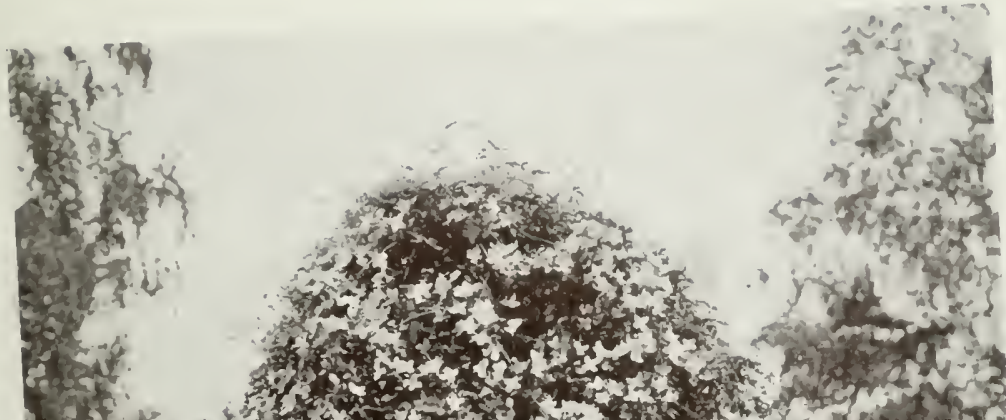

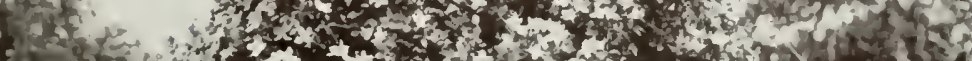

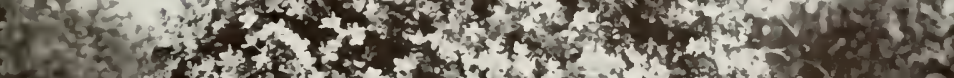
s.

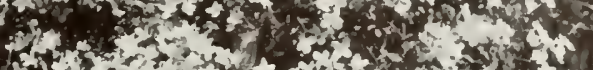

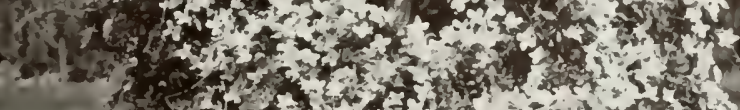
4

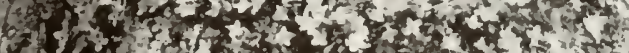

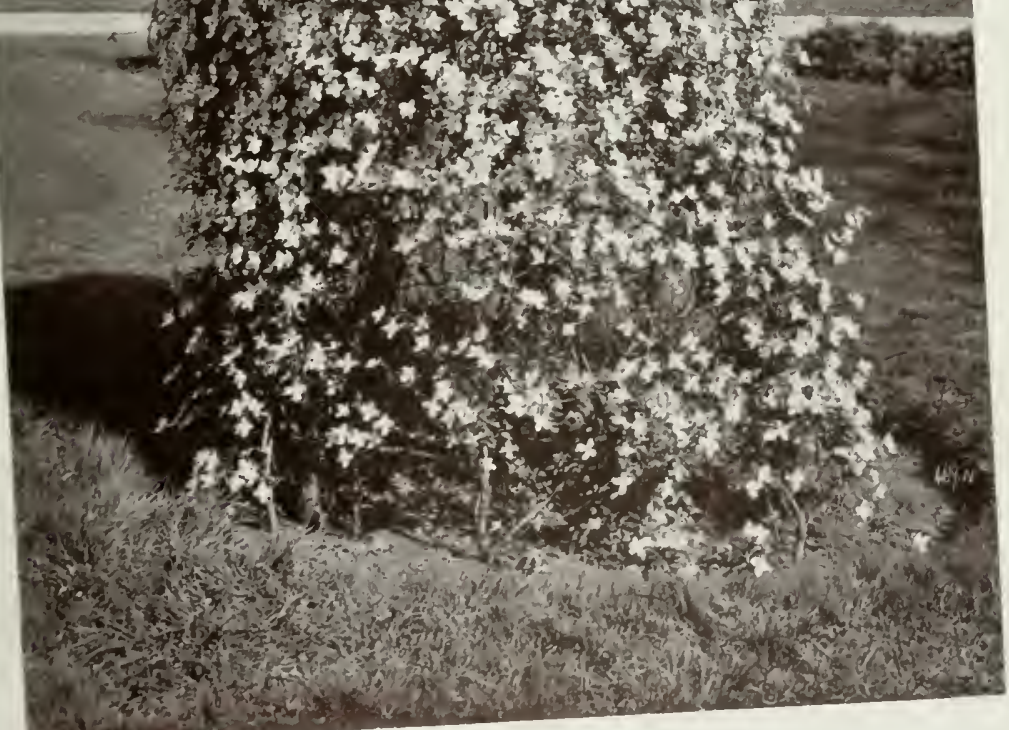

THE NEW RED MOUNTAIN CLENATIS.

Clematis montana rubens.

For description sce Part IV. Photo by E. J. Wallis. 


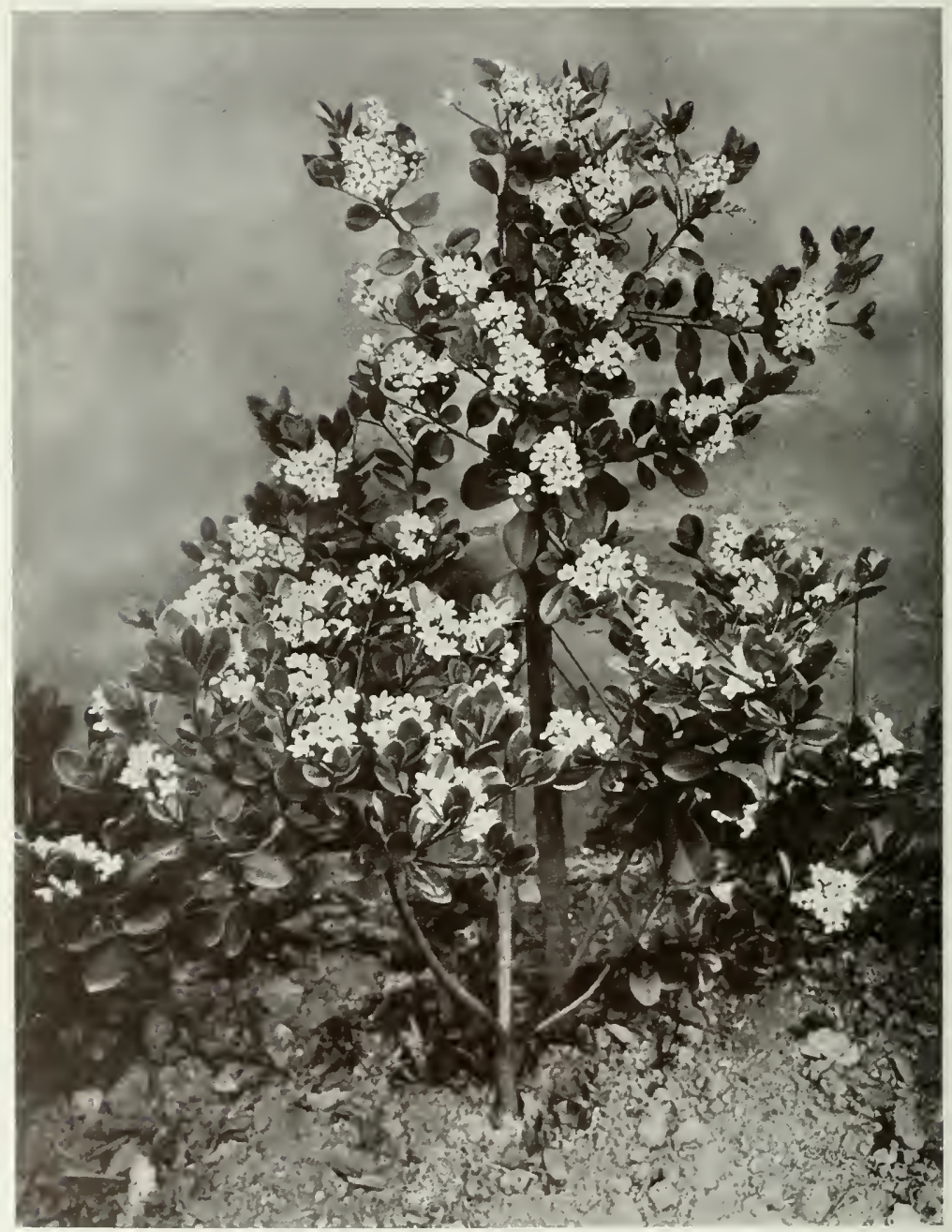

RAPIIIOLEPIS JAPONICA (R. OVATA).

A fine shrub for a sheltered wall. Photo by E. J. Wallis. 
may be cut to the ground in spring if the soil is deep, fertile and moist, as it will then produce splendid foliage. The shoots should be thinned to one. Giraldii has large compound leaves.

$A K E B I A$.- See Chapter XVIII.

ALATERNUS.-See Rhamnus.

ALDER.-The common Alder is Alnus glutinosa, and it is useful because it will thrive in swampy places. Several varieties of it are offered, of which the most popular is aurea (foliis aureis) with yellow tinted leaves. Crispa and laciniata are other varieties.

ALEXANDRIAN LAUREL.-See Ruscus.

$A I M O N D$.- One of the earliest blooming of deciduous trees, sometimes flowering as early as February. The beauty of the bloom is not injured by frost, and the only effect is that the fructifying organs are injured, so that the tree rarely develops fruit in Britain. The Almond belongs to the genus Prunus, to which reference should be made for the best species. Chapters IX. and XXVI. also contain references to it. Although the Almond likes a light soil, it is not fastidious. It thrives in suburban gardens.

ALPINE ROSE.-See Chapter XIX.

ALTHÆA.-See Hibiscus.

AMELANCHIER.-As stated in Chapter IX., A. canadensis (syn. Botryapium), is an attractive deciduous shrub and much the best of the genus. Apart from its flowers the autumn tint of the leaves must be considered in its favour. Florida is the same 
as alnifolia. Vulgaris is the common Amelanchier or Snowy Mespilus.

AMERICAN ALLSPICE.-See Calycanthus. All have white flowers in spring.

$A M E R I C A N$ ARBOR-VITAE.-See Thuja, and Chapter XVII. on Conifers.

AMORPHA.-Two species are generally offered: canescens, the Lead Plant; and fruticosa, the False Indigo. The former has blue and the latter purple flowers in late summer. The blossoms are Pea-shaped and produced in racemes. Height three to five feet. There are several varieties. The Amorphas are not thoroughly hardy and should have sheltered places.

AMPELOPSIS:-The best plant by far grown under this name is Veitchii (syn. tricuspidata), which botanists now call Vitis inconstans. Its rapid growth, perfect climbing habit, neat foliage and beautiful colour in autumn render it one of the best of house plants for warm aspects. It is not particular as to soil. Nurserymen offer plants in pots suitable for planting at any time, but if the site is hot, planting should be done before the end of March, and it is wise to cut down the plants to within a foot of the base, and mulch with short manure. There is a dark form called purpurea. A. hederacea (syn. quinquæfolia), the common Virginian Creeper, is an altogether coarser plant, but it colours in the fall; muralis is a form of it.

AMYGDALUS.-See Almond and Prunus. The Bitter Almond is Amygdalus communis amara and the Sweet Almond A. c. dulcis; but the genus is now merged in Prunus by botanists. 
ANDROMEDA.-The best known member of this genus, now that several species have been referred to other genera, is polifolia, which grows about a foot high and bears rosy flowers in June. Nurserymen offer a narrow-leaved form called angustifolia. They may also list arborea, which produces white bell-shaped flowers in late summer, and makes a handsome bush several feet high, and floribunda (Pieris floribunda) white flowers in Spring, three to five feet. In common with most of the Ericaceæ, the Andromedas thrive best in moist peaty soil in a sheltered place ; and they enjoy partial shade. See also Cassandra, Leucothoe, Pieris and Zenobia.

APPLE.-See Pyrus. The beauty of the orchard should be considered in connection with ornamental trees. The large flowered Apples are very beautiful in their mantle of pale pink bloom, and might be planted in gardens with ornament in view.

$A R A L I A$.- The most interesting plant in this genus for the garden is A. mandschurica, often grown under the name of Dimorphanthus mandschuricus; but chinensis, ricinifolium and spinosa (syn. Acanthopanax japonicum) are handsome hardy shrubs, valuable where sub-tropical bedding is carried on. There are silver-variegated and golden-variegated forms of mandschurica, both beautiful plants, suitable for sheltered, sunny spots.

$A R A U C A R I A$. - The only hardy species is imbricata, the Monkey Puzzle or Chile Pine, which is referred to in Chapter XVII.

ARBOR-VIT E.-See Thuja, Conifers, Chapter XVII., and Shrubs for Hedges, Chapter XXIV. 
ARBUTUS.-The beautiful Strawberry Tree, A. Unedo, is well worth planting where a sheltered place and light friable soil can be provided, as it will then make a fine evergreen shrub nine to twelve feet high. It is not only attractive by reason of its clusters of white flowers in late summer, but by its large dense red strawberry-like fruits, which are beautiful in winter. Nurserymen offer several varieties of it, Croomii, with scarlet honey-scented flowers, being one of the best; coccinea has pink and rubra red flowers; others are magnifica, microphylla, New Scarlet and rotundifolia. A. Andrachne is a small tree with laurel-like leaves, red bark and greenishwhite flowers. Other species are canadensis, densiflorus, furiens, hybrida, mollis and tomentosa. As members of the Ericaceæ the Arbutuses enjoy a peaty soil.

ARCTOSTAPHYLOS.-This evergreen genus is close to Arbutus. The best known species is Uvaursi, an evergreen trailer with pink flowers in April. It likes peaty soil. Californica is a variety of it.

ARISTOLOCHIA.-Sipho, the Dutchman's Pipe, with brown and yellow flowers in May, is a hardy rambler which may be used for pillars and pergolas. It is not particular as to soil.

ARISTOTELIA.-A small genus of evergreens. Macqui is the only species much grown. It grows up to six feet high, and has greenish flowers in May, followed by black berries. Variegata is a form of it. Sandy soil.

ARONIA.-See Cratægus and Pyrus. 
ARTEMISIA.-The species Abrotanum is the well-known Southernwood, a deciduous shrub of no great beauty, but liked for its powerful aromatic odour, which comes from the leaves. The yellow flowers are borne in summer. Camphorata is a small shrub with finely cut perfumed leaves.

$A R U N D I N A R I A .-$ See Bamboos.

$A R U N D O$.-Only inferior to the great Pampas Grass in effect, Arundo conspicua is well worth planting in moist spots or by the waterside. The silky white panicles may be eight feet high in August. A. Donax, the Great Reed, has reddish plumes fading to white, eight to twelve feet high. There is a dwarf form with striped leaves called versicolor, a variegated form called variegata, and one with very large leaves, called macrophylla. They should have a sheltered place and a covering over the stools in winter. Although used as shrubs and listed in shrub catalogues, they are really herbaceous, but they hold their panicles for several months.

$A S H$.- One of the most familiar of our large deciduous timber trees, the Ash, Fraxinus excelsior, has several forms, such as arbutifolia, argenteo-variegata, (silver variegated), aucubæfolia and pendula (drooping). The last named may be used for a lawn tree. F. Ornus is the Flowering or Manna Ash, which produces panicles of creamy flowers in May : angustifolia, Mariesii and variegata are forms of it; Mariesii is the best. F. Americana is the White Ash. They are not particular as to soil.

The Mountain Ash is Pyrus aucuparia. 
$A S P E N$.-Populus tremula, see Poplar and Chapter IX.

ATHROTAXIS.--See Conifers, Chapter XVII. $A T R A G E N E$.- See Clematis.

$A U C U B A$.-This popular evergreen is dealt with in Chapters $\mathrm{XX}$. and $\mathrm{XXV}$. It will grow in almost any soil and situation. Those grown are all varieties of japonica. There are both male and female forms of the type. The following are female forms : limbata, fructu-alba, (white fruit), longifolia, vera nana and viridis. Only female forms bear berries, and a male plant is necessary for fructification.

AUSTRIAN PINE.-See Chapters IX., XVII., etc. $A Z A L E A$.-See Rhododendrons, also Chapters IX., XIII., and XXVI. The varieties named in the last are also good for the garden.

$A Z A R A$.-Pretty evergreens with fragrant flowers, suitable for low walls, or open bush culture. None, with the possible exception of microphylla, are thoroughly hardy, so that if grown in the open they should have a sheltered place. Gilliesii, with yellow flowers in spring and foliage resembling Holly, is perhaps the best. Microphylla, however, is well worth growing for its vanilla-like scent and autumn berries. Dentata, integrifolia, lanceolata and serrata are also offered by nurserymen. Leaf mould and peat may be added to the soil, which should be well drained.

$B A C C H A R I S$.- The species halimifolia, the Groundsel Tree, is useful for seaside gardening; it has white flowers in summer. Ordinary soil.

BALSAM POPLAR.-Populus Balsamifera. 
$B A M B O 0$. - We have seen in previous chapters that Bamboos make beautiful clumps on lawns, and are appropriate for an approach to the waterside. They are full of grace, and make a splendid foil for more massive evergreens, such as Rhododendrons. Given sheltered positions and fairly fertile and moist soil, they grow into magnificent masses. They like a peaty soil, but are not very fastidious. Leaf mould may be added to stiff soil. They dislike strong cold winds, and exposed sites are therefore unsuitable. The Bamboos are made up of four botanical genera : Arundinaria, Bambusa, Phyllostachys, and Thamnocalamus. Nurserymen are liable to confuse these, and the pitfalls are indicated in the following selection of the best: Arundinaria.-Fortunei variegata, Hindsii, Japonica (Bambusa metake) nitida (a very graceful species with purple stems) and Simonii (syn. Bambusa Simoni); variegata is a form. Bambusa.arundinacea, marmorea, Nagoshima, nana and palmata. Phyllostachys.-aurea, Castillonis, flexuosa, Henonis, nigra, mitis and viridi-glaucescens. Thamnocalamus.falcata (syns. Arundinaria falcata and Bambusa gracilis) and Falconeri. The last is very hardy. Arundinaria Veitchii (syn. Bambusa Veitchii) is beautiful but far from hardy. Practically, all the Phyllostachys are commonly grown under the name Bambusa. The Bambusa tessellata sometimes met with in gardens is the same thing as Arundinaria Veitchii. If grown outside it might be put in a sheltered part of a large rock garden. Large Bamboos sometimes throw up flower-stems freely after growing 


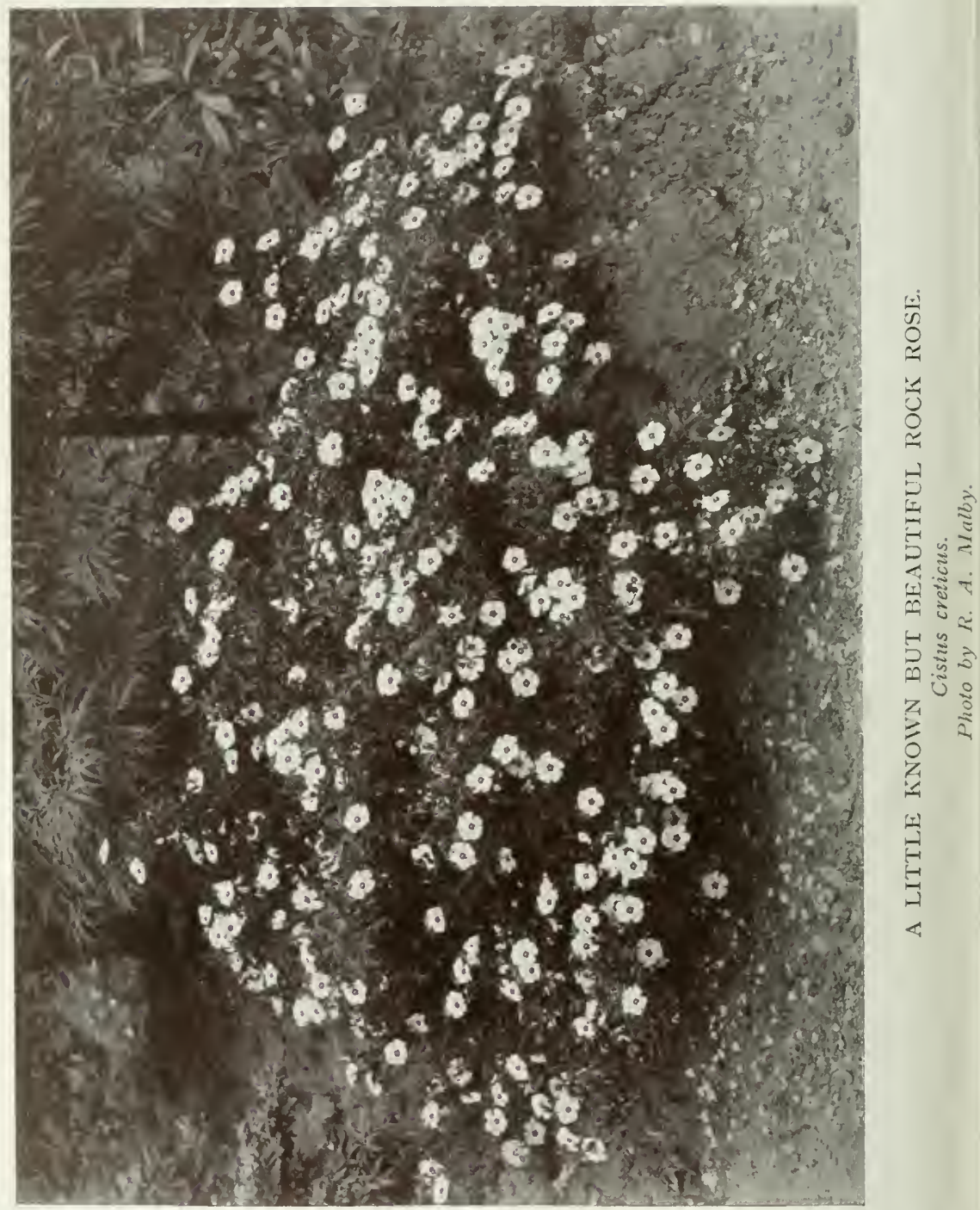


(syn. dulcis), Darwinii (the best), Knightii, Fortuneii, stenophylla and Wallichiana (syn. Hookeri); of the deciduous, concinna, Thunbergii and vulgaris and its varieties. The newer kinds are described in Section A. There are several forms of stenophylla, such as corallina, diversifolia, erecta, gracilis, Irwinii (good for the rockery) and latifolia. Pruinosa is a rare Chinese species with glaucous leaves.

$B E R C H E M I A$.- Most of the members of this genus are not hardy, but volubilis, which bears greenish white flowers in summer, may be grown on a pillar or pergola. Racemosa variegata is beautiful on stakes in a pot ; the foliage is exquisitely tinted.

BETULA (BIRCH).-The common silver Birch, so much admired for its creamy bark, which peels off in large flakes in autumn, one of the best known of our smaller trees, is Betula alba. There are several varieties of it, differing in the form of the leaf or habit, notably fastigiata, laciniata, pendula, latifolia, pendula Youngii and purpurea. It will grow in almost any soil. Lenta is the North American Cherry Birch, and is a forest tree, as is papyrifera. Populifolia resembles the silver Birch, but is rather smaller.

BIGNONIA.-Only capreolata is hardy (see Chapter XVIII. also Chapter XIII. for pruning) unless grandiflora and radicans are included ; botanists now put these under Tecoma. Both are scarlet. Thunbergii is a late-blooming variety of radicans. Both ought to have wall shelter. Ordinary soil.

BIOT A.-See Thuja.

BIRCH.-See Betula. 
BIRD CHERRY.-See Prunus Padus.

$B L A C K T H O R N$.- See Prunus spinosa.

BLADDER SENNA.-See Colutea.

$B O X$. - The usefulness of this evergreen was seen in Chapters IX. XVI. and XXIII., while in Chapter XXIV. its value as a hedge plant was shown. The garden forms of Buxus sempervirens, such as argentea and Handsworthiensis, are dense evergreens that will thrive in almost any soil. They have an aromatic odour. The fact that Box will bear clipping, and is long-lived, makes it no mean rival for the Yew, with those who like formal bushes and topiary. See Chapter XXIII. Suffruticosa is the form used for low edgings.

$B R A M B L E$.-See Rubus.

$B R I D G E S I A$ SPICATA.-See Ercilla.

$B R O O M$.--Reference to the Brooms was made in Chapter IX., also in Chapter XIX., where some of the best Cytisuses and Genistas are named. The Butcher's Broom is Ruscus aculeatus. See Chapter XVI., also Cytisus and Section A.

BROUSSONETIA.-A small genus of deciduous Japanese trees, of which only one species, papyrifera, is much grown. Dissecta (syn. laciniata) and cucullata are forms of it. The foliage is handsome, and they are worth growing in a large collection of shrubs, but a sheltered place must be provided, as they are none too hardy. Ordinary soil.

BRUCKENTHALIA.-Spiculifolia, which is offered in some catalogues, is a Heath-like plant with purplish flowers, liking peaty soil. The height is about a foot. 
It might be grown with other small members of the Ericaceæ in a peat bed at the foot of a rockery .

$B R Y A N T H U S$.-A member of the Ericaceæ, liking moist peaty soil. Empetriformis (syn. Menziesia empetriformis) with purplish flowers in summer, height about six inches, is offered.

$B U D D L E I A$.- This genus of deciduous shrubs is dealt with in Chapters IX. and XVIII. Globosa makes a useful and compact small tree, and is both attractive and interesting when bearing its little golden balls. It should have light friable soil and a sheltered place. Variabilis Veitchiana bears splendid panicles of purplish inflorescence. B. V. magnifica resembles it, but has deeper coloured flowers. Both of these are hardier than globosa, but enjoy a wall border. Colvilei, crimson, is beautiful but tender. They flower in summer and hold their leaves until winter.

BUPLEURUM.-One member of this genus, namely, fruticosum, is a hardy evergreen shrub. It grows four to six feet high and has yellow flowers in summer. It does best when pruned hard every spring. Ordinary soil.

BUTCHER'S BROOM. (Ruscus aculeatus).-See Chapter XXV.

$B U X U S .-$ See Box.

CESALPINIA.-Most of the members of this genus are tender, but sepiaria (syn. japonica) may be grown out of doors in mild districts. It is a beautiful spreading deciduous shrub, with prickly stems and large racemes of yellow flowers with prominent red 
filaments. It blooms in spring. It should be given a fertile, friable soil.

CALLUNA.-Vulgaris is the common Ling or Heather, which grows so abundantly on the peaty uplands as to form a carpet. White Heather is particularly esteemed. Searlii (or Serlei) and Hammondii are two good white forms. Argentea, aurea and cuprea have coloured foliage. There are many other varieties. The Callunas are closely related to the Ericas, and are often grown under that name. Although peaty soil is desirable it is not essential.

CALOPHACA.-Nurserymen offer wolgarica, a deciduous member of the Pea order, growing about a yard high, with yellow flowers in early summer. Ordinary soil.

CALYCANTHUS.-Floridus, the American Allspice, a deciduous shrub, was referred to in Chapter XVIII. C. præcox is the same as Chimonanthus fragrans, which was alluded to in the same chapter. These deciduous, piquantly perfumed shrubs are most at home in the angle of two walls.

CAMELLIA.-These magnificent evergreens are unhappily too tender to grow in the open air, in northern climes, except in favoured localities. One sees glorious bushes of them, however, in Cornish gardens, where they are as beautiful as Rhododendrons. The species Sasanqua may be grown on a warm wall, and covered with a mat in severe weather. It has white flowers, but there are varieties with single red, double pink and double white flowers. A fertile compost of good loam with leaf mould should be provided. 


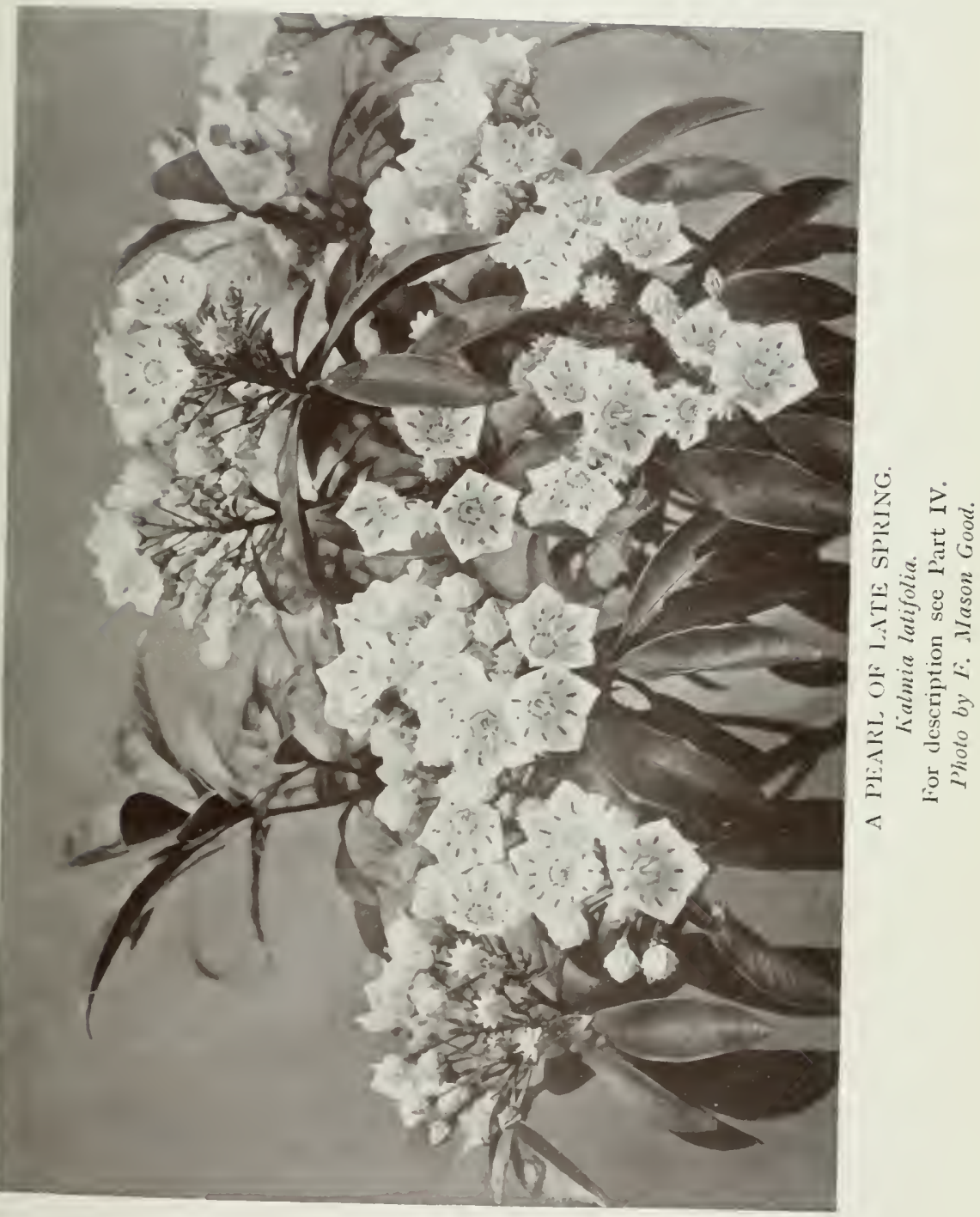




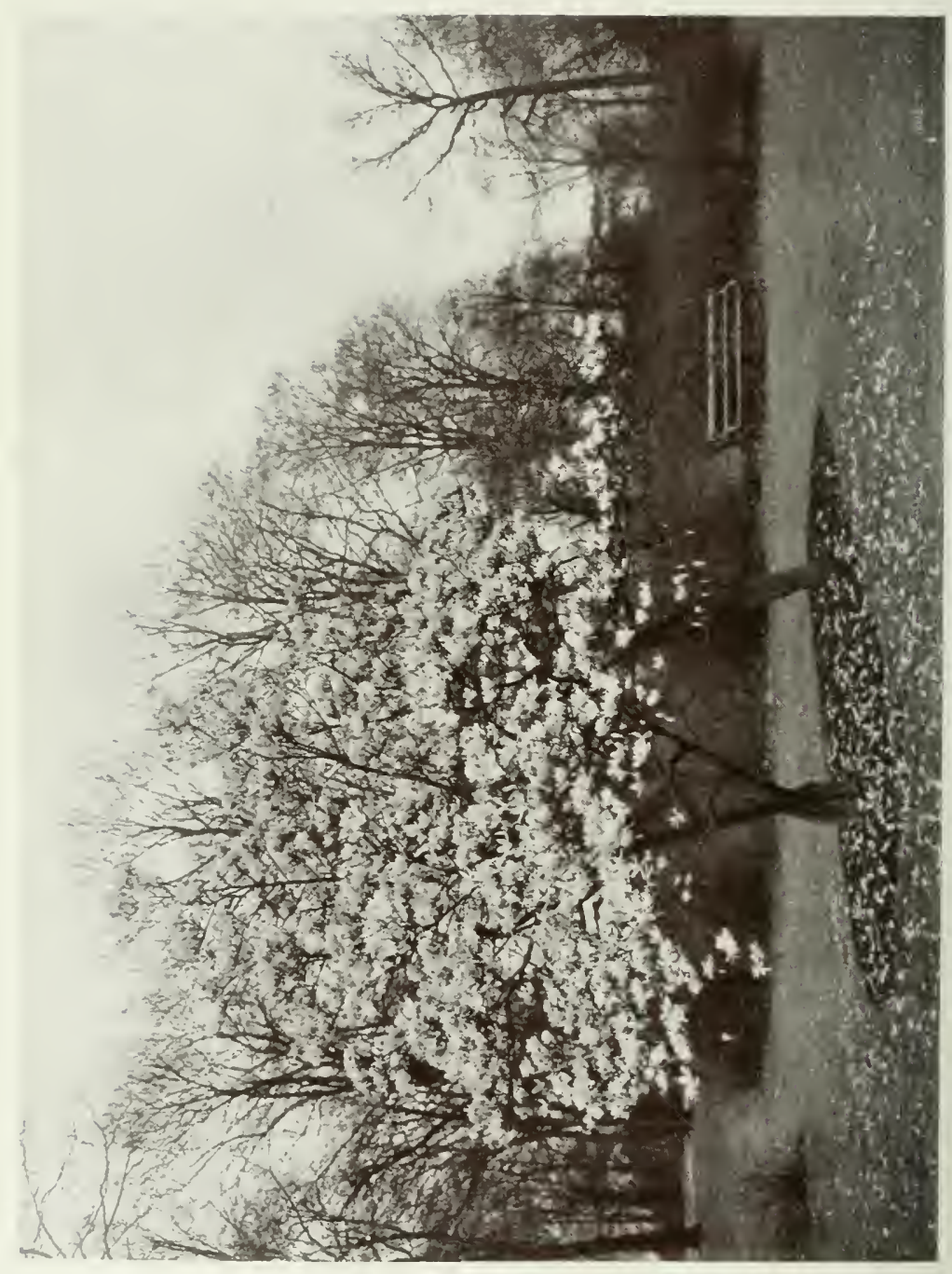

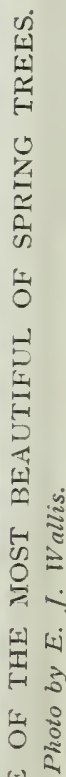
竞

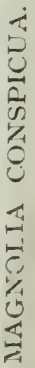


Planters should be guarded in accepting advice to plant Camellias in cold places, which is based mainly on successes achieved under special conditions, as in Cornwall and mild parts of the Thames Valley. It is, however, the fact that examples of success can be quoted in which the conditions are not favourable, and some suggest planting in the open rather than against walls in order that the wood may become well matured; nevertheless, cold places should not be chosen, for Camellias bloom early and the flowers might be injured when the plant was not. In Cornwall varieties of japonica make splendid bushes up to eighteen feet high. Reticulata is also finely represented; this species has very large semi-double rose flowers. Donckelaari is one of the best varieties of japonica.

CANDLEBERRY MYRTLE.-See Myrica.

CAPRIFOLIUM.-See Lonicera and Honeysuckle. CARAGANA.-This deciduous genus belongs to the Pea order (Leguminosæ). Very few are offered, but arborescens and its drooping form pendula are sometimes seen ; more rarely one meets with Redowskii and spinosa (syn. ferox and Robinia ferox). All have yellow flowers in spring. They like a well-drained loamy soil, not a damp, heavy soil and site.

CARPENTERIA.-The only species, californica, is one of the most beautiful of the rarer evergreens, having large white fragrant flowers in spring. It is best grown on a low wall except in very mild districts, as it is not fully hardy. Ordinary soil suffices.

CARPINUS.-This is the botanist's name for the Hornbeam, a tree resembling Beech, and having the 
same character of holding its withered leaves for a long time in winter. It makes a good tall hedge. The common Hornbeam is C. Betulus. Incisa is a variety of it with ornamental leaves, and there are variegated sorts. Ordinary soil. It thrives on moist clay.

$C A R Y A$.-The species alba is the Hickory or American Walnut, a deciduous tree of low growth, but valuable on account of its tough timber.

CARYOPTERIS.-The species Mastacanthus (syn. Mastacanthus sinensis) is one of the most interesting of the smaller deciduous shrubs, and is admirable for a collection of choice species, growing only about two feet high, and bearing blue flowers in autumn; there is a white variety, alba. Although hardy they are not comfortable in an exposed spot, and should have a sheltered place. Ordinary soil.

$C A S S A N D R A$.- This genus is often associated with Andromeda. Caliculata and its form angustifolia have white waxy flowers in spring. The shrub is a member of the Ericaceæ and likes peaty soil. It grows two to three feet high. A hot, dry, sunny position does not suit it.

CASSINIA.-See Diplopappus.

CASSIOPE.-A genus of the order Ericaceæ, allied with Andromeda. Tetragona, a low shrub about a foot high, with white flowers in Spring, is offered. They require, like the Cassandras, a moist peaty soil with shade and shelter.

CAST ANEA (SPANISH CHESTNUT) - C. sativa is the sweet Chestnut, the nuts of which are roasted 
and eaten. Silvel-variegated and golden-variegated, together with other forms, are offered. They are handsome deciduous trees with greenish white flowers.

CASTANOPSIS.-Only one species is generally offered, this being chrysophylla, the Golden Chestnut. The upper surface of the leaves is deep glossy green, the lower golden yellow. It is an evergreen shrub, and grows slowly. Ordinary soil.

CATALPA.--One of the best of deciduous town trees, $C$. bignonioides is unaccountably neglected, for its flowers are very beautiful, and they come much later than the blossom of the majority of flowering trees. The foliage, too, is handsome. It is not a rapid grower, and rarely attains to a height of more than twenty feet. Syringiæfolia is the same as bignonioides. Aurea is a yellow-leaved and purpurea a dark form. Japonica (sweet), Kæmpferi and speciosa (syn. cordifolia) are also offered. C. bignonioides makes a nice lawn tree. Ordinary soil.

CEANOTHUS.-References to this useful genus will be found in Chapters IX. and XVIII.

CEDAR (CEDRUS).--See Chapter XVII.

CELASTRUS.--Scandens is a hardy deciduous climber with yellow flowers in May. Articulatus is not worth growing for its flowers, but the red fruits are pretty. It should have plenty of room. Ordinary soil.

CELTIS.-Occidentalis is a hardy deciduous climber with greenish flowers in spring. Ordinary soil.

CEPHALANTHUS.-Occidentalis, the Button Wood, grows up to seven feet high and bears white flowers in summer. It likes peaty soil. 
CEPHALOTAXUS.-Of the Chinese Yews, drupacea, Fortunei and pedunculata with its variety fastigiata (syn. Taxus japonica), are offered. They are small Conifers, rarely more than ten feet high.

Chapter XVII. is devoted to Conifers, and references to Conifers for lawns are made in Chapter XIV. The claim of the Cephalotaxus for inclusion may be considered in connection with other Conifers described.

CERASUS.-This genus, which includes the Cherry, is now merged in Prunus by botanists. It is important to the tree-lover, because it yields several beautiful spring-flowering trees. See Prunus, also Chapters V., VI. and XXVI. The plants offered in nurseries under the name Cerasus include the evergreen species, Laurocerasus and its varieties (see Laurel), and the following deciduous species and their varieties: Avium (varieties Juliana, pendula, latifolia pendula and multiplex), Mahaleb (varieties pendula and variegata), Padus (the Bird Cherry), Pseudocerasus (syns. Sieboldii and Watereri ; James H. Veitch is a beautiful double pink form ; Choskin is paler, see plate; Yoshimo is a charming light pink, see plate); semperflorens (All Saints Cherry); serrulata, the beautiful double white Japanese Cherry ; and sinensis pendula rosea, a drooping single pink form.

CERCIDIPH YLLUM.-One species, japonicum, is offered. It is a half-hardy deciduous shrub only met with out of doors in mild, sheltered places. The height is four feet. Greenish flowers in summer.

CERCIS.-A small deciduous tree of the Pea order (Leguminosæ) of much interest and beauty. The 

PRUNUS PSEUDO-CERASUS CHOSKIN. Colour photo by R. A. Malby. 


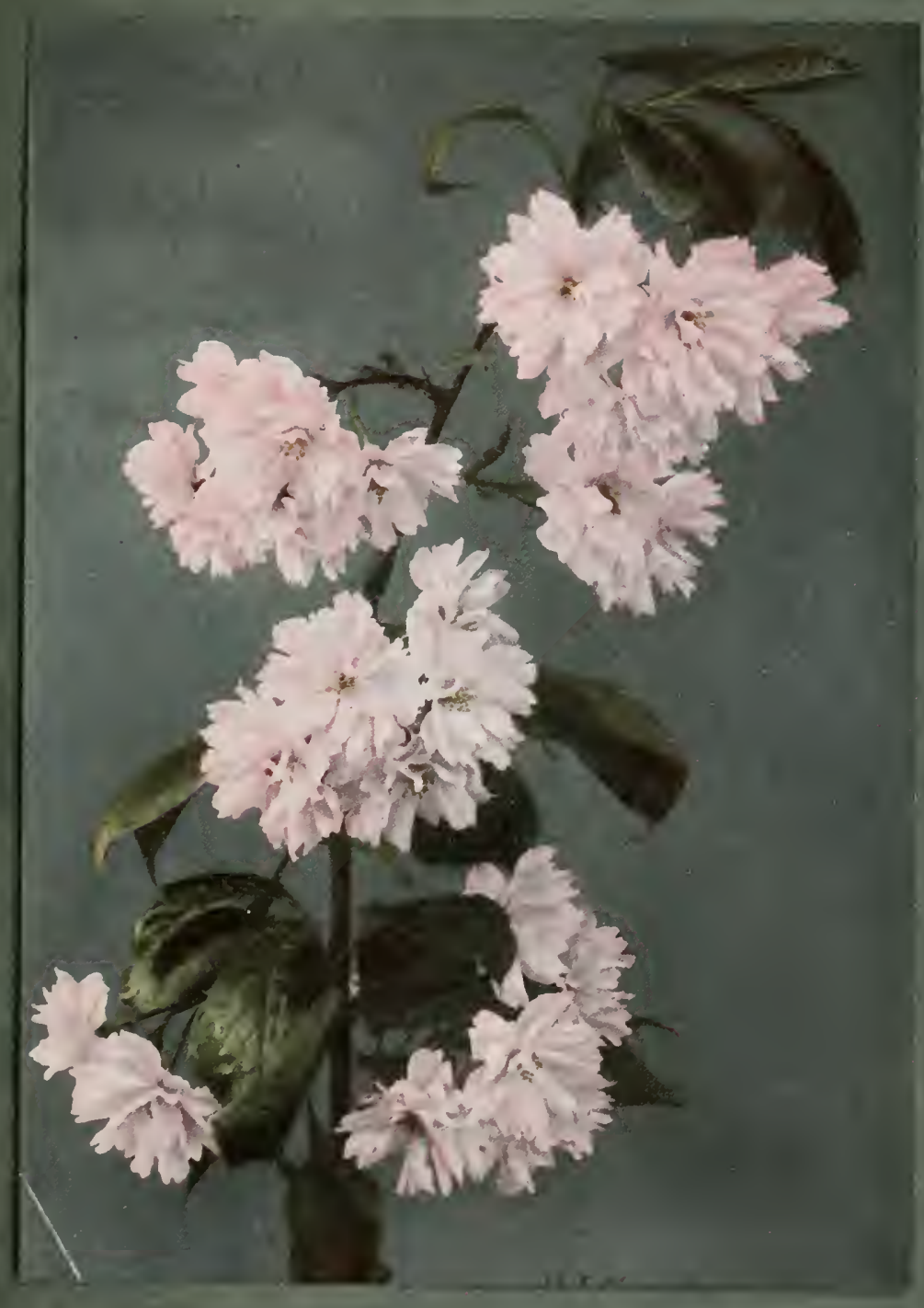




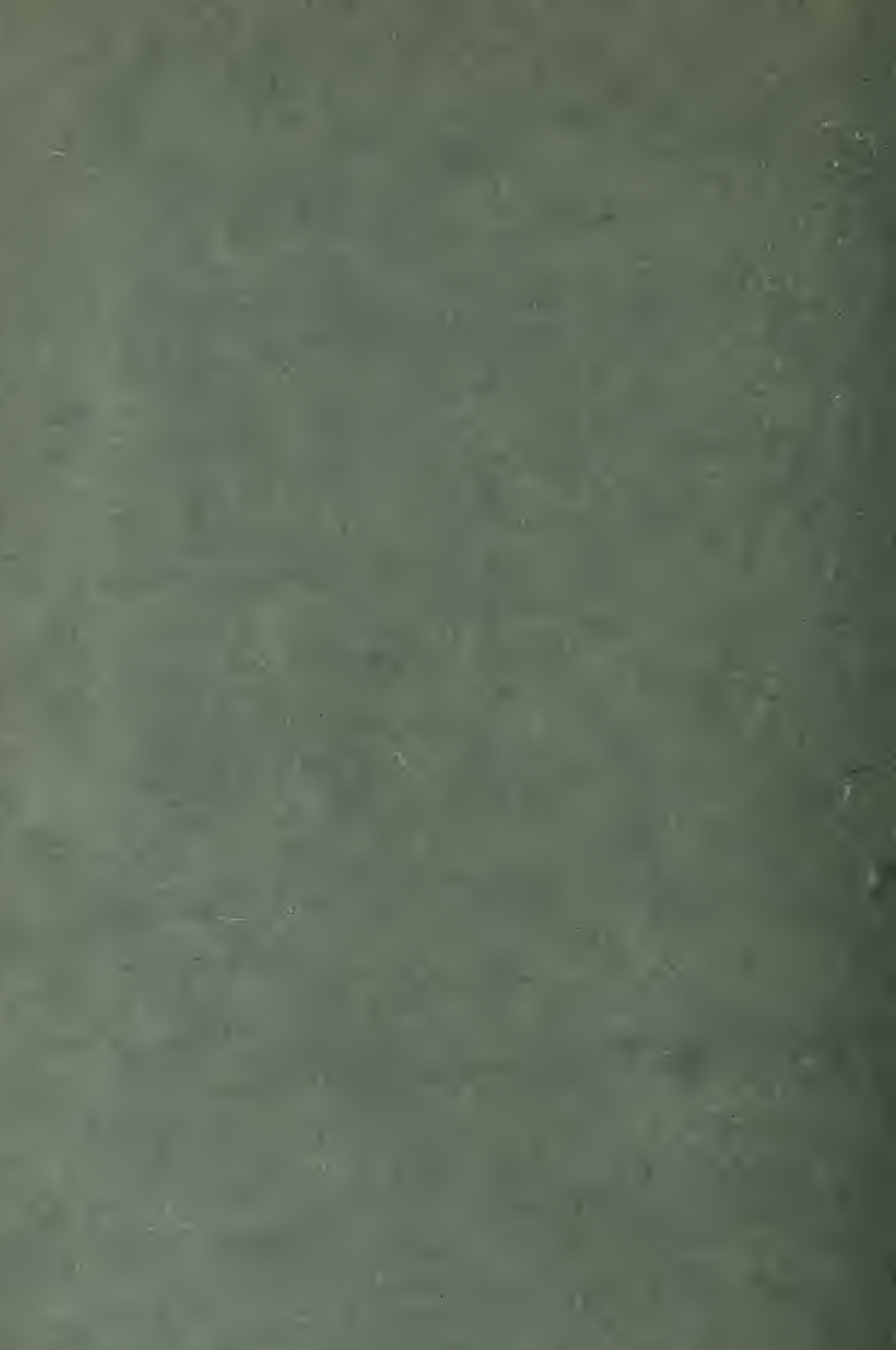


most popular species is Siliquastrum, the Judas Tree, which is hardy except in cold districts, where it should have a wall and well-drained friable loamy soil. The flowers are purple and white. The reddish seed pods are also attractive. There is a white form, alba. Canadensis, a species with red flowers, is also offered. There are several other species, but they are little grown. All bloom about mid-spring, before the leaves appear.

\section{CHAM ECYPARIS (WHITE CEDAR)-See} Cupressus.

CHERRY.-See Cerasus. The best of the forcing Cherries are referred to in Chapter XXVI.

CHERRY PLUM.-This is Prunus cerasifera or Myrobalana, much used as a hedge plant under the name of Myrobella or Myrobalan Plum. See Shrubs for hedges, Chapter XXIV. The variety cerasifera atropurpurea is the well known purple-leaved tree Prunus Pissardii.

CHESTNUT.-See Æsculus and Castanea. The Chestnuts are referred to in Chapters IX. and XX.

CHILE PINE.-See Araucaria.

CHIMONANTHUS.-Fragrans is referred to in Chapter XVIII. See also Calycanthus. Two or three flowers of $\mathrm{C}$. fragrans in a saucer of water will scent a large room.

CHINESE ARBOR-VITEE.-Biota orientalis, the same as Thuja orientalis See Thuja.

CHINESE PEAR.-See Pyrus.

CHINESE YEW.-See Cephalotaxus.

CHIONANTHUS (FRINGE TREE).-Two species 
are offered : retusus and virginica. They are beautiful small deciduous trees, flowering in May and June. C. retusus has white drooping flowers with strap-shaped petals. Virginica also has white flowers. They like peaty soil such as suits the Ericaceæ.

CHOISYA.-The species ternata is a much admired small evergreen shrub, not considered to be fully hardy, and often grown on a sheltered border or against a wall, but it is probably hardier than is supposed, as it thrives on clay in an exposed place at Aldenham House, near London. The habit is compact and dense, the abundant foliage glossy. It produces its white flowers in early summer. Good friable soil is desirable.

CHRIST'S THORN.-See Paliurus.

CISSUS.-See Vitis.

CISTUS.-The best of the Rock Roses are described in Chapter XIX. They are splendid shrubs for hot dry banks.

CITRUS.-This genus includes the Orange and Lemon, which can only be grown under glass in northern climes. One species, however, is hardy, and that is trifoliata, an evergreen shrub growing about four feet high, with white flowers in summer.

CLADRASTIS.-Deciduous trees, of which two species are offered: amurensis (syn. Maackia) and tinctoria (syn. Virgilia lutea), the Yellow Wood. Both have white flowers in summer. Sandy loam is desirable as damp, stiff ground does not suit them.

CLEMATIS.-Some good varieties of Clematis are described in Chapter XVIII. The shrub-lover may 
well be excused if he feels embarrassed by the multitude of riches when he surveys this important genus, for in addition to the richly coloured hybrids and garden varieties there are many beautiful species. The problem will probably be solved by the space available for supporting the plants. Where there are pergolas, arbours, arches, summer-houses and other erections on the place, accommodation can be found for a good collection. A great effort will be made to find room for C. montana and its red form rubens; and by those who love novelties for montana Wilsoni, which has larger white flowers than the species and blooms several weeks later. Rubens will flower when only a foot high, and is charming for covering a stump or old tree. Flammula, the Virgin's Bower, is both pretty and sweet ; there is a garden form of this called rubromarginata, the creamy flowers of which are edged with red. Of the other species, æthusifolia, with small linear, much-lobed leaves and small white bell-shaped flowers in late summer; alpina (Atragene austriaca), light blue; calycina, cream; coccinia, scarlet; cirrhosa, white, evergreen; crispa, lilac; grata, bluish white, blooms in autumn; graveolens, yellow; orientalis, white, sweet, and its variety tanghutica, golden yellow (flowers in spring on previous year's wood); and paniculata, white, sweet, an autumn bloomer, will evoke admiration. Vitalba is that beautiful wilding the Traveller's Joy, the feathery white achenes of which cloud the tall hedges in autumn. Coccinea is represented in many gardens by hybrid forms such as Countess of Onslow, violet; 
Duchess of Albany,. pink; Duchess of York, blush ; Grace Darling, rosy carmine ; and Sir Trevor Lawrence, crimson. These are quite distinct in form from the majority of Clematises, having tubular urn-shaped flowers. Florida, white, a September bloomer; lanuginosa, blue, early summer; Viticella, blue, summer; and patens, white, early summer, are not much grown as species, but are represented in gardens by their hybrids, some of which are described in Chapter XVIII. These differ in their flowering habit, and consequently the notes on pruning in Chapter XIII. should be carefully followed. Davidiana, a form of heracleæfolia with blue flowers in summer, is herbaceous; and so is recta (syn. erecta) with white flowers in summer. Indivisa and its beautiful variety lobata are shrubs, but are not hardy enough to be grown out of doors. The Clematises are not very particular as to soil, but they do not care for damp, stiff ground, nor for poor dry soil. Heavy soil should be drained and made friable. Light soil should be liberally manured. Plants can be bought in pots at almost any time, but it is not desirable to plant in hot weather, unless the plants can be shaded and watered till established. It is wise to cut Jackmanii and its forms hard back after planting, so as to encourage them to throw up strong shoots from the base. This fine hybrid and its varieties never give better results than when pruned hard back late in spring every year. The new shoots thus encouraged bloom much better than the old. It is the same with the Viticella varieties. But such treatment would not do for florida, montana, 
lanuginosa, patens and their varieties. For modern Clematises see the chapter on new plants.

CLERODENDRON.-The deciduous species trichotomum may be grown out of doors in mild districts; the white flowers with red calyx are produced in August.

CLETHRA.--Alnifolia and canescens, both with white flowers in summer, height three to four feet, are hardy. The latter produces its flowers in long panicles. They belong to the Ericaceæ and like peaty soil.

CLIMBER.S.-See Chapter XVIII. and various paragraphs in the present section.

CLUSTER PINE.--Pinus Pinaster.

COCKSPUR THORN.-Cratægus Crus-galli

COCCULUS.-See the chapter on modern plants.

COLUTEA.-Arborescens is the Bladder Senna, so called because of its inflated seed pods. It is a deciduous shrub growing eight to ten feet high, with yellow flowers in summer. It will grow in almost any soil and does not dislike an exposed site. Cruenta, which has red and yellow flowers in summer, is also offered.

COMPTONIA.-See Myrica. Asplenifolia is offered.

CONIFERS.-See Chapters V., XIII., XIV., XVII., $\mathrm{XVIII}$, and various paragraphs in the present section. CORCHORUS.-See Kerria.

CORIARIA.-A small genus of which japonica, with rose flowers in June, height up to five feet, is one of the best. The Coriarias are not considered to be fully hardy, but japonica is hardy on the clay at Aldenham House, near London. 
CORK OAK.-Quercus Suber.

CORNELIAN CHERRY.-Cornus mas.

CQRNISH ELM.-Ulmus campestris cornubiensis.

CORNUS (DOGWOOD).-These valuable shrubs are esteemed alike for their flowers and their foliage. C. kousa, formerly known as Benthamia japonica, with red and yellow flowers, height up to eight feet, is rather shy when young, but blooms freely when established. The varieties of alba-in itself a good shrub, which grows up to ten feet and bears white flowers in July-are extremely useful ; Spathi and variegata are two of the best; the latter is very beautiful. Capitata has already been referred to under the name of Benthamia fragifera, by which it is still known. This grows up to ten feet, and has white flowers in late summer, followed by strawberry-like fruits. Florida is one of the best species; it grows up to fifteen feet and has white flowers in spring. Nurserymen offer a red form, rubra ; and there is also one with drooping habit, pendula. Mas (syn. Mascula) which grows up to fifteen feet high and has yellow flowers in late winter, is good; varieties called elegantissima aurea and variegata are offered; and there are others. C. Mas is known as the Cornelian Cherry. The common Dogwood is C. sanguinea, which has greenish flowers in early summer, followed by black berries. Its red stems make it ornamental in winter. Besides these, alternifolia, Amomum, brachypoda, circinata, glabrata, macrophylla, Nuttallii and stolonifera are met with in large collections. Nuttallii colours brilliantly in autumn. Ordinary soil. 
COROKIA.-The species Cotoneaster, an evergreen with yellow flowers, height up to ten feet, is offered. It is not fully hardy, and should be grown on a border under a warm wall. Ordinary soil.

CORONILLA.-Most of the Coronillas are herbaceous, but Emerus, the Scorpion Senna, is a deciduous hardy shrub. It belongs to the Pea order (Leguminosæ) and has yellow flowers in April. Height about three feet. Ordinary soil.

CORSICAN PINE.-Pinus Laricio.

CORTADERIA.-See Gynerium.

CORYLOPSIS.-Two species: pauciflora and spicata, are offered. Both have yellow flowers in winter, opening in advance of the leaves, and grow up to six feet high. They ought to be grown on a wall border. Ordinary soil.

CORYLUS.-See Hazel.

COTONEASTER.-See Chapter XVI. and XVIII. For special kinds see the chapter on modern plants.

CRABS.-The best Crabs, varieties of Pyrus baccata and $\mathrm{P}$. prunifolia, are worth growing both for use and ornament. Crimson Siberian, Chicago, Dartmouth, John Downie, Fairy Apple, Montreal Beauty, Cheal's Scarlet Siberian, Lady Crab and Transcendent are all beautiful and fragrant in fruit and have a brisk flavour. Niedwetzkyana, with rich crimson flowers and brilliant fruits, is a fine Crab from Turkestan; it has also good autumn leaf colour to recommend it. Other beautiful Crabs, whether in flower or fruit or both, are Pyrus floribunda, Halliana, melanocarpa (black-fruited) Ringo (Japanese Crab), Scheideckeri, spectabilis, Kaido 
and Toringo; the last is a dwarf kind. The Crabs are beautiful small trees for the shrub beds.

CRANBERRY.-Oxycoccus macrocarpus.

CRAT EEGUS.-See Chapter XVI. also Thorns, Chapters XVIII. and IX. Special mention was made of the beautiful evergreen thorn, C. Pyracantha and its variety Lalandii, as splendid plants for low walls, not least because they hold their berries all through the winter and do well in town gardens; another variety called crenulata is also offered. These evergreen Thorns are splendid for walls with a north or east aspect. Of the deciduous species, coccinea, Crus-Galli (Cockspur Thorn) and Oxyacantha are the most important. Azarolus, Carrierei, cordata, Douglasii, flava, heterophylla, Korolkowii, melanocarpa, nigra, orientalis, punctata and tanacetifolia are also met with. Coccinea has white flowers and bright red fruit; corallina, corallina nova and maxima are garden varieties of it. Crus-Galli has long, curved thorns ; arbutifolia, Layi, ovalifolia, prunifolia, pyracanthifolia and splendens are garden varieties of it. Douglasii is an early species with white flowers. Oxyacantha is the common Hawthorn or Whitethorn ; there are many good garden varieties of it, notably aurea, yellow berries; coccinea plena (Paul's double scarlet), one of the best for a small standard tree; foliis-argenteis, silvery leaves ; fructu-luteo, yellow fruit ; multiplex, double white; pendula, drooping; præcox, early (the Glastonbury Thorn); punicea, scarlet; and rosea, pink. A selection of these should be grown in every garden. Standards three or four 

RHODODENDRON LODERII.

Painted by Josephine GUNdRY. 


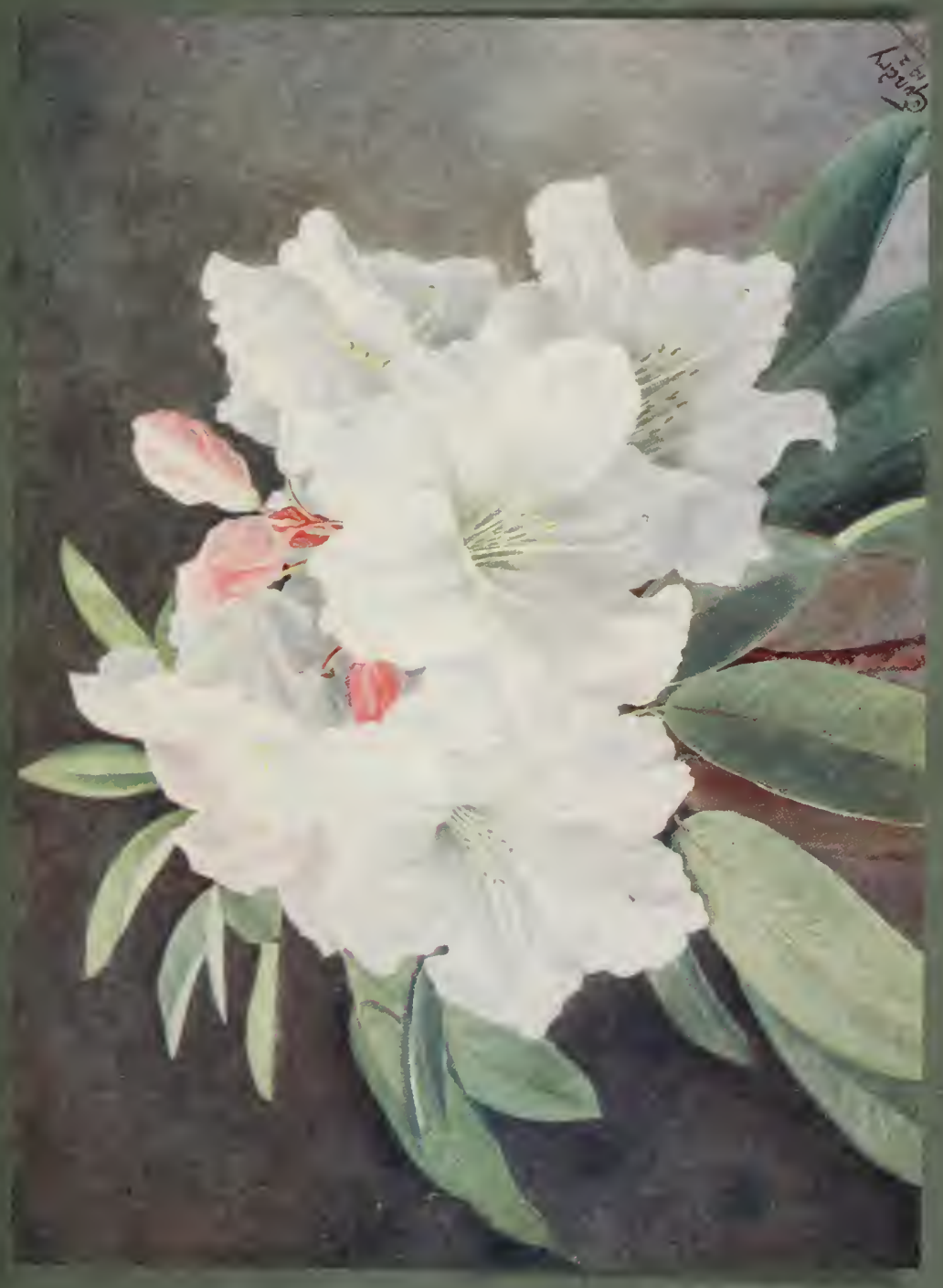



years old should be set among shrubs. The Thorns are not fastidious as to soil. For hedge Quick, see Chapter XXIV. The Blackthorn is not a Cratægus but a Prunus, species spinosa. The lover of Thorns may soon have a selection of the best American Hawthorns, introduced through the Arnold Arboretum in America, at his service, such as Arnoldiana, Baxteri, coccinoides, Dunbari, Durobrivensis, Ellwangeriana, ferentaria, formosa, Holmesiana, Laneyi, pedicillata, Pringlei and spissiflora.

CRINODENDRON.--See Triscuspidaria.

CRYPTOMERIA.-See Chapter XVII., Japonica is the Japanese Cedar and elegans is a variety of it.

CUNNINGHAMIA.-See Chapter XVII. This Conifer must have a sheltered place.

CUPRESSUS (CYPRESS).-See Chapter XVII. The two most important species are certainly Lawsoniana and macrocarpa, but arizonica, funebris, Goveniana, Macnabiana, nootkatensis (syn. Thujopsis borealis), obtusa, sempervirens, thyoides (white cedar) and torolusa (half hardy) are sometimes met with. Lawsoniana is extremely valuable, and its varieties alba spica nana, white tipped; alba variegata, white variegated; Allumi, blue tint ; erecta viridis, columnar rich green; filifera, threadlike; gracilis and gracilis aurea, yellow tinted; lutea, yellow ; nana, dwarf ; and Stewartii, yellow, are charming shrubs. Crippsii is a variegated and lutea a yellow variety of macrocarpa. The forms of Lawsoniana are so neat in habit and pretty in tint that they are ideal evergreens for 
small borders, vying with the exquisite Thujas. Ordinary soil. Obtusa and pisifera are commonly grown under the name of Retinospora in gardens and nurseries.

CYDONIA.-See Chapter XVIII., C. Japonica (syn. Pyrus Japonica) is the deciduous Japanese Quince. Variety of colour or size is yielded by such garden forms as atropurpurea, dark; Aurora, salmon pink ; cardinalis, coccinea, Knap Hill Scarlet, Moerloezii, candida, princeps, rosea and Simoni. The last is very rich. Flore pleno has double flowers. Maulei is also good ; alba, Leichtlini, perfecta and superba are good varieties of it. They are all good for borders and low walls. Ordinary soil.

CYPRESS.-See Cupressus.

CYTISUS.-This is the Broom genus. The Brooms are among the most beautiful of spring shrubs. Growing on most soils, they are perhaps at their best on light, dry, sandy ground. Of dense habit, they flower profusely. They make beautiful beds as dwarf plants and are also useful as standards. The following are the best hardy kinds: albus, the white Spanish Broom, a strong, rapid grower; Ardoinii, a yellowflowered trailer; Beanii, yellow, a hybrid between Ardoinii and biflorus ; biflorus, yellow, early ; decumbens, yellow, prostrate; Kewensis, cream or pale yellow, prostrate habit, a hybrid; præcox, cream or pale yellow, early, a hybrid ; purpureus, purple; and scoparius, common yellow Broom; the crimson blush variety Andreanus, the cream albus (not Cytisus albus); the pale yellow sulphureus and the new forms 
described in the chapter on new plants are forms of scoparius.

See also Chapter XIX.

$D A B O E C I A$.- See Chapter IX. and XIX.

$D A P H N E$.- See Chapter IX. Mezereum and its forms alba, white; and atro-rubra, dark red, are deciduous. All the following are evergreen : Blagayana, a charming white trailer, blooming in April, sweet; Cneorum, a pink trailer, April, major is a large rose form of it; Genkwa, lilac flowers in April, three feet high; and Laureola, the Spurge Laurel, greenish flowers in winter, height up to three feet, purpurea is a dark form of it. Hybrida, hyemalis and pontica are also offered. Odora (syn. indica) and its variety Mazellii are not hardy. All the evergreens are suited by sandy peat. Mezereum likes a more substantial loamy soil. See also Section A.

DAPHNIPH YLLUM.-Glaucescens, an evergreen with ovate-lanceolate leaves having red midribs, and a form called viridis are offered.

DARTMOUTH CRAB.-See Crabs.

$D A V I D I A$. - See new plants.

$D E C A I S N E A$.-Fargesii is offered as a hardy shrub, but it should certainly have a sheltered place if grown out of doors. It has pinnate leaves, yellow flowers in May, and violet, sausage-shaped fruits. It is deciduous and grows up to eight feet high. It is much the same as insignis. Sandy loam.

DECIDUOUS CYPRESS.-Taxodium distichum. DESFONTAINEA.-Spinosa is a beautiful evergreen, growing up to three feet high, with long tubular 
scarlet and yellow flowers in August. It is not fully hardy, and should not be planted in places exposed to cold winds. A warm border under a wall, with an admixture of peat and sand in the soil, suit it.

DESMODIUM.-Two species are commonly offered : tiliæfolium (syn. nutans) and penduliflorum. The latter is the same as Lespedeza bicolor. Tiliæfolium has blue flowers in summer. They are deciduous.

DEUTZIA.-These early and free-blooming deciduous shrubs are very useful in the border, particularly crenata and its varieties, of which the double white, flore pleno, is one of the best. Eburnea is a new ivory variety of crenata. They flower profusely, indeed, if pruned as advised in Chapter XIII. they will be wreathed in blossom in spring. The bright canes are not without ornamental importance. Height up to six feet. Gracilis is smaller and is often reserved for pot culture; there are forms of it called hybrida (or gracilis) rosea, carminea, campanulata, eximia, multiflora and venusta. Lemoinei, which flowers later, is a hybrid; height about two feet; there are forms of this called Apple blossom, Boule de Neige, Boule Rose, Avalanche and compacta. Corymbiflora, white, height up to five feet, and its garden form erecta, must be considered. Discolor is a species from China, growing up to three feet high, but compact, and bearing rosy white flowers in clusters on the whole length of the arching one-year old wood in June. Discolor purpurascens, with comparatively long toothed leaves, dark above and 


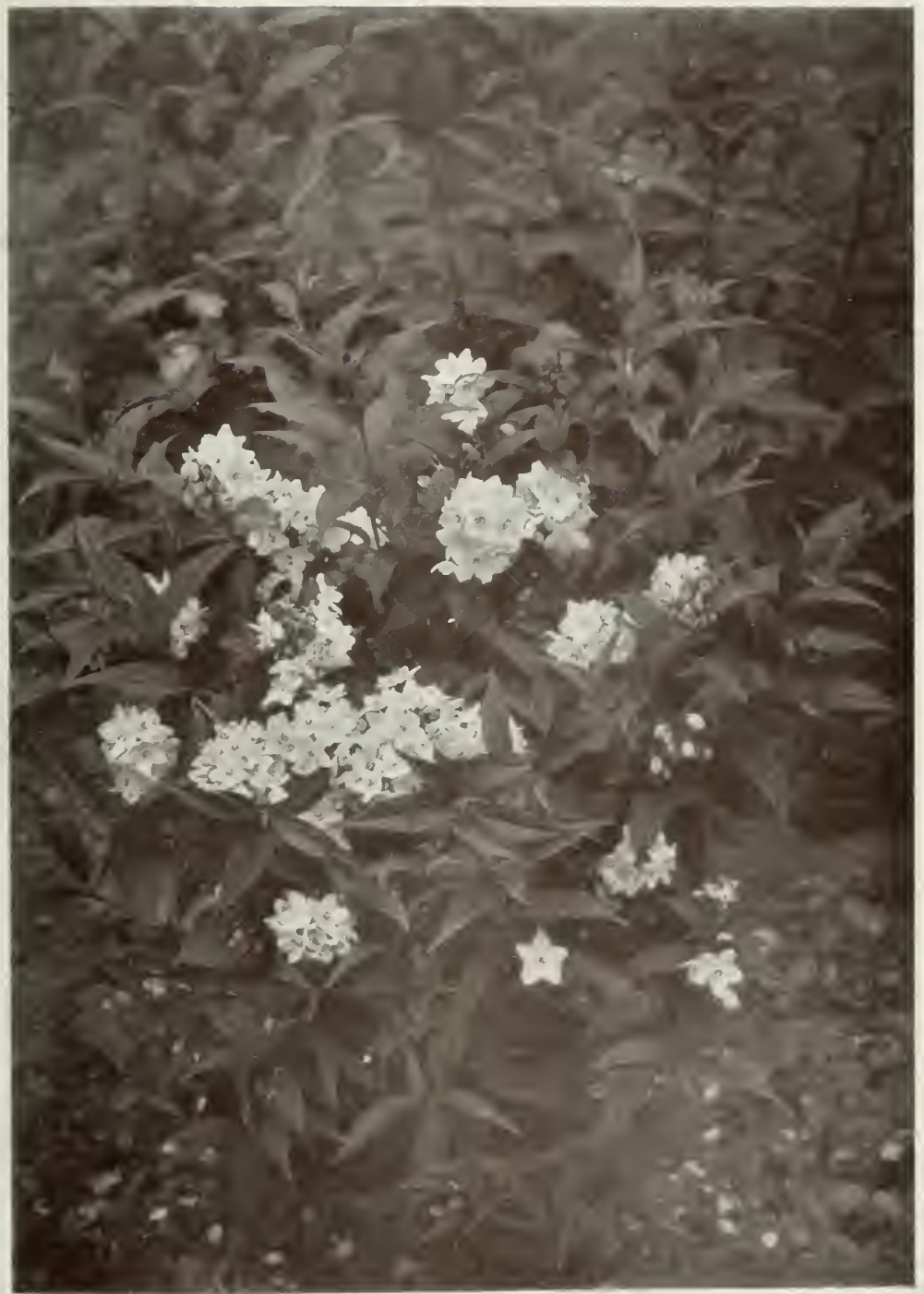

A QUEEN OF MODERN DEUTZIAS.

$D$. discolor grandiflora.

For description see Part IV.

Photo by R. A. Malby. 


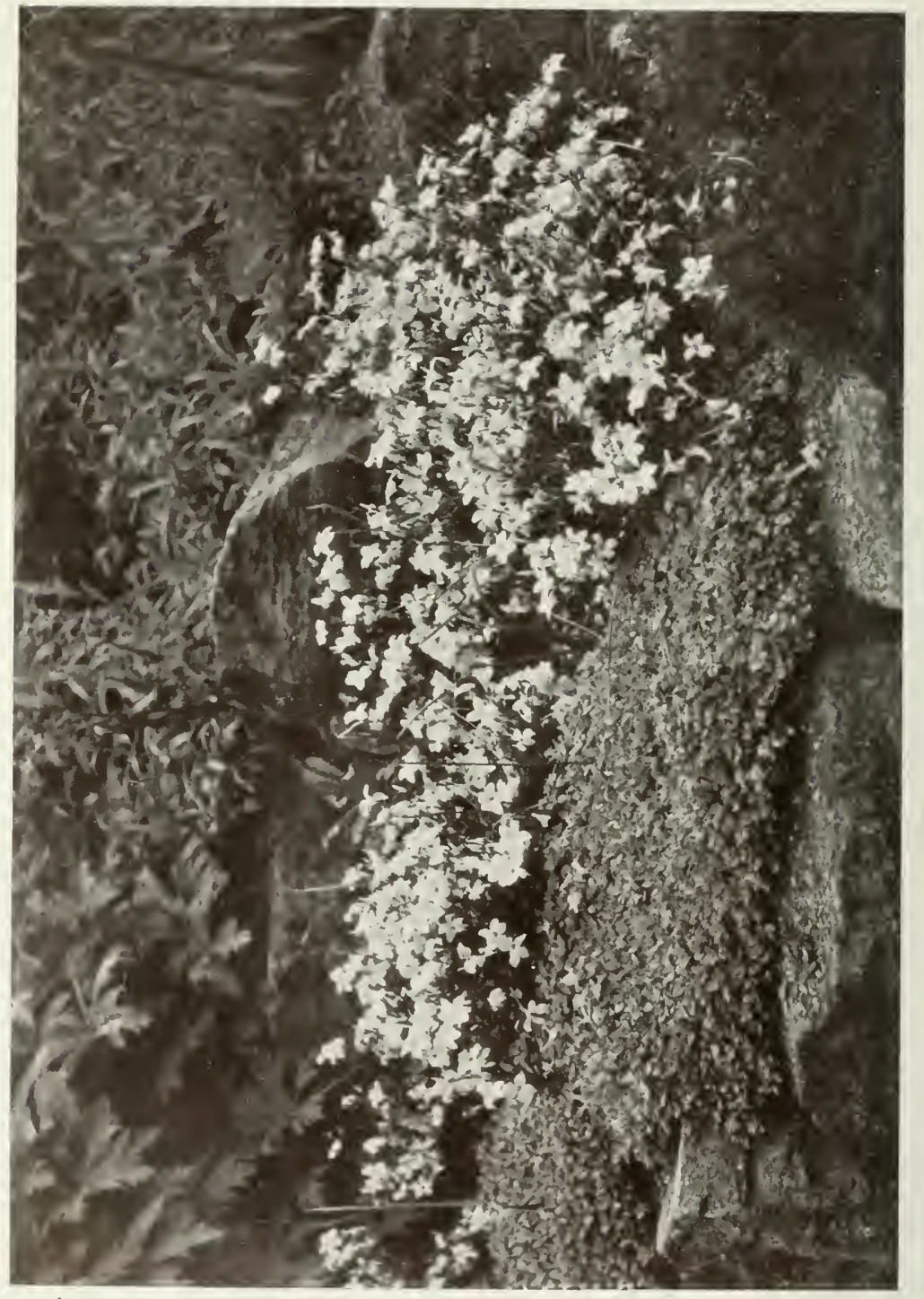

年 
pale below, is a form of it, as is fasciculata, rose tinted. Discolor floribunda and discolor grandiflora are hybrids between discolor and gracilis. Discolor major comes from Central China and has clusters of white flowers in June. Kalmiæflora, three feet, silvery rose, is a hybrid (discolor purpurascens and parviflora). Parviflora, white, flowers in clusters, is very early. Myriantha, a slender shrub with white flowers in June, is a hybrid (corymbiflora crossed with parviflora). Scabra, height up to six feet, has white flowers in late spring. There is confusion between this and crenata, and the double white and double purple scabras of the nurseries are certainly forms of crenata, not of scabra, which is a stronger grower. Ordinary soil. See also Section A.

DIERVILLA.--The same as Weigela. The hybrid and variegated forms of rosea are grown under the latter name in gardens and nurseries. Nurserymen often offer Middendorffiana and sessilifolia under the name of Diervilla. Both grow about four feet high, and produce yellow flowers in summer. They may offer amabilis and rosea as Weigelas, but these are the same species, and are also synonymous with florida. Height up to eight feet. The reddish flowers are borne profusely in late spring. Numerous beautiful garden forms are offered, such as Candida, white; Eva Rathke, dense red; Conquerant, Dame Blanche, Gloire des Bosquets, Looysmannii aurea, Madame Abel Carrière, Pascal, P. Duchartre and Saturne. The Weigelas are easily in the front rank of hardy deciduous shrubs. They will thrive on almost any soil, and if 
pruned hard after flowering (see Chapter XIII.) will be dense masses of beautiful bloom for several weeks.

DIMORPHANTHUS MANDSCHURICUS.-- See Aralia.

DYOSPYROS.-Kaki is the Japanese Date Palm, remarkable for its beautiful orange fruit. The foliage colours well in autumn. It is not fully hardy, but may be grown out of doors in mild districts if put on a south wall. Canon Ellacombe, however has recorded his belief in its hardiness. Light sandy loam suits it. D. Virginiana is the Persimmon. D. Latus is the European Date Plum.

DIPLOPAPPUS.-Chrysophyllus is the same as Cassinia fulvida, an evergreen growing up to four feet high, with white flowers in August. Leptophyllus is not quite hardy.

DIRCA.-Palustris, the Leather wood, is offered. It is a deciduous shrub growing up to five feet high, with yellow flowers in late winter. Peaty soil.

DOGWOOD.-See Cornus.

DRIMYS.-Winteri yields winter's bark, which is used as a substitute for cinnamon. It is not quite hardy, and must have a sheltered place. An evergreen with a large oval leaf, and brown stem. Height up to thirty feet. White flowers in May. Loam and peat for preference, but will succeed on clay.

EDGEWORTHIA.-Chrysantha (syn. papyrifera) a shrub with yellow scented flowers in spring, height up to three feet, is offered in some lists of hardy deciduous shrubs, but it is best grown in the greenhouse. 


\section{EDWARDSIA.-See Sophora.}

ELEEAGNUS (Wild Olive).-The evergreen species are the most appreciated, such as glabra and its variegated and yellow forms ; macrophylla, and pungens and its forms aureo-maculata, aureo-picta and variegata. Argentea (good for seaside) longipes and umbellata are deciduous. Longipes is the same as multiflora, and is a large handsome creamy shrub in the gardens of the Royal Horticultural Society at Wisley. Ornamental berries follow the flowers. Ordinary soil.

ELDER.-See Chapter XX. The Elders do well in town gardens and at the seaside. As grown in gardens they are forms of Sambucus nigra, aurea being the Golden Elder. There are many varieties, such as silver-variegated, white-fruited, cut-leaved (laciniata), and pyramidal. Canadensis is the North American Elder, which grows up to twelve feet high and produces large cymes of cream flowers, followed sparingly by purple fruits; it does well at the waterside. Racemosa has scarlet berries; there are two or three forms of this. Ordinary soil, if not dry. The use of Elderberries for wine is well known in the country districts.

ELM.-See Chapter IX. The Elms are species of Ulmus, with their forms; thus the English Elm is U. campestris, and the Scotch or Wych Elm is U. montana. U. glabra-vegeta is called the Huntingdon Elm and glabra cornubiensis the Cornish Elm. Dampieri aurea and Louis van Houtte are popular varieties of the English Elm. There are several forms of the Wych Elm, including pyramidal (fastigiata), drooping (pendula) and dark (purpurea). The Elm is a park 
rather than a garden tree, and should not be planted in avenues, owing to its habit of casting large branches in summer. Elm foliage colours brightly in autumn. The Wych Elm is a good seaside tree.

EMBOTHRIUM COCCINEUM.--See Chapter XVIII.

EMPETRUM.-Nigrum and its forms scoticumrubrum and tomentosum are pretty little berried evergreens resembling Heaths, growing barely a foot high, and thriving in peaty soil in a moist place.

ENKIANTHUS.-There are several species, but only one, campanulatus, is frequently met with. It is deciduous, grows up to six feet high and has red flowers resembling Andromedas in summer. It is not fully hardy, but may be grown outdoors in mild districts. Peat and loam.

$E P I G E A$.-The only species, repens, is the Mayflower, a pretty evergreen trailer belonging to the Ericaceæ, with white fragrant flowers in summer. Peaty soil, with shade and moisture.

ERCILLA.-Volubilis (syn. spicata) is the same as Bridgesia spicata. It is an evergreen creeper with purple flowers and might be used for walls like Ivy, as it clings well. Ordinary soil.

ERICA (HEATH).-A Heath garden is no uncommon feature of large places where the soil is peaty. There is the peat of a wet bog and there is the peat of a sandy upland; it is the latter which suits Ericas. There is no connection between the names Erica and Heath, the former indicating the brittleness of the stems, the latter a barren waste. The common Heath 
or Heather, vulgaris, has been dealt with under Calluna. Of those generally grown under the name of Erica, arborea, australis, carnea (syn. herbacea) and c. alba, ciliaris, cinerea and its forms alba and atropurpurea, codonodes (syn. lusitanica) Mackayana, mediterranea and its varieties alba and hybrida, Tetralix and its varieties alba, intermedia and rubra, vagans (Cornish Heather) and its forms alba, carnea and rubra, are the most important. Scoparia, stricta and Veitchii are also met with. Carnea and codonodes (lasting till summer) flower in the winter; vagans in later summer or autumn; arborea, mediterranea and australis in spring ; ciliaris, stricta and Tetralix in summer.

ERIOBOTRYA.-Japonica is the Loquat or Japanese Medlar. It is not hardy, and can only be grown out of doors on a wall in a warm district. The white flowers may be followed by orange fruit under glass, but not out of doors. Syn. Photinia Japonica.

ESCALLONIA.-See Chapters XVI. and XVIII Ingramii and sanguinea are forms of the popular rose species macrantha. Langleyensis and exoniensis are hybrids. Floribunda and Philippiana are also grown; both have white flowers in July, but the former is not quite hardy. Ordinary soil. We find macrantha quite at home on an exposed chalk bank, much windswept and the soil poor. It is also to be recommended for seaside gardens. It is the most generally useful, with its dense habit and rich evergreen foliage, but Langleyensis is very beautiful, with its long sprays of pink flowers, and it grows rapidiy. 
EUCALYPTUS.-These are not hardy, but may pass the winter in mild districts. Globulus, the Blue Gum, is the best known, but Gunnii, ficifolia and coccinea are also offered. Peat and loam suit them.

EUCOMMIA ULMOIDES.-See Section A on modern shrubs.

EUCRYPHIA.-Pinnatifolia is offered, a beautiful shrub, nominally evergreen but often deciduous, growing up to ten feet high, with large white flowers composed of four petals; the prominent golden anthers add to their beauty; they are produced in July and August. Peat and loam. Its hardiness has been questioned, but it has passed through severe winters unharmed at Kingston, near London. It is a Chilian species. So, too, is cordifolia, an evergreen with simple downy leaves and white flowers, not hardy. Billardieri is an evergreen with simple leaves and white flowers. An Australian species, not hardy.

EUGENIA.-Evergreens closely related to the Myrtles and far from hardy. Ugni is sometimes grown against a wall, but it must have protection in severe weather. The fruit is ornamental.

EUONYMUS.-See Chapters IX., XVI., and $\mathrm{XXI}$. The forms of japonicus, such as yellowmargined, gold-variegated and silver-variegated, also radicans variegatus and radicans Silver Gem, are beautiful evergreens. The Japanese set are splendid for leaf-colour all the year round and are very suitable for the seaside. The forms of radicans are suitable for edgings. Europæus, the white-flowered Spindle Tree, is deciduous: angustifolia, fructu-coccinea and 
fructu-alba are forms of it. Americanus, atropurpureus, latifolius and verrucosus are also deciduous: but it should be noted that there is a form of the evergreen japonicus called latifolius, and sub-forms of it are offered in the catalogues. Ordinary soil suits the Euonymuses.

EUPTELEA.-See Section A.

EURYA.-Although sometimes listed as hardy, these are best kept in the greenhouse. Latifolia variegata is very popular as a pot plant.

EURYBIA.-See Olearia. Eurybia Gunniana and Olearia Gunnii are the same.

EVERGREENS.-See Chapter XVI.

EVERGREEN OAK.-Quercus Ilex, see Chapter IX. also Oak.

EVERGREEN THORN.-Cratægus Pyracantha.

EXOCHORDA.-Two species are offered, Alberti and grandiflora, both growing up to six feet high in favourable circumstances, and bearing white flowers in May, followed by fruits. They are beautiful deciduous shrubs, worthy of a wall border with a warm aspect. Macrantha has sweet white flowers in spring. Ordinary soil.

FABIANA.-Imbricata is a beautiful but not quite hardy evergreen, suitable only for warm, sheltered sites. Its height is about two feet, and it bears white, trumpet-shaped flowers in May. Sandy peat.

FAGUS.-See Beech.

FENDLERA RUPICOLA.-A Mexican shrub with white flowers in terminal clusters, height up to six feet, lanceolate leaves. Best against a wall. 
FIRS.-See Chapter XVII.

FITZROYA.-A hardy evergreen Conifer, from Southern Chile. Patagonica is offered.

FLOWERING ASH.-See Ash.

FORS YTHIA.-See Chapter IX. Three are offered, intermedia, suspensa and viridissima ; the first is a hybrid between the other two; all with yellow flowers, height eight to twelve feet. There is a variegated form of viridissima. Spectabilis is a good form of intermedia. Densiflora and vitellina are also good. The Forsythias are among the brightest of earlyblooming deciduous shrubs. They flower profusely in advance of the leaves, the flowers drooping from top to bottom of one-year wood. Ordinary soil. They may be grown in open shrubberies or on walls, and do well in town gardens.

FOT HERGILLA.-The species Gardeni (syn. alnifolia) is offered. It is a handsome deciduous shrub, growing four to five feet high, with white fragrant flowers in spring. Moist sandy peat is desirable.

FRAXINUS.-See Ash.

FREMONTIA.-There is but one species, californica, a charming deciduous shrub, growing up to twelve feet high, with yellow flowers one to three inches across in spring and onwards. It is not fully hardy, and should have a warm sheltered place except in very mild districts. In cold districts it might be tried on a warm wall. Sandy loam with peat, or some other light, friable, well-drained compost is desirable.

FRINGE TREE.-See Chionanthus.

FUCHSIA.-Few shrubs are so graceful in gardens 
by the sea in mild districts as the hardier Fuchsias, such as coccinea and the forms of macrostemma, namely, corallina, gracilis, and Riccartonii, which are often listed as species. They have scarlet, crimson, or purple and red flowers in summer. Corallina is the most vigorous and may be used as a pillar or pergola plant. The others form beautiful bushes up to six or eight feet high. Ordinary soil. Propagation by cuttings in summer. They are best treated as herbaceous plants; as frost generally affects the stems these can be cut down, and the stools covered with ashes. We know of plants treated in this way that are of very old standing on Wealden Clay in Kent.

FURZE or GORSE.-Ulex europæus, a well known wilding of the Cornish and other moors, where its peculiar rather cloying odour fills the air. It is nearly always in bloom, hence the Cornish saying "when the Gorse is out of bloom kissing is out of fashion." There is a double form, flore pleno, and it is far superior to the single for gardens. It is one of the best shrubs for dry, stony, or gravelly soil. Ordinary soil.

$G A R R Y A$.-Elliptica is a well known evergreen, with greenish yellow catkins in spring, height up to ten feet in the open, perhaps more on a wall. It does well at the seaside. Ordinary soil.

GAULTHERIA.-These shrubs are useful for shady places, and like a moist, peaty soil. Procumbens, the Partridge Berry, only grows a few inches high and has white flowers in summer, followed by dark fruit. Shallon is an evergreen, grows up to four feet high, and has white flowers in May; there is a form of this 
called acutifolia. Nummularioides (syn. nummularifolia) white or pale pink flowers in spring, is also offered. GEAN.-The wild Cherry.

GENISTA.-See Broom and Chapter XIX.

GINKGO.-See Chapter XVII. Biloba, the Maidenhair Tree, is the same as Salisburia adiantifolia. There are several garden forms, including a drooping and a variegated, but they are not generally offered. It is a deciduous Conifer, and does well in towns. Ordinary soil.

\section{GLASTONBURY THORN.-See Cratægus.}

GLEDITSCHIA.-The most popular species is triacanthos, the Honey Locust, a really handsome deciduous tree of the Pea order (Leguminoseæ), up to fifty feet high, with greenish flowers in July. The foliage is beautiful. A garden form called excelsa pendula is offered. Sinensis (syns. horrida and ferox) is also met with, and is remarkable for the large clusters of formidable spines on the stems and main branches; a drooping form called pendula is offered and there are others. Height up to twenty-five feet, greenish flowers in early summer. Ordinary soil. The garden forms are grafted on to the species.

GLYCINE.-See Wistaria.

GOLDEN ARBOR-VIT E.-See Thuja.

GOLDEN LARCH.-See Larch.

GOLDEN-LEAVED CHESTNUT.-See Chestnut and Castanea.

GOLDEN WILLOW.-See Willow and Salix.

GORDONIA.-A rare genus. Lasianthus and pubescens, both white-flowered, are nominally hardy, 
but owing to the non-ripening of their late growth in the often sunless autumns of Great Britain, they are frequently injured. They need a sunny spot, but a cool, moist, yet well-drained soil. Both are beautiful and worth an effort on the part of connoisseurs, especially those who enjoy grappling with difficult subjects.

GORSE.-See Furze.

GREVILLEA.-While some of the species, notably rosmarinifolia, may be grown out of doors, in mild districts, the genus is generally represented by robusta grown as a pot plant for conservatories and rooms. It is very graceful.

GRISELINIA.-Littoralis, a small evergreen tree growing up to twenty feet high, and its form macro phylla, are offered as hardy subjects, but they should have favoured sites, and fertile sandy loam. At the seaside they are much hardier than inland, growing into dense bushes. The flowers are not important and fruit does not develop in Great Britain.

GUELDER ROSE.-See Viburnum.

GUM CISTUS.-See Cistus and Chapter XIX.

GYMNOCLADUS.-The best known species is canadensis, the Kentucky Coffee Tree, a hardy deciduous tree growing up to thirty feet high, with white flowers. The foliage is attractive, being divided into numerous leaflets. Pods rarely develop in Great Britain.

GYNERIUM.-The noble species argenteum (syn. Cortaderia argentea) is almost too well-known to need comment. It is the finest of grasses, and as grand an 
ornament for lawns as the best of shrubs. It should be given a prominent site, sheltered from cold winds. Ordinary soil, well manured. Give top-dressings of manure every two or three years. Several garden forms are offered, such as albo-lineata, aureo-lineata, monstrosum, Roi des Roses and Rendatleri.

HALESIA.-Two species are offered : hispida (syn. Pterostyrax hispidum) and tetraptera, both small deciduous trees with white flowers in late spring. Tetraptera, the Snowdrop Tree, is the better known, and it is one of the most beautiful of garden objects when covered with its lovely drooping flowers. It is quite worth a good place on a lawn in a sheltered place. Good loamy soil, not very dry.

HALIMODENDRON.-One species is offered, namely argenteum, the Salt Tree, a deciduous shrub with hoary leaves and pink flowers, growing up to six feet high in good loamy soil.

HAMAMELIS. (WITCH HAZEL).-As winter bloomers these small but beautiful deciduous shrubs with their quaint crinkled flowers have a special claim on attention. Mollis is a lovely object when full of golden bloom in advance of its leaves on a winter day, bright and cheerful amid frost and snow. Arborea, claret and yellow; japonica, yellow, and its variety Zuccariniana, yellow and brown; and virginica, yellow, are also offered. They should be planted at the front of the shrubbery or under a wall, preferably in groups. Well drained friable soil will do, but loam with a little peat gives the best results.

HAWTHORN.-See Cratægus. 
HAZEL.-The Hazel Nut tree is Corylus Avellana, and is more important for economic than for ornamental purposes, nevertheless, such forms as aurea, laciniata, pendula and the purple-leaved purpurea (syn. maxima atropurpurea) may be considered for the shrubbery, particularly the last named, which has rich purple foliage. It is best pruned hard back every three years, when it colours splendidly and makes an admirable base or background for golden and silvery leaved shrubs and small trees. Ordinary soil.

HEATH.-See Erica and Chapter XIX.

$H E D E R A$.-This is the Ivy genus. For good varieties see Chapter XVIII.

HEDGEHOG HOLLY.-See Holly.

HEDGE PLANTS.-See Chapter XXIV.

HEDYSARUM.-Multijugum is a deciduous shrub growing up to five feet high, with purplish red flowers in summer. Ordinary soil. Coronarium, the French Honeysuckle, is herbaceous.

HELIANTHEMUM.-See Chapter XIX. The named varieties of gardens and nurseries are forms of vulgare and are valuable for hot, dry, sunny banks, where the soil is poor and shallow. They will grow almost anywhere, are evergreen, and bloom all the summer.

HEMLOCK SPRUCE.-Abies canadensis.

HIBISCUS (ROSE OF SHARON).-The garden forms of syriacus (syn. Althæa frutex), such as rubis, Celeste, Meehani, Totus albus, La Reine, Admiral Dewey, Violet clair, Pompon Rouge, Puniceus, Alice, Leopoldii, monstruosa, Boule de feu and albo-plenus 
(there are many others, single and double) are very useful dwarf deciduous shrubs owing to their late period of flowering, which is late summer and autumn. There is a variegated form. The habit is neat and compact. The foliage is distinct and handsome. They are very good as standards. Ordinary soil if not damp and cold.

HICKORY.-See Carya.

HIPPOPHAE.-Rhamnoides is the Sea Buckthorn, which grows on sand hills by the sea and has silvery foliage and yellow berries in late summer. It is suitable for planting inland near water. See Chapter XXII. Two forms are offered: fœmina and mascula; and as the sexes are on different plants it is necessary to plant both-as in the case of Aucubasto insure berries. The forms are much alike in spring and summer. The female form is quite tree-like on clay soil at Aldenham House, near London, and berries freely on the lower part under the influence of a small bush of the male form growing near.

HOLLY.-The Hollies of our gardens are forms of Ilex Aquifolium, the common Holly, which is too familiar to call for description. Its use for hedges is dealt with in Chapter XXIV., for planting in shade in Chapter XXV. It should be carefully knife-pruned towards the end of winter. Thriving in most soils, it grows freely when established, but in its early years moves slowly. Nurserymen offer many forms, of which the following are some of the best: Broad Silver, Camelliæfolia, Donningtonensis, ferox (Hedgehog Holly) and the sub-forms $f$. argentea and $f$. aurea, 
flavescens (yellow berries), Golden King, Golden Queen, Handsworthiensis, Hodginsii, Madame Briot, pendula argentea variegata (weeping variegated), scotica, Silver Queen and Watereriana. While most good ordinary soil suits Holly it does not care for a poor dry soil. Planting and shifting are best done during damp weather in April or August. Holly does well in town gardens if kept clean, and also at the seaside. Ilex cornuta, the horned Holly; and I. dipyrena are worth growing. See also new plants.

HONEYSUCKLE. - For selections see Chapter XVIII. These fragrant favourites are species and varieties of Lonicera. Not only are the forms of Caprifolium and Periclymenum very sweet, but their fruits are ornamental. In addition to the popular species and varieties named in Chapter XVIII., flava, yellow ; grata, red ; and Hildebrandiana, buff or pink are good climbers. Alpigena, red, spring bloomer ; and Xylosteum, yellow, early summer, flowers and fruits in pairs, are two good bush species; there are several forms of the latter with fruit of different colours. See also Section A.

HOP TREE.-See Ptelea.

HORNBEAM.-See Carpinus and Hedges, Chapter XXIV.

HORSE CHESTNUT.-See Æsculus.

HYDRANGEA.-See Chapters V., IX., XVIII., and XXVI., also the chapter on modern shrubs. The most popular species is hortensis (syn. hortensia), but it is often represented in gardens by its varieties, such as Avalanche, Bouquet Rose, Dentelle, Mariesii, 
Innocence, Madame Mouilliêre, La Lorraine, Otaksa, rosea, Thomas Hogg, variegata and Veitchii. Mariesii has very large pink or reddish mauve sterile flowers and blossoms freely in a small state; the newer Veitchii resembles it in form, but is white. Otaksa is pink and Thos. Hogg white; variegata has green and white foliage. The species has nominally pale pink flowers, but it is well known that in certain soils they become blue, and the change of colour can be induced artificially by watering with a solution of alum, IOz. to a gallon of water. Although the species is not perfectly hardy it sometimes lives for years outdoors in mild districts. There is one at Shanklin which has carried 600 heads of blue flowers. It is, of course, grown largely in pots. Paniculata grandiflora (syn. p. hortensis) is a very popular plant with white flowers in autumn; it is hardy. Quercifolia is sometimes grown against walls in mild districts, and the same may be said of petiolaris, which has Ivy-like leaves and white flowers in spring. Ordinary soil.

HYMENANTHERA.-Only one species is hardy and that is crassifolia, a New Zealand evergreen with yellow flowers and white berries. Sandy peat.

HYPERICUM.-(St. John's Wort).-Calycinum (see Chapter XVI.), is the principal shrubby St. John's Wort; but Moserianum, a hybrid between that and patulum, is a good plant. The former is about a foot high, the hybrid about three feet. Androsæmum, the Tutsan, has dark fruit; height up to three feet. All have yellow flowers and bloom in summer. Reptans is an Alpine trailer. Others offered are 


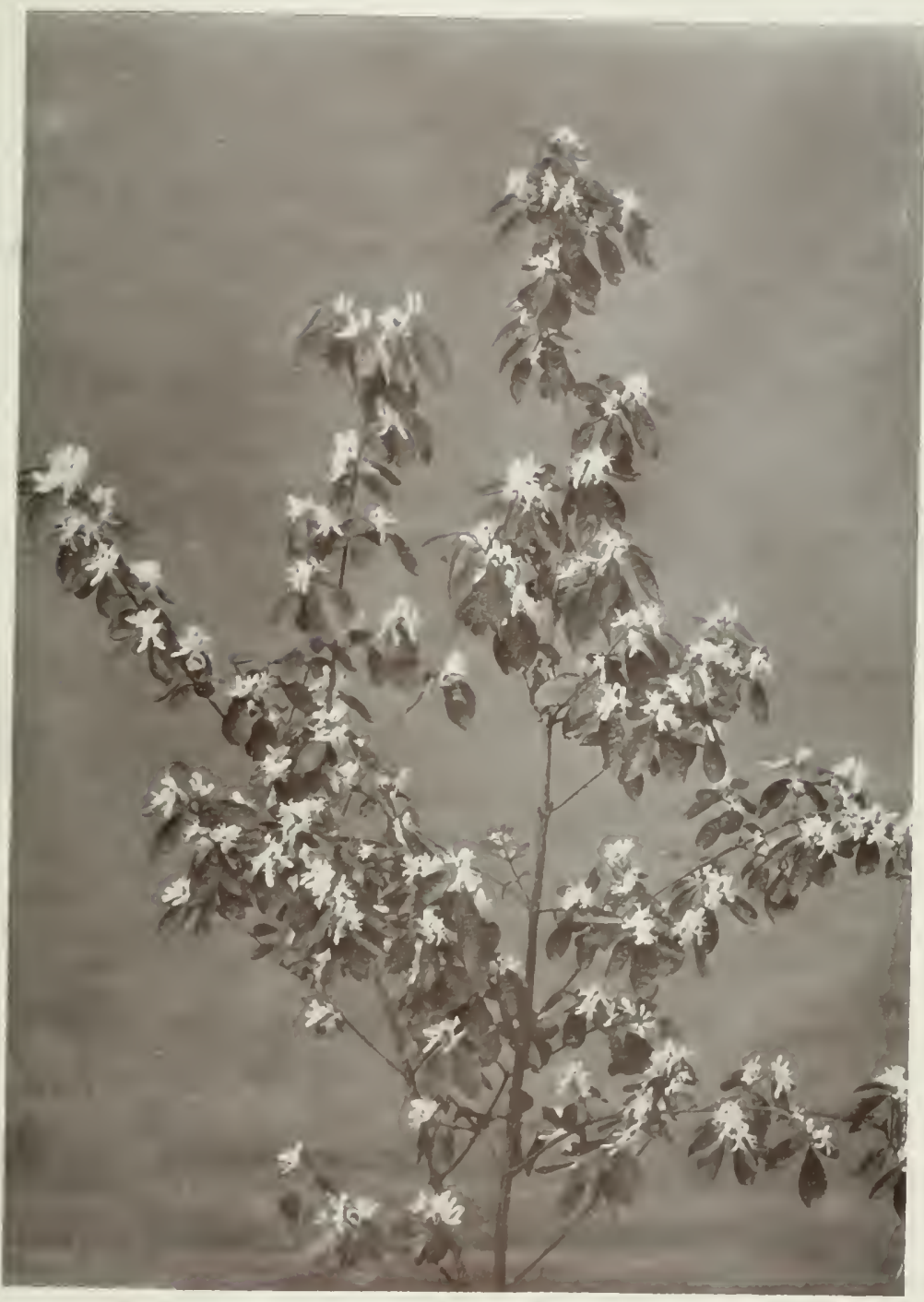

A MODERA HONEYGTCIIE.

Lonicera Maackii.

For description see l'art IV: Photo by R. A. Mallyy. 


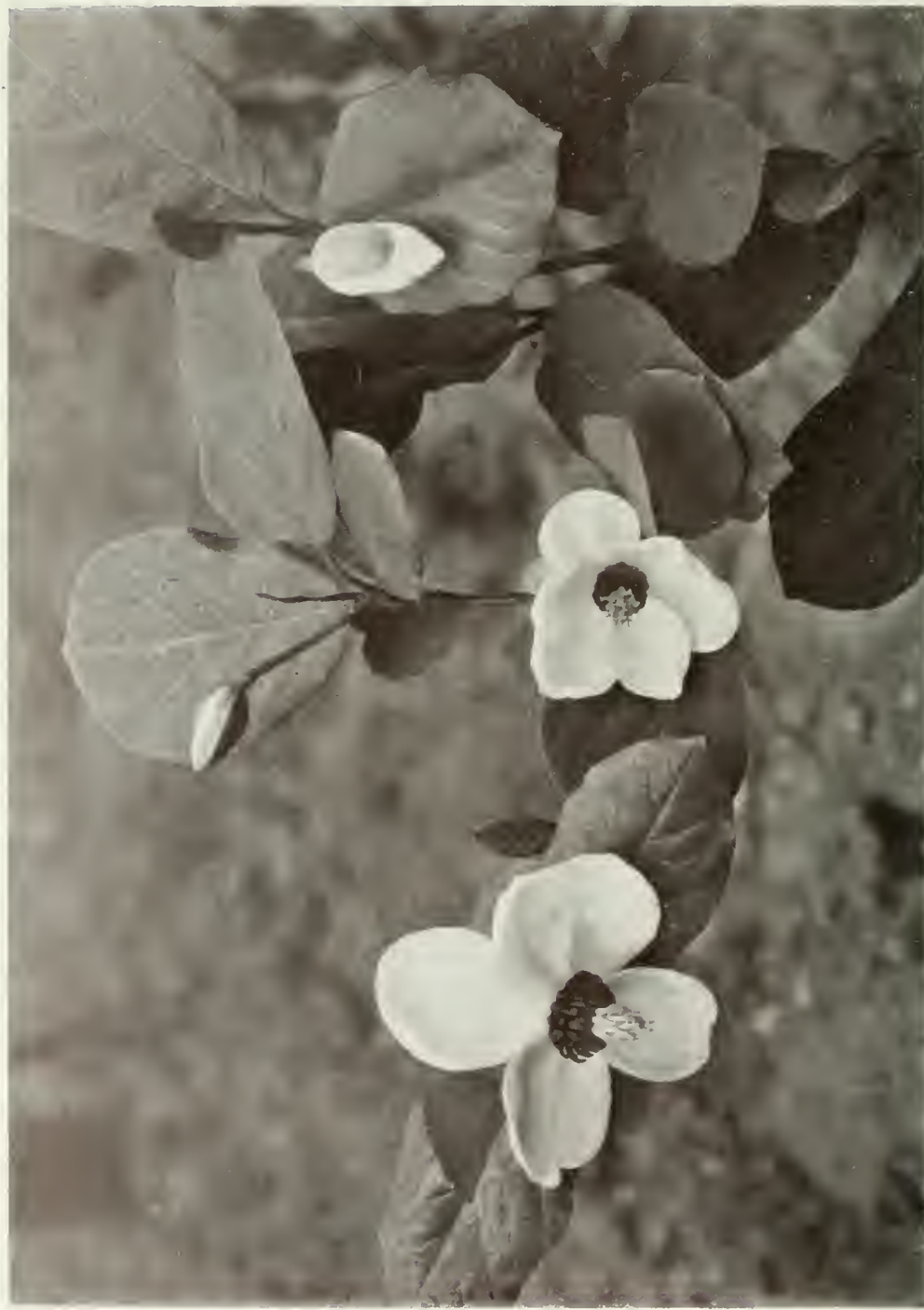

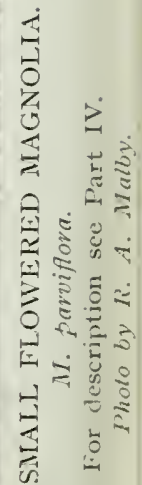


Ascyron, aureum (a form of Androsæmum), hirsutum, elatum, Kalmianum and Hookerianum (syn. oblongifolium). Ordinary garden soil. Calycinum and Androsæmum may be planted in shade.

IDESIA.-The only species offered is polycarpa, a Japanese tree with large heart-shaped leaves on long crimson stems, yellow perfumed flowers in terminal racemes and small orange berries in the case of the female form. Ordinary soil.

\section{ILEX.-See Holly.}

ILLICIUM.-Floridanum, an evergreen growing a few feet high, with red fragrant flowers in May, is offered as hardy, but it should have a warm wall and winter protection. Loam with good additions of peat and sand. Religiosum is a sacred tree in Japan; there is a variegated form of it.

INCENSE CEDAR.-Libocedrus decurrens.

INDIGOFERA.-Gerardiana (syns. floribunda and atropurpurea of gardens) is hardy and has pale red flowers in July. Decora and its white variety are sometimes offered as hardy, but are better in the greenhouse. Both are best on walls in the open. They are deciduous. Good loam, with leaf mould and sand.

IRISH HEATH.-See Daboëcia, Chapters IX. and XIX.

IRISH IVY.-Hedera Helix canariensis.

IRISH YEW.-Taxus baccata fastigiata.

ITEA.-Virginica is offered in catalogues and may be grown in sandy peat in a moist position. It grows up to six feet high and has white flowers in July. 


\section{IVY.-See Chapter XVIII.}

$J A M E S I A$.-One species is available, namely, americana, which grows up to six feet high, is deciduous and has white flowers in spring. Ordinary soil.

JAPANESE CEDAR.-See Cryptomeria.

$J A P A N E S E Q U I N C E$.-Cydonia or Pyrus japonica.

$J A S M I N E$. - The Jasmines are referred to in Chapter XVIII., where the value of Jasminum nudiflorum is pointed out. Revolutum and Wallichianum, both with yellow flowers in summer, are also hardy. The latter is probably the same as humile, and revolutum is a form. Other hardy members of the genus are floridum (syn. subulatum) and fruticans, both with yellow flowers in summer. Primulinum is a good Jasmine from Yunnan, but not fully hardy and must have a warm wall if grown out of doors. It resembles nudiflorum, indeed, Dr. Henry considers it to be a variety of that species.

JUDAS TREE.-See Cercis.

$J U G L A N S$.- This is the Walnut genus. J. regia is the common Walnut and J. nigra the black Walnut. Laciniata is a cut-leaved and pendula a drooping form of regia. The other species are not in general cultivation. Deep loamy soil suits.

JUNIPERUS.-The Junipers are referred to in Chapter XVII. They are evergreen Conifers of rugged aspect.

KALMIA.-Angustifolia, glauca and latifolia are the principal species, indeed, these are the only ones generally listed. They are useful evergreens, loving cool, moist peat and, like Rhododendrons, disliking 
lime. Pumila and rubra are forms of angustifolia; myrtifolia is a form of latifolia. Glauca, which has rosy flowers in May and grows up to two feet high, is a beautiful dwarf bedding shrub, blooming profusely and pleasing in colour. Latifolia, which has larger leaves, is also very beautiful.

$K E R R I A$.-The only species is japonica (syn. Corchorus japonicus) a not particularly impressive deciduous shrub. The double, flore pleno, is not only more vigorous, but also more lasting and free, and one of the most useful dwarf yellow-flowered deciduous shrubs of spring. It will thrive on a north wall. Ordinary soil, including poor limestone, which it prefers to clay. There is also a variegated form of japonica.

KOLREUTERIA-Paniculata, a deciduous tree growing up to fifteen feet high, with yellow flowers in summer, is offered. Good soil and a warm sheltered site are needed.

$L A B U R N U M$ - No spring-flowering tree is better known than the common yellow deciduous Laburnum (see Chapter IX.). It is really beautiful when in full bloom, but unsightly afterwards because of the slow decay of its inflorescence. This is the Laburnum vulgare of botanists, and there are many varieties of it, such as Alschengeri, Carlieri, grandiflorum, autumnale, giganteum, monstrosum, m. cristatum, quercifolium and Vossii. Alpinum, the Scotch Laburnum, does not differ greatly from vulgare; biferum, grandiflor um, Parksii and Watereri are good varieties of it. Adami (syn. vulgare purpurascens 
and Cytisus Adami) is a graft hybrid, which has the interesting peculiarity of producing yellow and purple flowers separately on the same tree in some cases, but not in all. This is partly explained by the fact that the parents were Cytisus purpureus and the common Laburnum. The latter is used as a stock for budding and grafting the choicer Brooms. Ordinary soil.

LARCH (LARIX).--See Chapters XII. and XVII. $L A R D I Z A B A L A$. - The only species, biternata, is a climbing shrub with purple flowers in autumn. It must have a warm wall if grown outdoors. Peat and loam.

LAUREL.-See Chapters XIII. and XXIV. The common Laurel is Prunus Laurocerasus; camellieifolia, caucasica, colchica and latifolia are garden forms of it. The Portugal Laurel is C. lusitanica; azorica and myrtifolia are forms of it. Kalmia angustifolia is called the sheep Laurel. The Laurel is a good town and seaside shrub, and useful for forming quick shelter.

LAURUS.-Nobilis is the evergreen Sweet Bay; angustifolia and salicifolia are garden varieties of it. It has yellow flowers in sping, followed by purple berries. In good soil and an open situation it may grow to thirty feet high. It makes a good lawn tree, especially when trained as a neat pyramid. Good loam.

LAURUSTINUS (or LAURESTINUS).--See Chapters IX. and XVI. Viburnum Tinus is one of the most useful of cheap evergreens, growing almost 


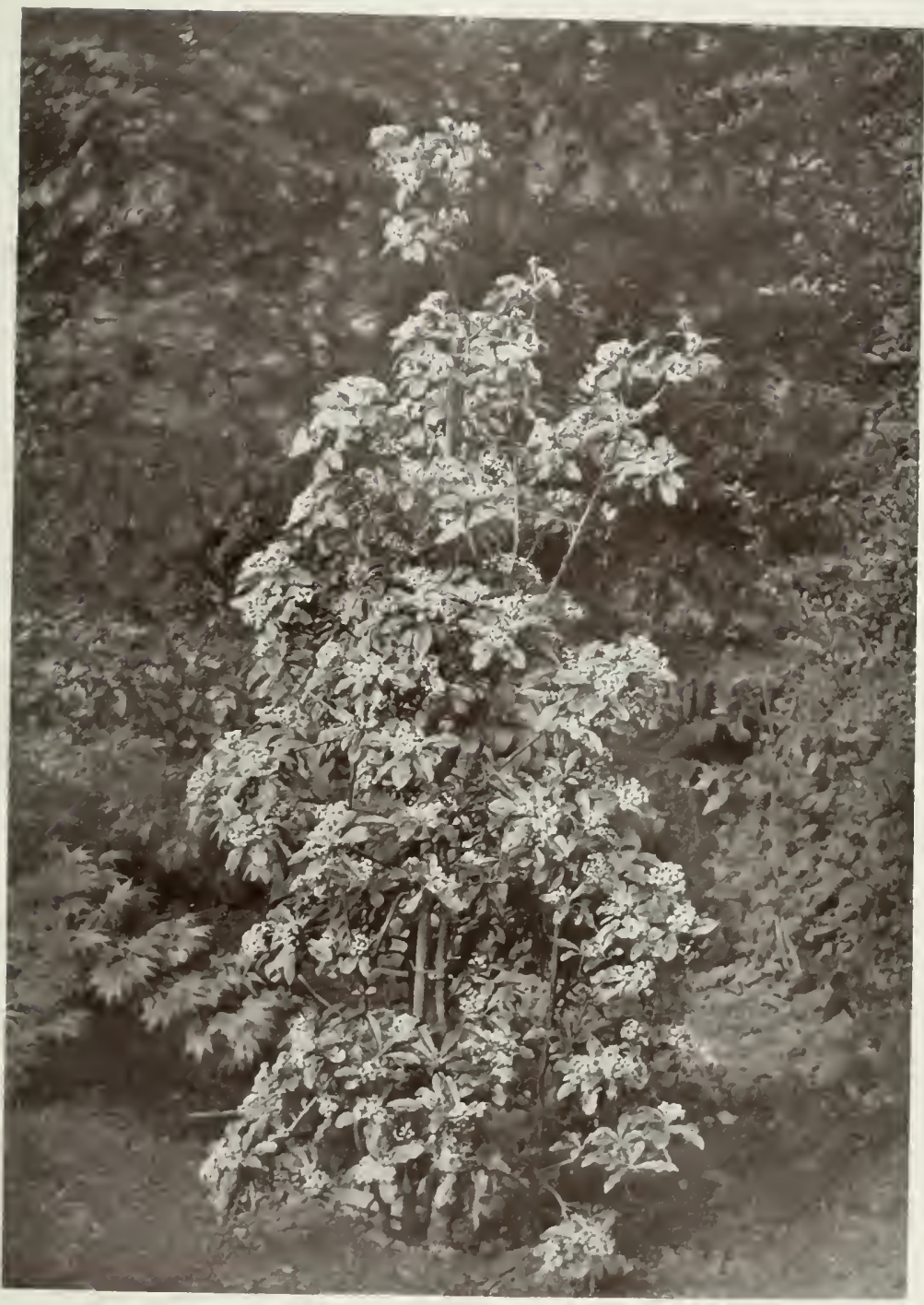

A MODERN゙ CHINESE SHRUB

Stranvaesia undulata.

For description see Part IV

Photo by R. A. Walby. 


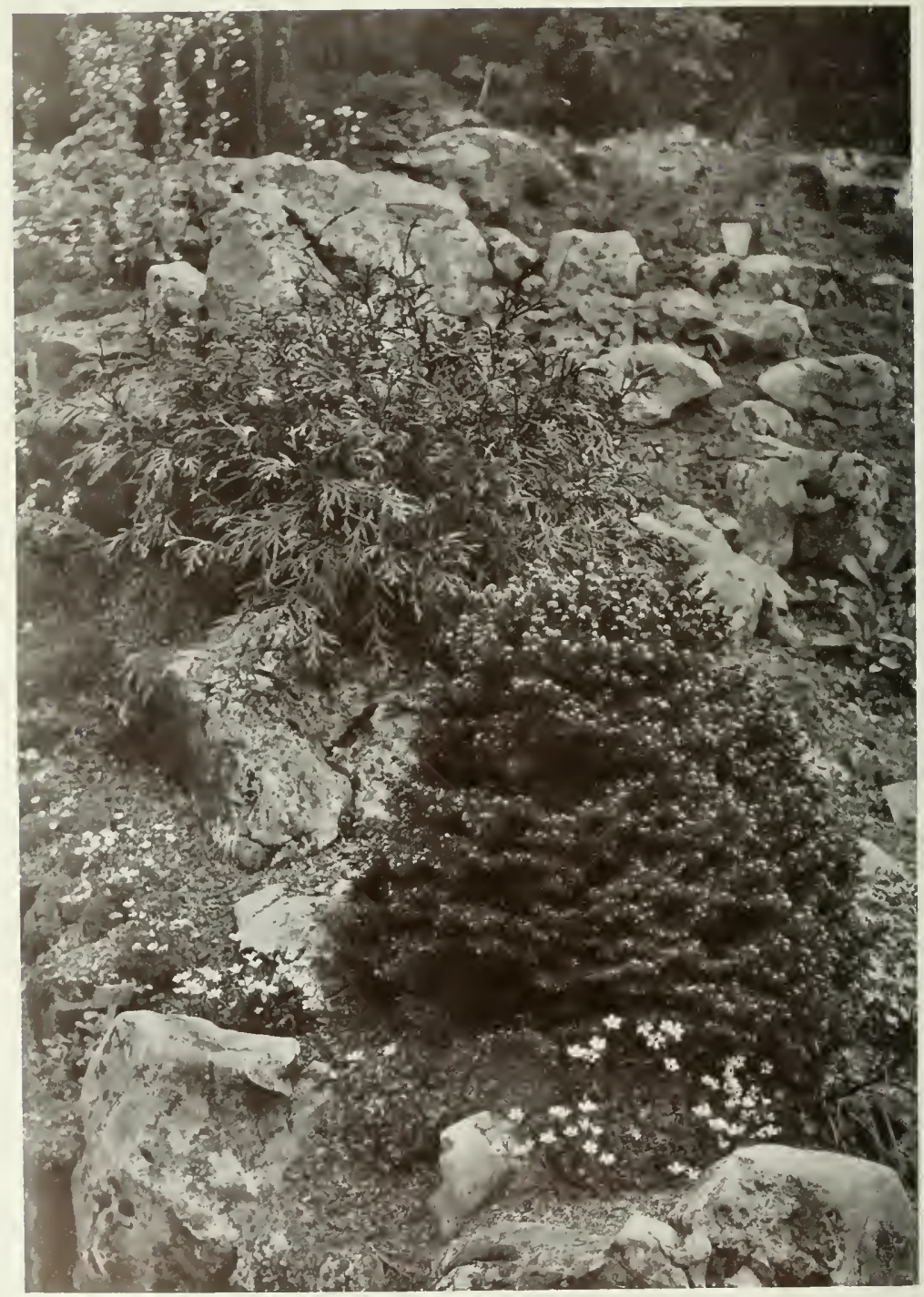

TWO LSEFUI, ROCK GARDEN SHRUBS.

Upper-Thuja dolabrata nana.

Lower-Picea excelsa Remontin. 
anywhere, doing well on poor limestone soil, neat and compact in habit, always bright, and flowering in winter. Very little pruning is required.

LAVENDER.-This fragrant evergreen is Lavandula vera spica of some botanists; alba is a white garden variety. Everybody knows lavender, which is extensively grown for making perfume, and much used by housewives as a preservative of linen. The shrub will grow in almost any soil, and bear frequent shifting. It thrives on poor limestone. Clumps of lavender should be grown in every garden. A line beside a walk will scent the air delightfully for many weeks.

\section{LEAD PLANT.-See Amorpha.}

\section{LEATHERWOOD.-See Dirca.}

LEDUM.-Handsome evergreens, the best known species of which is latifolium, which grows about three feet high and has white flowers in April; angustifolium is a narrow-leaved variety of it. Palustre, white, May, is also offered. They are peat-lovers.

LEIOPHYLLUM.-Near the Ledums; L. buxifolium is the same as Ledum buxifolium; it grows about a foot high and has white flowers in May; prostratum is a garden form. Peat.

LESPEDEZA.-Bicolor, a deciduous shrub growing about three feet high, with purple and rose flowers in September, is offered. It should be grown on a warm border or a wall. Loam and peat.

LE UCOTHOE.-Axillaris, Catesbaei and Davisiae are offered; the two first are now classed with the Andromedas by botanists. They are all peat-lovers. 
LEYCESTERIA.-The only species offered is formosa, a good deciduous shrub growing up to eight feet high, with purple and white flowers in summer, followed by fruit. It does well at the seaside. Variegata is a form of it. Ordinary soil.

LIBOCEDRUS.-See Conifers, Chapter XVII. Decurrens is the Incense Cedar and makes a good lawn tree; there is a golden-variegated form. Chilensis, Doniana and macrolepis are also offered. The last is a good Chinese species, but not hardy enough for ordinary culture without protection. These Conifers like a rich deep soil.

LIGUSTRUM.-This is the Privet genus; see Chapters XVI. and XXIV. Ovalifolium is the popular evergreen Privet so much used for hedges; elegantissimum is a garden form. Other species offered are Ibota; japonicum and its variety macrophyllum; lucidum and its forms aureo-variegatum and tricolor (very beautiful); coriaceum (syn. lucidum coriaceum), curled leaves; Quihoui; sinense and its form floribundum; and vulgare, the common Privet. The Golden Privet is a form of ovalifolium. One or two of the best garden forms are procurable as standards. Ordinary soil, including poor limestone. The Privets do well in town gardens. See Section A for modern species.

LILAC.-See Syringa, also Section A, and Chapters IX. and XXVI. The varieties named in the latter are all suitable for the garden.

LIME.-One of the most popular of deciduous town trees. It belongs to the genus Tilia, europæa (syn. 
vulgaris) being the common Lime or Linden ; this tree, with its yellow, sickly-sweet flowers beloved of bees, is very familiar; there is a variegated form. T. alba is the Silver or White Lime, T. americana the American White Wood or Basswood, $\mathrm{T}$. petiolaris the Crimean Lime. Other species met with are dasystyla (syn. euchlora) and platyphyllos; there are several varieties of the latter, such as asplenifolia (syn. laciniata), rubra, pendula and pyramidalis. Good loamy soil.

IINDERA.-Deciduous shrubs, the best known member of which is Benzoin (syn. Laurus Benzoin), which grows up to fifteen feet high and has yellow flowers in spring. Præcox, sericea and triloba are also offered. Loam.

LIQUIDAMBAR.-Of the several species, styraciflua is the only one generally met with, a small deciduous tree growing up to thirty or forty feet high and remarkable for its rich autumn colour; moreover, it is fragrant. Loam.

LIRIODENDRON.--Tulipifera is the beautiful Tulip tree, with large yellow and green flowers in summer; there are several forms, of which aurea is the best known. The Tulip tree is worth a good position; even though it does not flower in a young state it is always handsome. Deep loamy soil.

LOCUST TREE.-See Robinia.

LONICERA.-See Honeysuckle.

LOQUAT.-See Eriobotrya.

LOROPETALUM.-The only species is chinense, a beautiful deciduous shrub growing up to eight or ten feet high in good loamy soil, and in a sheltered 
spot; and with white flowers in autumn. It is often grown in pots.

LUPINUS.-The tree Lupine, L. arboreus, is an evergreen shrub, but not quite hardy ; it is, however, easily raised from seed. There are several forms, including a good yellow and a white (Snow Queen). The true Lupine grows up to six feet high in deep, well-manured soil. The flowers are very sweet.

LYCIUM (BOX THORN).-Deciduous shrubs, of which barbarum, a climber with purple and yellow flowers in summer; and europæum, an erect spiny shrub with violet flowers in August, are most often met with; chinense is near the latter and there is a variegated form. They are generally grown on walls, and do well near the sea. Ordinary soil.

MACLURA.-The only species, aurantiaca, is the Osage Orange, a deciduous tree growing up to twenty feet high, with yellow flowers in summer followed by golden fruit. Sandy loam.

$M A G N O L I A$.-One of the most important genera of hardy shrubs, comprising both evergreen and deciduous species, all distinguished by large and beautiful flowers. See Chapters XVI., XVIII. and XIX. The best known evergreen is the large-leaved grandiflora, which is often seen on house walls. The Exmouth variety is very good, and there is also a form called ferruginea. Delavayi is a modern evergreen species with large glaucous evergreen foliage from Southern China. See section on modern shrubs. Of the deciduous species, conspicua, the Yulan, which grows up to twenty feet high and has large pure white flowers 

MAGNOLIA LENNEI.

Cólour photo by $R$. A. Malby. 


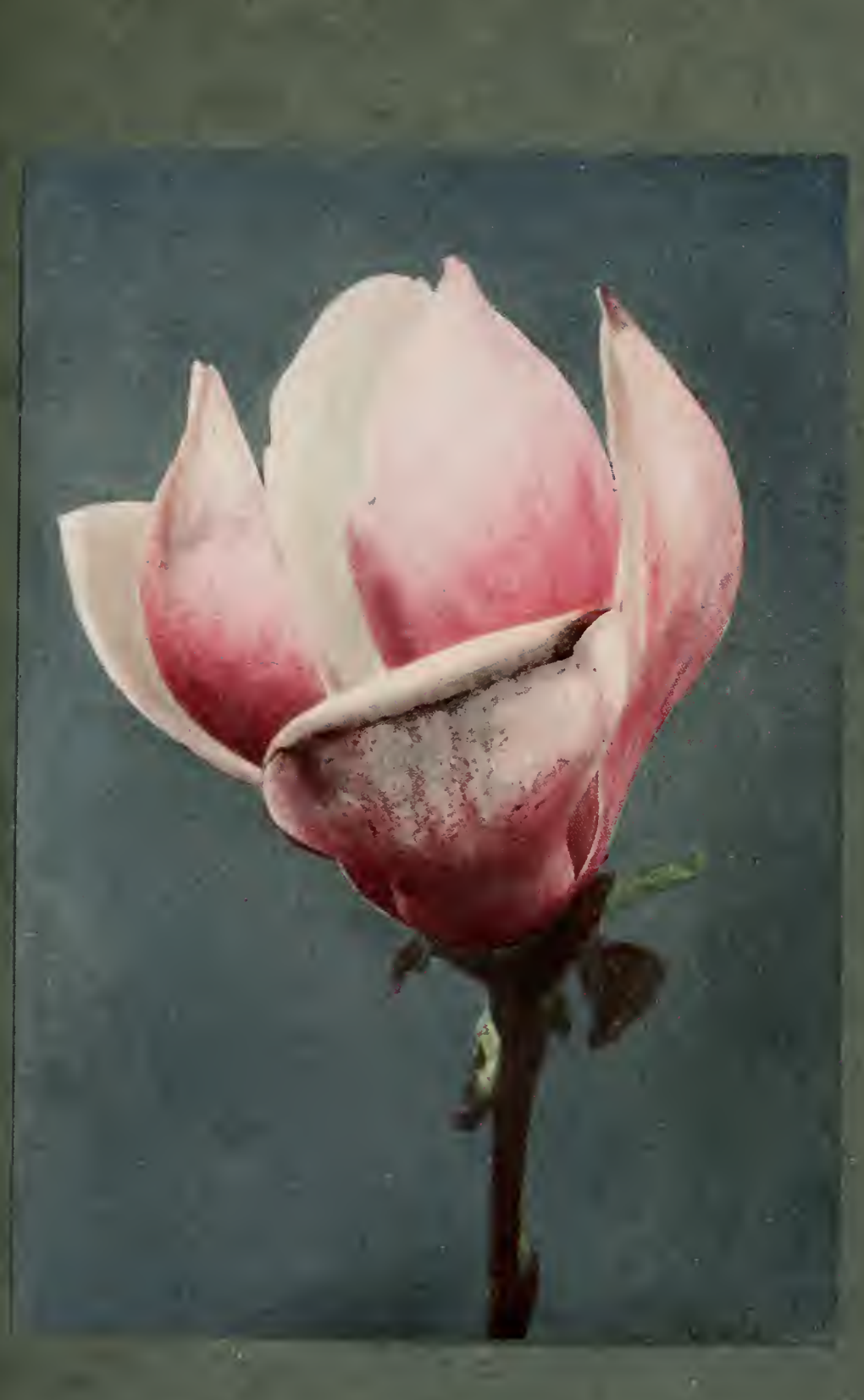




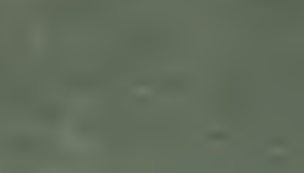
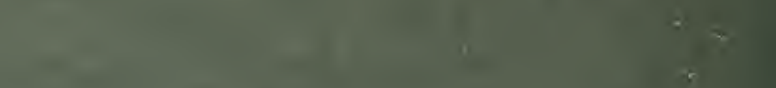

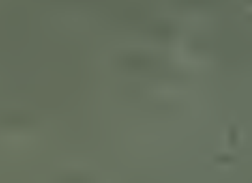

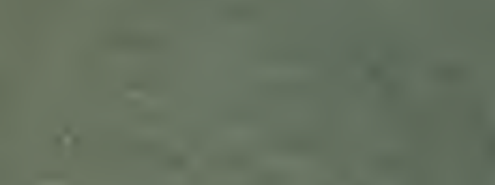

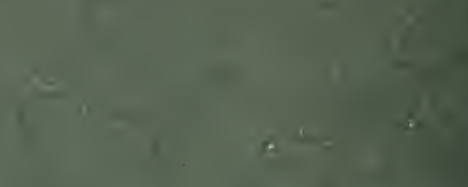

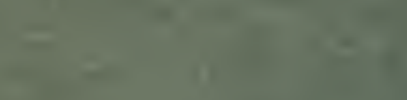

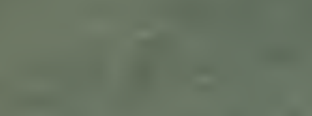

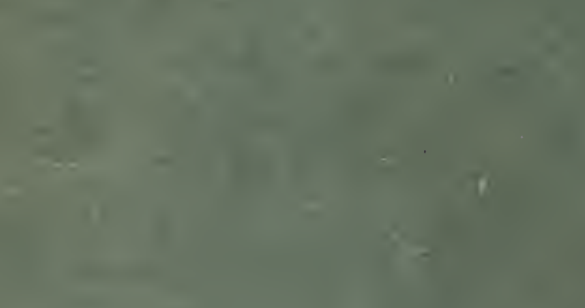

$-1$

Piv

(1)

$$
\begin{aligned}
& -\quad-\frac{1}{4}= \\
& +1=-1
\end{aligned}
$$

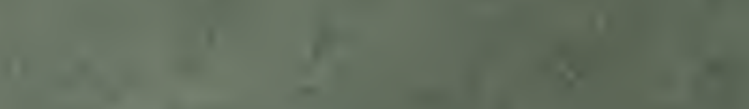

$=$

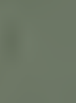$$
1
$$

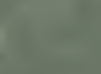

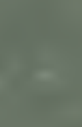$$
5=
$$

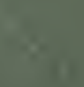

$=$

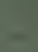

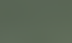

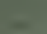

a.

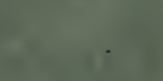

$x$

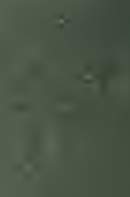

6

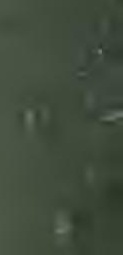

$5=$

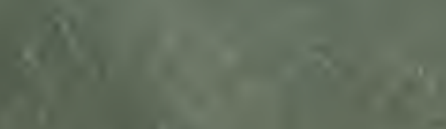

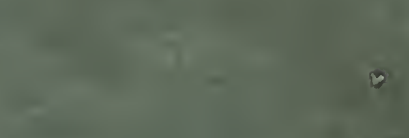


in advance of the leaves in spring; Fraseri, yellow, spring, a shy bloomer; hypoleuca, cream, red anthers, sweet, spring ; Lennei, purplish red, spring, a nybrid, flowers in advance of the leaves; macrophylla, white, summer ; parviflora, cream, late spring ; Soulangeana, rose, spring, flowers in advance of the leaves; stellata (syn. Halleana), white, spring, flowers in advance of the leaves, there is a variety rosea; and Watsoni, cream, sweet, spring, not hardy, are the most important. Acuminata, yellow, early summer; glauca, white, early summer; Kobus, purple and white, spring; and tripetala, white, spring, are all beautiful. Alba superba is a form of conspicua, and Soulangeana is also sometimes classed as a variety of the species. Stellata flowers profusely in a young state and is exquisitely beautiful. Others are Campbelli, rustica rubra, salicifolia, cordata, glauca and pumila. Rich, loamy soil is best. Very little pruning is required. There should be as little root disturbance as possible.

MAHONIA.-See Berberis and Chapter IX. M. aquifolia is Berberis aquifolium. See Chapter XXV.

MAIDENHAIR TREE.-See Ginkgo.

$M A P L E$.-See Acer and Chapter XV.

MELIOSMA MYRIANTHA.-A rare Japanese shrub, with large oval toothed leaves and white flowers.

MENISPERMUM.-A small genus of deciduous climbers, of which canadense, with shield-shaped leaves and yellow flowers in summer, is alone met with to any extent. It is a good subject for a shady wall. Loam.

MENZIESIA.-Polifolia is the same as Daboëcia polifolia. See Chapters IX. and XIX. Empetriformis 
is the same as Bryanthus empetriformis. See Bryanthus. M. globularis has pink flowers in May, height three to five feet. Moist peat.

MOCK ORANGE.-See Chapter IX. and Philadelphus.

MORUS.-Nigra is the common Mulberry, a handsome deciduous tree with greenish flowers in early summer, followed by dark red fruit which cannot be relied on to ripen unless the tree is grown on a wall. Alba, the white Mulberry, is the species grown for feeding silkworms; there is a variety of it called pendula, in addition to several others. The Mulberry is an interesting tree. There are famous examples in English gardens at Syon House, Isleworth; and the Chapter Garden at Canterbury. People who see them have sometimes an impulse to plant Mulberries, but as a matter of fact few are put in and the tree is declining.

MOUNTAIN ASH.-Pyrus Aucuparia, a graceful small deciduous tree with brilliant berries. Ordinary soil.

MUEHLENBECKIA.-Complexa and varians are offered and are suitable for growing on walls, but they are of little importance. Sandy loam.

MUI.BERRY.-See Morus.

$M Y R I C A R I A$.- See Tamarix.

$M Y R I C A$.-The species cerifera is the Candleberry Myrtle, so called because candles were once made from the berries; and Gale is the Sweet Gale or Bog Myrtle, which is pleasantly scented and does well at the waterside. Cerifera grows up to twenty feet 
high, Gale about four feet; it is a twiggy, deciduous shrub with brownish inconspicuous flowers. Moist peat.

MYRTUS (MYRTLE).-See Chapter XVIII. There are several species, but the Myrtles grown in gardens are nearly all varieties of communis, which has white flowers in July ; and there are many of them, including narrow-leaved (angustifolia), slender-leaved (tenuifolia), orange-leaved, Thyme-leaved, Rosemary-leaved and variegated. The Myrtles are generally grown for their fragrant evergreen foliage. They are best grown against walls and protected in winter. Loam and leaf mould.

NANDINA.-The only species, domestica, is not fully hardy, and can only be grown out of doors in mild districts. It is an evergreen, with fern-like foliage, white flowers and rosy fruits. It is known as the Heavenly Bamboo in Japan. Loam and peat, an open but sheltered site and shade from mid-day sun favour it.

NEGUNDO.-See Acers. Several are offered in catalogues under the name of Negundo, notably californicum aureum and fraxinifolium (syn. aceroides) and its varieties, such as white variegated and yellow variegated.

NEILLIA.-These are now referred to Spiræas, but opulifolia, height up to eight feet, a deciduous shrub with white flowers in June, and its goldenleaved form lutea, are often grown under the original name. Loam.

NETTLE TREE.-See Celtis. 
NEVIUSIA.-The one species, alabamensis, is a deciduous North American shrub growing up to six feet high and with white flowers in May. Ordinary soil.

NORWAY MAPLE.-See Acer.

NORWA Y SPRUCE.-Picea or Abies excelsa. See Chapter XVII.

NOTOSPARTIUM.-Australis and Carmichaeliæ are offered, the latter most commonly; it is a Broomlike New Zealand evergreen growing up to twenty feet high, with pink flowers in early summer. Loam and peat.

NUTT ALLIA.-The only species generally met with is cerasiformis, a deciduous shrub growing up to ten feet high, with white flowers in spring. It should be grown in a sheltered place. Loam.

$O A K$. - This grand old tree belongs to the genus Quercus, and pedunculata is generally given as the species; it is, however, a form of Robur with stalked cups; there are several sub-varieties, such as Concordia, fastigiata (pyramidal), silver variegated, pectinata, asplenifolia, purpurascens, pendula, leucocarpa (yellow) and heterophylla. The stalkless form of Robur is called sessiliflora. These are the giant Oaks of the great parks. Cerris, the Turkey Oak, is a somewhat smaller but still large tree; rubra is the Red Oak; there is a beautiful variety called aurea. There is a silver-variegated form of Cerris among several others. Lucombe's Oak is a sub-evergreen. Other species of medium size are coccinea, the North American Scarlet Oak, which has beautiful colour in 


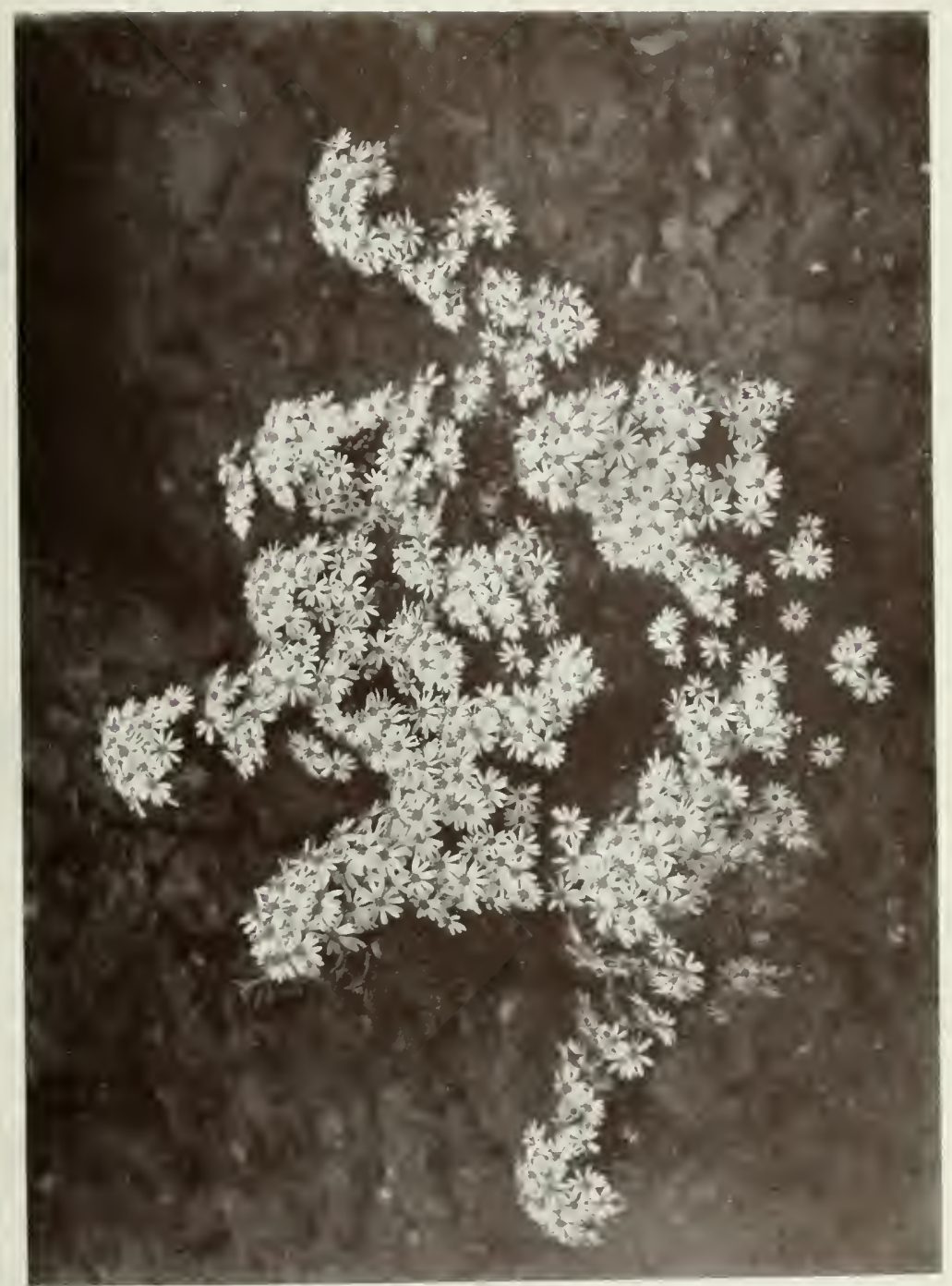

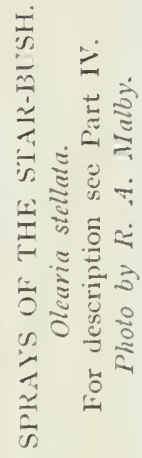




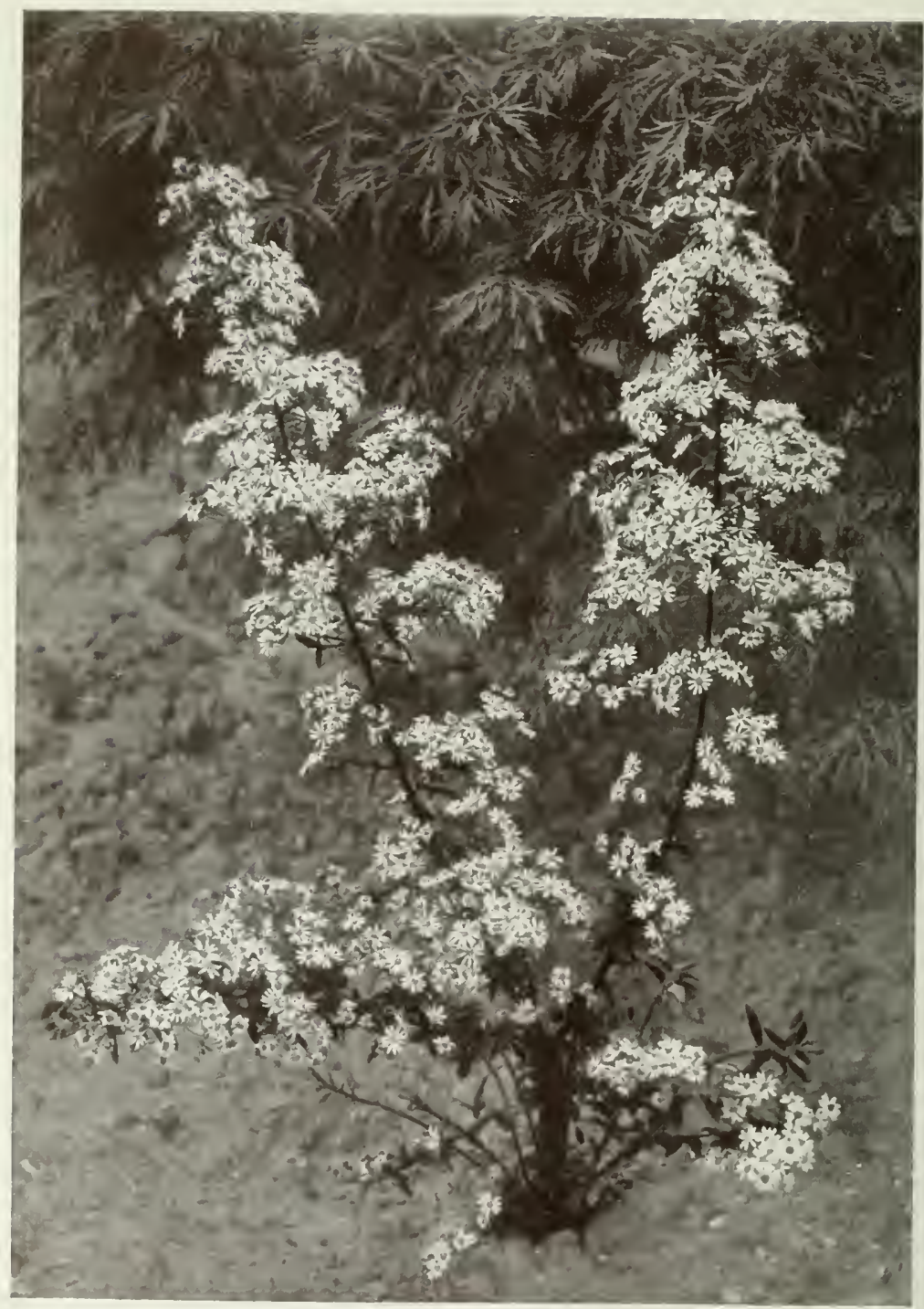

AN UNCOMIION STAR-BUSH.

Olearia macrosepala.

For Olearias see Part IV.

Photo by R. A. Malby. 
autumn (Waterer's variety, or Knap Hill Scarlet is good) ; conferta (syn. pannonica) the Hungarian Oak, a handsome, deeply-lobed species of very quick growth; palustris, the Pin or Marsh Oak, another North American species with fine colour in the fall; macrocarpa, the Burr Oak; Mirbeckii (syn. Zang) a very handsome species; and heterophylla, narrowleaved. The common evergreen Oak (also known as Holm Oak and Holly Oak) is Q. Ilex, a useful hardy but rather dull tree. There are, however, several other good evergreen species, such as acuta and serrata, both small species from Japan; cuspidata and its variegated form; and glabra. Other species are Phellos, the Willow Oak, with long, narrow leaves; Suber, the Cork Oak, which gives the commercial cork; and Prinus, the Chestnut Oak. The Evergreen and Turkey Oaks are good seaside trees and the former thrives in towns. Deep loamy soil.

OLEA (OLIVE).-The species europæa is the wild Olive, which is cultivated for its oil. It is a shrub growing up to six feet high, with white flowers in July. In northern climes it should have a warm, sheltered place. Fragrans is the same as Osmanthus fragrans. Peat and loam.

OLEARIA.-Handsome evergreens, of which the best known are stellulata (syn. Eurybia Gunniana), height up to four feet, white flowers in late spring or early summer, a very beautiful but not hardy shrub (Olearia Gunnii or Gunniana of gardens is the same); and Haastii, three to four feet, white, very free, late summer, the hardiest, if cut by frost breaks up again 
rapidly. Others are angustifolia, white, sweet ; argophylla, white, woolly, musk-scented leaves ; dentata, white, yellow centre, not hardy; Forsteri, white, summer, not quite hardy ; insignis, white, yellow centre, not hardy; macrodonta, silvery leaves, white fragrant flowers; nearly hardy; nummulariæfolia, cream flowers and thick stemless leaves, nearly hardy ; and Chathamica which was exhibited by a Cornish amateur, the Rev. A. T. Boscawen, in London in I9I3, when it received a Botanical Certificate from the Royal Horticultural Society ; the leaves are lanceolate, dull green, downy below; the flowers single, soft lilac, about two inches across. The less hardy Olearias may be grown on wall borders. Ordinary soil.

ONONIS.-Of the several shrubs in this genus, fruticosa, growing up to two feet high, with purple flowers in summer, is the best known; it is deciduous, and suitable for the rock garden. Rotundifolia, a dwarf shrub with rose flowers in summer, is also met with. Ordinary soil.

OSAGE ORANGE.-See Maclura.

OSMANTHUS.-Useful evergreens, thriving in town and seaside gardens and good for winter bedding. The most important is ilicifolius, which is generally offered as a species, although really a variety of Aquifolium; it is a shrub growing up to four feet high, with dark, Holly-like leaves and white flowers in August. There are silver-variegated and golden variegated forms of ilicifolius, also a dark, purpureus. Myrtifolius has nospines. Thespecies fragrans is the same as Olea fragrans. The Osmanthuses do best in sandy loam. 
OSTEOMELES.-Anthyllidifolia is an evergreen growing up to three feet high, with white flowers in summer, but it is only safe out of doors in mild districts. Loam.

OTHERA.-Japonica is the same as Ilex integra, an evergreen with white flowers in summer.

OXYCOCCUS.-Macrocarpus, a creeping shrub with pink flowers in May, followed by fruits, is the American Cranberry. Palustris (syn. vulgaris) is the common Cranberry. Moist peat.

OXYDENDRON.-Arboreum, a tree growing up to thirty feet high, with white flowers in summer, is the same as Andromeda arborea. Moist peat.

OZOTHAMNUS.-Rosmarinifolius is a half-hardy evergreen with yellow flowers. Loam and peat. It is now united to Helichrysum by botanists.

PAEONIA (PAEONY).-Moutan, the Tree Pæony, is a deciduous shrub, and the finest of the modern varieties make beautiful groups in beds or at the front of shrubberies. The flowers are of enormous size and brilliant in colour. The plants are often forced in pots. Any deep, rich soil suits. Basal shoots of all kinds should be removed as they appear. Although the plants are hardy the buds are sometimes cut by severe late frost and protection should be given in hard weather. Better still, plant in a sheltered place where the sun will not strike on them before II a.m., because then frost may be harmless. The following may be grown : single: Etna, fiery red; Illinois, carmine; Missouri, pink; Pennsylvania, salmon; Wisconsin, pink, violet stripe; double: De Bugny, 
white, violet flakes; Jeanne d'Arc, salmon; Lactea, cream; La Ville de St. Denis, white, violet ground; Louise Mouchelet, salmon-pink; Madame Stuart Low, salmon-red; Queen Elizabeth, rosy red; Archduc Ludovic, violet; and Souvenir de Ducher, violet red. A fine hybrid, named La Lorraine, with soft yellow flowers, has been raised by crossing the yellow Tree Pæony, P. lutea, with a variety of P. moutan. P. lutea itself is a fine plant with clear yellow flowers. It was found in Yunnan and first flowered in Europe in I89I. It should have a warm sheltered place and rich friable loamy soil. P. Veitchii, purplish red, several blooms on each stem, is also interesting.

PALIURUS.-Australis (syn. aculeatus), "Christ's Thorn," is a deciduous shrub growing up to six feet high, with spiny stipules and clusters of yellow flowers in June. It is reputed to be the plant from which the crown of thorns was made. Ordinary soil.

PAMPAS GRASS.-See Gynerium.

PARROTIA.-Persica (syn. Hamamelis persica) a deciduous shrub, growing up to fifteen feet high, with scarlet flowers in summer, is worth growing for the brilliant colour of its foliage in autumn. Jacquemontana, yellow, white bracts, is also offered.
PASSIFLORA
(PASSION
FLOWER).-See Chapter XVIII. Peat and loam.

PAULOWNIA.-Imperialis, a handsome small tree, makes a fine "sub-tropical " bed when grown in deep, rich soil, cut down in spring, and the resulting basal shoots thinned to one, for it may grow ten feet high and produce splendid foliage. 


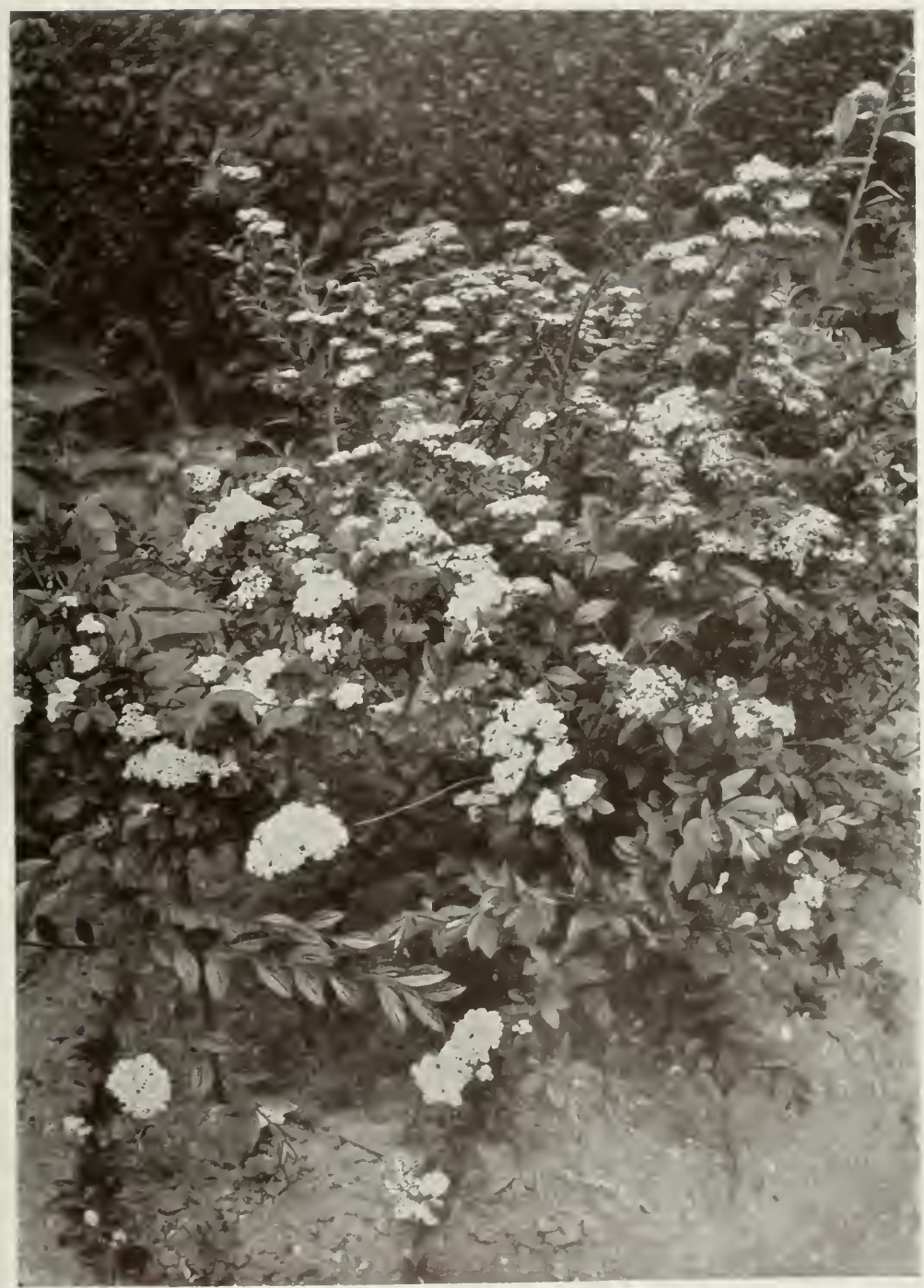

ONE OF THE NEWER MEADOWSWEETS.

Spiraa llemy?

For description see I'art IV.

Photo by R. A. Malby. 

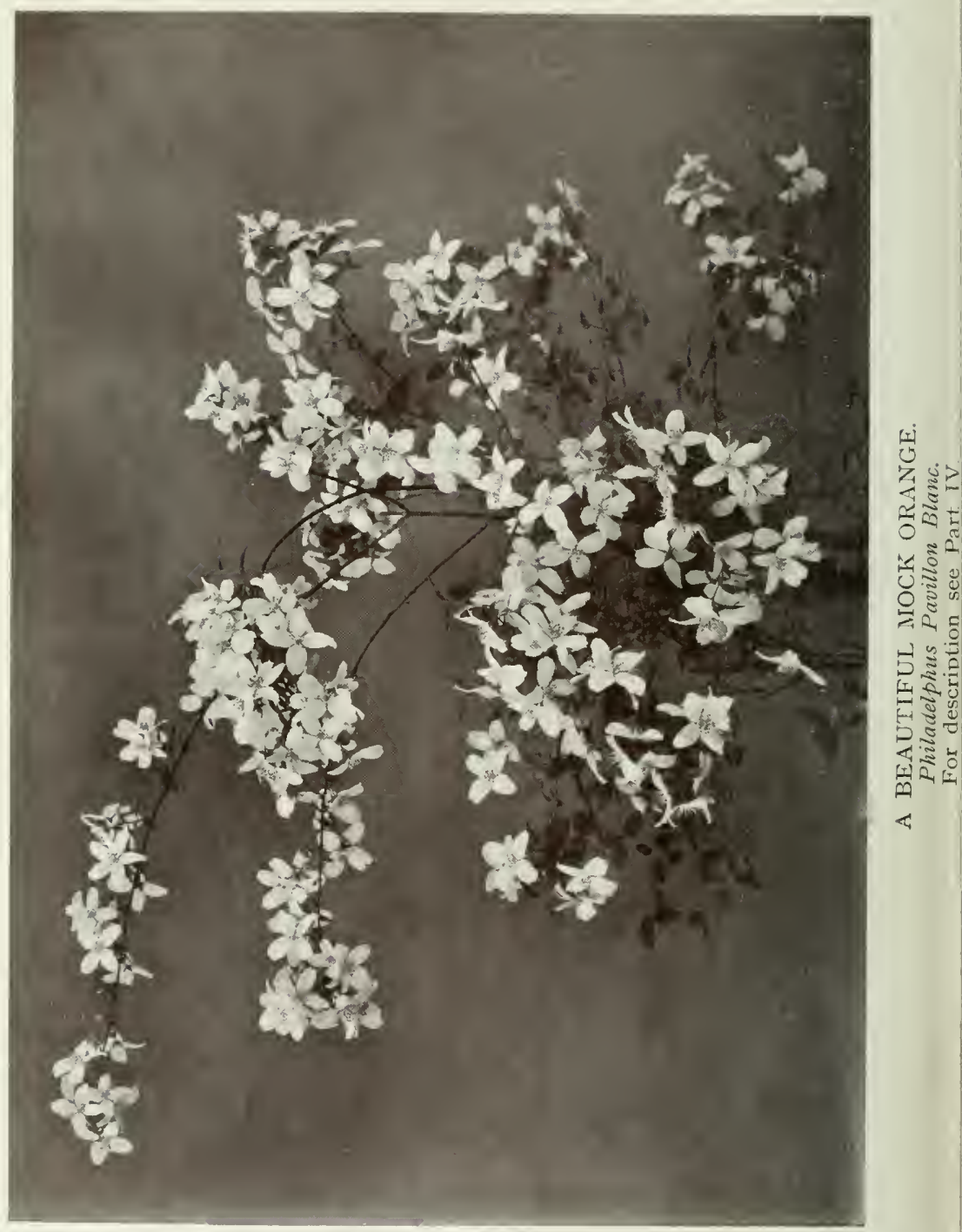
PAVIA.-See Esculus.

$P E A C H$.- See Chapter XXVI. for notes on forcing Peaches for early bloom. See also Chapters V. and VI. and Prunus.

PEAR.-See Chapter XXVI. for forcing for early bloom, also Pyrus.

PENTSTEMON.-This semi-shrubby genus has been dealt with in the companion volumes: ALPINE Flowers and Rock Gardens, and Hardy Perennials AND HERBACEOUS Borders.

PERIPLOCA.-See Chapter XVIII. P. græca thrives in ordinary soil.

PERIWINKLE.-See Chapters XVI. and XXV.

PERNETTYA.-See Chapters XV. and XIX.

The forms of mucronata are charming little berried evergreens, excellent for winter decoration. The varietal names coccinea, carnea, lilacina and nigra refer to the colours of the berries. Peat and loam.

PEROWSKIA.-Atriplicifolia is a handsome deciduous shrub, having white woolly leaves and long spikes of blue flowers in autumn.

PERSIMMON.-See Diospyros.

PHILADELPHUS (MOCK ORANGE).-See Chapter IX. This is one of the best of hardy deciduous shrubs, owing to its vigour, profuse blooming and adaptability to all kinds of soil. The common Mock Orange, coronarius and its forms, are very sweet; the larger grandiflorus is not so fragrant; the latter is, however, a splendid species for the border, owing to its great size and profusion. There are many forms of coronarius, including gold-variegated and silver- 
variegated, double, and dwarf (nanus). Great interest is taken in the modern hybrids, of which Lemoinei is typical: under this are grouped such forms as Fantaisie, white fimbriated flowers, faint tint of rose in the centre, sweet; Purpureo-maculatus, white, spotted purple, sweet, dwarf ; Virginal white ; Rosace, cream, double, sweet; Avalanche, large, white, sweet; Pavillon Blanc, white, clustered; Boule d'Argent, white, double, sweet ; Candelabre, white, dwarf, sweet ; Bouquet Blanc, white; and Voie Lactée, white. Microphyllus is a good species for the rockery and very sweet. Ordinary soil, including poor limestone.

PHILESIA.-Buxifolia is a beautiful evergreen, growing up to four feet high, with red flowers in early summer resembling the Lapageria. It is not fully hardy and should have a sheltered place. Peat.

PHILLYRAEA.-Useful evergreens, of which angustifolia, height up to ten feet, white flowers in May ; Iatifolia, taller, white, May; and media, fifteen feet, white, May, are the principal species. Ilicifolia and rotundifolia are forms of latifolia. Decora (syn. Vilmoriniana) is also grown. Ordinary soil. The Phillyræas do well in towns and at the seaside.

PHLOMIS.-A genus of herbaceous plants and shrubs. The best of the latter is fruticosa, the Jerusalem Sage, an evergreen growing about a yard high, with yellow flowers in June. Ferruginea is also a yellow-leaved shrub. Ordinary soil.

PHOTINIA.-Several of this genus are evergreens, including arbutifolia, the Californian May bush; height up to fifteen feet, white flowers in summer; 
serrulata (syn. glabra), white, the Chinese Hawthorn; Benthamiana and ovata. Villosa (syn. variabilis) is deciduous. Japonica (syn. Mespilus japonica) is now called Eriobotrya japonica; this is the Japan Medlar or Loquat. Sandy loam.

PHYLLOSTACHYS.-See Bamboos.

PICEA.-See Chapter XVII.

PIERIS.-A genus closely allied to Andromeda and thriving under the same conditions. P. floribunda and A. floribunda are the same (syn. Zenobia floribunda.) P. formosa is a good white-flowered evergreen, but needs a sheltered place. P. japonica has white flowers in drooping clusters. Peat.

PINE, PINUS.-See Conifers, Chapter XVII., also Chapters V. and XIV.

PIPTANTHUS.-Nepalensis (syns. Baptisia nepalensis and Thermopsis laburnifolia) the Evergreen Laburnum, is a beautiful wall shrub, with yellow flowers in spring; the variety aureus has yellowish bark. Tomentosus only differs from nepalensis in being hairy. Sandy loam.

PITTOSPORUM.-This evergreen genus is not hardy, but several species, notably Buchanani, Colensoi, crassifolium, eugenioides and its form variegata, Tobira and undulatum may be grown outside in mild districts. Crassifolium, height up to six feet, chocolate flowers in spring; and Tobira, up to twelve feet, white, spring, very sweet, are two of the best. Tenuifolium makes a splendid bush at Aldenham House, near London, on clay soil. The small flowers are almost black. 
PLAGIANTHUS.-Lyallii is an attractive shrub, with white drooping flowers in the axils of the leaves, but it came from New Zealand and is not hardy, and can only be grown outdoors in northern climes in sheltered places.

PLANERA.-See Zelkova.

PLANE, PLATANUS.-We have seen in Chapter $\mathrm{XX}$. that the Plane is one of the best of town trees. The London Plane is Platanus acerifolia, which has Maple-like leaves and greenish flowers in spring. Sütnerii is a strong variety with deeply cut marbled leaves. Occidentalis, the Western Plane, has fiveangled leaves; there is a variegated form. Orientalis is the Eastern or Common Plane; there are deeply cut and variegated-leaved forms. Ordinary soil if not dry.

PLUM, PURPLE-LEAVED.-Prunus Pissardii.

PODOCARPUS.-Evergreen Conifers, imperfectly hardy, and therefore requiring sheltered places. The principal species are alpina, chilina, macrophylla, nubigena and Totara. The first only grows up to about twelve feet high and is fairly hardy. The others are much larger. Loam.

POISON IVY.-See Rhus.

POISON OAK.-See Rhus.

POLYGALA.-Most of these are not hardy, but Chamæbuxus, a low sub-shrub with creamy flowers in summer, may be grown outside ; there is a purpleleaved form called purpurea. Peat.

POLYGONUM.-Most of this genus are hardy herbaceous perennials, but Baldschuanicum (see 
Chapter XVIII.) multiflorum and molle are subshrubby. The two first named are good ramblers, particularly Baldshuanicum. Ordinary soil.

POMEGRANATE.-See Punica.

POPULUS (POPLAR).-See Chapters VIII. and IX. P. alba (Abele) is the white Poplar; P. nigra, the black Poplar; P. nigra pyramidalis, the Lombardy Poplar; P. tremula, the Aspen; P. balsamifera, the Balsam Poplar; P. canescens, the Grey Poplar; P. deltoides (syns. canadensis, cordata and monilifera) the Necklace Poplar. They are hardy, cheap and useful trees, thriving in most soils; alba and tremula like a deep moist soil; there is a form of tremula called purpurea, the young growth of which is purple.

PORTUGAL LAUREL.-See Laurel.

POTENTILLA.-Most of the Cinqueioils are herbaceous, but fruticosa, height up to eight feet, with yellow flowers in summer, is a deciduous shrub, and so is the hybrid Friedrichsenii, which has pale yellow flowers and is rather dwarfer than fruticosa. Glabra is a form of the latter. Ordinary soil. There are several Alpine species, suitable for the rock garden.

PRINOS.-Glaber is the same as Ilex glabra. Ordinary soil.

PRIVET.-See Ligustrum, and Chapters XIV. and XXIV.

PRUMNOPITYS.-A small genus of Conifers, of which the best known is elegans (syns. Stachycarpus andina and Podocarpus andina), the Plum Fir. Spicata, the Black Pine, is less hardy. They are trees growing up to fifty feet high in deep loamy soil. 
PRUNUS.-The many references to this great genus in preceding chapters will have conveyed an idea of its importance. It includes the Almond, the Cherry, the Apricot, the Plum and the Laurel. It provides many varieties of the utmost value for forcing. The following are the most important for ornamental purposes: Almond section (Amygdalus): Communis is the common pink ; flore pleno, double red, and macrocarpa, large pink, are both varieties of it. C. amara is the bitter Almond and $\mathrm{C}$. dulcis the sweet Almond. Davidiana is pale rose; it has a white form, alba. Nana is the dwarf Almond. Incana is the hoary Almond. Orientalis is the silver Almond. Apricot section : Mume is the Japanese Apricot, dwarf, with white, scented flowers in March; there are double pink and double white forms and various singles. Triloba is pale rose; it has a double form, flore pleno. Tomentosa is white. Bird Cherry section: Padus, white, spring ; there is a double form, flore pleno, and also a splendid single called Albertii, with long white spikes like small Lilacs. Mahaleb, white, fragrant; there are yellow-fruited and drooping forms. Cherry section: (Cerasus). Avium is the wild Cherry or Gean, white; there is a double form, flore pleno; and a large-leaved, decumana. Cerasus, the common Cherry; there is a splendid double white form of this called Rhexii flore pleno. Japonica (syn. sinensis) the Japanese Cherry, white ; does best when pruned hard after flowering; there are double white and double rose forms. Pseudo-cerasus, the Bastard Cherry; there is a splendid double pink form of this called 
James $H$. Veitch and a beautiful blush, larger and even freer than the preceding, named Shirofugen. Serrulata, white. Pumila, dwarf, white. Peach section: Persica, rose, the Peach ; there is a good double red form of this called Clara Mayer; there are also double rose, double white and purple-leaved forms. Plum section: Cerasifera, the Myrobalan or Cherry Plum; the dark-leaved form of this named atropurpurea is the same as Prunus Pissardii; there is a beautiful sub-form called Hessei, the narrow leaves of which vary a good deal in colour ; and also a subform named Moseri flore pleno, with double rose flowers. Spinosa, the Sloe; there is a double white form and also a dark-leaved, purpurea. For forcing the foregoing, see Chapter XXVI. Laurel section: Laurocerasus, the common Laurel ; and Lusitanica, the Portugal Laurel (see Laurels). For other references to the genus Prunus see the various chapters. A distinct Prunus with glaucous grey leaves and cherrylike fruit is Besseyi.

PSEUDOLARIX.-Kæmpferi (syn. Larix Kæmpferi) is the Japanese Golden Larch.

PSEUDOSTUGA.-The only species of any importance is P. Douglasi (syn. Abies Douglasi). See Chapters V., XIV. and XVII. (Conifers). There are several garden forms of this beautiful tree, including glaucous and drooping. It does not care for a cold, exposed site.

PTELEA.-Trifoliata is the Hop Tree, a deciduous tree growing up to eight feet high, with yellow flowers in summer; there is a form called aurea, 
the new spring foliage of which is tinted yellow. Ordinary soil.

PTEROCARYA.-Deciduous trees, of which caucasica (syn. fraxinifolia) growing up to thirty feet high, with greenish flowers in May; and stenoptera (syn. laevigata) are met with. Loam.

PTEROSTYRAX.-See Halesia.

PUNICA.-Granatum is the Pomegranate, a deciduous tree growing up to thirty feet high, with red flowers in summer, followed by large orange-like fruits. It does not bear in northern climes, and may not even bloom unless grown on a south wall. There is a double form. Loam and leaf mould.

PYRACANTHA.-See Cratægus.

PYRUS.-This great genus, which includes the Apple, the Pear, the Quince, the Service and the Mountain Ash, has been referred to in several preceding chapters. P. Aria is the White Beam Tree; there is a golden form, chrysophylla ; P. baccata is the Crab (see Crab); P. Aucuparia is the Mountain Ash; P. communis is the Pear; P. Cydonia is the Quince; P. japonica (syn. Cydonia japonica) is the Japanese Quince; P. Malus is the Apple; P. prunifolia is the Siberian Crab (see also baccata); P. Sorbus is the true Service Tree; and P. Terminalis is the wild Service Tree. For references to P. floribunda, P. Scheideckeri and P. spectabilis see Chapters IX. and XXVI. ; for Crabs see Chapters IX. and XV.; for the Mountain Ash see Chapter IX. ; for Japonica, see Cydonia and Chapter XVIII. With respect to other Pyruses, the following are good 
garden trees: coronaria, the Canadian $\mathrm{Crab}$ and its double pink form flore pleno, which is both beautiful and sweet; Maulei, golden fruit, good for a low wall (see also Cydonia); sinensis, white flowers in spring; salicifolia, white, narrow lanceolate leaves, and its form pendula; and vestita, white, pyramidal habit. QUERCUS.-See Oak.

QUICK.-See Cratægus and Chapter XXIV.

QUINCE.-See Pyrus and Cydonia; also Chapter XVIII.

RAPHIOLEPIS.-The best known is japonica, an evergreen with white fragrant flowers in spring, best grown on a wall and protected with a mat in severe weather. Loam and peat.

RETINOSPORA.-Handsome small Conifers, which botanists now class with Cupressus, but which are grown in gardens and nurseries under the name Retinospora. See Chapter XVII.

RHAMNUS (BUCKTHORN).-These include both evergreen and deciduous species. The most important of the former is Alaternus, a tree growing up to twenty feet high, with green flowers in spring; there are narrow, broad-leaved and silver-variegated forms. The narrow-leaved (angustifolia, syn. Perrieri) is the best. Californicus is also evergreen and grows up to twelve feet high. The most important of the deciduous species is Frangula, the Black Dogwood, which grows up to ten feet high and has greenish-white flowers followed by black fruit; there are narrow-leaved and golden variegated forms; it does well by water. Alpinus is also deciduous and has black fruits. Ordinary soil. 


\section{RHODODENDRON.}

Botanists, pointing to the trifling differences between Azaleas and Rhododendrons, amalgamate them. Even if we consider them as separate genera the Rhododendron is supreme, with the Azalea it is unchallengable. There are, however, shrub-lovers who have to dispense with Rhododendrons in their gardens, owing to the soil containing lime. The Azalea and Rhododendron belong to the botanical order Ericacæe, the members of which are lovers of peat. While, however, they enjoy this earth, it need not be assumed that they will not thrive in other soils. Many authorities on these shrubs would not use peat exclusively if they were making special beds, although they would gladly avail themselves of a natural peaty soil for these and other of the beautiful and fascinating Ericacæe if circumstances took them into a district where it prevailed. When making special beds they would use a good deal of fibrous loam in addition to peat; for it has been proved that this soil suits Rhododendrons if it is free from lime. From the garden point of view it is convenient to keep Azaleas and Rhododendrons separate, because, in the main, they serve distinct purposes; moreover, they are separate in most of the catalogues. The Azaleas of the mollis and sinensis sections, and their hybrids, are deciduous, and of low or medium growth. The most important Rhododendrons are evergreen, and are of almost tree-like habit in suitable soil. There are, of course, deciduous Rhododendrons, but the broad distinction will serve. 
The species of Azaleas and Rhododendrons are, as a rule, of little interest to amateurs, although of great interest to botanists. The long lists of named sorts in the catalogues-the Anthony Kosters and Pink Pearls, the Glory of Boskoops and John Waterers, of nurserymen-are garden forms of hybrid origin. The garden-lover does not know whence they came, and it would be a difficult task to trace the parentage of the best modern varieties. Few species of Azalea are met with in gardens, and for all practical purposes they can be dismissed. One can hardly go so far with Rhododendrons. We have already seen that ferrugineum and hirsutum, the Alpine Roses, are grown in rock gardens. Racemosum is used for the same purpose, as well as for winter-blooming in pots. Ponticum is planted extensively in woods. Campylocarpum, catawbiense and caucasicum are sometimes met with. But in nine gardens out of ten it is the hybrid offspring of some of these and other species which are grown. The principal species which have been used as parents for Rhododendrons are ponticum, catawbiense, arboreum, maximum, caucasicum and purpureum. With respect to Azaleas, what are known as Ghent Azaleas sprang from the species pontica (not Rhododendron ponticum, but the plant known to botanists as Rhododendron flavum, a yellow-flowered deciduous shrub, a native of the Caucasus), calendulaceum (occidentale), nudiflorum and viscosum, all hardy North American species. Although the Ghent Azaleas are hardy they are mostly used for pot culture and are grown in enormous quantities by Belgian florists for winter bloom 
under glass. Azalea mollis (Rhododendron sinense of botanists) is known to have been crossed with pontica, and has probably been crossed with others. Several hybrid sections are offered by nurserymen and the exact parentage is doubtful. Coming to the purely gardening aspect of the subject, we have seen in previous chapters that Rhododendrons and Azaleas are magnificent shrubs for lawn beds, and also for large borders. The coloured plates show with what remarkable effect they can be grouped, forming brilliant colour masses. We have also considered propagation and other cultural matters. It may be well to make clear that when peat is referred to the peat of a stagnant bog is not meant, but sweet sandy peat. Rhododendrons love cool but not waterlogged spots. A humid climate suits them better than a dry one, witness the grand plants in the famous Cornish gardens. But Rhododendrons are at home in Surrey, particularly on the upland sandy peats around Bagshot and Woking. When sites are prepared for them the imported soil should be put in mounds above the ground level, not in pits made by carting the native soil away. In the latter case lime, if present, would eventually work its way into the bed some time in the future. If the soil is light and sandy leaf mould may be added with advantage. Rhododendrons have great tenacity of life, and when suited by soil and climate are the easiest of plants to grow. Lime has a singular toxic effect on them the exact nature of which is not known. Cunningham's White, will, however, thrive on limestone. Thefollowing are splendid hardy Rhododendrons 
in the various colours: Bicolor: Sappho, Mrs. A. Walter, Francis B. Hayes and Lady C. Walsh. Blush or pale pink: Pink Pearl, Gomer Waterer and Mrs. E. C. Stirling. Deep pink and rose: Lady C. Mitford, Kate Waterer, Strategist and Lord Palmerston. Red: Cynthia, John Waterer, John Walter, Doncaster. Purple or plum: Baron Schröder, Melton and Old Port. White: The Queen, Mrs. J. Clutton and Memoir. Where only one of each colour is required the first named may be chosen. The following newer varieties are beautiful, but it may be expected that the cost of them will be higher; Alice, a giant of deeper colour than Pink Pearl; Princess Juliana, blush; Gill's Goliath, blush with deeper pink edge; and Cornubia (Thomsoni +Shilsoni) bell-shape, dense blood red; some good hardy deciduous Azaleas are described in Chapters IX. and XXVI. The flowerheads of Rhododendrons should be pinched off short when they fade, using finger and thumb carefully so that the growing bud at the base is not broken off. This removal of fading flowers prevents seed pods forming and the plants bloom the better for it the following year. We have often been struck with the way in which old Rhododendrons that were getting bare below have broken up green, fresh and strong when headed at midwinter to hard wood as thick as a man's leg. This should interest and encourage those who have gawky plants. Growth will break from brown barky wood that shows no sign of buds. A dressing of leaf mould or decayed manure is spread over the roots. For other references to Azaleas and 
Rhododendrons see Section A. on modern shrubs, also Chapters III., VII., XI. (propagation) XIII. (pruning), XIV., XIX. (rock subjects), XXV. and XXVI. (forcing).

RHODORA - One species with purple and red flowers is often met with under the name of Rhodora canadensis (syn. Rhododendron Rhodora). It needs the same treatment as Rhododendrons.

RHODOTYPOS.-The only species is kerrioides, a deciduous shrub growing up to twelve feet high, with white flowers in April. Ordinary soil.

RHUS (SUMACH).--Several of the Sumachs, notably Cotinus, glabra and typhina, are much esteemed for the rich colour of their foliage in autumn. The first named, the Smoke Plant, is also effective when the seed plumes form after the flowers. The principal species are copallina, height up to six feet, yellow flowers in summer ; Cotinus, eight feet, pale purple, purpurea is a dark-leaved form; cotinoides; glabra, twelve feet, yellow, laciniata is a cut-leaved form ; and typhina, twelve feet, greenish yellow, fine foliage; laciniata is a cut-leaved form of it. R. Toxicodendron, the Poison Oak or Poison Ivy, is a rambler with greenish yellow flowers, and must be dressed with gloved hands; radicans is a creeping form. Ordinary soil.

RIBES.-This genus includes the fruiting Currants and Gooseberries. Several of the species are beautiful flowering deciduous shrubs and bloom early. The principal ornamental species are aureum, height up to six feet, yellow, April, there are several forms, including an early, præcox; Gordonianum, eight feet, 
a hybrid between aureum and sanguineum, yellow and red, spring; sanguineum, eight feet, rose, March, several varieties, including white, deep red, double and pale pink; and speciosum, eight feet, red, summer, very beautiful. Sanguineum is one of the most useful shrubs for exposed places and poor limestone soil. The foliage has an agreeable aromatic odour, especially after rain.

ROBINIA.-Amongst the most useful of small trees, because the foliage is graceful, the flowers are attractive and they will thrive in town gardens. The principal species are hispida, the Rose Acacia, height up to eight feet, rose flowers in May, inermis (syn. macrophylla) is a superior form without prickles; neo-mexicana, thirty feet, rose flowers in autumn; Pseudacacia, the Locust Tree, False or Bastard Acacia, thirty to fifty feet, white flowers in spring, angustifolia, aurea, Bessoniana, crispa, robusta Vignei, Decaisneana, inermis, i. variegata, semperflorens and tortuosa are good varieties of it; and viscosa (syn. glutinosa), thirty feet, rose flowers in May. Ordinary soil.

ROCK ROSE OR ROCK CISTUS.-See Cistus.

ROSE.-See Chapters VII., XI., XV., XVIII. and XIX.

ROSE ACACIA.-See Robinia.

ROSEMARY.-Rosmarinus officinalis is the Rosemary, a dense evergreen, growing about four feet high, with small deep green aromatic foliage and lilac flowers. There is a form called prostrata, well suited to the rock garden. Ordinary soil.

$R U B U S$.- This genus includes the Blackberry and Raspberry. The principal ornamental species are 
biflorus, height up to ten feet, white flowers in pairs in May, white stems ; deliciosus, six feet, white, May, edible fruit, does well when pruned as a bush; lasiostylus, valuable for its white stems; leucodermis, ten feet, white, early summer, black fruit ; and odoratus, six feet, purplish red, yellow fruit. $\mathrm{R}$. Idæus is the Raspberry; R. laciniatus the parsley-leaved Blackberry or Bramble; and R. phœricolasius the Wineberry. The so-called Strawberry-Raspberry is a form of $\mathrm{R}$. rosaefolius. Three other handsome Rubuses are bambusarum, with trailing branches, trifoliate leaves and black fruit; flagelliformis, a species from Central China with metallic leaves and white flowers; and innominatus, trifoliate leaves, pubescent stems and orange fruits in long panicles. Good loamy soil. RUSCUS.-Aculeatus is the Butcher's Broom, see Chapters XVI. and XXV. Racemosus is the Alex.andrian Laurel, an evergreen growing about four feet high, with greenish yellow flowers in April. Hypoglossum, one foot, has yellow flowers in May. Aculeatus will thrive under trees. Both male and female forms must be planted to insure fruit. Ordinary soil.

SALISBURIA.-See Ginkgo.

SALT TREE.-See Halimodendron.

SALIX (WILLOW).-The best of these are described in Chapter XXII.

$S A M B U C U S$.- See Elder.

SARCOCOCCA.-See Section A.

$S A X E G O T H \not E A$.-Conspicua is the Conifer called Prince Albert's Yew. Culture as for Yews. 
SCARLET ELDER.-See Elder.

SCARLET MAPLE.-See Acer.

SCHIZOPHRAGMA.-See Section A on modern shrubs.

SCIADOPITYS.-Verticillata is the Umbrella Pine, an evergreen Conifer with whorled leaves in large bunches, suitable for a lawn tree and growing up to eighty feet high, but developing slowly. It should have good, well-drained soil in a sheltered place and be frequently mulched with decayed leaves.

SCOTCH ELM.-See Elm.

SCOTCH LABURNUM.-See Laburnum.

SCOTCH FIR OR PINE.-Pinus sylvestris.

$S E N E C I O .-\mathrm{A}$ ferw of the Ragworts are evergreen shrubs, including compacta, elæagnifolius (not quite hardy) Grayii and rotundifolius.

SEA BUCKTHORN.-See Hippophae.

SEQUOIA.-See Conifers, Chapter XVII.

SERVICE TREE.-See Pyrus.

SHEPHERDIA.-A small genus of deciduous shrubs, of which argentea alone, with yellow flowers in April followed by acid scarlet berries, is met with in cultivation. It likes the same conditions as Hippophae.

SIBERIAN CRAB.-See Pyrus.

SKIMMIA.-Useful evergreens, Fortunei, height up to three feet, greenish white flowers in spring, followed by berries; and japonica, three feet, spring, white, with its variety fragrans, are generally grown. Japonica is a great favourite and fruits well if both male and female forms are planted. Peat and loam. 
SLOE.-Prunus spinosa.

SMILAX.-See Chapter XVIII.

SNOWBALL TREE.-Viburnum opulus sterile.

SNOWBERRY.-Symphoricarpus racemosus.

SNOWDROP TREE.-Halesia tetraptera.

SNOWY MESPILUS.-See Amelanchier.

SOLANUM.-One member of this large genus is a hardy shrub against a wall, and that is crispum, which has beautiful blue flowers in summer followed by yellow and white fruit. Loam.

SOPHORA.-Japonica, the Pagoda Tree, is a popular deciduous tree growing up to thirty feet high, with white flowers in August; pendula is a drooping variety of it and there is a variegated form. Sandy loam.

SOUTHERNWOOD.-See Artemisia.

SPANISH BROOM.-See Spartium.

SPANISH CHESTNUT.-See Castanea.

SPARTIUM.-Junceum is the Spanish Broom. which grows up to eight or nine feet high and has yellow flowers in summer; there is a double variety. Ordinary soil.

SPINDLE TREE.-See Euonymus.

SPIRAEA.-A large genus, comprising both herbaceous and shrubby kinds. Some of the best of the latter are dealt with in Chapters IX. and XIX. Forcing is treated in Chapter XXVI. The following are all good shrubs and have white flowers except where otherwise stated; the figures indicate the average height: Aitchisonii, cream, 6, summer; arguta, 4, late spring or early summer; discolor ariaefolia, 
8, summer ; bella, 3, red, July ; bracteata, 3, June ; bullata (syn. crispifolia), pink, $\mathrm{I} \frac{1}{2}$, summer; japonica (syn. callosa), rose, 4, June; j. Anthony Waterer, crimson, 3, summer ; j. Bumalda, crimson, 3, summer; atrosanguinea, pumila alba and superba are also forms of japonica (note that japonica is not the Spiræa japonica of bulb merchants, which is Astilbe japonica); media (syn. confusa), 3, June; Douglasii, rose, 6, August; Lindleyana, 6, August; prunifolia flore pleno, 3, spring, double ; Cantoniensis (syns. corymbosa and Reevesiana) 3, summer; canescens (syn. rotundifolia), 4, summer; salicifolia, pink, 4, July ; and sorbifolia, 4, summer. Others are hypericifolia, lævigata, nobleana, opulifolia (syn. Neillia opulifolia) and tomentosa; Lævigata has foliage resembling the Spurge Laurel.

SPRUCE FIR.-Picea excelsa.

SPURGE LAUREL.-Daphne Laureola.

ST. JOHN'S WORT.-See Hypericum.

STACHYCARPUS.-See Prumnopitys.

STACHYURUS.-Præcox (syn. japonicus) bears pendulous yellow catkins in spikes in spring; it should be grown on a wall. Ordinary soil, if friable and welldrained. It should have full exposure to sun.

STAPHYLEA.-Deciduous shrubs, of which colchica, which grows up to five feet high and bears ivory white drooping flowers in spring, is the best known; it forces well. See Chapter XXVI. Bumalda, Coulombieri and pinnata, all with white flowers, are also offered. Other species are monadelpha, serrata and virginica. 
STAUNTONIA.-Evergreen climbers. Hexaphylla has sweet white flowers in spring. Latifolia is the same as Holboellia latifolia. Loam and leaf mould.

STEPHANANDRA.-Deciduous shrubs, worth growing for their autumn colour. Both flexuosa and Tanakæ grow about three feet high and have white flowers in summer. The leaves of Tanakæ colour well in autumn. Ordinary soil.

STONE PINE.-Pinus Pinea.

STRANVESIA.-See Section A.

STRAWBERRY TREE.-See Arbutus.

STUARTIA.-Beautiful deciduous shrubs with flowers like small single Camellias. Pentagyna and Pseudo-Camellia both grow six to ten feet high and have creamy flowers in summer. The latter is the stronger, and the leaves have rich autumn colour. Blooming as they do later than most shrubs, and intrinsically beautiful, the Stuartias should be very popular, but they are not planted much. They are rather slow growers and not perfectly hardy, but if planted in loam in a moist sheltered spot where the roots can be protected from hot sun without the whole plant being shaded they will thrive. A bleak spot and a cold or very dry soil do not suit them. Annual mulchings of peat, loam and decayed manure are beneficial.

STYRAX.-Beautiful deciduous trees. Japonica grows eight to twelve feet high and has deep green ovate-lanceolate leaves on horizontal branches and fragrant drooping white flowers in early summer. 
Obassia blooms freely in white pendulous scented racemes in June. Loam and leaf mould.

SUMACH.-See Rhus.

SWEET BAY.-See Laurus.

SWEET GALE - Myrica Gale.

SYCAMORE.-This popular tree is referred to in Chapter IX., also under Acer. The Sycamore is Acer Pseudo-platanus; there are forms called atropurpureum, Leopoldii, lutescens, Prinz Handjery and Worlei. It is a good town and seaside tree.

SYCOPSIS SINENSIS.-See Section A on modern shrubs.

SYMPHORICARPUS.-Racemosus is the Snowberry, a deciduous shrub about six feet high, with rose flowers in summer, followed by abundant small white fruits; purpureus is a dark form. Acutus (syn. mollis), pink flowers in summer, and the variegated form of orbiculatus (syn. vulgaris) are also met with. Ordinary soil.

SYMPLOCOS CRATAEGIOIDES.-A rare tree with panicles of white flowers.

SYRINGA.-This is the Lilac genus. The name Syringa is commonly, but erroneously, applied to the Mock Orange (Philadelphus). S. vulgaris is the common Lilac; see Chapters IX. and XXVI. where good varieties, suitable alike for garden and forcing, are named. S. persica is the Persian Lilac, which is smaller in all its parts than vulgaris; there is a white form. Other Syringas which should have the shrublover's attention are Emodii, white, spring-blooming, height up to nine feet; there is a form with variegated 
leaves ; Josikaea, lilac, eight feet ; pekinensis, white ; and villosa, rose. Japonica is a late bloomer with cream flowers that have the scent of Privet.

TAMARIX (TAMARISK).-One of the best of seaside shrubs ; see Chapter XXI. Gallica, with pink flowers in summer, height up to eight feet, is generally met with; but hispida aestivalis, a beautiful shrub with rosy mauve inflorescence, is better for the garden, especially when grown in rich soil and cut hard back in spring. Tetrandra has white flowers. Germanica is now referred to the genus Myricaria. Parvifiora of gardens is the same as Gallica; and Pallasii is a form of it. Loam.

TAXODIUM.-Distichum is the deciduous or Swamp Cypress, a handsome tree with swollen buttresses near the base; it likes a damp site. Several forms are met with, notably a weeper, pendulum.

TAXUS (YEW).-This genus is dealt with in Chapter XVII., where some of the best varieties are named. See also Chapter XXIII. on Clipped Trees and Chapter XXIV. on Hedges. Ordinary soil.

TEUCRIUM.-Most of this genus are herbaceous, but fruticans, which grows about three feet high and has blue flowers in August, is a shrub; it should be grown on a wall. Ordinary soil.

THAMNOCALAMUS.--See Bambocs.

THERMOPSIS.-Laburnifolia is the same as Piptanthus nepalensis.

THORNS.--See Chapters VIII., IX., XIII. and XXIV., also Cratægus. 
THUYA.-Remarks on these beautiful Conifers will be found in Chapter XVII.

THUYOPSIS.-See Thuya.

TILIA.-See Lime and Section A.

TOPIARY.-See Chapter XXIII.

TORREYA.-A small genus of evergreen Conifers, of which californica, grandis, nucifera and taxifolia are the most important species. They have an unpleasant odour. Ordinary soil.

TRAVELLER'S JOY.-Clematis Vitalba.

TREE IVY.-Hedera arborea; chrysophylla and elegantissima are varieties; they are good as standards.

TREE P IEONY.-See Prony.

TRICUSPIDARIA.-The plant first called Crinodendron Hookerianum and subsequently named Tricuspidaria dependens is a beautiful South American gem, with foliage resembling the Bog Myrtle (Myrica), and drooping coral-pink flowers in spring. We are now told that it should be called lanceolata, and that the true dependens has drooping, white, fringed flowers. It thrives best on the western seaboard of the British Isles in loam and peat. In colder districts it should be planted against a wall.

TROCHODENDRON.-The only species, aralioides, is an uncommon evergreen with glossy green leaves, growing up to twelve feet high, and bearing greenish flowers in spring. It can only be grown outside in mild districts. Sandy peat.

TSUGA.-Evergreen Conifers closely related to Abies, Picea and Pinus. The best known species is canadensis (syn. Abies, Picea and Pinus canadensis) 
the Hemlock Spruce; there are several garden forms, notably argentea, silvery; parvifolia, small-leaved; and pendula, drooping. Hookeriana (syn. Abies Albertiana and Abies and Pinus Mertensiana), and Pattoniana (syn. Pinus Pattoniana) are other good species. Deep loam.

TULIP TREE.-See Liriodendron.

TURKEY OAK.-Quercus Cerris.

ULEX.-See Furze.

ULMUS.-See Elm.

UMBRELLA PINE.-See Sciadopitys.

$V A C C I N I U M$.-A large but not very important genus, mostly composed of deciduous shrubs. Myrtillus, with rose flowers in spring, height up to two feet, is the Bilberry, Blueberry or Whortleberry; the fruit is dark blue. Ovatum, rose flowers in spring, height up to five feet, dark red fruit; pennsylvanicum, brightly coloured in autumn, dwarf, dark blue fruit; stamineum, purple, three feet; uliginosum, pink, dwarf; and Vitis-Idæa, pink, evergreen, red fruit, dwarf, the Cowberry, are a few of the principal species. Moist sandy peat.

VERONICA.-See Chapters IX., XVIII. and XIX.

$V I B U R N U M$.-A large genus, and one which includes some very beautiful shrubs, notably Opulus, the Guelder Rose, and its form sterile, the Snowball Tree ; and plicatum. V. Lantana is the Wayfaring Tree of the hedgerows, one of the most attractive of our common wildings, alike in flower and fruit, well worth growing in dry-soil gardens. V. Tinus is the evergreen Laurustinus; see Laurustinus. Sieboldi, 
with dark green opposite leaves, resembles plicatum. Among the deciduous species not mentioned, dilatatum, height up to ten feet, white flowers in early summer; prunifolium, twelve feet, white; macrocephalum, twenty feet, white, early summer; and nudum, white, May, ten feet, are the most important. Opulus sterile, with its white balls as large as oranges, is certainly the most beautiful of the Viburnums, but it is pressed hard by plicatum, a form of tomentosum, which covers itself with white flowers in May ; plicatum does well in peat. Opulus fruits, but the form sterile is barren. Ordinary soil. See also Section A on modern shrubs.

VINCA.-See Chapter XXV.

VIRGILIA.-See Cladrastis.

VIRGINIAN CREEPER.-See Chapter XVIII., also Ampelopsis in this section.

VIRGIN'S BOWER.-Clematis Flammula.

VITEX.-Agnus-castus is hardy; it is a deciduous shrub growing about six feet high, with lilac flowers in August. Sandy loam.

VITIS.-See Chapter XVIII. and Ampelopsis in this section.

WALNUT.--See Juglans.

WEEPING WILLOW.-See Chapter XXII.

WEIGELA.-See Diervilla.

WELLINGTONIA.--See Chapter XVII.

WEYMOUTH PINE.-Pinus Strobus.

WHITE BEAM TREE.-Pryus aria.

WHITETHORN.-Cratægus Oxyacantha.

WILLOW.-See Chapter XXII. 
WILLOW OAK.-Quercus Phellos.

WINTER'S BARK.-See Drimys.

WISTARIA.--See Chapter XVIII. for varieties. Good loamy soil suits them.

WITCH HAZEL.-See Hamamelis.

WYCH ELM - See Elm.

$X A N T H O C E R A S$.-The only species is sorbifolia, a small deciduous tree growing up to fifteen feet high, with white, red-spotted flowers in July. It should not be grown in an exposed place. Sandy loam.

$X A N T H O R R H I Z A$ (or ZANTHORRHIZA).-The only species is apiifolia, a deciduous shrub growing up to three feet high, with purple flowers in April. Loam.

$Y E W$.-See Chapters XVII., XXIII. and XXIV.

YUCCA.-See Chapters XVI. and XIX. for selections. They like sandy loam.

YULAN.-See Magnolia conspicua.

ZELKOVA.-A small genus of deciduous trees resembling Elms. Acuminata (syn. Planera acuminata) which grows up to forty feet high, with the male flowers in green racemes in April, is the only one grown to any great extent. Davidiana is a small slender tree from Mongolia.

ZENOBIA.-Speciosa, the only one grown, is a shrub growing about four feet high, with small white drooping cup-shaped flowers in summer. It is the same as Andromeda cassineæfolia and A. speciosa. There are few more beautiful shrubs than this when it is grown in moist peat. 


\section{Index.}

A.

Abele (see also Poplar), 240.

Abelias, 240.

Abies, I46, I 50, 240.

Abutilons, 240.

Acacia (see Robinia).

Acanthopanax (see Aralia).

Acers, I 28, I 30, I 31, I 33, 222, 241 .

Actinidias, 156, 223, 242.

Adenocarpus, 242.

Æsculus (see also Chestnut), 242.

Ailantus, 242.

Akebia quinata, I 56 .

Alaternus (see Rhamnus).

Alders, I 30, 19 I, 243.

Alexandrian Laurel (see Ruscus).

Almonds (see also Prunus), 77.

Alpine Roses (see also Rhododendrons), 174.

Althæa (see Hibiscus).

Amelanchier, 75, I 34, 243.

American Allspice (see Calycanthus.

American Arbor-vitæ (see Thuya and Conifers).

Amorphas, 244.

Ampelopsis (see also Vitis), 244.

Amphirapis albescens, 223.

Amygdalus (see Almonds and Prunus.)

Andromedas, 245.

Apples, 76 .

Apricots (see Prunus).

Aralias, 245.
Araucarias, 147, 245.

Arbor-vitæ (see Thuya and Hedges).

Arbutuses, 246.

Arctostaphylos, 246.

Aristochias, 156, 223, 246.

Aristotelia, 246.

Aronia (see Cratægus and Pyrus).

Arrangement of Shrubs and Trees for Shelter and Beauty, 69.

Artemisias, 247.

Arundinarias (see Bamboos).

Arundo, 247.

Ash, 129, 132, 229, 247.

Aspen, 72, 190, 248.

Athrotaxis, I 54 .

Atragene (see Clematis).

Atriplex Halimus, 186.

Aucubas, 181, 206, 248.

Austrian Pine (see Conifers).

Azaleas, 78, I76, 214.

Azaras, 248.

B.

Baccharis, 223, 248.

Balsam Poplar (see Poplar).

Bamboos, 129, 192, 249.

Barberries (see Berberis).

Bay (see Laurus).

Beeches, 131, 202, 250.

Benthamia, 250.

Berberidopsis corallina, 156 .

Berberises, 74, 76, 77, I 31, I33, I $39,184,202,206,223,250$.

Berchemia, $25 \mathrm{I}$. 
Betula (see also Birch), 251.

Bignonias, I 57, $25 \mathrm{I}$.

Birches, 71, 132, 224.

Bird Cherry (see Prunus Padus). Bladder Senna (see Colutea).

Bleak places, Shrubs and Trees for (see Chapter XXI.).

Box, 74, 128, 139, 252.

Box Thorn (see Lycium).

Bramble (see Rubus).

Briers, 135.

Bridgesia (see Ercilla).

Brooms, 79, I 32, 177, 252.

Broussonetia, 224, 252.

Bruckenthalia, 252.

Bryanthus, 253.

Buckthorn (see Rhamnus).

Buckthorn, Sea (see Hippophae).

Buddleias, 80, I 57, 224, 253.

Bupleurums, 253.

Butcher's Broom (see also Ruscus), I41, 208.

Buxus (see Box).

\section{c.}

Casalpinias, 253.

Calluna, 254.

Calophaca, 254.

Calycanthus, I 57, 254.

Camellias, $225,254$.

Candleberry Myrtle (see Myrica).

Caprifolium (see Lonicera and Honeysuckle).

Caraganas, 225, 255 .

Carpenteria, 255.

Carpinus, 255 .

Carya, 256.

Caryopteris, 256 .

Cassandras, 256.

Cassinia (see Diplopappus).

Cassiope, 256 .

Castanea, 256.

Castanopsis, 257 .

Catalpas, $130,133,225,257$.

Ceanothuses, 81,157 .
Cedars, I 47.

Cedrus (see Cedar).

Celastrus, 225, 257 .

Celtis, 257 .

Cephalotaxus, I 54, 257, 258.

Cerasus (see also Prunus), 258 .

Cercidiphyllum, 258 .

Cercis, 258.

Chamæcyparis (see Cupressus).

Cherries (see also Cerasus and Prunus), 2 I 5.

Cherry Plum, 259.

Chestnuts (see also Castanea and Asculus) 73, I 33, I 8 I.

Chile Pine (see Araucaria).

Chimonathus, I 57, 259.

Chinese Arbor-vitæ (see Thuya).

Chinese Pear (see Pyrus).

Chinese Shrubs and Trees, 221.

Chinese Yew (see Cephalotaxus).

Chionanthus, 259.

Choisya, 260.

Christ's Thorn (see Paliurus).

Cissus (see Vitis).

Cistuses, 175 .

Citrus, 260.

Cladrastis, 260.

Clematises, I 58, $225,260$.

Clerodendron, $225,263$.

Clethra, 263.

Climbers, I 55 .

Clipped Trees, 193.

Cluster Pine (see Pinus Pinaster).

Cocculus, 226.

Cockspur Thorn, Cratægus Crusgalli.

Colutea, 263.

Comptonia (see Myrica).

Conifers, I43, I79, I86, I9I.

Corchorus (see Kerria).

Coriaria, 226, 263.

Cork Oak (see Quercus Suber).

Cornelian Cherry (see Cornus Mas).

Cornish Elm (see Elm).

Cornuses, 129, I 32, 264. 
Corokia, 265.

Coronillas, $26_{5}$.

Corsican Pine (see Pinus Laricio).

Cortaderia (see Gynerium).

Corylopsis, 226, 265.

Corylus (see Hazel).

Cotoneasters, I 33, I 35, I 59, I 79 , 226.

Cranberry (see Oxycoccus macrocarpus).

Crabs, I 35, 265.

Cratægo-Mespilus, 227.

Cratæguses, I 34, I40, I60, 266.

Crinodendron (see Tricuspidaria).

Cryptomerias, 147, 267.

Cunninghamia, I 54, 267.

Cupressus, I $48,267$.

Currants, Flowering (see Ribes).

Cuttings of Shrubs and Trees, 94-I00.

Cydonias, I 36, I60, 268.

Cypress (see Cupressus).

Cytisuses, 80, I 77, 227, 268.

\section{D.}

Daboêcias, 79, 174.

Dacrydium, I 54 .

Daphnes, 79, 140, I 76, 227, 269.

Daphniphyllum, 269.

Dartmouth Crab (see Crabs).

Davidia, 227.

Decaisnea, 269.

Deciduous Cypress (see Taxodium distichum).

Desfontainea spinosa, 269.

Desmodiums, 270.

Deutzias, 228, 270.

Diervillas, 79, $27 \mathrm{I}$.

Dimorphanthus mandshuricus (see Aralia).

Diospyros, 272.

Dipelta, 228 .

Diplopappus, 272.

Dirca, 272.

Dividing Shrubs and Trees, 105.
Dogwood (see Cornus).

Draining, 189.

Drimys, 228, 272.

Dryas octopetala, 177.

Dutch garden, 193.

E.

Edgeworthia, 272.

Edwardsia (see Sophora).

Elæagnuses, I29, 186, 273.

Elders, I 30, I 82, 191, 273.

Eleutherococcus, 229.

Elms, I $30,273$.

Embothrium coccineum, 160.

Empetrums, 274.

Enemies of Shrubs and Trees, I06.

Enkianthus, 274.

Epigæa, 274.

Ercilla, 274.

Ericas, I 74, 274.

Eriobotrya, 275.

Eriobolus, 228.

Escallonias, 140, I60, 275.

Eucalyptus, 276.

Eucommia, 229.

Eucryphias, 276.

Eugenia, 276.

Euonymuses, 75, 129, I31, I40, $182,229,276$.

Euptelea, 229.

Eurya, 277.

Eurybia (see Olearia).

Evergreen Oak (see also Quercus Ilex), 73 .

Evergreens, 82, I 37 .

Evergreen Thorn (see Cratægus Pyracantha).

Exochorda, 229, 277.

F.

Fabiana, 277.

Fagus (see Beech).

Fendlera, 277. 
Firs, 72 .

Fitzroya, 278.

Flowering Ash (see Ash).

Forcing, Shrubs and Trees for, 210.

Forsy thias, 4I, 79, 229, 278.

Fothergilla, 278.

Fraxinus (see Ash).

Fremontia, 278.

Fringe Tree, (see Chionanthus).

Fuchsias, 278.

Furze, 279.

\section{G.}

Garden seclusion, I9.

Garrya elliptica, I6I, 279.

Gaultherias, 208, 279.

Genistas (see also Broom), 177.

Ginkgo biloba, I 34, I 49, 280.

Glastonbury Thorn (see Cratægus).

Gleditschias, 229, 280.

Goat Moth, 107.

Golden Arbor-vitæ (see Thuya).

Golden Laurel (see Larch).

Golden Chestnut (see Castanea).

Gordonia, 280.

Gorse (see Furze).

Grafting Shrubs and Trees, IOI.

Grevillea, 281 .

Griselinia, 28I.

Group-planting, 74 .

Guelder Rose (see Viburnum).

Gum Cistus (see Cistus).

Gymnocladus, 230, 28 I.

Gynerium, 28I.

\section{H.}

Halesia, 282.

Halimodendron, 282.

Hamamelis, 282.

Hawthorn (see Cratægus).

Hazel, 283.

Heaths (see also Erica), 174.

Hederas (Ivy), I29, I6I.
Hedgehog Holly (see Holly).

Hedges, Shrubs and Trees for, 199.

Hedysarum, 283.

Helianthemums, 177, 283.

Hemlock Spruce (Abies canadensis).

Hibiscuses, 283.

Hickory (see Carya).

Hippophae, I 35, 284.

Hollies, 128, 129, 203, 207, 230, 284.

Honey Locust (Gleditschia triacanthos).

Honeysuckles, I 30, I6 $3,285$.

Hop Tree (see Ptelea).

Hornbeam (see Carpinus, also Hedges, Chapter XXIV).

Horse Chestnut (see Chestnut).

Hydrangeas, 40, 80, I62, 230 , 285.

Hymenanthera, 286.

Hypericums, 140, 286.

I.

Ideal, an, I 3 .

Idesia, 287.

Ilex (see Holly).

Illicium, 287.

Incense Cedar (Libocedrus decurrens).

Indigofera, 287.

Irish Heath (see Daboẽcia).

Irish Ivy (Hedera Helix canariensis).

Irish Yew (Taxus baccata fastigiata).

Itea, 287.

Ivies, 129,161 .

\section{J.}

Jamesia, 288 .

Japanese Cedar (see Cryptomeria). 
Japanese Quince (see Pyrus Japonica).

Japanese Dwarf trees, 216.

Jasmines, I 30, 162, 23I, 288.

Judas tree (see Cercis Siliquastrum).

Juglans, $231,288$.

Junipers, 150.

K.

Kalmias, 140, 288.

Kerria, 1 29, 163, 289.

Kolreuteria, 289.

L.

Laburnums, 75, 289.

Landscape effects, 56 .

Larches, 108, 150.

Lardizabala, 290.

Larix, see Larch.

Laurels, I5 I, 201, 290.

Laurus, 290.

Laurustinus, 75, 290.

Lavender, $29 \mathrm{I}$.

Lavender Cotton, I 29.

Lawns, Shrubs and Trees for, I23.

Layering Shrubs and Trees, IO4. Lead Plant (see Amorpha).

Leatherwood (see Dirca).

Ledums, 291.

Leaf tints, 127 .

Leiophyllum, 291.

Leptospermum, 23 I.

Lespedeza, 291.

Leucothoê (see Andromeda).

Leycesteria, 292.

Libocedrus, $154,292$.

Ligustrums, 231, 292.

Lilacs, $75,212$.

Lime Tree (Linden), I 80, 292.

Lindera, 293.

Ling, 130.

Liquidambar, 231, 293.
Liriodendron, 231.

Locust Tree (see Robinia).

Lonicera (see also Honeysuckle), 232.

Loquat (see Eriobotrya).

Loropetalum, 293.

Lupinus, 294.

Lycium, 294.

II.

Maclura, 294.

Magnolias, I 34, I 40, 164, 177 , $215,232,294^{\circ}$.

Mahonia (see Berberis).

Naidenhair Tree (see Ginkgo biloba).

Manure not essential, 49.

Naples, I28, I3I, I 33 .

Meliosma myriantha, 295.

MIenispermum, 295.

Menziesia (see Daboêcia).

Miespilus (see Amelanchier).

Mock Oranges (see Philadelphus).

IIorus, 296.

MIountain Ash, 76, I 35, 296.

Moving Shrubs and Trees, 50, 83 .

IIuehlenbeckia, 296.

Nulberry (see also MIorus), i 81.

Nyrica, 296.

Myricaria (see Tamarix.)

Iyrobalan Plum (see Hedges, Chapter XXIV.).

Myrtles, 164, 297.

$$
\text { N. }
$$

Nandina, 297.

Negundo, 297.

Neillia, I 30, 297.

Nettle Tree (see Celtis).

Neviusia, 298.

Norway IIaple, (see Acer).

Norway Spruce (Abies excelsa).

Notospartium, 298. 
Nuts, I 30, I 31 .

Nuttallia, 298.

O.

Oaks, 73, 130, I 34, 298.

Olea, 299.

Olearias, 86, 299.

Ononis, 300 .

Osage Orange (see Maclura).

Osmanthus, 75, I29, I 31, 232, 300.

Osteomeles, 301.

Othera, 30I.

Oxycoccus, 301 .

Oxydendron, 30r.

Ozothamnus, 30 r.

\section{P.}

Pachysandra, 233.

Pæonies, Tree, 76, 301.

Paliurus, 302.

Pampas Grass (see also Gynerium), I 25 .

Parrotia, 302.

Passiflora (Passion flower), I64.

Paulownias, 233, 302 .

Pavia (see Asculus).

Peaches, 2 I 2, 303.

Pears, 303.

Pergolas, 155 .

Periploca, I65, 303 .

Periwinkle, I4I, 208.

Pernettyas, I 35, $174,303$.

Perowskia, 303 .

Persimmon (see Diospyros).

Philadelphuses, 76, I 29, I 30, 303.

Philesia, 304.

Phillyræa, 233, 304.

Phlomis, 304.

Photinia, 304.

Phyllostachys (see Bamboos).

Piceas, 146, I 50.

Pieris, 305 .

Pines'(Pinus), 7 I, 15 I.
Piptanthus, 305.

Pittosporum, 305 .

Plagianthus, 306.

Planera (see Zelkova).

Planes, I80, 306.

Planting Shrubs and Trees, 77.

Platanus (see Planes).

Plum, Purple-leaved (Prunus Pissardii).

Plum, Myrobalan, 202.

Podocarpus, I 54, 306. !

Poison Ivy (see Rhus Toxicodendron).

Poison Oak (see Rhus Toxicodendron).

Poliothyrsis, 233.

Polygala, 306.

Polygonums, 165, 306.

Pomegranate (see Punica).

Poplars, 72, 1 29, I 30, 190, 233. 307.

Portugal Laurel (see Laurel).

Potentillas, 233, 307 .

Prinos, 307.

Privet, 129, I 42, 20 I, 208.

Propagation of Shrubs and Trees, 91.

Prumnopitys, I 54, 307.

Pruning Shrubs and Trees, 5I, I09.

Prunus, 76, 1 31, 234, 308.

Pseudolarix, I 54, 309.

Pseudostuga, I 52, 309.

Ptelea, 309.

Pterocarya, 3 Io.

Pterostyrax (see Halesia).

Punica, 3 Io.

Pyracantha (see Cratægus).

Pyruses, 74, 76, 143, 212, 2 I 5. 310.

Q.

Quercus (see Oak).

Quick, 200.

Quince, I 36. 
R.

Raphiolepis, 3 II.

Retinosporas, I 49.

Rhamnus, 3 II.

Rhododendrons, 48, 78, 1 IO, 142, I 74, 207, 21 5, 234, 312.

Rhodora, 316.

Rhus, 3 I 6 .

Ribes, 40, 236, 316.

Robinias, 3 I 7 .

Rock Gardens, Shrubs for, I70, 179.

Rock Roses, 175.

Rose Acacia (see Robinia).

Rosemary, 317 .

Roses, 48, I 35, 165, I77, 236.

Rubus, 132, $236,317$.

Ruscus, 318 .

\section{S.}

St. John's Wort (see Hypericum). Salisburia adiantifolia (see Ginkgo biloba).

Salt Tree (see Halimodendron).

Salix (see Chapter XXII.).

Sambucus (see Elder).

Sarcococca, 209, 236.

Saxegothæa, I 54, 318.

Scarlet Maple (see Acer).

Sciadopitys, I 54, 319.

Schizophragma, 237.

Scotch Elm (see Elm).

Screening unsightly objects, 59.

Sea Buckthorn (see Hippophae),

Seaside, Shrubs and Trees for, I 84 .

Sceds of Shrubs and Trees, 92.

Senecio, 319.

Sequoia, 152.

Service Tree (see Pyrus).

Shade, Shrubs for, 141, 205.

Shelter planting, $7 \mathrm{I}$.

Shepherdia, 319.
Shrub Beds and Borders, 36.

Shrubs for Shade and Undergrowth, 205.

Shrubs for Forcing, 2 Io.

Shrubs for Rock Gardens, 170.

Siberian Crab, 76 .

Skimmias, 3 I9.

Sloe (see Prunus spinosa).

Smilax, I67.

Snowball Trec (see Viburnum Opulus sterile).

Snowberry (see Symphoricarpus racemosus.

Snowdrop Tree (see Halesia tetraptera).

Snowy Mespilus (see Amelanchier).

Soils, Special, 53.

Solanum, 320.

Sophora, 320.

Southernwood (see Artemisia Abrotanum).

Spanish Broom (sec Spartium).

Spanish Chestnut (see Castanea).

Spartium, 320.

Spindle Tree (see Euonymus).

Spiræas, 76, 80, I 78, 2 16, 237, 320.

Spring Beauty, 36.

Spruce Fir (Picea excelsa).

Spurge Laurel (see Daphne Laureola).

Stachycarpus (see Prumnopitys).

Stachyurus, 321 .

Staking Trees, 77 .

Staphyleas, $216,321$.

Stauntonias, 322.

Stem tints, 127.

Stephanandra, 322.

Stone Pine (Pinus Pinea).

Stranvasia, 237 .

Strawberry Tree, (see Arbutus).

Stuartias, 322.

Styrax, 237, 322.

Suburban Shrubs and Trees, 180.

Sumachs (sec also Rhus), I34, 136.

Swect Bay (see Laurus). 
Sweetbrier, 203.

Sweet Gale (see Myrica Gale).

Sycamore, 73, 129, 1 31, 323.

Sycopsis, 237.

Symphoricarpus, 75, 323 .

Syringas, 323 .

\section{T.}

Tamarix, I 86, 324.

Taxodium, I 54, 324 .

Taxus, 152,324 .

Tetracentron, 238 .

Teucrium, 324.

Thamnocalamus (see Bamboo).

Thermopsis (see Piptanthus nepalensis).

Thorns, 74, 132, 134.

Thuya, I 53.

Thuyopsis (see Thuya).

Tilia (see also Lime Tree), 238.

Topiary, 193.

Torreya, $154,325$.

Town Shrubs and Trees, I 80.

Travellers' Joy (see Clematis Vitalba).

Tree Ivy (see Ivy and Hedera).

Tree of Heaven (see Ailantus glandulosa).

Tree Pæony (see Pæony).

Trees for Forcing, 240.

Trees for Shelter and Shade, 205.

Tricuspidaria, 325 .

Trochodendron, 325 .

Tsuga, I 53,325 .

Tulip Tree (see Liriodendron tulipifera).

Turkey Oak (see Quercus Cerris).

\section{U.}

Ulex (see Furze).

Ulmus (see Elm).

Umbrella Pine (see Sciadopitys verticillata).

Undergrowth, 205.
V.

Vacciniums, 326.

Veronicas, $76,140,167,178$, 238.

Viburnums, 75, 238, 326.

Vincas (see Chapter XXV.).

Vine (see Vitis).

Virgilia (see Cladrastis).

Virginian Creeper (see also Ampelopsis and Vitis), I32, I 33,167 .

Virgin's Bower (see Clematis Flammula).

Vitex, 327 .

Vitis, 133, I67, 239.

W.

Walks, Shaded, 27.

Walnut (see Juglans).

Water for Young Shrubs and Trees, 50.

Waterside Planting, 67.

Waterside, Shrubs and Trees for, I 88.

Weeping Trees, I23.

Weeping Willow (see Chapter XXII.).

Weigelas (see also Diervillas), 79.

Wellingtonia, 152 .

Weymouth Pine (Pinus Strobus).

White Beam Tree (see Pyrus Aria).

Whitethorn (see Cratægus Oxyacantha).

Willows, I32, I9I.

Willow Oak (Quercus Phellos).

Wilson, E. H., 222.

Window Boxes, Conifers for, I 54 .

Wistarias, I68.

Witch Hazel (see Hamamelis). 
Witch-knots, 107.

Wood Leopard MIoth, I07.

Woodland, 23.

Woodland Mystery, 19.

Wych Elm (see also Ulmus), 180.

$\mathrm{X}$.

Xanthoceras, 328.

Xanthorrhiza, 328.
Y.

Yews, $152,202$.

Yuccas, $141,178$.

Ýulan (see Magnolia conspicua).

$Z$.

Zelkova, 328.

Zenobia, 328. 



SB $435^{\circ}$ Wa.

University of British Columbia Library DUE DATE

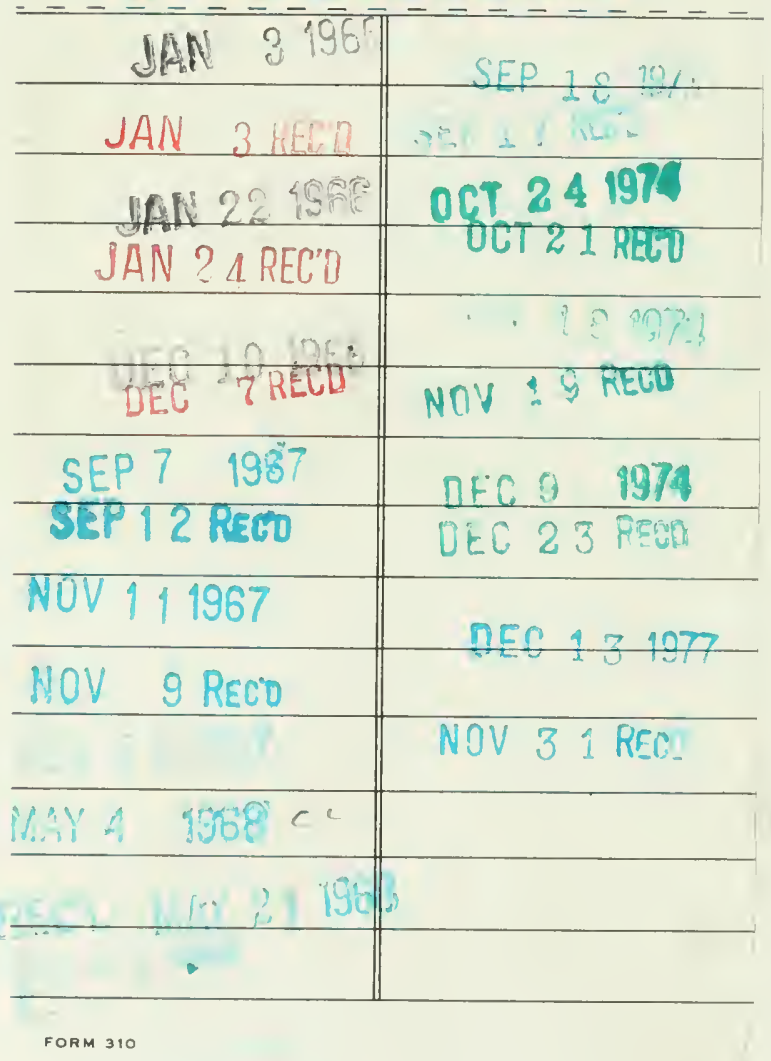




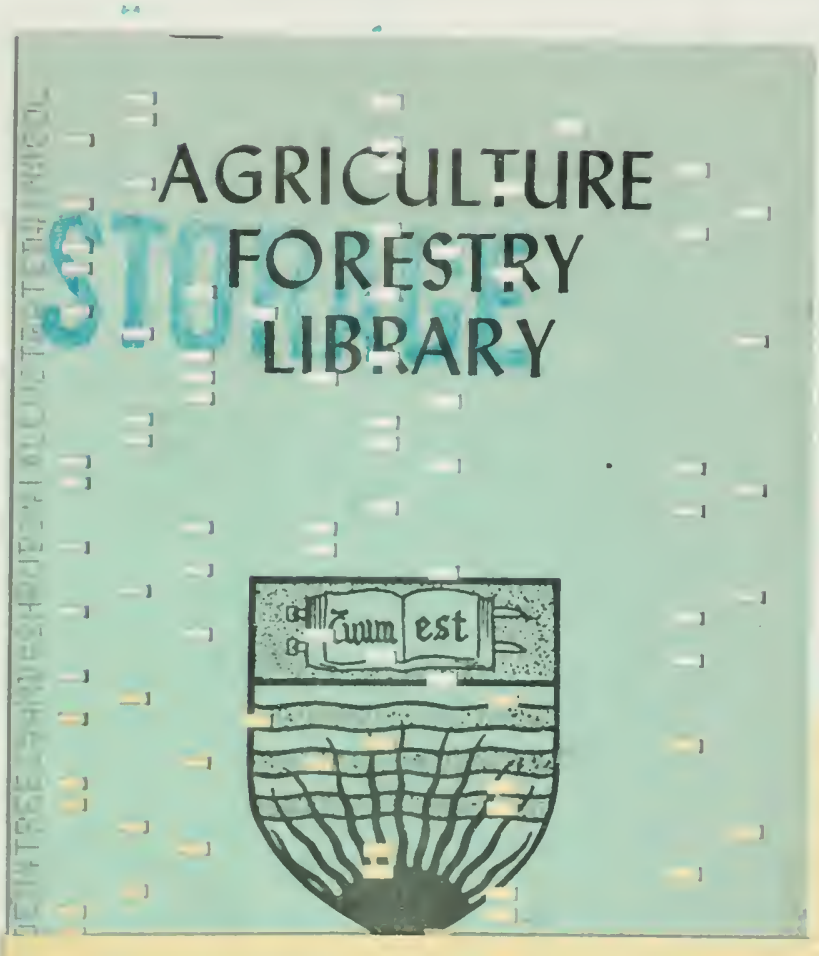

FORESTRY

AGRICULTURE

\section{LIBRARY}




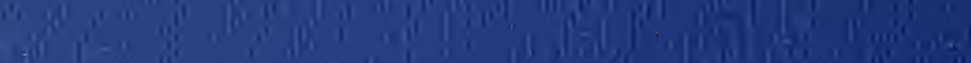

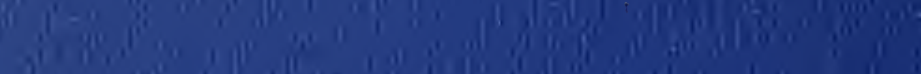

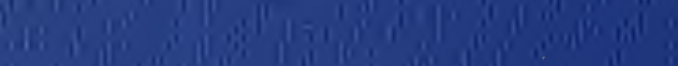

(1) Notis (1) (a) (1)

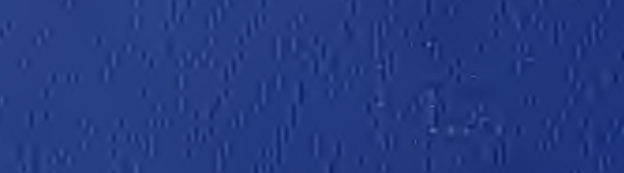

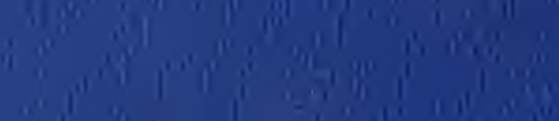

V.

I

$$
\text { I: }
$$$$
\text { I. }
$$$$
\text { a) } 10.010
$$

"

1)
$a^{\prime \prime}$

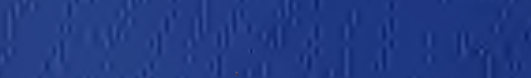

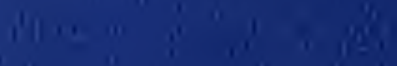

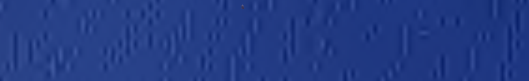

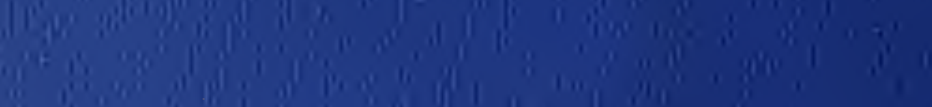

(1)

10.0.0.

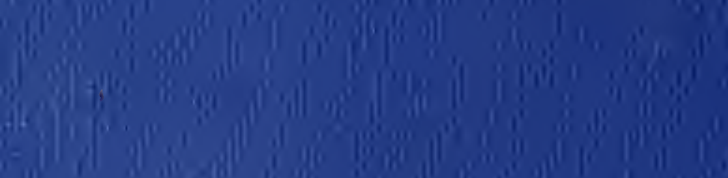

(1)

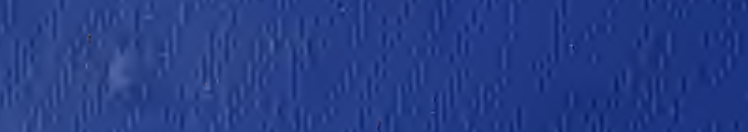

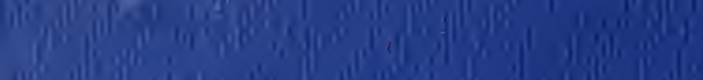

Fon

al lo

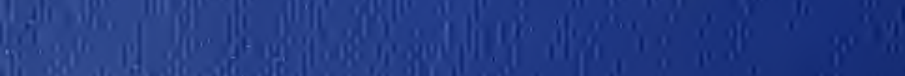

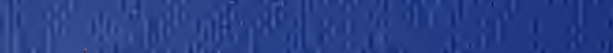

